\title{
Haemodynamics in deep venous obstruction
}

\author{
Citation for published version (APA):
}

Kurstjens, R. L. M. (2016). Haemodynamics in deep venous obstruction: Advances towards a tailored treatment. [Doctoral Thesis, Maastricht University]. Maastricht University. https://doi.org/10.26481/dis.20161214rk

Document status and date:

Published: 01/01/2016

DOI:

10.26481/dis.20161214rk

Document Version:

Publisher's PDF, also known as Version of record

\section{Please check the document version of this publication:}

- A submitted manuscript is the version of the article upon submission and before peer-review. There can be important differences between the submitted version and the official published version of record.

People interested in the research are advised to contact the author for the final version of the publication, or visit the DOI to the publisher's website.

- The final author version and the galley proof are versions of the publication after peer review.

- The final published version features the final layout of the paper including the volume, issue and page numbers.

Link to publication

\footnotetext{
General rights rights.

- You may freely distribute the URL identifying the publication in the public portal. please follow below link for the End User Agreement:

www.umlib.nl/taverne-license

Take down policy

If you believe that this document breaches copyright please contact us at:

repository@maastrichtuniversity.nl

providing details and we will investigate your claim.
}

Copyright and moral rights for the publications made accessible in the public portal are retained by the authors and/or other copyright owners and it is a condition of accessing publications that users recognise and abide by the legal requirements associated with these

- Users may download and print one copy of any publication from the public portal for the purpose of private study or research.

- You may not further distribute the material or use it for any profit-making activity or commercial gain

If the publication is distributed under the terms of Article $25 \mathrm{fa}$ of the Dutch Copyright Act, indicated by the "Taverne" license above, 


\section{Haemodynamics in}

Deep Venous Obstruction

Advances towards a tailored treatment 
Cover design: Anke Meijs

Layout: Ralph Kurstjens

Printing: Off Page, Amsterdam

ISBN: 978-94-6182-744-9

Copyright (C) Ralph L.M. Kurstjens, Rotterdam, 2016

All rights reserved. This publication may not be reproduced or transmitted, in any form or by any means, electronic, mechanical, photocopying, recording or otherwise, without the prior permission of the author. 


\title{
Haemodynamics in
}

Deep Venous Obstruction

\section{Advances towards a tailored treatment}

\author{
PROEFSCHRIFT \\ Ter verkrijging van de graad van doctor aan de Universiteit Maastricht, \\ op gezag van de Rector Magnificus, Prof. dr. Rianne M. Letschert \\ volgens het besluit van het College van Decanen, \\ in het openbaar te verdedigen \\ op woensdag 14 december 2016 om 10:00 uur \\ door
}

Ralph Lambertus Maria Kurstjens 


\section{Promotores}

Prof. dr. C.H.A. Wittens

Prof. dr. J.E. Wildberger

\section{Co-promotor}

Dr. R. de Graaf

\section{Beoordelingscommissie}

Prof. dr. H. ten Cate (voorzitter)

Dr. L.C. van Dijk (HagaZiekenhuis)

Prof. dr. ir. C. Ince (AMC)

Prof. dr. M.J.H.M. Jacobs

Prof. dr. P.M. Steijlen 


\section{Table of contents}

Chapter 1 General introduction 7

Chapter 2 The predictive value of haemodynamic parameters for outcome 19 of deep venous reconstructions in patients with chronic deep vein obstruction: a systematic review

Chapter 3 The value of haemodynamic measurements by air plethysmography in diagnosing venous obstruction of the lower limb

Chapter 4 The ability of air plethysmography to identify patients who will 51 benefit from stenting of deep venous obstruction

Chapter 5 Abdominal and pubic collateral veins as indicators of deep venous obstruction

Chapter 6 Haemodynamic significance of collateral blood flow in chronic 77 venous obstruction

Chapter 7 Intravenous pressure changes in patients with post-thrombotic deep venous obstruction: results using a treadmill stress test

Chapter 8 The effect of stenting on venous hypertension: results using a treadmill stress test in patients with deep vein obstruction

Chapter 9 Arteriovenous fistula geometry in hybrid recanalisation of postthrombotic venous obstruction

Chapter 10 General discussion

Addenda

Summary

Nederlandse samenvatting

Valorisation addendum

Dankwoord

Curriculum Vitae

List of publications 


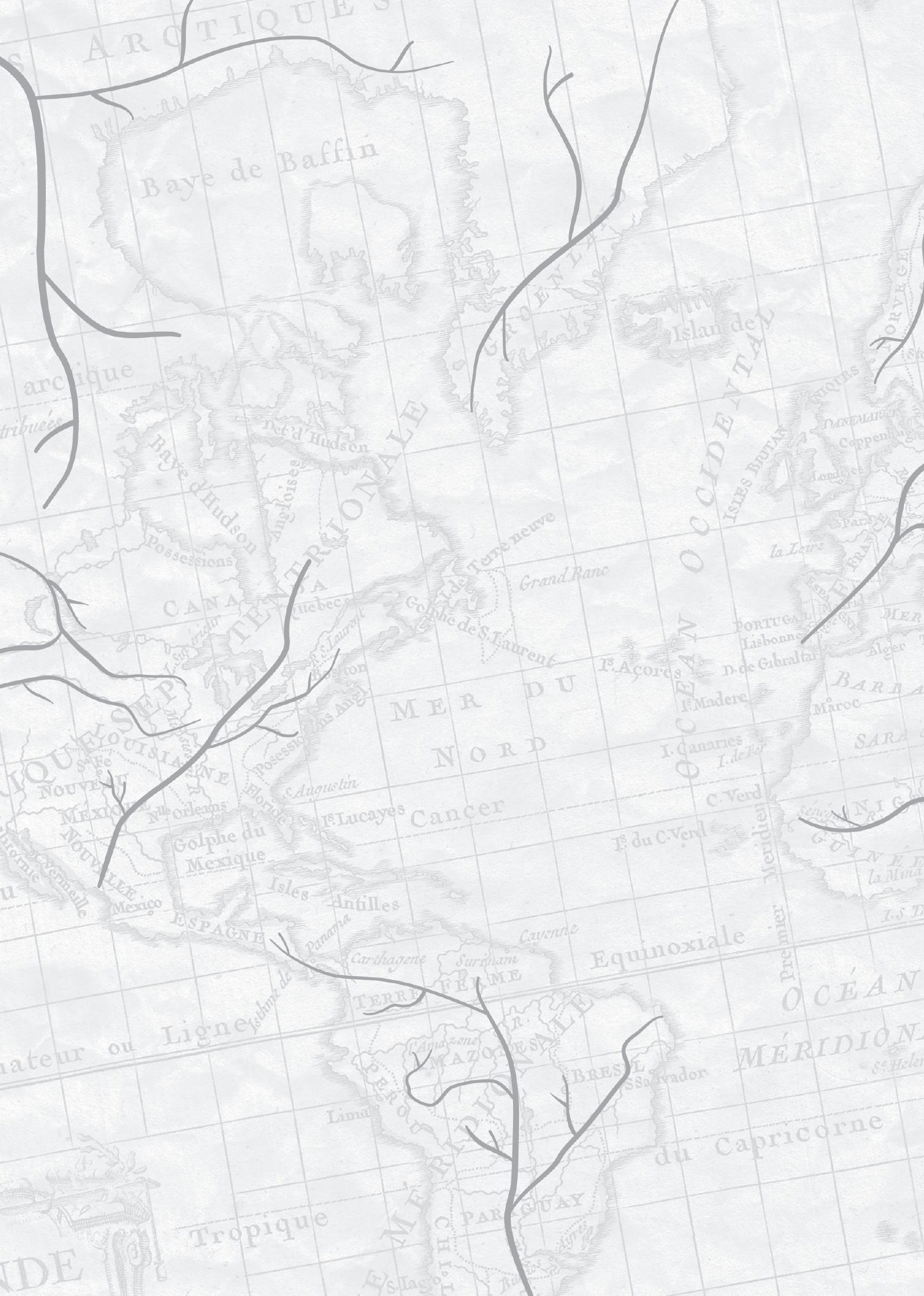




Deep venous obstruction is mainly caused by inadequate recanalisation after deep vein thrombosis (DVT). ${ }^{1,2}$ The prevalence of DVT is one to two per 1000 per year in the Western population. ${ }^{3,4}$ Standard treatment of DVT is currently aimed at preventing pulmonary embolism or recurrent DVT through use of oral anticoagulation for three to six months, compression therapy and mobilisation. ${ }^{5}$ This leaves resolution of the thrombus up to natural process. However, in $25-56 \%$ of patients ${ }^{6-10}$ recanalisation proves inadequate and the patient develops complaints, which is called the post-thrombotic syndrome (PTS) ${ }^{11,12}$ In the case of an iliofemoral DVT, the incidence of PTS can even be as high as $70 \% .{ }^{13}$ Because the whole outflow of the lower limb is impaired, PTS tends to be more severe. ${ }^{14}$ This is an important observation as patients suffering from P'TS show significant loss of quality of life, comparable to chronic obstructive pulmonary disease, congestive heart failure and diabetes mellitus. ${ }^{6,15}$

Another important cause of deep venous obstruction is external compression by overlying arteries. ${ }^{1,2}$ Usually, this pertains to compression of the left common iliac vein by the overlying right common iliac artery against the vertebral column, often referred to as May-Thurner Syndrome (Figure 1.1). ${ }^{16,17}$ However, iliac vein compression syndrome or non-thrombotic iliac vein compression are more suitable terms as the external iliac vein or the contralateral iliac vein can also be compressed, and different artery segments can also cause the compression. ${ }^{18,19}$ The prevalence of such compression syndromes is unclear because its relevance is poorly understood. Studies have suggested that compression of $>50 \%$ is present in $24 \%$ of the general population, ${ }^{20}$ yet most do not develop complaints.

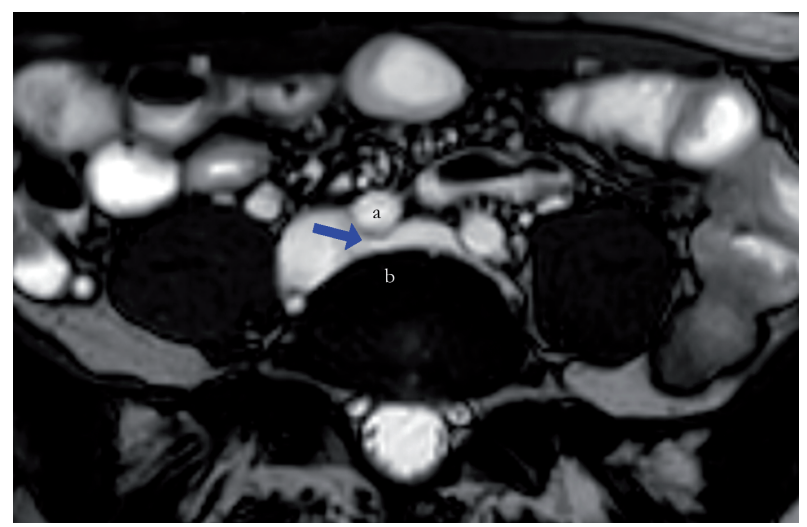

Figure 1.1 Magnetic resonance image of an iliac vein compression.

The arrow points out the left common iliac vein, which is being compressed by the right common iliac artery (a) against the fifth lumbar vertebra (b).

\section{Clinical signs and symptoms}

The most debilitating symptom of such obstructions is venous claudication; the occurrence of pain during walking, which subsides when the patient assumes the sitting or supine position with the lower limb elevated. ${ }^{21,22}$ Leg swelling and a feeling of heaviness are two other frequent complaints. ${ }^{2,8}$ When patients suffer from post-thrombotic obstruction, cramps, paraesthesia and pruritus can also occur. ${ }^{8}$ Ultimately, obstruction can also result in a venous ulcer, which occurs 
Table 1.1 Venous Clinical Severity Score. ${ }^{26}$

\begin{tabular}{|c|c|c|c|c|}
\hline & None: 0 & Mild: 1 & Moderate: 2 & Severe: 3 \\
\hline Pain or other discomfort & None & $\begin{array}{l}\text { Occasional, i.e. not } \\
\text { restricting regular } \\
\text { daily activities }\end{array}$ & $\begin{array}{l}\text { Daily, i.e. interfering } \\
\text { with but not } \\
\text { preventing regular } \\
\text { daily activities }\end{array}$ & $\begin{array}{l}\text { Daily, i.e. limits } \\
\text { most regular daily } \\
\text { activities }\end{array}$ \\
\hline Varicose veins & None & Few, scattered & $\begin{array}{l}\text { Confined to calf or } \\
\text { thigh }\end{array}$ & $\begin{array}{l}\text { Involves calf and } \\
\text { thigh }\end{array}$ \\
\hline Venous oedema & None & $\begin{array}{l}\text { Limited to foot and } \\
\text { ankle area }\end{array}$ & $\begin{array}{l}\text { Extends above ankle } \\
\text { but below knee }\end{array}$ & $\begin{array}{l}\text { Extends to knee } \\
\text { and above }\end{array}$ \\
\hline Skin pigmentation & None or focal & $\begin{array}{l}\text { Limited to } \\
\text { perimalleolar area }\end{array}$ & $\begin{array}{l}\text { Diffuse over lower } \\
\text { third of calf }\end{array}$ & $\begin{array}{l}\text { Wider distribution } \\
\text { above lower third } \\
\text { of calf }\end{array}$ \\
\hline Inflammation & None & $\begin{array}{l}\text { Limited to } \\
\text { perimalleolar area }\end{array}$ & $\begin{array}{l}\text { Diffuse over lower } \\
\text { third of calf }\end{array}$ & $\begin{array}{l}\text { Wider distribution } \\
\text { above lower third } \\
\text { of calf }\end{array}$ \\
\hline Induration & None & $\begin{array}{l}\text { Limited to } \\
\text { perimalleolar area }\end{array}$ & $\begin{array}{l}\text { Diffuse over lower } \\
\text { third of calf }\end{array}$ & $\begin{array}{l}\text { Wider distribution } \\
\text { above lower third } \\
\text { of calf }\end{array}$ \\
\hline Active ulcer number & 0 & 1 & 2 & $\geq 3$ \\
\hline $\begin{array}{l}\text { Active ulcer duration, longest } \\
\text { active }\end{array}$ & $\mathrm{N} / \mathrm{A}$ & $<3$ months & $\begin{array}{l}>3 \text { months but }<1 \\
\text { year }\end{array}$ & $>1$ year \\
\hline Active ulcer size, largest active & $\mathrm{N} / \mathrm{A}$ & Diameter $<2 \mathrm{~cm}$ & Diameter 2-6 cm & Diameter $>6 \mathrm{~cm}$ \\
\hline Use of compression therapy & Not used & Intermittent use & $\begin{array}{l}\text { Wears stockings } \\
\text { most days }\end{array}$ & Full compliance \\
\hline
\end{tabular}

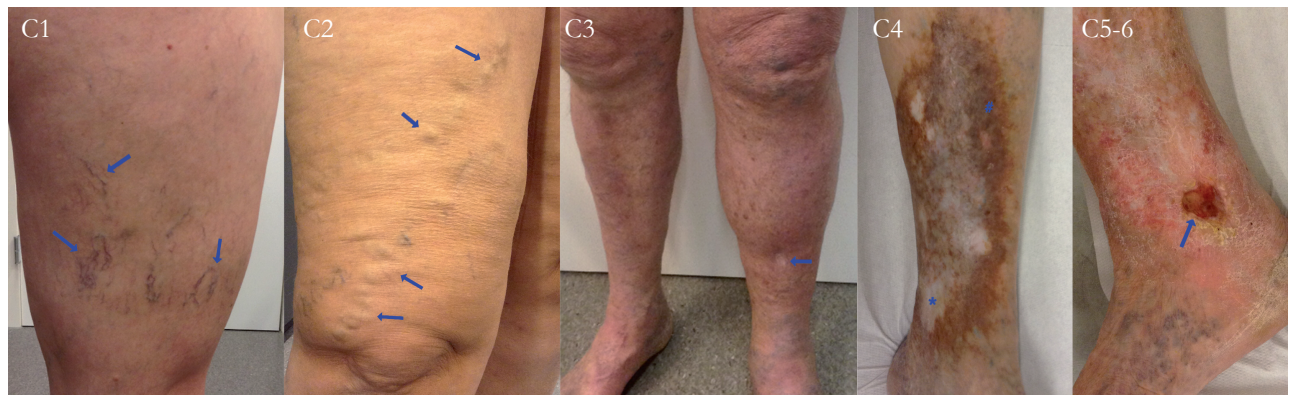

Figure 1.2 C-classes of Clinical-Etiology-Anatomy-Pathophysiology classification.

C0: $\quad$ No signs of venous disease, not depicted

C1: Telangiectasies or reticular veins

C2: $\quad$ Varicose veins, diameter of $3 \mathrm{~mm}$ or more

C3: Oedema, present in the left limb, arrow depicts "pitting" after digital pressure

C4a: Hyperpigmentation (\#) and eczema, not depicted

C4b: Lipodermatosclerosis, induration of the skin giving the appearance of an upside-down champagne bottle, and atrophie blanche $\left(^{*}\right)$

C5: $\quad$ Healed venous ulcer

C6: $\quad$ Active venous ulcer 
in $3 \%$ of patients with obstruction and in $24 \%$ of patients with a combination of obstruction and valve incompetence. ${ }^{23}$ Given the fact that ulcers represent $1 \%$ of Western health care expenditure, ${ }^{24}$ this is a point of concern.

In order to compare scientific results, symptoms and signs need to be reported in a structured fashion using a sound scoring system. Venous disease can generally be identified by using the Clinical-Etiology-Anatomy-Pathophysiology classification. ${ }^{25}$ The C-part of this score can be obtained by physical examination and is shown in Figure 1.2. Although this scoring system can identify sequelae of deep venous obstruction, it lacks information on patient complaints. The Venous Clinical Severity Score is a widely used, validated scoring system that does take complaints into account, yet is hardly affected by them (Table 1.1) ${ }^{26}$ For post-thrombotic disease, the Villalta scale is the most widely used scoring system. ${ }^{27-29}$ This scale assesses pain and other signs and symptoms, though the most important sign, venous claudication, is still not represented (Table 1.2).

\section{Additional imaging}

When deep venous obstruction is suspected, additional imaging needs to be performed to identify the obstruction and establish whether it can be treated or not. Duplex ultrasound is an economically sensible choice to evaluate the deep venous system from inferior vena cava down to the ankle. ${ }^{30,31}$ Furthermore, duplex ultrasound is a dynamic tool and can be used to identify valve incompetence. However, this technique can be technically difficult above the level of the groin and is operator-dependent. Computed tomography venography and magnetic resonance venography are two more extensive modalities that can be used to identify obstructive changes in the whole deep venous trajectory. ${ }^{31,32}$ Whereas computed tomography is easier to perform and less costly, magnetic resonance venography can detect intraluminal changes and is thus the preferred approach (Figure 1.3). ${ }^{32,33}$ Finally, intravascular ultrasound and conventional venography are two more invasive techniques that can be used to identify obstruction. Intravascular ultrasound is the

Table 1.2 Villalta scale. ${ }^{27,29}$

\begin{tabular}{|c|c|c|c|c|}
\hline & None & Mild & Moderate & Severe \\
\hline \multicolumn{5}{|l|}{ Symptoms } \\
\hline Pain & 0 points & 1 point & 2 points & 3 points \\
\hline Cramps & 0 points & 1 point & 2 points & 3 points \\
\hline Heaviness & 0 points & 1 point & 2 points & 3 points \\
\hline Paraesthesia & 0 points & 1 point & 2 points & 3 points \\
\hline Pruritus & 0 points & 1 point & 2 points & 3 points \\
\hline \multicolumn{5}{|l|}{ Clinical signs } \\
\hline Pretibial oedema & 0 points & 1 point & 2 points & 3 points \\
\hline Skin induration & 0 points & 1 point & 2 points & 3 points \\
\hline Hyperpigmentation & 0 points & 1 point & 2 points & 3 points \\
\hline Redness & 0 points & 1 point & 2 points & 3 points \\
\hline Venous ectasia & 0 points & 1 point & 2 points & 3 points \\
\hline Pain on calf compression & 0 points & 1 point & 2 points & 3 points \\
\hline Venous ulcer & Absent & Present & & \\
\hline
\end{tabular}




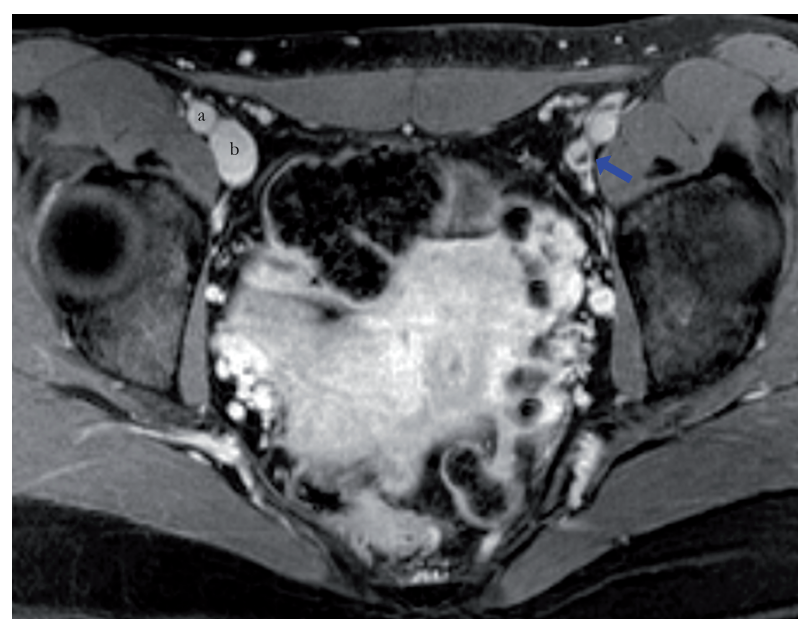

Figure 1.3 Magnetic resonance image showing intraluminal postthrombotic changes.

The arrow denotes the lack of signal reception caused by post-thrombotic changes in the left external iliac vein. The external iliac artery (a) and external iliac vein (b) are marked on the right side. On the left a similar external iliac artery can be seen, though the external iliac vein is markedly smaller.

preferred method for diagnosing iliac vein compression; ${ }^{33,34}$ though no comparative studies have identified its potentially superior role to magnetic resonance venography.

\section{Treatment of post-thrombotic venous obstruction}

In the past, PTS used to be treated by compression therapy and mobilisation alone, which is still the mainstay of treatment. ${ }^{35}$ Only in the most severe cases surgical bypass was considered. However, in the recent past, percutaneous transluminal angioplasty with stenting has emerged as a treatment option for patients with iliofemoral post-thrombotic obstruction. ${ }^{33,36}$ During this procedure, the patient is under general anaesthesia or deep sedation. Access to the venous system is obtained by ultrasound-guided cannulation of the femoral vein. A sheath is placed inside the vein, through which contrast is injected and a venogram is obtained as a road map for the procedure (Figure 1.4A). Subsequently, recanalisation is performed with the use of a hydrophilic guidewire. Following recanalisation, balloon angioplasty is performed to assist stent deployment, which is the next step. Balloon angioplasty is performed again after stenting to ensure maximal alignment of the stent with the vessel wall (Figure 1.4B).

In certain cases, post-thrombotic disease is too extensive for a good landing zone of the stent in the common femoral vein. In such cases, stent occlusion is almost guaranteed due to insufficient inflow..$^{37,38}$ To improve inflow an endophlebectomy is performed. First, an incision is made in the groin, and the common femoral vein and common femoral artery with their side branches are identified. Then, a longitudinal incision in the common femoral vein is made, and desobstruction of the scarring tissue where the thrombus used to be located is performed. The origins of large tributary veins draining into the common femoral vein are also desobstructed. Due to the increased thrombogenicity of this procedure, an arteriovenous fistula is created between the common femoral artery and the common femoral vein (Figure 1.5). To avoid 


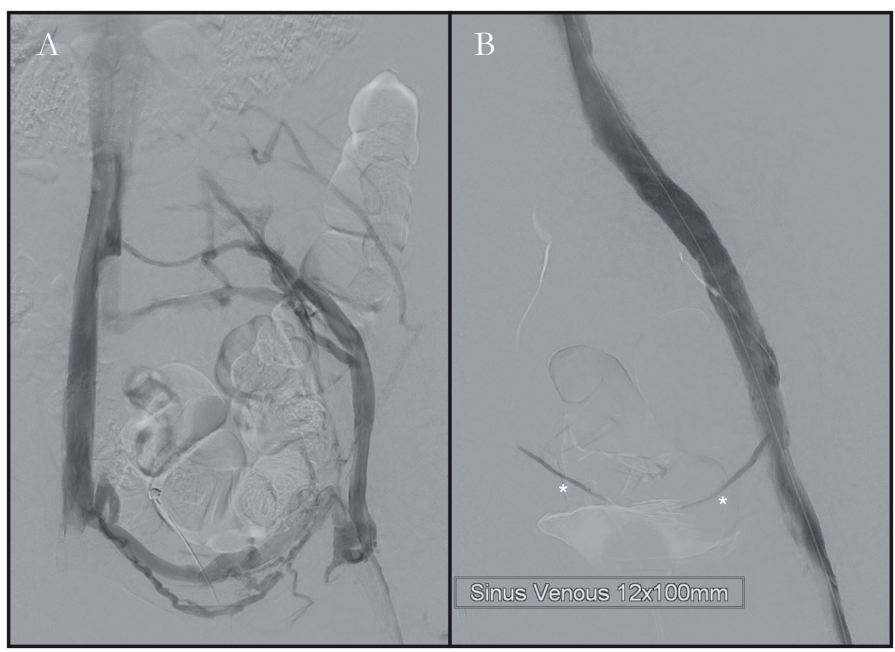

Figure 1.4 Venograms of a post-thrombotic iliac vein obstruction before and after stenting.

A. Post-thrombotic obstruction of the left iliac tract with extensive collateralisation to the contralateral side. B. Flow to the left iliac tract is restored after stenting, *ureters.

long-term complications from the arteriovenous fistula, it is percutaneously occluded after six weeks to three months.

Both patients undergoing stenting or the latter mentioned hybrid procedure receive therapeutic doses of oral anticoagulation for at least six months after intervention. Furthermore, frequent outpatient follow-up visits are necessary to monitor stent patency.

Several studies have shown excellent technical success for this treatment, with a primary patency of $50-80 \%$, assisted primary patency of $76-82 \%$ and secondary patency of 82 $100 \%{ }^{36,39-41}$ Although no randomised clinical trials have been performed as of yet, several large case series have shown a positive effect on quality of life ${ }^{40,42}$ and validated clinical scoring systems. ${ }^{39,40}$ One comparative non-randomised study has been performed, also showing positive results as assessed by the Villalta scale. ${ }^{43}$

\section{Treatment of non-thrombotic iliac vein compression}

Obstruction caused by non-thrombotic iliac vein compression was not well recognised in the past and therefore not routinely treated. Treatment options were compressions stockings or, in severe debilitating cases, surgical reconstruction. ${ }^{44}$ However, percutaneous angioplasty with stenting can also be performed

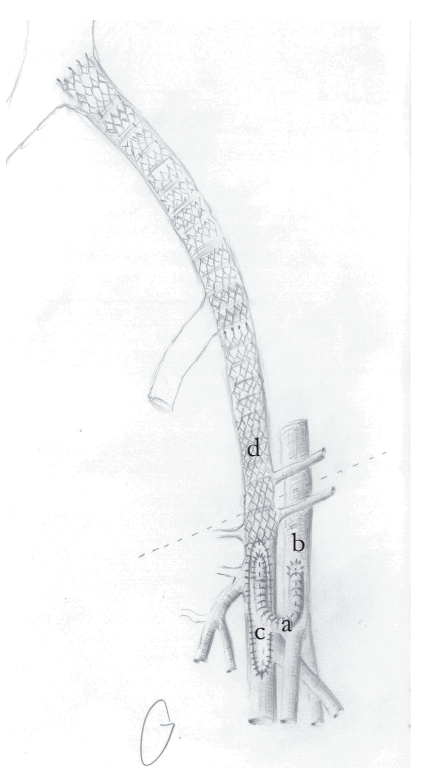

Figure 1.5 Schematic image of a hybrid recanalisation.

Shows an arteriovenous fistula (a) connecting the common femoral artery (b) with the common femoral vein in the area of the endophlebectomy (c) to ensure proper flow into the stented tract (d). 
for this type of obstruction. Patients only need to be stented at the point of compression, which can be done under local anaesthetics. Technical success is excellent with primary patency rates up to $100 \%$. Large case series have demonstrated significant improvement in clinical scores and quality of life. ${ }^{36,39-41}$

\section{Points of concern}

Notwithstanding these results, $15-20 \%$ of patients show little to no improvement after stenting, often despite adequate recanalisation and patent stents. ${ }^{45}$ Moreover, very little is known about the haemodynamic impact of deep venous obstruction or the effect of stenting. ${ }^{19,46,47}$ Most studies were performed with incompetence as its main focus, ${ }^{48-50}$ whilst others have focused on the effects of deep venous obstruction by using parameters originally established for use in deep vein incompetence. ${ }^{19,40}$ Moreover, most studies did not compare results with healthy controls. ${ }^{19,40,46}$ Therefore, more insight into the haemodynamic changes of deep venous obstruction and its treatment by stenting is warranted.

\section{Aims of this thesis}

This thesis aims to achieve the following:

- To gain more insight into the haemodynamic changes caused by deep venous obstruction.

- To establish the haemodynamic implications of treatment aimed at abolishing deep venous obstruction.

- To identify points of reference for further research into the selection of patients who will benefit from treatment of deep venous obstruction.

\section{Outline of this thesis}

In chapter two, this thesis will present the results of a systematic review investigating the predictive ability of haemodynamic parameters for success of recanalisation in deep venous obstruction. This chapter will demonstrate that there is little evidence on the subject, ratifying the further studies presented in this thesis.

The ensuing chapters will assess the usefulness of air plethysmography in deep venous obstructive disease. Chapter three evaluates its diagnostic abilities when used according to current consensus documents, whereas chapter four will provide a more in-depth analysis of absolute volumetric changes. Furthermore, it assesses the value of air plethysmography as a predictor for success of stenting, as measured by quality of life.

Next, the importance of collateralisation in deep venous obstruction will be discussed. Chapter five will describe the predictive value of collateral veins on the abdominal wall or over the pubic bone for the presence of potentially treatable deep venous obstruction. These veins can be observed by the naked eye during physical examination, and thus could be useful as an alarm sign for primary care physicians to refer a patient to a vascular specialist. In chapter six we describe the importance of collateral circulation by comparing pressure effects of post-thrombotic obstruction to an acute occlusion and a healthy control situation in the same participants.

Subsequently, this thesis aims to elucidate current knowledge concerning the haemodynamic impact of post-thrombotic iliofemoral venous obstruction and the impact of abolishing this 
obstruction. Chapter seven will give insight into the pressure profiles of obstructive disease at both the level of the groin and the foot during ambulation, leading to a better understanding of venous claudication. Chapter eight will demonstrate how these pressure profiles change following stenting and how this correlates with patient complaints.

Finally, chapter nine will explore the possibilities of deep venous reconstruction in cases where post-thrombotic disease is extensive and impaired inflow poses a problem for long-term success of treatment. This chapter will evaluate two different techniques of arteriovenous fistula creation and identify important determinants for stent patency.

\section{References}

1. Raju S, Neglen P. High prevalence of nonthrombotic iliac vein lesions in chronic venous disease: a permissive role in pathogenicity. J Vasc Surg 2006;44(1):136-43; discussion 44.

2. Meissner MH, Eklof B, Smith PC, et al. Secondary chronic venous disorders. J Vasc Surg 2007;46 Suppl S:68S-83S.

3. Cohen AT, Agnelli G, Anderson FA, et al. Venous thromboembolism (VTE) in Europe. The number of VTE events and associated morbidity and mortality. Thromb Haemost 2007;98(4):756-64.

4. Naess IA, Christiansen SC, Romundstad P, Cannegieter SC, Rosendaal FR, Hammerstrom J. Incidence and mortality of venous thrombosis: a population-based study. J Thromb Haemost 2007;5(4):692-9.

5. Kearon C, Akl EA, Ornelas J, et al. Antithrombotic Therapy for VTE Disease: CHEST Guideline and Expert Panel Report. Chest 2016;149(2):315-52.

6. Kahn SR, Shbaklo H, Lamping DL, et al. Determinants of health-related quality of life during the 2 years following deep vein thrombosis. J Thromb Haemost 2008;6(7):1105-12.

7. Mohr DN, Silverstein MD, Heit JA, Petterson TM, O’Fallon WM, Melton LJ. The venous stasis syndrome after deep venous thrombosis or pulmonary embolism: a population-based study. Mayo Clin Proc 2000;75(12):1249-56.

8. Prandoni P, Villalta S, Bagatella P, et al. The clinical course of deep-vein thrombosis. Prospective long-term followup of 528 symptomatic patients. Haematologica 1997;82(4):423-8.

9. Schulman S, Lindmarker P, Holmstrom M, et al. Post-thrombotic syndrome, recurrence, and death 10 years after the first episode of venous thromboembolism treated with warfarin for 6 weeks or 6 months. J Thromb Haemost 2006;4(4):734-42.

10. Tick LW, Kramer MH, Rosendaal FR, Faber WR, Doggen CJ. Risk factors for post-thrombotic syndrome in patients with a first deep venous thrombosis. J Thromb Haemost 2008;6(12):2075-81.

11. Kahn SR, Solymoss S, Lamping DL, Abenhaim L. Long-term outcomes after deep vein thrombosis: postphlebitic syndrome and quality of life. J Gen Intern Med 2000;15(6):425-9.

12. Prandoni P, Lensing AW, Cogo A, et al. The long-term clinical course of acute deep venous thrombosis. Ann Intern Med 1996;125(1):1-7.

13. Akesson H, Brudin L, Dahlstrom JA, Eklof B, Ohlin P, Plate G. Venous function assessed during a 5 year period after acute ilio-femoral venous thrombosis treated with anticoagulation. Eur J Vasc Surg 1990;4(1):43-8.

14. Strijkers RH, Arnoldussen CW, Wittens CH. Validation of the LET classification. Pblebology 2015;30(1 Suppl):14-9.

15. Carradice D, Mazari FA, Samuel N, Allgar V, Hatfield J, Chetter IC. Modelling the effect of venous disease on quality of life. BrJ Surg 2011;98(8):1089-98.

16. May R, Thurner J. [A vascular spur in the vena iliaca communis sinistra as a cause of predominantly left-sided thrombosis of the pelvic veins]. Z Kreislaufforsch 1956;45(23-24):912-22.

17. May R, Thurner J. The cause of the predominantly sinistral occurrence of thrombosis of the pelvic veins. Angiology 1957;8(5):419-27.

18. de Wolf MA, de Graaf R, Kurstjens RL, Penninx S, Jalaie H, Wittens CH. Short-Term Clinical Experience with a Dedicated Venous Nitinol Stent: Initial Results with the Sinus-Venous. EurJ Vasc Endovasc Surg 2015.

19. Neglen P, Berry MA, Raju S. Endovascular surgery in the treatment of chronic primary and post-thrombotic iliac vein obstruction. Eur J Vasc Endovasc Surg 2000;20(6):560-71.

20. Kibbe MR, Ujiki M, Goodwin AL, Eskandari M, Yao J, Matsumura J. Iliac vein compression in an asymptomatic patient population. J Vasc Surg 2004;39(5):937-43.

21. Killewich LA, Martin R, Cramer M, Beach KW, Strandness DE, Jr. Pathophysiology of venous claudication. J Vasc Surg 1984;1(4):507-11.

22. Delis KT, Bountouroglou D, Mansfield AO. Venous claudication in iliofemoral thrombosis: long-term effects on venous hemodynamics, clinical status, and quality of life. Ann Surg 2004;239(1):118-26.

23. Neglen P, Thrasher TL, Raju S. Venous outflow obstruction: An underestimated contributor to chronic venous disease. J V asc Surg 2003;38(5):879-85.

24. Ruckley CV. Socioeconomic impact of chronic venous insufficiency and leg ulcers. Angiology 1997;48(1):67-9.

25. Eklof B, Rutherford RB, Bergan JJ, et al. Revision of the CEAP classification for chronic venous disorders: consensus statement. J V asc Surg 2004;40(6):1248-52. 
26. Vasquez MA, Rabe E, McLafferty RB, et al. Revision of the venous clinical severity score: venous outcomes consensus statement: special communication of the American Venous Forum Ad Hoc Outcomes Working Group. J Vasc Surg 2010;52(5):1387-96.

27. Kahn SR, Partsch H, Vedantham S, et al. Definition of post-thrombotic syndrome of the leg for use in clinical investigations: a recommendation for standardization. J Thromb Haemost 2009;7(5):879-83.

28. Kahn SR. Measurement properties of the Villalta scale to define and classify the severity of the post-thrombotic syndrome. J Thromb Haemost 2009;7(5):884-8.

29. Villalta S, Bagatella P, Piccioli A, Lensing A, Prins M, Prandoni P. Assessment of validity and reproducibility of a clinical scale for the post-thrombotic syndrome. Haemostasis 1994;24(Suppl 1):158a.

30. Labropoulos N, Borge M, Pierce K, Pappas PJ. Criteria for defining significant central vein stenosis with duplex ultrasound. J Vasc Surg 2007;46(1):101-7.

31. Arnoldussen CW, Toonder I, Wittens CH. A novel scoring system for lower-extremity venous pathology analysed using magnetic resonance venography and duplex ultrasound. Phlebology 2012;27 Suppl 1:163-70.

32. Arnoldussen CW, de Graaf R, Wittens CH, de Haan MW. Value of magnetic resonance venography and computed tomographic venography in lower extremity chronic venous disease. Phlebology 2013;28 Suppl 1:169-75.

33. Wittens C, Davies AH, Baekgaard N, et al. Editor's Choice - Management of Chronic Venous Disease: Clinical Practice Guidelines of the European Society for Vascular Surgery (ESVS). EurJ V asc Endovasc Surg 2015;49(6):678737.

34. Neglen P, Raju S. Intravascular ultrasound scan evaluation of the obstructed vein. J Vasc Surg 2002;35(4):694-700.

35. Kahn SR, Comerota AJ, Cushman M, et al. The postthrombotic syndrome: evidence-based prevention, diagnosis, and treatment strategies: a scientific statement from the American Heart Association. Circulation 2014;130(18):163661.

36. Seager MJ, Busuttil A, Dharmarajah B, Davies AH. Editor's Choice - A Systematic Review of Endovenous Stenting in Chronic Venous Disease Secondary to Iliac Vein Obstruction. Eur J Vasc Endovasc Surg 2016;51(1):100-20.

37. de Wolf MA, Arnoldussen CW, Wittens CH. Indications for endophlebectomy and/or arteriovenous fistula after stenting. Phlebology 2013;28 Suppl 1:123-8.

38. Jalaie $\mathrm{H}$, Arnoldussen $\mathrm{C}$, Barbati $\mathrm{M}$, et al. What predicts outcome after recanalization of chronic venous obstruction: hemodynamic factors, stent geometry, patient selection, anticoagulation or other factors? Phlebology 2014;29(1 suppl):97-103.

39. de Wolf MA, de Graaf R, Kurstjens RL, Penninx S, Jalaie H, Wittens CH. Short-Term Clinical Experience with a Dedicated Venous Nitinol Stent: Initial Results with the Sinus-Venous Stent. Eur J Vasc Endovasc Surg 2015;50(4):518-26.

40. Neglen P, Hollis KC, Olivier J, Raju S. Stenting of the venous outflow in chronic venous disease: long-term stentrelated outcome, clinical, and hemodynamic result. J V asc Surg 2007;46(5):979-90.

41. Wen-da W, Yu Z, Yue-Xin C. Stenting for chronic obstructive venous disease: A current comprehensive metaanalysis and systematic review. Phlebology 2016;31(6):376-89.

42. Catarinella FS, Nieman FH, de Wolf MA, Toonder IM, de Graaf R, Wittens CH. Quality-of-life in interventionally treated patients with post-thrombotic syndrome. Phlebology 2015;30(1 Suppl):89-94.

43. Yin M, Shi H, Ye K, et al. Clinical Assessment of Endovascular Stenting Compared with Compression Therapy Alone in Post-thrombotic Patients with Iliofemoral Obstruction. Eur J V asc Endovasc Surg 2015;50(1):101-7.

44. Ferris EJ, Lim WN, Smith PL, Casali R. May-Thurner syndrome. Radiology 1983;147(1):29-31.

45. de Wolf MAF, Arnoldussen CW, Grommes J, et al. Minimally invasive treatment of chronic iliofemoral venous occlusive disease. Journal of Vascular Surgery: Venous and Lymphatic Disorders 2013;1(2):146-53.

46. Delis KT, Bjarnason H, Wennberg PW, Rooke TW, Gloviczki P. Successful iliac vein and inferior vena cava stenting ameliorates venous claudication and improves venous outflow, calf muscle pump function, and clinical status in post-thrombotic syndrome. Ann Surg 2007;245(1):130-9.

47. Negus D, Cockett FB. Femoral vein pressures in post-phlebitic iliac vein obstruction. BrJ Surg 1967;54(6):522-5.

48. Kolbach DN, Neumann HA, Prins MH. Definition of the post-thrombotic syndrome, differences between existing classifications. Eur J Vasc Endovasc Surg 2005;30(4):404-14.

49. Nicolaides AN, Zukowski AJ. The value of dynamic venous pressure measurements. World J Surg 1986;10(6):91924.

50. Nicolaides AN. Investigation of chronic venous insufficiency: A consensus statement (France, March 5-9, 1997). Circulation 2000;102(20):E126-63. 



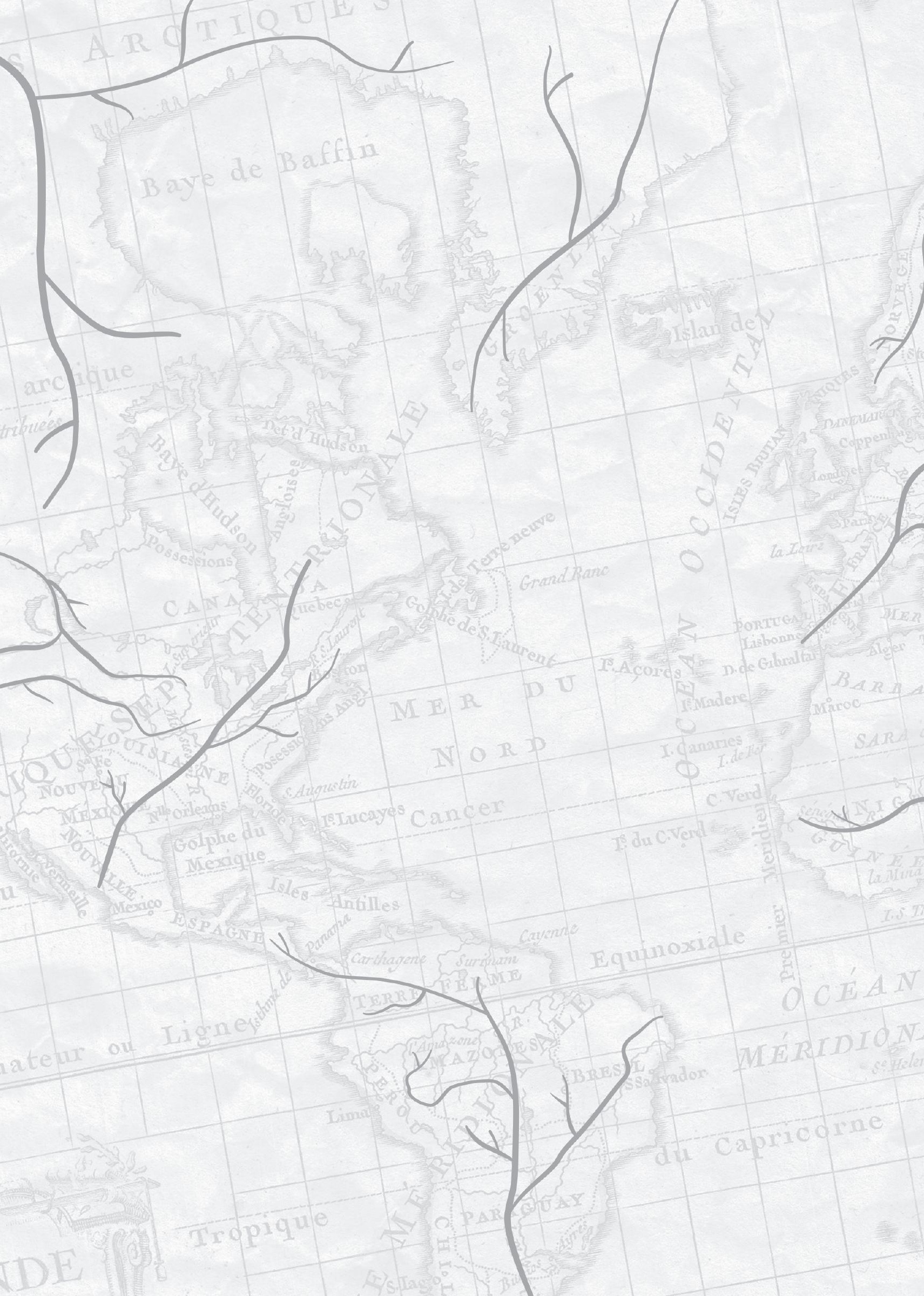




\section{CHAPTER 2}

The predictive value of haemodynamic parameters for outcome of deep venous reconstructions in patients with chronic deep vein obstruction: a systematic review

Ralph L.M. Kurstjens Mark A.F. de Wolf Jos Kleijnen Rick de Graaf Cees H.A. Wittens

Pblebology. 2016 Oct 27 [Published Online First] 


\begin{abstract}
Objective: The aim of this study was to investigate the predictive value of haemodynamic parameters for success of stenting or bypass surgery in patients with non-thrombotic or postthrombotic deep venous obstruction.

Methods: EMBASE, MEDLINE and trial registries were searched up to February 5th, 2016. Studies needed to investigate stenting or bypass surgery in patients with post-thrombotic obstruction or stenting for non-thrombotic iliac vein compression. Haemodynamic data needed to be available with prognostic analysis for success of treatment. Independently, two authors selected studies and extracted data, with risk bias assessment using the Quality in Prognosis Studies tool.

Results: Two studies using stenting and two using bypass surgery were included. Three investigated plethysmography, though results varied and confounding was not properly taken into account. Dorsal foot vein pressure and venous refill times appeared to be of influence in one study, yet confounding by deep vein incompetence was likely. Another investigated femoral-central pressure gradients without finding statistical significance; however, sample size was small without details on statistical methodology. Reduced femoral inflow was found to be a predictor for stent stenosis or occlusion in one study, though patients also received additional surgery to improve stent inflow. Data on prediction of haemodynamic parameters for stenting of non-thrombotic iliac vein compression was not available.

Conclusions: Data on the predictive value of haemodynamic parameters for success of treatment in deep venous obstructive disease is scant and of poor quality. Plethysmography does not seem to be of value in predicting outcome of stenting or bypass surgery in post-thrombotic disease. The relevance of pressure-related parameters is unclear. Reduced flow into the common femoral vein seems to be predictive for in-stent stenosis or occlusion. Further research into the predictive effect of haemodynamic parameters is warranted, and the possibility of developing new techniques that can measure certain haemodynamic aspects should be explored.
\end{abstract}




\section{Introduction}

Chronic venous outflow obstruction of the lower extremity can be caused by extravascular compression, congenital abnormalities or inadequate recanalisation following deep venous thrombosis (DVT). ${ }^{1}$ DVT can lead to fibrosis of the affected vessels and destruction of venous valves, resulting in post-thrombotic obstruction and incompetence. ${ }^{2}$ This leads to an inability to adequately empty the venous system of the lower limb, resulting in (ambulatory) venous hypertension. When obstruction and reflux persist, chronic venous disease can develop. ${ }^{1,3}$ Moreover, when lower limb outflow is severely impaired, venous claudication occurs. During exercise the flow into the leg increases greatly, yet the obstruction leads to impaired outflow, resulting in pain. ${ }^{4}$ Causes of extravascular compression can vary. The most common cause is compression of the left common iliac vein by the overlying right common iliac artery, called MayThurner syndrome. ${ }^{5,6}$ Compression of other venous segments by different arterial segments can occur. Such non-thrombotic obstructions can also lead to venous claudication.?

In the past, venovenous bypasses were only performed in severe cases of obstruction to alleviate complaints. ${ }^{8,9}$ Nowadays, this is considered even more of a last-resort treatment option, as percutaneous transluminal angioplasty (PTA) with stenting has been shown to be an effective form of treatment in chronic iliofemoral and iliocaval obstruction. Literature with long-term follow-up demonstrates primary patency rates of 50-90\%, assisted primary patency rates of $76-$ $95 \%$ and secondary patency rates of $82-100 \%$ in patients with post-thrombotic obstruction. ${ }^{7,10-14}$ In patients with non-thrombotic deep venous obstruction, primary patency is reported to be 79$100 \%$ and assisted-primary and secondary patency $100 \% \cdot{ }^{7,10,15}$ Furthermore, quality of life and scoring systems for severity of venous disease improve significantly after PTA and stenting. ${ }^{70,16}$ Nevertheless, a minority of patients show little to no improvement of complaints, ${ }^{17}$ even after successful recanalisation. Moreover, little information is available on the haemodynamic impact of deep venous obstruction and its treatment by stenting, nor does there appear to be adequate insight into the value of haemodynamic parameters as a predictor for outcome of stenting.

It is important to establish whether certain haemodynamic parameters can be used as predictors for outcome to prevent unnecessary interventions in patients who will not benefit from successful recanalisation. If pre-operative haemodynamic parameters are of prognostic value, these parameters could be used to determine the necessary treatment approach in a specific patient. Patients who will experience inadequate clinical response to treatment may be identified and could be advised to adhere to conservative management instead of undergoing stenting. Also, it could be determined that extended treatment with anticoagulation post-intervention; a more frequent follow-up; or additional interventions like endophlebectomy, creation of arteriovenous fistulas and stent extension are indicated to reduce risk of stent occlusion. Thus, given that we did not identify any existing systematic reviews, the objective of this systematic review is to determine the predictive value of haemodynamic parameters for outcome of deep venous reconstructions in patients with obstruction in order to identify which patients will clinically benefit from treatment and which will not. 


\section{Methods}

\section{Criteria for considering studies for this review}

Types of studies

In our protocol, we planned that prospective studies with multivariable analysis of haemodynamic parameters would be used. In case less than five eligible studies were to be identified, retrospective studies with multivariable analysis of haemodynamic parameters were also to be included. If, again, less than five viable studies were to be found, studies without a multivariable analysis were also to be included.

\section{Types of participants}

Patients with post-thrombotic syndrome of the lower extremity or non-thrombotic iliac vein compression and an indication for deep venous reconstruction were the target population. This included patients treated with PTA and/or stenting and bypass surgery for postthrombotic obstruction and PTA and/or stenting for non-thrombotic iliac vein compression.

\section{Types of prognostic factors}

Haemodynamic parameters that were investigated are (ambulatory) venous pressure, flow, pull-through pressure gradient, hand-foot pressure differential, hyperaemia-induced pressure, plethysmography results (air plethysmography, strain-gauge plethysmography, foot volumetry, photoplethysmography and impedance plethysmography) and presence of collaterals.

\section{Types of outcome measures}

Primary outcome was measured in quality of life scores, both disease-specific and generic. Secondary outcomes were ulcer healing rate; ulcer recurrence rate; clinical scores, including Venous Clinical Severity Score, Villalta scale, Clinical-Etiology-Anatomy-Pathophysiology classification, Widmer classification, Brandjes score and Van Ginsberg score; presence of venous claudication; and general reduction of symptoms. Technical secondary outcome parameters were primary patency, assisted primary patency and secondary patency.

\section{Search methods for identification of studies}

\section{Electronic search}

A systematic search in EMBASE and MEDLINE, without any language restrictions, was performed for both post-thrombotic obstruction and non-thrombotic iliac vein compression on July $29^{\text {th }}, 2015$. The search was updated on February $5^{\text {th }}, 2016$. An example search in EMBASE is presented in Table 2.S1. Full search strategies in all resources are available via the authors.

ClinicalTrials.gov, the World Health Organization International Clinical Trials Registry and Current Controlled Trials were also searched.

\section{Searching other resources}

All references of randomised controlled trials, systematic reviews, meta-analyses and other relevant papers were checked to identify possible missing studies. 


\section{Data collection and analysis}

\section{Study selection}

Authors RK and MW independently selected studies eligible for inclusion on the basis of title and abstract. Next, complete text articles of the remaining studies were acquired and read independently by both authors. Studies that did not comply with the inclusion criteria were excluded from the review. If authors disagreed, the problem was discussed between them. Disputes were planned to be decided by author RG, though authors RK and MW were able to resolve all disagreements.

\section{Data extraction}

Data were extracted independently by authors RK and MW, following a standardised form. This form assessed methodological aspects, study population characteristics, the aforementioned prognostic factors, and primary and secondary outcome parameters. Forms were compared and discrepancies were discussed and resolved by both authors.

\section{Risk bias assessment}

Risk of bias was independently assessed by authors RK and MW for all included studies. During this process, specific attention was given to the selection and inclusion process, validity and precision of outcome measurements, follow-up duration, and missing data and loss to follow-up. After assessing the studies, risk bias was classified as either low, moderate or high according to the Quality In Prognosis Studies (QUIPS) tool. ${ }^{18}$

\section{Measures of prognostic value}

We envisaged that most of the studies would have used multivariable models to evaluate the prognostic value of haemodynamic parameters. For dichotomous outcomes we planned to extract odds ratios (OR) with 95\% confidence intervals (CI) or standard errors (SE) from logistic regression models, whereas for continuous outcomes we planned to extract means with $95 \% \mathrm{CI}$ or SE.

\section{Missing data}

We contacted study authors to obtain any missing data or resolve any queries during the data extraction.

\section{Heterogeneity assessment}

Due to the expected variation in studies, we describe the compatibility of the included studies in a narrative fashion, looking at definitions of patients, prognostic factors and outcomes.

\section{Publication bias}

It was not possible to create funnel plots to investigate possible small study biases because of the lack of uniformity in outcome parameters. 


\section{Data synthesis}

A narrative summary of all of the included studies is presented. This includes a summary of the characteristics and risk of bias of the studies, according to QUIPS, including any factors that may limit the generalisability of the findings.

\section{Subgroup analysis}

Prognostic parameters are investigated individually. We did not envisage that meta-analysis would be possible, so subgroup analysis analyses were not performed

\section{Results}

\section{Study selection}

The post-thrombotic search yielded a total of 5,418 hits, of which four studies were included in this review. The search for non-thrombotic iliac vein compression yielded a total of 2,144 hits, of which one study was included in this review. More information on the inclusion and exclusion process can be found in the study flow charts (Figures 2.1 and 2.2). All included studies were either prospective or retrospective case series. One investigated stenting with subgroup analyses for post-thrombotic and non-thrombotic obstruction, ${ }^{10}$ one evaluated stenting in combination with endophlebectomy and creation of an arteriovenous fistula (hybrid procedure), ${ }^{19}$ one investigated bypass surgery, ${ }^{20}$ and one study was a larger case series with a subgroup of patients treated with surgical bypass (Table 2.1). ${ }^{21}$

\section{Study characteristics}

\section{Stenting for post-thrombotic obstruction}

Neglén et al. ${ }^{10}$ published a prospective case series of their clinical experience with stenting of post-thrombotic deep venous obstruction (464 limbs) and non-thrombotic iliac vein compression (518 limbs) with sub-group analyses for the two aetiology types. Median age for the whole cohort was 54 years (14-90), with 2.6 times as many women than men. Median follow-up was 24 months ( 1 month to 8.75 years) with 7\% loss to follow-up. This study was not designed to assess prognostic effects. Ambulatory venous pressure (AVP) drop, measured at the dorsal foot vein after ten tiptoe movements, and the time required for pressure to return to base level (venous filling time, VFT); hand-foot pressure differential; hyperaemiainduced pressure increase; and venous filling index, venous volume, ejection fraction and residual volume fraction determined by air plethysmography (APG) were compared between nonhealing and healing limbs. However, nonhealing and healing were not properly defined, and these results were not divided in post-thrombotic and non-thrombotic aetiology.

Kurstjens et al. ${ }^{19}$ published a retrospective cohort study that investigated the risk of thrombotic events between two methods of hybrid recanalisation of post-thrombotic femoro-iliocaval obstruction, i.e. stenting with desobstruction of the common femoral vein and creation of an arteriovenous fistula (AVF). One group consisted of 42 limbs with the AVF placed cranially, and the other group of 23 limbs with the AVF placed caudally in the endophlebectomy area. Mean age was $39.5 \pm 16.6$ years for the cranial and $38.8 \pm 11.6$ years for the caudal group. In the first group $64.3 \%$ were female and in the latter $56.5 \%$. Mean follow-up was $6.9 \pm 5.0$ months for the cranial and $17.8 \pm 8.6$ months for the caudal group. Reduced femoral inflow was one of the 

Records identified with electronic search
\[ (n=5,409) \]
Records identified through other sources $(n=9)$

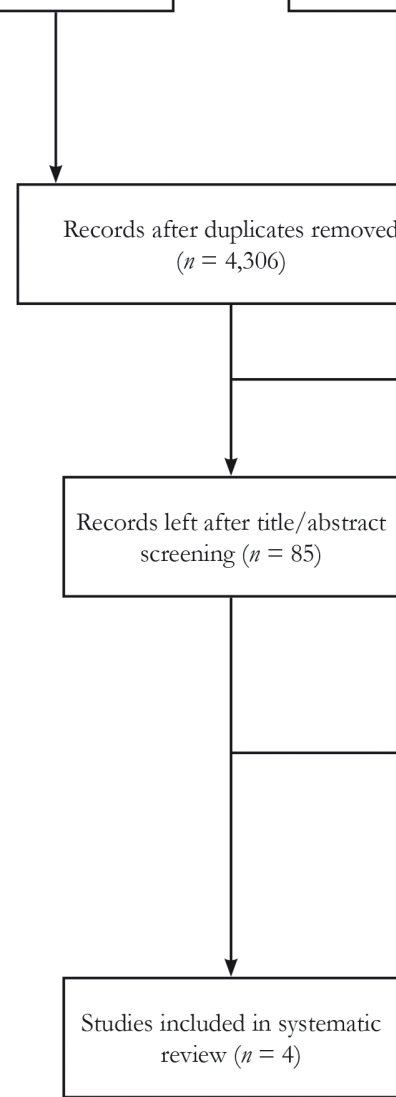

Records excluded $(n=4,221)$

Records excluded $(n=81)$ :

Case report $(n=9)$

Only abstract $(n=5)$

Narrative review $(n=12)$

Expert opinion $(n=1)$

Only diagnostics $(n=2)$

Different intervention $(n=6)$

No post-thrombotic obstruction $(n=1)$

Mix of aetiology $(n=14)$

More recent paper available $(n=5)$ Not able to contact author for full text $(n=5)$

No haemodynamic tests $(n=13)$

No prognostic analysis $(n=7)$

No data available yet $(n=1)$

Figure 2.1 Study flow chart for post-thrombotic search.

None of the records identified through other sources were ultimately included.

parameters included in the multiple logistic regression performed. This was defined as postthrombotic changes in the femoral vein, deep femoral vein or both on duplex and/or magnetic resonance venography ( 0 if none were affected, 1 if one vein was affected, and 2 if both were affected).

\section{Bypass surgery for post-thrombotic obstruction}

AbuRahma et al. ${ }^{20}$ performed a retrospective cohort study to determine the haemodynamic, clinical and anatomical predictors of long-term outcome of two types of venous bypass: 24 crossover femoral vein saphenofemoral bypasses (CFVB) and 19 saphenopopliteal bypasses (SPVB). Mean age was 47.1 years for CFVB and 45.7 years for SPVB, 62.5\% of CFVB and $68.4 \%$ of SPVB were female. Mean follow-up was 61.2 months for CFVB and 66.2 months for SPVB, 5 patients died during follow-up. Haemodynamic tests performed were maximum venous outflow (MVO) measured by strain gauge plethysmography (SPG), venous refill time (VRT) measured by photoplethysmography (PPG) and foot vein pressure measurements with calf exercise through dorsiflexion. 
Records identified with electronic search $(n=2,143)$
Records identified through other sources $(n=1)$

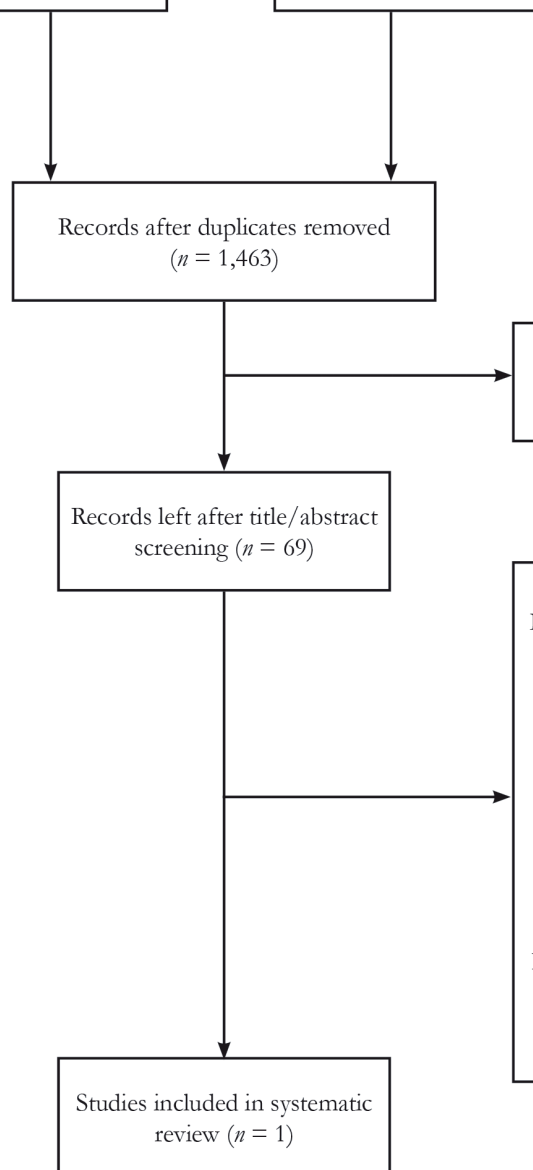

Records excluded $(n=1,394)$

Records excluded $(n=68)$

Double publication in different journal $(n=1)$

Case report $(n=8)$

Only abstract $(n=8)$

Narrative review $(n=14)$

Expert opinion $(n=1)$

Comment $(n=3)$

Different intervention $(n=1)$

No intervention $(n=1)$

Mix of aetiology $(n=10)$

Post-thrombotic disease $(n=7)$

More recent paper available $(n=3)$

Not able to contact author for full text $(n=1)$

No haemodynamic tests $(n=8)$

No follow-up $(n=1)$

No data available yet $(n=1)$

Figure 2.2 Study flow chart for non-thrombotic iliac vein compression search.

None of the records identified through other sources were ultimately included.

Glovickzi et al. ${ }^{21}$ published a prospective consecutive case series of their experience with reconstructions of large veins of the chest, thoracic outlet, abdomen or pelvis for benign obstructive disease. Reconstructions for malignant disease were excluded. Twelve limbs in eleven patients were treated by externally supported, expanded polytetrafluoroethylene bypass (one femoroiliac, three femorocaval, one bifemorocaval, one femoroatrial, four iliocaval, one cavoatrial). Save for one inferior vena cava injury during liver transplantation, all were performed for post-thrombotic obstruction. Mean age for this subgroup was 43.7 years (13-81), three of eight patients were female, and three underwent previous inferior vena cava interruption. Eight patients received an AVF. Median follow-up was 9 months (2 weeks to 5 years). Impedance plethysmography (IPG) was performed in ten patients, SPG in four, and femoral-central pressure gradient was determined in nine. 


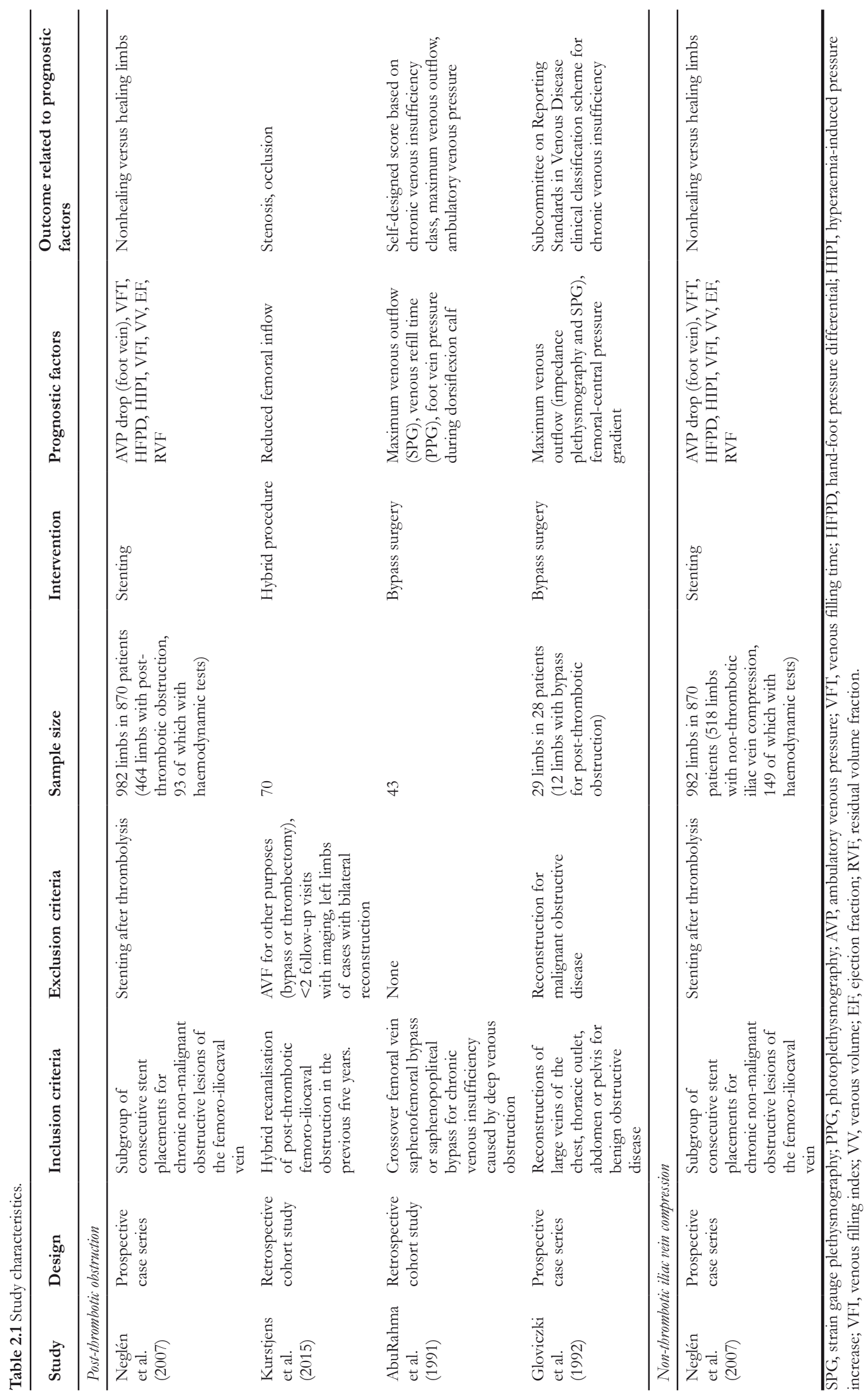




\section{Stenting for non-thrombotic iliac vein compression}

As mentioned in the section for post-thrombotic stenting, the study by Neglén et al. ${ }^{10}$ also applies for non-thrombotic iliac vein compression. Although most analyses were reported separately for this subgroup, prognostic information was indistinguishable from postthrombotic disease.

\section{Risk of bias (Table 2.2, Figure 2.3)}

Neglén et al. ${ }^{10}$ tested haemodynamic parameters in only $25 \%$ of the total study population, the reason for this selection and its process are not reported. Furthermore, whilst outcome measurements were clearly defined overall, no clear definitions were given for nonhealing and healing limbs, which were the units of outcome measure for the prognostic factors. Additionally, information on reflux with respect to the prognostic values is unclear, which could confound APG and AVP results.

Kurstjens et al. ${ }^{19}$ evaluated femoral inflow in all subjects, though based on post-thrombotic state of the femoral and/or deep femoral vein, which does not discriminate between the variations of flow quality that are possibly present within post-thrombotic veins. Furthermore, loss to follow-up could be more insightful, and the effect of more experience due to the historic nature of the case series or effects of poor adherence to post-operative anticoagulation cannot be ruled out. Other possible confounding factors, such as issues with stent configuration, number of stents, AVF size, and venotomy closure by patch or not, were included in regression analysis. The population was a subset with extensive disease requiring hybrid intervention as opposed to sole stenting.

AbuRahma et al. ${ }^{20}$ did not elaborate on the precise nature of deep venous obstruction; not all patients had a DVT in their history, though patients suffering from compression did not account for all the others. Another serious issue is the fact that the clinical outcome score contained elements pertaining to the investigated haemodynamic parameters, leading to bias of outcome measurement. Also, possible confounders were not mentioned.

Gloviczki et al. ${ }^{21}$ did not report on possible confounders, nor is there sufficient information on loss to follow-up. Moreover, information on predictive properties is limited and no information is given with respect to statistical analysis.

\section{Prognostic factors}

\section{Stenting for post-thrombotic obstruction}

Neglén et al. ${ }^{10}$ found that "nonhealing" limbs demonstrated a higher AVP drop (42 $\pm 19 \%$ vs. $58 \pm 21 \%$ drop), a shorter VFT (10 \pm 6 s versus $16 \pm 15 \mathrm{~s})$ and a greater VFI (5.1 \pm 2.5 $\mathrm{mL} / \mathrm{s}$ versus $3.3 \pm 1.5 \mathrm{~mL} / \mathrm{s}$ ) at baseline compared with "healing limbs". Hand-foot pressure differential, hyperaemia-induced pressure increase, VV, EF and RVF did not differ between limbs at baseline. These analyses were not reported per aetiology. It should be noted that AVP drop was significantly lower and VFI significantly higher for post-thrombotic limbs than for non-thrombotic limbs at baseline (AVP drop $59 \pm 20 \%$ vs. $70 \pm 18 \%$; and VFI $2.7 \pm 2.0$ s vs. $1.8 \pm 1.4 \mathrm{~s})$. VFT did not significantly differ at baseline between post-thrombotic and nonthrombotic limbs $(31 \pm 30 \mathrm{~s}$ and $37 \pm 29 \mathrm{~s})$. Venous volume, which was not different between nonhealing and healing limbs, was lower at baseline for thrombotic limbs compared with non- 


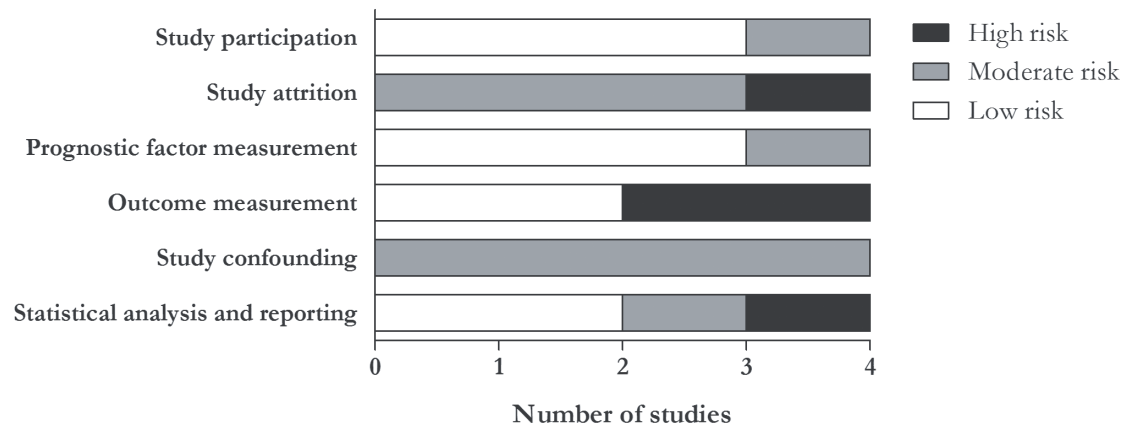

Figure 2.3 Summary of risk of bias for all studies.

Table 2.2 Risk bias assessment per study according to Quality In Prognosis Studies (QUIPS).

\begin{tabular}{|c|c|c|c|c|}
\hline & Neglén et al. & Kurstjens et al. & AbuRahma et al. & Gloviczki et al. \\
\hline Study participation & Low risk & Low risk & Moderate risk & Low risk \\
\hline Study attrition & High risk & Moderate risk & Moderate risk & Moderate risk \\
\hline Prognostic factor measurement & Low risk & Moderate risk & Low risk & Low risk \\
\hline Outcome measurement & High risk & Low risk & High risk & Low risk \\
\hline Study confounding & Moderate risk & Moderate risk & Moderate risk & Moderate risk \\
\hline Statistical analysis and reporting & Moderate risk & Low risk & Low risk & High risk \\
\hline
\end{tabular}

thrombotic limbs $(76 \pm 40 \mathrm{~mL}$ vs. $88 \pm 39 \mathrm{~mL})$. Kurstjens et al. ${ }^{19}$ found that reduced femoral inflow, based on pre-procedural post-thrombotic state of the femoral and deep femoral vein, had a significant effect on any patency-related event (occlusion or stenosis) with an odds ratio of 2.934 (95\% CI, 1.148-7.494). When solely taking the risk of occlusion into account, the odds ratio was 3.391 (95\% CI, 0.911-12.617).

\section{Bypass surgery for post-thrombotic obstruction}

AbuRahma et al. ${ }^{20}$ found that an abnormal MVO on SPG at baseline was predictive for clinical improvement in bypass surgery (CFVB $P=0.0002$, SPVB $P=0.0062)$; lower MVO correlated with higher clinical outcome score (standardised regression coefficient -0.74 for CFVB, $P<$ 0.0001 ; and -0.70 for SPVB, $P=0.0008)$. VRT $<10 \mathrm{~s}$ was only predictive for SPVB $(P=0.0472, \mathrm{CFVB}$ $P=0.1128$ ); higher VRT was correlated with a better clinical outcome score (standardised regression coefficient $0.53, P=0.0196$ ). Gloviczki et al. ${ }^{21}$ were not able to find a correlation between pre-operatively assessed venous outflow, measured by IPG and SPG, and clinical outcome or graft patency for ipsilateral bypasses.

Baseline foot vein pressure was not predictive for clinical improvement in either CFVB $(P=0.8296)$ or SPVB $(P=0.6455)$ in the study by AbuRahma et al. ${ }^{20}$ Baseline median femoralcentral pressure gradient was $16 \mathrm{mmHg}$ (5-27) for patients with excellent clinical outcome compared with $8 \mathrm{mmHg}$ (4-17) for those with no clinical improvement in the study by Gloviczki et al., ${ }^{21}$ who performed various ipsilateral bypasses (not significant, unclear what statistical test used). 


\section{Stenting for non-thrombotic iliac vein compression}

As mentioned with post-thrombotic disease, Neglén et al. ${ }^{10}$ found that AVP drop was higher, VFT shorter and VFI greater in nonhealing limbs. However, no differentiation was made between post-thrombotic disease and non-thrombotic compression syndromes in this analysis. VFT did not differ at baseline between post-thrombotic and non-thrombotic patients, yet AVP drop was higher and VFI lower for non-thrombotic limbs.

\section{Discussion}

Knowledge on the predictive effect of haemodynamic parameters for outcome of stenting deep venous obstruction is scant. Only a small amount of studies attempted to gain more insight into the prediction of success of treatment. Plethysmography has been the primary method of choice in most of these studies. Maximum venous outflow determined by SPG was found to correlate with clinical outcome in bypass surgery, ${ }^{20}$ whilst another study, mainly using IPG, was not able to find such an effect ${ }^{21}$ and no correlation was found with APG in a stenting population. ${ }^{10}$ Various reasons could explain this discrepancy. First, AbuRahma et al. ${ }^{20}$ used a self-designed tool for outcome measurement, which encompassed the investigated haemodynamic parameters. Thus, correlation between baseline measurement and outcome is a given. Second, Glovickzi et al. ${ }^{21}$ only made a statement that no correlation was found, without detailing how parameters were used and what statistical analyses were performed. Third, the definition for "nonhealing" and "healing" limbs is not given by Neglén et al., ${ }^{10}$ ergo it is unclear what exact outcome effect was tested. Fourth, the general role of plethysmography in deep venous obstruction remains debatable. ${ }^{22-27}$

APG parameters originally designed for incompetence were also tested before and after stenting. The only difference found between healing and nonhealing limbs was a higher VFI for nonhealing limbs at baseline. ${ }^{10}$ It is unclear whether this difference is present in both post-thrombotic and non-thrombotic venous obstructive disease. Post-thrombotic limbs demonstrated a higher VFI at baseline than limbs with non-thrombotic iliac vein compression. Thus, VFI might not be predictive for patients only suffering from compression. Moreover, these results are likely confounded by the presence of deep vein incompetence in post-thrombotic limbs, which is substantiated by the fact that the parameters did not change after stenting without adjunctive procedures for incompetence. ${ }^{10}$

Concerning pressure measurements, dorsal foot vein pressure was not predictive for clinical outcome in bypass surgery, yet higher venous refill time was correlated with a better clinical outcome in SPVB patients. ${ }^{20}$ Conversely, percentage drop in foot vein pressure after ten tiptoe movements at baseline was significantly lower in "healing" limbs in a population undergoing stenting. Venous filling time was longer for these patients, which corresponds with the bypass data. ${ }^{10}$ While most aforementioned caveats apply for these results as well, effects of venous reflux should especially be noted. It is highly likely that venous refill time and foot vein pressures epitomise the effects of deep vein incompetence, as SVPB is primarily performed to treat deep vein incompetence and VFT and AVP drop did not improve after sole stenting. Therefore, future research might better be directed at common femoral vein pressures. ${ }^{28}$ One study investigating such pressures during exercise was identified in the clinical trials databases; data are expected to be published in the near future. Femoral-central pressure gradients were not found to be of statistical significance in predicting outcome of bypass surgery. However, gradients were 16 $\mathrm{mmHg}(5-7)$ for patients with excellent clinical outcome compared with $8 \mathrm{mmHg}$ (4-17) for 
those with no clinical improvement in a small population where no information on statistical testing was supplied. ${ }^{21}$ Despite the broad ranges, it might be worthwhile to investigate this further in a larger population. Conversely, pressure measurements during exercise may be superior as it better represents situations during which patients develop complaints.

Long-term technical success of stenting might be predicted by flow measurements as reduced inflow yielded an odds ratio of 2.934 (95\% CI, 1.148-7.494) for the risk of stenosis or occlusion. ${ }^{19}$ Reduced inflow was determined by post-thrombotic state of the femoral and deep femoral veins, which lacks nuance in daily clinical practice. Further research should therefore focus on developing techniques to adequately assess common femoral vein inflow. Theoretically, flow may also be able to predict whether patients with successful recanalisation will have significant improvement in quality of life, as changes in flow can indicate severity of resistance caused by venous obstruction.

In addition to flow, formation of a collateral network may be an important factor in postthrombotic obstruction. ${ }^{29-33}$ Although no data on its predictive value was found with this systematic review, it has been reported that collaterals remaining visible after stenting might be a risk factor for in-stent restenosis, ${ }^{34}$ and that formation of a collateral network likely diminishes elevated intravenous pressure. ${ }^{29}$ Presence or absence of certain collateralisation patterns might therefore also be an indicator for clinical response to treatment. Similar to femoral flow, extent and quality of collateralisation cannot be appropriately determined; hence better techniques should be developed to investigate its importance.

Bias in this systematic review is unlikely. The search strategy was set up comprehensively, leading to little potential loss of eligible publications. Also, references of relevant publication were checked and both selection of studies and extraction of data were performed independently by two authors, limiting the risk of improper study exclusions even further.

\section{Conclusions}

Data on the predictive value of haemodynamic parameters for success of treatment in deep venous obstructive disease is scant and of poor quality. No proper conclusions can be drawn for stenting of non-thrombotic iliac vein compressions syndromes, as predictive data was not analysed by aetiology subgroup. Plethysmography does not seem to be of value in predicting clinical or technical outcome of stenting or bypass surgery in post-thrombotic disease (level 4 evidence $^{35}$ ). The relevance of dorsal foot vein pressure, venous refill times and femoral-central pressure gradients are unclear in predicting success of treatment in stenting or bypass surgery (level 4 evidence $^{35}$ ); results are likely confounded by deep vein incompetence. Reduced flow into the common femoral vein seems to be predictive for in-stent stenosis or occlusion (level 2 evidence $^{35}$ ), yet further investigations are necessary to improve quantification of venous flow. To conclude, more research into the predictive effect of haemodynamic parameters is warranted to be able to identify which patients will experience significant improvement in quality of life after stenting and which will not. In addition, the possibility of developing new techniques that evaluate the myriad of haemodynamic aspects should be explored.

\section{References}

1. Nicolaides AN. Investigation of chronic venous insufficiency: A consensus statement (France, March 5-9, 1997). Circulation 2000;102(20):E126-63.

2. Meissner MH, Eklof B, Smith PC, et al. Secondary chronic venous disorders. J Vasc Surg 2007;46 Suppl S:68S-83S. 
3. Recek C. Conception of the venous hemodynamics in the lower extremity. Angiology 2006;57(5):556-63.

4. Killewich LA, Martin R, Cramer M, Beach KW, Strandness DE, Jr. Pathophysiology of venous claudication. J Vasc Surg 1984;1(4):507-11.

5. May R, Thurner J. [A vascular spur in the vena iliaca communis sinistra as a cause of predominantly left-sided thrombosis of the pelvic veins]. Z Kreislaufforsch 1956;45(23-24):912-22.

6. May R, Thurner J. The cause of the predominantly sinistral occurrence of thrombosis of the pelvic veins. Angiology 1957;8(5):419-27.

7. de Wolf MA, de Graaf R, Kurstjens RL, Penninx S, Jalaie H, Wittens CH. Short-Term Clinical Experience with a Dedicated Venous Nitinol Stent: Initial Results with the Sinus-Venous Stent. Eur J Vasc Endovasc Surg 2015;50(4):518-26.

8. Garg N, Gloviczki P, Karimi KM, et al. Factors affecting outcome of open and hybrid reconstructions for nonmalignant obstruction of iliofemoral veins and inferior vena cava. J V asc Surg 2011;53(2):383-93.

9. Jost CJ, Gloviczki P, Cherry KJ, Jr., et al. Surgical reconstruction of iliofemoral veins and the inferior vena cava for nonmalignant occlusive disease. J Vasc Surg 2001;33(2):320-7; discussion 7-8.

10. Neglen P, Hollis KC, Olivier J, Raju S. Stenting of the venous outflow in chronic venous disease: long-term stentrelated outcome, clinical, and hemodynamic result. J Vasc Surg 2007;46(5):979-90.

11. Oguzkurt L, Tercan F, Ozkan U, Gulcan O. Iliac vein compression syndrome: outcome of endovascular treatment with long-term follow-up. Eur J Radiol 2008;68(3):487-92.

12. Rosales A, Sandbaek G, Jorgensen JJ. Stenting for chronic post-thrombotic vena cava and iliofemoral venous occlusions: mid-term patency and clinical outcome. Eur J Vasc Endovasc Surg 2010;40(2):234-40.

13. Wen-da W, Yu Z, Yue-Xin C. Stenting for chronic obstructive venous disease: A current comprehensive metaanalysis and systematic review. Phlebology 2016;31(6):376-89.

14. Hartung O, Loundou AD, Barthelemy P, Arnoux D, Boufi M, Alimi YS. Endovascular management of chronic disabling ilio-caval obstructive lesions: long-term results. Eur J Vasc Endovasc Surg 2009;38(1):118-24.

15. Ye K, Lu X, Li W, et al. Long-term outcomes of stent placement for symptomatic nonthrombotic iliac vein compression lesions in chronic venous disease. J Vasc Interv Radiol 2012;23(4):497-502.

16. Catarinella FS, Nieman FH, de Wolf MA, Toonder IM, de Graaf R, Wittens CH. Quality-of-life in interventionally treated patients with post-thrombotic syndrome. Phlebology 2015;30(1 Suppl):89-94.

17. de Wolf MAF, Arnoldussen CW, Grommes J, et al. Minimally invasive treatment of chronic iliofemoral venous occlusive disease. Journal of Vascular Surgery: Venous and Lymphatic Disorders 2013;1(2):146-53.

18. Hayden JA, van der Windt DA, Cartwright JL, Cote P, Bombardier C. Assessing bias in studies of prognostic factors. Ann Intern Med 2013;158(4):280-6.

19. Kurstjens RL, de Graaf R, Barbati ME, et al. Arteriovenous fistula geometry in hybrid recanalisation of postthrombotic venous obstruction. Phlebology 2015;30(1 Suppl):42-9.

20. AbuRahma AF, Robinson PA, Boland JP. Clinical, hemodynamic, and anatomic predictors of long-term outcome of lower extremity venovenous bypasses. J Vasc Surg 1991;14(5):635-44.

21. Gloviczki P, Pairolero PC, Toomey BJ, et al. Reconstruction of large veins for nonmalignant venous occlusive disease. J Vasc Surg 1992;16(5):750-61.

22. Delis KT, Bountouroglou D, Mansfield AO. Venous claudication in iliofemoral thrombosis: long-term effects on venous hemodynamics, clinical status, and quality of life. Ann Surg 2004;239(1):118-26.

23. Hurst DR, Forauer AR, Bloom JR, Greenfield LJ, Wakefield TW, Williams DM. Diagnosis and endovascular treatment of iliocaval compression syndrome. J Vasc Surg 2001;34(1):106-13.

24. Kalodiki E, Calahoras LS, Delis KT, Zouzias CP, Nicolaides AN. Air plethysmography: the answer in detecting past deep venous thrombosis. J Vasc Surg 2001;33(4):715-20.

25. Labropoulos N, Volteas N, Leon M, et al. The role of venous outflow obstruction in patients with chronic venous dysfunction. Arch Surg 1997;132(1):46-51.

26. Lattimer CR, Geroulakos G, Kalodiki E. Calf volume changes with venous occlusion air plethysmography in assessment of patients after deep venous thrombosis. Journal of Vascular Surgery: Venous and Lymphatic Disorders 2014;2(4):416-23.

27. Locker T, Goodacre S, Sampson F, Webster A, Sutton AJ. Meta-analysis of plethysmography and rheography in the diagnosis of deep vein thrombosis. Emerg Med J 2006;23(8):630-5.

28. Kurstjens R, de Wolf M, de Graaf R, Wittens C. Hemodynamic changes in iliofemoral disease. Phlebology 2014;29(1 suppl):90-6.

29. Kurstjens RL, de Wolf MA, van Laanen JH, de Haan MW, Wittens CH, de Graaf R. Hemodynamic significance of collateral blood flow in chronic venous obstruction. Phlebology 2015;30(1 Suppl):27-34.

30. Umeoka S, Koyama T, Togashi K, Kobayashi H, Akuta K. Vascular dilatation in the pelvis: identification with CT and MR imaging. Radiographics 2004;24(1):193-208.

31. Neglen P, Raju S. Balloon dilation and stenting of chronic iliac vein obstruction: technical aspects and early clinical outcome. J Endovasc Ther 2000;7(2):79-91.

32. Arnoldussen CW, Toonder I, Wittens CH. A novel scoring system for lower-extremity venous pathology analysed using magnetic resonance venography and duplex ultrasound. Phlebology 2012;27 Suppl 1:163-70.

33. Thomas ML, Fletcher EW, Cockett FB, Negus D. Venous collaterals in external and common iliac vein obstruction. Clin Radiol 1967;18(4):403-11. 
34. Ye K, Lu X, Jiang M, et al. Technical details and clinical outcomes of transpopliteal venous stent placement for postthrombotic chronic total occlusion of the iliofemoral vein. Journal of Vascular \& Interventional Radiology 2014;25(6):925-32.

35. Neglen P, Thrasher TL, Raju S. Venous outflow obstruction: An underestimated contributor to chronic venous disease. J V asc Surg 2003;38(5):879-85. 
Table 2.S1 EMBASE search for post-thrombotic obstruction.

\begin{tabular}{|c|c|}
\hline $\begin{array}{l}\text { Post-thrombotic } \\
\text { obstruction terms }\end{array}$ & 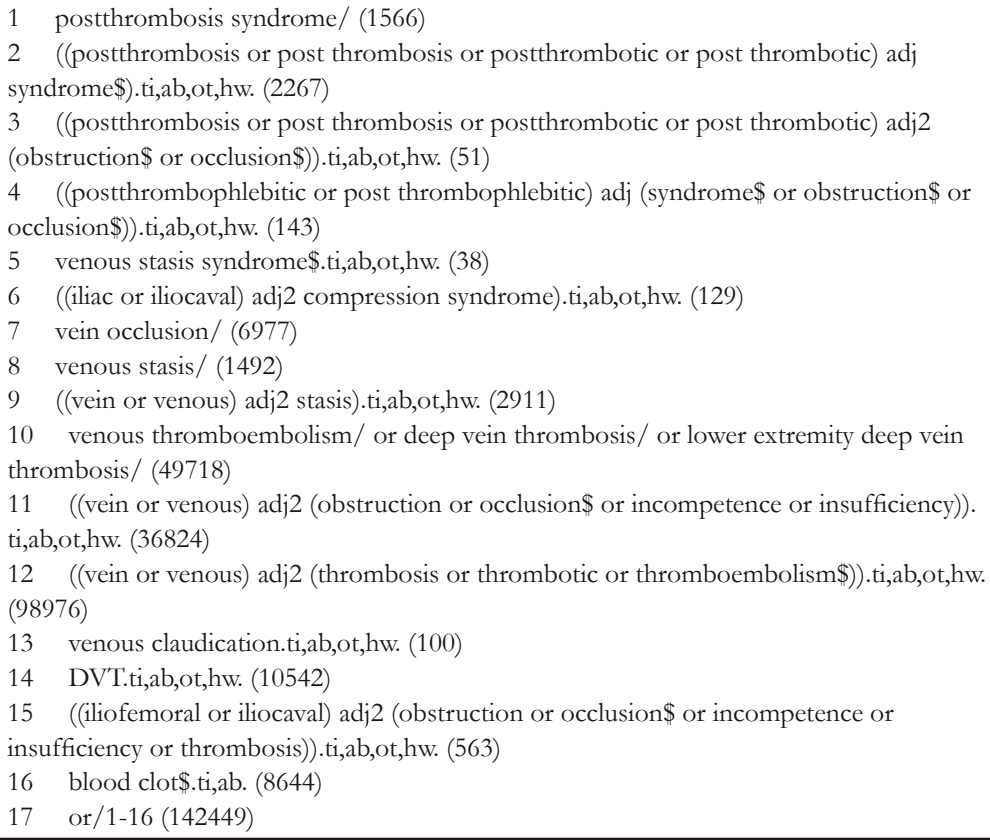 \\
\hline $\begin{array}{l}\text { Haemodynamic } \\
\text { parameters terms }\end{array}$ & $\begin{array}{l}18 \text { exp hemodynamic parameters/ or exp hemodynamics/ (758632) } \\
19 \text { (h?emodynamic parameter\$ or h?emodynamics).ti,ab,ot,hw. (179433) } \\
20 \text { (venous pressure or intravenous pressure or blood pressure or iliofemoral pressure or } \\
\text { iliocaval pressure).ti,ab,ot,hw. (460538) } \\
21 \text { (diastolic pressure or systolic pressure).ti,ab,ot,hw. (27527) } \\
22 \text { venous volume.ti,ab,ot,hw. (333) } \\
23 \text { (pressure gradient or pressure differential or pressure rise).ti,ab,ot,hw. (15237) } \\
24 \text { ((blood or venous) adj2 (flow or outflow or inflow)).ti,ab,ot,hw. (301080) } \\
25 \text { (flow adj2 measur\$).ti,ab,ot,hw. (36788) } \\
26 \text { plethysmography.ti,ab,ot,hw. (25128) } \\
27 \text { photoplethysmography.ti,ab,ot,hw. (1262) } \\
28 \text { (collateral pathway\$ or collateral system\$ or collaterali?ation or collateral circulation). } \\
\text { ti,ab,ot,hw. (16005) } \\
29 \text { (presence adj2 collateral\$).ti,ab,ot,hw. (429) } \\
30 \text { foot volumetry.ti,ab,ot,hw. (65) } \\
31 \text { or/18-30 (978225) }\end{array}$ \\
\hline $\begin{array}{l}\text { Obstruction AND } \\
\text { haemodynamics }\end{array}$ & 17 and 31 (18268) \\
\hline $\begin{array}{l}\text { Exclude animal-only } \\
\text { studies }\end{array}$ & $\begin{array}{l}33 \text { animal/ or animal experiment/ ( } 3629991) \\
34 \text { (rat or rats or mouse or mice or murine or rodent or rodents or hamster or hamsters } \\
\text { or pig or pigs or porcine or rabbit or rabbits or animal or animals or dogs or dog or cats or } \\
\text { cow or bovine or sheep or ovine or monkey or monkeys).ti,ab,ot,hw. (5892686) } \\
3533 \text { or } 34(5892686) \\
36 \text { exp human/ or human experiment/ (15301130) } \\
37 \quad 35 \text { not ( } 35 \text { and } 36)(4686065) \\
38 \quad 32 \text { not } 37(16634)\end{array}$ \\
\hline Prognosis filter & $\begin{array}{l}39 \text { follow-up.mp. or prognos\$.tw. or ep.fs. (2372974) } \\
4038 \text { and } 39 \text { (2984) }\end{array}$ \\
\hline
\end{tabular}





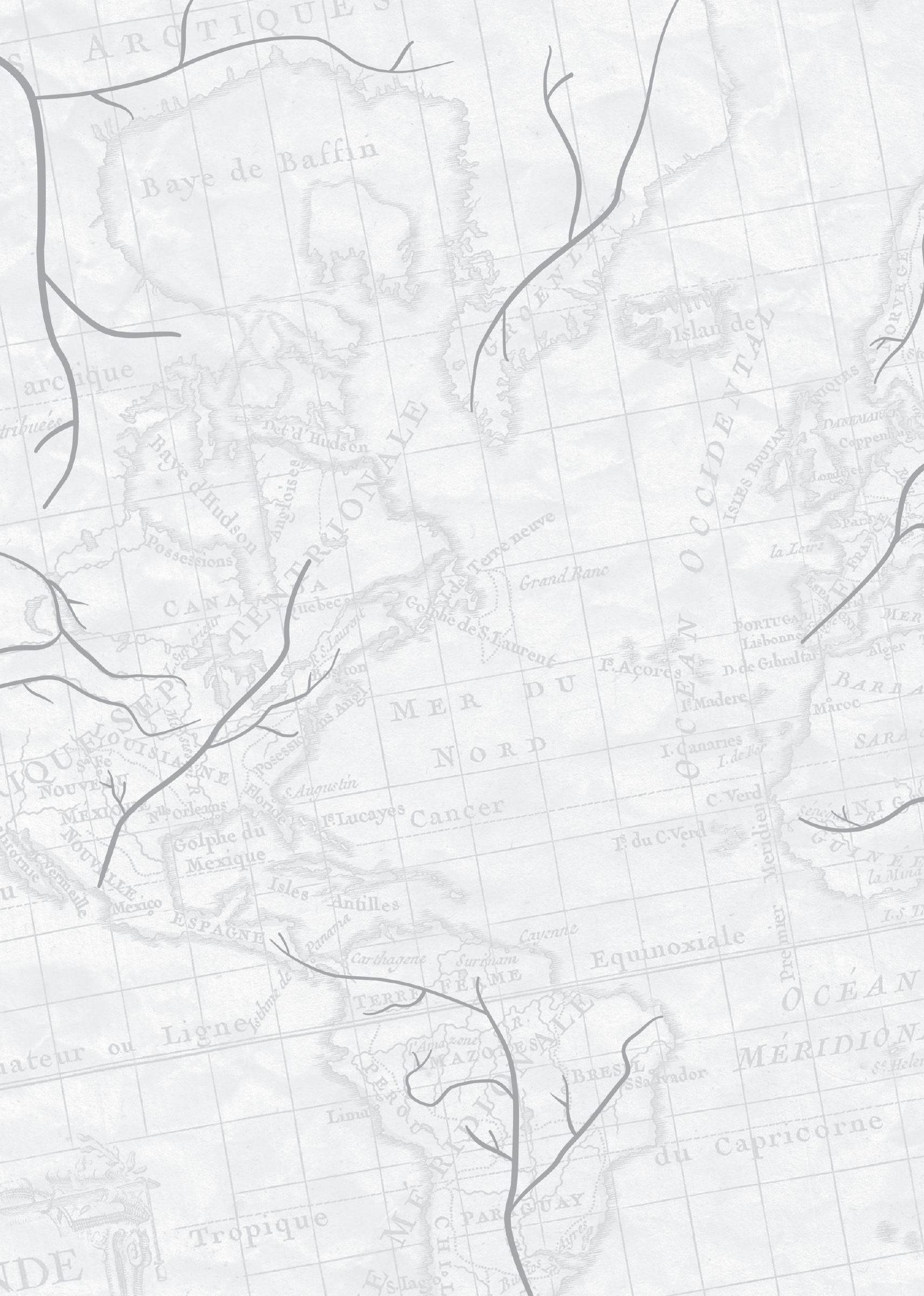




\title{
Chapter 3
}

The value of haemodynamic measurements by air plethysmography in diagnosing venous obstruction of the lower limb

\author{
Ralph L.M. Kurstjens \\ Mark A.F. de Wolf \\ Sarah A. Alsadah \\ Carsten W.K.P. Arnoldussen \\ Rob H.W. Strijkers \\ Irwin M. Toonder \\ Cees H.A. Wittens
}

J Vasc Surg Venous Lymphat Disord. 2016;4(3):313-9 


\begin{abstract}
Objective: Air plethysmography (APG) is a functional, non-invasive test that can assess volumetric changes in the lower limb and might therefore be used as a diagnostic tool in chronic deep venous disease. However, use of APG in chronic deep venous obstructive disease remains debatable. This study assessed the clinical value of APG in identifying chronic deep venous obstruction.

Methods: All patients referred to our tertiary, outpatient clinic between January 2011 and August 2013 with chronic venous complaints and suspected outflow obstruction underwent an outflow fraction $(\mathrm{OF})$, ejection fraction $(\mathrm{EF})$ and residual volume fraction (RVF) test using APG. Duplex ultrasound and magnetic resonance venography were used to establish whether and where obstruction was present. Diagnostic values of these tests were assessed for obstructions at different levels of the deep venous system.

Results: A total of 312 limbs in 248 patients were tested. Mean age was $45.5 \pm 14.0$ years, and $62.5 \%$ were female. In post-thrombotic disease, specificity and positive predictive value for $\mathrm{OF}$ were as high as 98\% and 95\% respectively. However, sensitivity was 35\% and negative predictive value was $30 \%$, with no clinically relevant positive or negative likelihood ratios. No clinically relevant differences were observed when stratifying for level of obstruction. EF and RVF were as inconclusive. Neither could these parameters be used in diagnosing non-thrombotic iliac vein compression.

Conclusions: We found a poor correlation between OF, EF or RVF, determined by APG, and the presence of chronic deep venous obstruction. Therefore, use of its relative parameters is unwarranted in daily clinical practice.
\end{abstract}




\section{Introduction}

With the advancing knowledge of chronic venous disease it has become apparent that primary superficial or deep vein incompetence is not the only cause of persisting venous complaints in the lower limb. ${ }^{1-3}$ Often, deep venous obstruction is present, which can occur as a result of inadequate recanalisation after deep venous thrombosis, external compression or congenital abnormalities. Percutaneous angioplasty with stenting has been accepted as a primary treatment option in patients with moderate to severe venous complaints due to obstructive disease central to the femoral confluence. This has good clinical results, with patency rates ranging from $60 \%$ to 100\%.4-6 Deep venous obstruction can be diagnosed using duplex ultrasound (DUS), magnetic resonance venography (MRV), computed tomography venography, intravascular ultrasound and venography, ${ }^{7-9}$ although most can be difficult to perform in these types of patients and are not routinely used in non-specialised centres. Thus, a different non-invasive test should be available to identify what patients need further examining.

Air plethysmography (APG) is a functional, non-invasive test that can be used to assess volumetric changes in the lower leg. This test uses an air-inflated cuff, placed around the calf, to detect pressure changes resulting from small variations in calf circumference and can therefore be used to monitor volumetric changes of the calf. The technique has been validated for quantifying valve incompetence, ${ }^{10,11}$ although research showed that APG might also be used to assess the presence of deep venous obstruction through an outflow fraction (OF) test. ${ }^{12,13}$ Consequently, this test might be used to differentiate which patients need more extensive imaging and which patients do not. However, results relating to chronic obstructive disease remain debatable, with evidence suggesting that it mainly tests elastic recoil properties. ${ }^{12-19}$ The aim of this study was to assess the clinical value of APG in identifying chronic deep venous obstruction of the lower limb.

\section{Methods}

\section{Study design and participants}

In this study, diagnostic abilities of the OF obtained by APG to identify the presence of deep venous obstruction were assessed. Cut-off values for obstruction were used as recommended in literature.

All patients referred to our tertiary, specialised, venous outpatient clinic for evaluation of chronic venous complaints during the period from January 2011 until August 2013 were prospectively analysed. Only patients with suspected venous outflow obstruction were analysed using APG. Criteria for further examination of suspected deep venous obstruction were the presence of venous claudication; an abdominal wall collateral vein; $\mathrm{C}_{4}-\mathrm{C}_{6}$ disease according to the ClinicalEtiology-Anatomy-Pathophysiology (CEAP) classification; the recurrence of varicosities in $<5$ years after treatment; and a history of deep venous thrombosis. All DUS results were collected from patient files, and MRV results were re-evaluated by authors RK or CA. All APG traces were checked for inaccuracies by authors RK, MW and SA. In addition, Venous Clinical Severity Score (VCSS), Villalta scale, CEAP classification and information on venous claudication were collected from patient files to determine whether outflow obstruction was clinically significant.

Retrospective analysis of these data was approved by the medical ethical review board (METC 14-4-193, March 5, 2015). Patient consent for retrospective analysis of clinical data does not need to be actively sought after in the Netherlands; no patients registered an objection to anonymous use of data. 


\section{Airplethysmography}

APG was performed by one of five dedicated physician researchers, following a standardised operating procedure and using the APG Air Plethysmograph C-1000 (ACI Medical, San Marcos, CA, USA). In the supine position, the affected limb was elevated above the level of the heart and rested on a foam block. A rapid deflatable cuff was fastened around the affected limb, proximal to the knee, and inflated to $80 \mathrm{mmHg}$. This enabled arterial inflow, but prevented venous outflow until venous volume reached a plateau phase. Then, outflow was measured by rapidly deflating the cuff above the knee, waiting until the collected blood had been ejected from the limb (Figure 3.1). OF was considered to be impaired when it was $\leq 38 \%$, with an $\mathrm{OF}<28 \%$ constituting severe outflow obstruction. ${ }^{20,21}$

Finally, venous reflux and calf muscle performance was evaluated as suggested according to the literature (Figure 3.2). ${ }^{20,21}$ Single-ejection capacity and overall performance of the calf muscle pump were assessed for this study to evaluate whether these parameters can be indicative of venous outflow obstruction. We hypothesised that a deep venous obstruction will cause impaired outflow, resulting in a poor ejection capacity of the calf muscle pump and thus in a low ejection fraction (EF) and high residual volume fraction (RVF). An EF of $\leq 60 \%$ was considered to represent impaired calf function and an RVF of $>35 \%$ was considered to be abnormal. ${ }^{20}$

In cases in which the difference in baselines at the beginning and end of the latter part of the APG was $>10 \%$, the tests for evaluation of venous reflux and calf muscle pump capacity were repeated. If no new measurement was performed, patients were excluded from analysis for EF and RVF. Patients with indefinable actions on the registered trace were excluded for the test

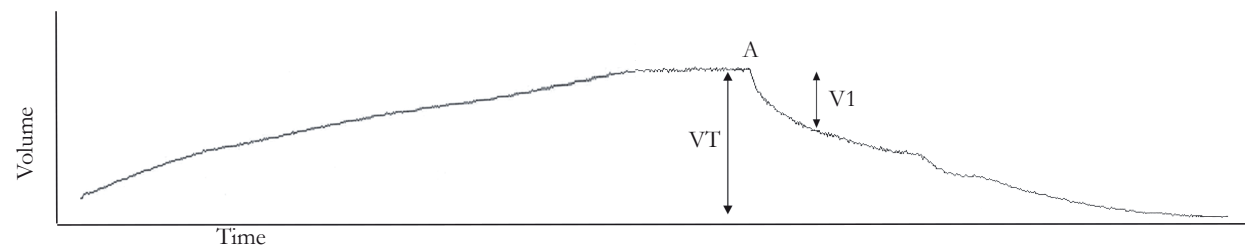

Figure 3.1 Outflow fraction test.

A maximum amount of blood is accumulated in the calf (A) and the proximal cuff is rapidly deflated. Outflow fraction equals volume at one-second outflow (V1) / total volume (VT) x 100\%.

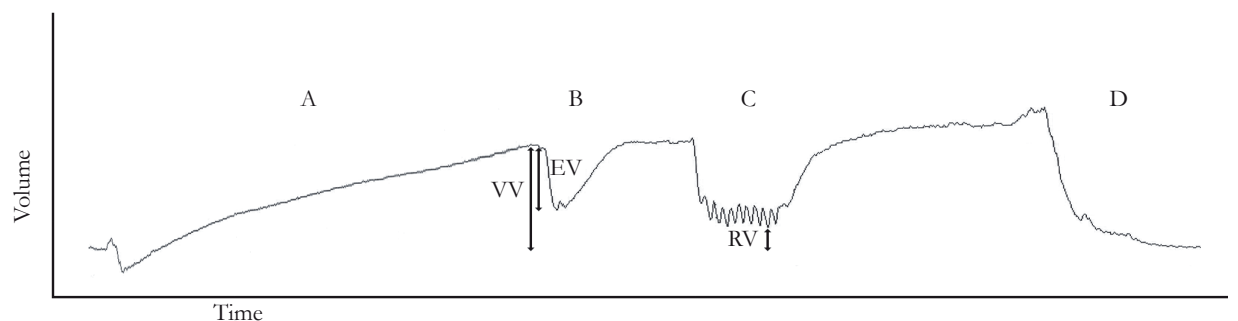

Figure 3.2 Air plethysmography curve for testing of reflux and calf muscle function.

A. After elevation of the leg, the patient will stand with the weight on the contralateral limb until maximum venous volume (VV) is reached. B. One tiptoe movement. C. Ten tiptoe movements. D. The patient returns to the supine position with the leg elevated. Ejection fraction equals ejection volume (EV) / VV x 100\%. Residual volume fraction equals residual volume (RV) / VV x 100\%. 
in question, as were patients showing evident air loss from the cuff or tubing on the trace. In patients with complaints of both limbs, the test was performed separately for each side.

\section{Imaging techniques}

The presence and extent of deep venous obstruction were determined by both DUS and MRV. If either diagnostic tool identified a post-thrombotic lesion, this segment was scored as positive. To avoid false positives, iliac vein compression was scored as positive if this was seen on both DUS and MRV.

DUS was performed in all patients using a Hitachi Aloka ProSound Alpha 7 Premier machine (Aloka, Tokyo, Japan) and following the protocol described in the literature. ${ }^{7}$ Vessel segments were considered to be post-thrombotic on DUS if flow division and intraluminal synechiae were observed. In addition, residual obstruction needed to be present. The extent of venous wall thickening or fibrosis was not assessed. Iliac vein compression was defined as a compression of the iliac vein of $>50 \%$, compared with a normal segment. Additionally, DUS was used to establish presence of venous reflux, which was considered pathologic if it lasted for $\geq 0.5 \mathrm{~s}^{22}$

MRV examinations were routinely performed in patients with suspected deep venous obstruction. This was done on a 1.5-T magnetic resonance imaging system (Intera; Philips Medical Systems, Best, the Netherlands) using gadofosveset trisodium (Ablavar; Lantheus Medical Imaging, Billerica, MA, USA) as a contrast agent and following the protocol as described in literature. ${ }^{7}$ Post-thrombotic venous obstruction was identified as hypodense intraluminal changes, indicating trabeculation. Iliac vein compression was defined as $>50 \%$ lumen reduction of the common or external iliac vein with the presence of collaterals.

\section{Statistics and definitions}

Contingency tables, patient characteristics data and frequencies of venous obstruction were computed using IBM SPSS Statistics version 21.0 (IBM Corporation, Armonk, NY, USA). Continuous data are presented as mean values with standard deviation or median values with range. Sensitivity, specificity, positive predictive value (PPV), negative predictive value (NPV) and their concomitant 95\% confidence intervals (CI) were calculated using GraphPad Prism version 5.04 (GraphPad Software, San Diego, CA, USA). Positive and negative likelihood ratios (LR+, LR-) were calculated by hand to quantify the change in probability of disease, or lack thereof, due to APG. Separate analyses were performed for patients with intraluminal postthrombotic obstruction and iliac vein compression. In post-thrombotic disease, two groups can be distinguished: limbs with obstruction proximal to the femoral confluence, possibly with lesions extending below the confluence, and limbs with obstruction only distal to the femoral confluence. All limbs were considered as independent cases, as analyses with random exclusion of one of the limbs for patients with bilateral measurements did not yield different results. Correlation coefficients or the Pearson's $\chi^{2}$ test were used to assess the influence of complaints. $P$-values $\leq 0.05$ were considered as statistically significant.

\section{Results}

A total of 455 patients were referred to our clinic between January 2011 and August 2013. Analysis for suspected deep venous obstruction was performed for 331 limbs in 262 patients (57.6\%). In four cases, the OF test was not performed because of technical difficulties with the 
rapid deflatable cuff. For 19 limbs in 14 patients, OF data were excluded due to evident cuff or tube leakage. Data on EF and RVF were excluded for 59 limbs in 49 patients due to a high baseline difference, indefinable actions on the trace, or apparent cuff or tube leakage. After exclusion, 312 limbs in 248 patients remained, of which 308 could be used for OF analysis and 272 for EF and RVF analysis (Figure 3.3).

Mean age was $45.5 \pm 14.0$ years, and $62.5 \%$ were female. In $66.3 \%$ of all included limbs, intraluminal post-thrombotic obstruction was present. Of those post-thrombotic limbs, 150 $(72.5 \%)$ had obstruction proximal to the femoral confluence, whereas 39 (18.8\%) had postthrombotic changes solely distal to the common femoral vein. The remainder of limbs were suspected of iliac vein compression in combination with post-thrombotic changes below the femoral confluence. Iliac vein compression without post-thrombotic lesions was present in $8.3 \%$ of limbs. No obstruction was detected in $20.8 \%$ of limbs (Figure 3.4). In $52.5 \%$ of all limbs, some form of incompetence was found. In $92.0 \%$ of cases, some form of complaints was present (Table 3.1). In 110 patients (44.4\%), additional venography was performed for deep venous treatment or evaluation of femoral and deep femoral vein incompetence. In two instances, venography did not concur with DUS or MRV regarding lesions proximal to the femoral confluence: once no iliac vein compression was found with a positive finding on DUS and MRV, and once some minor recanalisation was observed in the inferior vena cava that

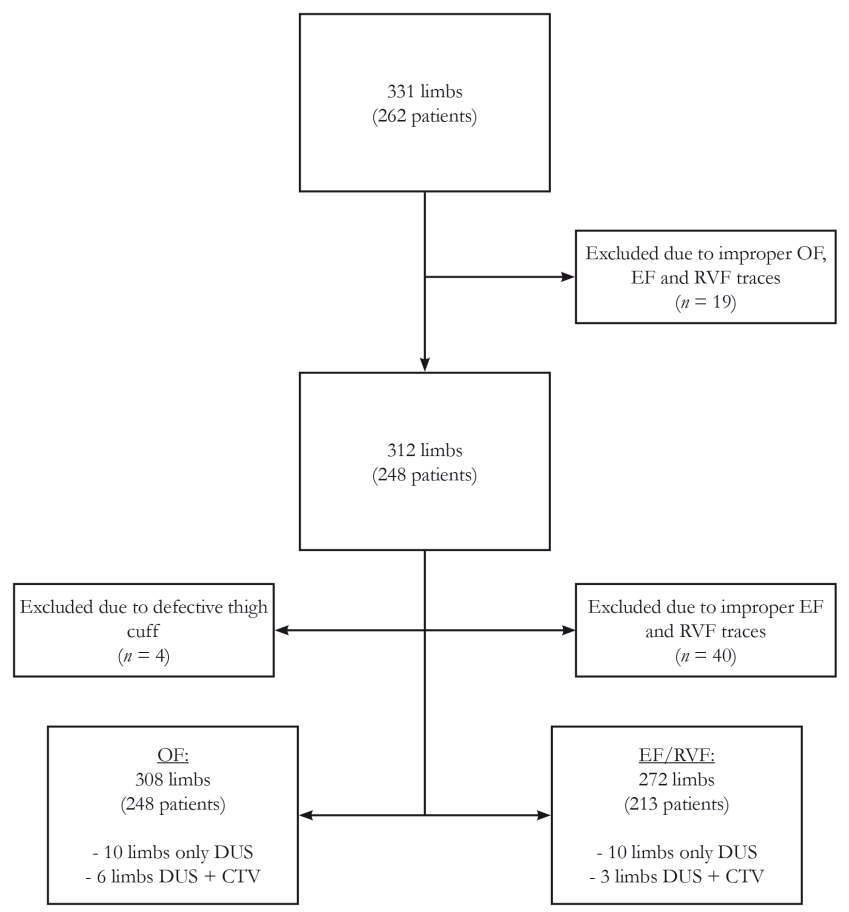

Figure 3.3 Inclusion and exclusion flow chart.

CTV, computed tomography venography (used when magnetic resonance venography was contraindicated or if patients did not consent to it); DUS, duplex ultrasound; EF, ejection fraction; OF, outflow fraction; RVF, residual volume fraction. 


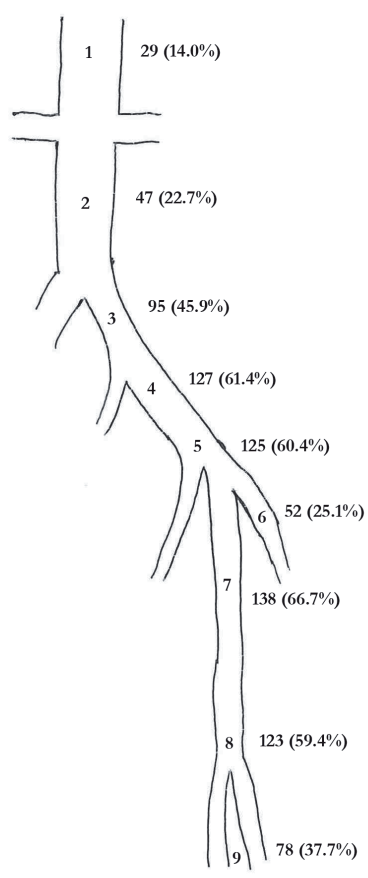

Figure 3.4 Location of intraluminal post-thrombotic obstruction $(n=207)$.

1, suprarenal inferior vena cava; 2, infrarenal inferior vena cava; 3 , common iliac vein; 4, external iliac vein; 5, common femoral vein; 6 , deep femoral vein; 7 , femoral vein; 8 , popliteal vein; 9, calf veins. The figures denote the amount of patients with intraluminal post-thrombotic obstruction in that specific segment; no distinction is made between right and left limbs.
Table 3.1 Patient characteristics.

\begin{tabular}{|c|c|}
\hline Number of patients & 248 \\
\hline Number of limbs, $n(\%)$ & 312 \\
\hline Left & $129(52.0)$ \\
\hline Right & $55(22.2)$ \\
\hline Bilateral & $64(25.8)$ \\
\hline Female sex, $n(\%)$ & $155(62.5)$ \\
\hline Age, years & $45.5 \pm 14.0$ \\
\hline Median duration of complaints, years & 3 (range, $1-52$ ) \\
\hline Venous claudication, $n(\%)^{*}$ & $170(54.5)$ \\
\hline History of previous venous intervention, $n(\%)$ & $80(32.4)$ \\
\hline \multicolumn{2}{|l|}{ Highest C of CEAP, $n(\%)^{\dagger}$} \\
\hline $\mathrm{C}_{0}$ & $26(8.4)$ \\
\hline $\mathrm{C}_{1}$ & $24(7.7)$ \\
\hline $\mathrm{C}_{2}$ & $56(18.1)$ \\
\hline $\mathrm{C}_{3}$ & $87(28.1)$ \\
\hline $\mathrm{C}_{4}$ & $82(26.5)$ \\
\hline $\mathrm{C}_{5}$ & $23(7.4)$ \\
\hline $\mathrm{C}_{6}$ & $12(3.9)$ \\
\hline \multicolumn{2}{|l|}{ Villalta scale, $n(\%)^{\ddagger}$} \\
\hline No PTS & $34(22.2)$ \\
\hline Mild PTS & $47(30.7)$ \\
\hline Moderate PTS & $44(28.8)$ \\
\hline Severe PTS & $28(18.3)$ \\
\hline Median VCSS & $6(\mathrm{IQR}, 4-9)$ \\
\hline Post-thrombotic disease, $n(\%)$ & $207(66.3)$ \\
\hline Iliac vein compression, $n(\%)^{4}$ & $26(8.3)$ \\
\hline No obstruction, $n(\%)$ & $65(20.8)$ \\
\hline Incompetent limbs, $n(\%)^{* *}$ & $145(52.5)$ \\
\hline Deep veins & $61(42.1)$ \\
\hline Superficial veins & $107(73.8)$ \\
\hline Perforating veins & $34(23.4)$ \\
\hline
\end{tabular}

CEAP, Clinical-Etiology-Anatomy-Pathophysiology; IQR, interquartile range; PTS, post-thrombotic syndrome; VCSS, Venous Clinical Severity Score. Plus-minus values are means \pm standard deviations.

*No data for 14 limbs ${ }^{\dagger}$ No data for two limbs ${ }^{\star}$ Only for limbs with post-thrombotic obstruction, no data for 54 limbs ${ }^{\S}$ No data for 68 limbs In 14 additional limbs, iliac vein compression was suspected on only one modality ${ }^{* *}$ No complete data pertaining to incompetence in 36 limbs. 
was not noted on DUS or MRV. The popliteal-femoral tract was not routinely assessed during venography and can thus not be properly compared with DUS and MRV.

\section{Outflow fraction}

The ability of the OF test to predict post-thrombotic deep venous obstruction, compared with DUS and MRV, was poor (sensitivity, 35\%; specificity, 88\%; PPV, 90\%; NPV, 30\%; LR+, 2.78 ; and LR-, 0.75). When the $28 \%$ cut-off value was used for OF, representing severe outflow obstruction, specificity and PPV improved to $98 \%$ and $95 \%$ respectively, whereas sensitivity was $9 \%$ and NPV was $25 \%$. The LR+ increased to 5.96 , although the LR- worsened (0.92). Stratifying for location according to treatability did not sufficiently change the diagnostic properties for either cut-off value (Table 3.2), nor did this change when only obstructions limited to the region between the common femoral vein and inferior vena cava were analysed (data not given).

In cases of iliac vein compression, diagnostic value was less (sensitivity, $15 \%$; specificity, 88\%; PPV, 33\%; NPV, 72\%; LR+, 1.23; and LR-, 0.97). The cut-off value for severe obstruction could not be used as only one positive APG result was found in a patient without any obstruction.

\section{Ejection fraction}

Using impaired EF as a parameter for possible chronic deep venous obstruction did not yield better results (sensitivity, 64\%; specificity, 48\%; PPV, 79\%; NPV, 31\%; LR+, 1.24; LR-, 0.74). Correction for any form of reflux (LR+, 1.21; LR-, 0.77) did not notably change diagnostic value. Overall diagnostic quality of the test did not improve when stratifying for level of obstruction (Table 3.2). For iliac vein compression, EF did not fare better as a possible parameter to identify chronic obstruction (sensitivity, 59\%; specificity, 48\%; PPV, 30\%; NPV, 76\%; LR+, 1.14; and LR-, 0.85). Correcting for reflux resulted in no true positive test results.

Table 3.2 Post-thrombotic obstruction stratified for level of obstruction.

\begin{tabular}{|c|c|c|c|c|c|c|c|}
\hline & & $\begin{array}{l}\text { Sensitivity, \% } \\
(95 \% \mathrm{CI})\end{array}$ & $\begin{array}{l}\text { Specificity, \% } \\
(95 \% \text { CI })\end{array}$ & $\begin{array}{l}\mathrm{PPV}, \% \\
(95 \% \mathrm{CI})\end{array}$ & $\begin{array}{l}\text { NPV, } \% \\
(95 \% \mathrm{CI})\end{array}$ & $\mathrm{LR}+$ & LR- \\
\hline \multirow[t]{2}{*}{$\mathrm{OF} \leq 38 \%$} & $\begin{array}{l}\text { Proximal to femoral } \\
\text { confluence }\end{array}$ & $\begin{array}{l}29 \\
(22-37)\end{array}$ & $\begin{array}{l}88 \\
(77-95)\end{array}$ & $\begin{array}{l}84 \\
(71-93)\end{array}$ & $\begin{array}{l}35 \\
(28-43)\end{array}$ & 2.32 & 0.81 \\
\hline & $\begin{array}{l}\text { Distal to femoral } \\
\text { confluence }\end{array}$ & $\begin{array}{l}44 \\
(28-60)\end{array}$ & $\begin{array}{l}88 \\
(77-95)\end{array}$ & $\begin{array}{l}68 \\
(47-86)\end{array}$ & $\begin{array}{l}72 \\
(61-81)\end{array}$ & 3.49 & 0.64 \\
\hline \multirow[t]{2}{*}{$\mathrm{OF}<28 \%$} & $\begin{array}{l}\text { Proximal to femoral } \\
\text { confluence }\end{array}$ & $\begin{array}{l}7 \\
(4-13)\end{array}$ & $\begin{array}{l}98 \\
(92-100)\end{array}$ & $\begin{array}{l}92 \\
(62-100)\end{array}$ & $\begin{array}{l}32 \\
(25-38)\end{array}$ & 4.76 & 0.94 \\
\hline & $\begin{array}{l}\text { Distal to femoral } \\
\text { confluence }\end{array}$ & $\begin{array}{l}18 \\
(8-34)\end{array}$ & $\begin{array}{l}98 \\
(92-100)\end{array}$ & $\begin{array}{l}88 \\
(47-100)\end{array}$ & $\begin{array}{l}66 \\
(56-76)\end{array}$ & 11.5 & 0.83 \\
\hline \multirow[t]{2}{*}{$\mathrm{EF} \leq 60 \%$} & $\begin{array}{l}\text { Proximal to femoral } \\
\text { confluence }\end{array}$ & $\begin{array}{l}65 \\
(55-73)\end{array}$ & $\begin{array}{l}48 \\
(35-62)\end{array}$ & $\begin{array}{l}72 \\
(63-80)\end{array}$ & $\begin{array}{l}40 \\
(29-52)\end{array}$ & 1.25 & 0.73 \\
\hline & $\begin{array}{l}\text { Distal to femoral } \\
\text { confluence }\end{array}$ & $\begin{array}{l}65 \\
(48-80)\end{array}$ & $\begin{array}{l}48 \\
(35-62)\end{array}$ & $\begin{array}{l}44 \\
(30-58)\end{array}$ & $\begin{array}{l}69 \\
(53-82)\end{array}$ & 1.26 & 0.73 \\
\hline \multirow[t]{2}{*}{$\mathrm{RVF}>35 \%$} & $\begin{array}{l}\text { Proximal to femoral } \\
\text { confluence }\end{array}$ & $\begin{array}{l}40 \\
(32-50)\end{array}$ & $\begin{array}{l}47 \\
(34-60)\end{array}$ & $\begin{array}{l}61 \\
(50-72)\end{array}$ & $\begin{array}{l}28 \\
(19-37)\end{array}$ & 0.76 & 1.28 \\
\hline & $\begin{array}{l}\text { Distal to femoral } \\
\text { confluence }\end{array}$ & $\begin{array}{l}60 \\
(42-75)\end{array}$ & $\begin{array}{l}47 \\
(34-60)\end{array}$ & $\begin{array}{l}41 \\
(28-55)\end{array}$ & $\begin{array}{l}65 \\
(49-79)\end{array}$ & 1.12 & 0.87 \\
\hline
\end{tabular}

CI, confidence interval; EF, ejection fraction; LR+, positive likelihood ratio; LR-, negative likelihood ratio; NPV, negative predictive value; $\mathrm{OF}$, outflow fraction; PPV, positive predictive value; RVF, residual volume fraction. 


\section{Residual volume fraction}

The RVF was the worst tested parameter in diagnosing chronic deep venous obstruction (sensitivity, 45\%; specificity, 47\%; PPV, 71\%; NPV, 22\%; LR+, 0.84; and LR-, 1.19). Correcting for reflux did not notably change results (LR+, 0.72; LR-, 1.38). When stratifying for level of obstruction, only the group with obstruction peripheral from the femoral confluence showed a slight, although clinically irrelevant, improvement (LR+, 1.12; LR-, 0.87; Table 3.2). In cases of iliac vein compression, RVF fared even worse (sensitivity, 41\%; specificity, 47\%; PPV, 22\%; NPV, $68 \%$; LR+, 0.77; LR-, 1.27). Correction for reflux was, again, not possible.

\section{Influence of patient complaints}

None of the parameters showed a good correlation with VCSS (OF, $R^{2}=0.008 ; \mathrm{EF}, \mathrm{R}^{2}=0.030$; RVF, $\left.R^{2}=0.029\right)$. Patients with venous claudication did not demonstrate significantly different results for the tested parameters $(\mathrm{OF}, P=0.437$; EF, $P=0.120$; RVF, $P=0.259)$. Villalta scale did not significantly influence test results either (OF, $P=0.498$; EF, $P=0.922$; RVF, $P=0.836$ ). Results were similar when only patients without reflux were analysed. Severity of oedema according to VCSS was not significantly different between positive and negative OF test results $(P=0.702)$.

\section{Discussion}

In our experience, the OF, EF and RVF determined by APG did not prove to be useful in identifying chronic deep venous obstruction determined by DUS and MRV. Although this is the first large population study reporting a negative finding for its diagnostic use, several other studies have already reported higher OFs in patients with confirmed, clinically relevant deep venous obstruction. ${ }^{15,17,23}$ Additionally, Labropoulos et al. ${ }^{12}$ already concluded that significant obstruction could be missed in some limbs, yet they showed that there was a good agreement between APG and venography in cases with iliocaval or iliofemoral obstruction. The fact that we could not reproduce this agreement might be explained by the larger population size in our study, as their standard deviations were markedly large. Kalodiki et al. ${ }^{13}$ compared APG with venography and found a sensitivity of $95 \%$ and specificity of $96 \%$ for chronic proximal venous obstruction. We used a combination of DUS and MRV as opposed to venography, although this cannot explain such differences, given the good visualisation of post-thrombotic disease using these modalities. ${ }^{7}$ Perhaps veins were not as extensively affected by fibrosis in our study, which could convey superior elastic recoil properties and thus result in a higher OF. The larger number of post-thrombotic limbs (207 vs. 96) in our study might also partly explain the incongruity. Whilst Lattimer et al. ${ }^{18}$ also showed favourable results for OF, especially in proximal obstruction, a number of obstructions were still missed. Furthermore, a quarter of these patients suffered from an acute deep vein thrombosis of $<3$ weeks old, which, coupled with the fact that most patients solely underwent DUS as a control measurement, might explain the differences in results.

Although Kalodiki et al. ${ }^{13}$ initially showed good results using the OF test, their results improved by eliminating collateral flow through compression of the great saphenous vein or other prominent superficial veins during the first second of outflow. We decided not to perform such compression in this study because it does not convey the only possible route for collateral flow. It therefore leads to selective elimination of certain collateralisation patterns while disregarding other forms of collateralisation. Moreover, the great saphenous vein is not part of collateralisation patterns 
in iliofemoral obstruction ${ }^{24}$; eliminating it as a collateral will not lead to adequate identification of patients eligible for treatment, as chronic obstructive lesions eligible for stenting generally need to be located above the femoral confluence.

The reason that $\mathrm{OF}$ might not be an adequate tool to assess outflow impairment of the lower limb could be the fact that it is a relative parameter. The OF is defined as the percentage of blood volume expelled within the first second of releasing the rapid deflatable cuff compared with the total increase in volume achieved by inflation of the cuff. Therefore, if the increase in volume after inflation of the proximal cuff is relatively small, the OF could be distortedly high with only a minor expelled absolute volume after deflation of the cuff. We hypothesised that substantial pre-existent oedema could lead to such results, yet severity of oedema as scored in VCSS was not significantly different between positive and negative test results. Conversely, the elasticity of the veins in combination with the void in the venous reservoir, left by the inflation of the cuff, will likely lead to a relatively good initial expulsion of blood. This possibly leads to a normal OF, which has also been noted by Lattimer et al. ${ }^{25}$ Furthermore, recanalisation and adequate collateralisation could explain proper expulsion during APG with an overall poor outflow after exercise. Hence, it might be better to examine the absolute volume changes, as opposed to the relative $\mathrm{OF}$, or to identify a different test altogether, ${ }^{26}$ possibly in combination with augmentation of central flow.

Our hypothesis that EF or RVF might also be used in deep venous obstructive disease, because of poor calf muscle ejection capacity caused by the increased outflow resistance of an obstruction, was not confirmed, despite correcting for venous incompetence. This could perhaps be explained by the presence of collateralisation and recanalisation over time in chronic post-thrombotic limbs. ${ }^{27}$ Moreover, these parameters might be too complex and dependent on too many different factors for their use in diagnosing chronic obstruction.

Given the questioned diagnostic quality of these APG parameters, they should not be used in daily clinical practice. Moreover, APG can be a cumbersome and technically difficult test. For example, due to the sensitivity of the cuff, the examiner has to be alert that no technical errors, such as external forces inflicted upon the cuff, occur while measuring. If a technical error occurs and a minimal amount of air escapes from the cuff during measurements, the test has to be repeated from the start. This can make the test time-consuming. Furthermore, some examinations showed great differences between baselines at the beginning and end of the EF and RVF tests. We believe this to be a sign that the test is not performed correctly and therefore decided to accept no baseline differences of $>10 \%$ for these tests. Consequently, $6.9 \%$ of all limbs had to be excluded for OF analysis and $17.8 \%$ for EF and RVF analysis. To our knowledge, this is the first study that actually reports such practical difficulties.

Notwithstanding, this study also has some limitations. Since only patients who were suspected of suffering from venous obstructive disease were analysed using APG, a selection bias cannot be ruled out. However, this does not explain the many false negative test results. Another limitation of our methodology is the diagnostic quality of the "gold standard" we used to objectify iliac vein compression, which can be a difficult diagnosis to make using only non-invasive modalities. Therefore, some bias due to misclassification of subjects cannot be completely ruled out, despite including only patients with positive iliac vein compression on both DUS and MRV. Additionally, due to the retrospective nature of this study, data were not complete in all patients, thus subtle differences in correlation with patient complaints or oedema may not have been identifiable. 


\section{Conclusions}

This study demonstrates that OF, determined by APG, cannot be used as a diagnostic tool for diagnosing chronic deep venous obstruction of the lower limb, nor does it identify EF or RVF as a better method. Although APG may remain a good physiologic tool to gain more insight into the haemodynamics of venous disease, use of its relative OF, EF and RVF in diagnosing chronic deep venous obstruction is unwarranted in daily clinical practice. Collateralisation and recanalisation over time can be of influence on outflow capacity and therefore might cause these negative results. Nevertheless, absolute volume changes or a different APG manoeuvre might be more informative than derivative parameters, analysis of which should be the focus of further APG research.

\section{References}

1. Beyth RJ, Cohen AM, Landefeld CS. Long-term outcomes of deep-vein thrombosis. Arch Intern Med 1995;155(10):1031-7.

2. Prandoni P, Lensing AW, Cogo A, et al. The long-term clinical course of acute deep venous thrombosis. Ann Intern Med 1996;125(1):1-7.

3. Kahn SR, Solymoss S, Lamping DL, Abenhaim L. Long-term outcomes after deep vein thrombosis: postphlebitic syndrome and quality of life. J Gen Intern Med 2000;15(6):425-9.

4. Neglen P, Hollis KC, Olivier J, Raju S. Stenting of the venous outflow in chronic venous disease: long-term stentrelated outcome, clinical, and hemodynamic result. J Vasc Surg 2007;46(5):979-90.

5. Oguzkurt L, Tercan F, Ozkan U, Gulcan O. Iliac vein compression syndrome: outcome of endovascular treatment with long-term follow-up. Eur J Radiol 2008;68(3):487-92.

6. Rosales A, Sandbaek G, Jorgensen JJ. Stenting for chronic post-thrombotic vena cava and iliofemoral venous occlusions: mid-term patency and clinical outcome. Eur J Vasc Endovasc Surg 2010;40(2):234-40.

7. Arnoldussen CW, Toonder I, Wittens CH. A novel scoring system for lower-extremity venous pathology analysed using magnetic resonance venography and duplex ultrasound. Phlebology 2012;27 Suppl 1:163-70.

8. Arnoldussen CW, de Graaf R, Wittens CH, de Haan MW. Value of magnetic resonance venography and computed tomographic venography in lower extremity chronic venous disease. Phlebology 2013;28 Suppl 1:169-75.

9. Neglen P, Raju S. Intravascular ultrasound scan evaluation of the obstructed vein. J Vasc Surg 2002;35(4):694-700.

10. Christopoulos D, Nicolaides AN, Szendro G. Venous reflux: quantification and correlation with the clinical severity of chronic venous disease. BrJ Surg 1988;75(4):352-6.

11. Gillespie DL, Cordts PR, Hartono C, et al. The role of air plethysmography in monitoring results of venous surgery. J Vasc Surg 1992;16(5):674-8.

12. Labropoulos $\mathrm{N}$, Volteas $\mathrm{N}$, Leon $\mathrm{M}$, et al. The role of venous outflow obstruction in patients with chronic venous dysfunction. Arch Surg 1997;132(1):46-51.

13. Kalodiki E, Calahoras LS, Delis KT, Zouzias CP, Nicolaides AN. Air plethysmography: the answer in detecting past deep venous thrombosis. J V asc Surg 2001;33(4):715-20.

14. Locker T, Goodacre S, Sampson F, Webster A, Sutton AJ. Meta-analysis of plethysmography and rheography in the diagnosis of deep vein thrombosis. Emerg Med J 2006;23(8):630-5.

15. Hurst DR, Forauer AR, Bloom JR, Greenfield LJ, Wakefield TW, Williams DM. Diagnosis and endovascular treatment of iliocaval compression syndrome. J Vasc Surg 2001;34(1):106-13.

16. Delis KT, Bountouroglou D, Mansfield AO. Venous claudication in iliofemoral thrombosis: long-term effects on venous hemodynamics, clinical status, and quality of life. Ann Surg 2004;239(1):118-26.

17. Raju S, Kirk O, Davis M, Olivier J. Hemodynamics of "critical" venous stenosis and stent treatment. Journal of Vascular Surgery: Venous and Lymphatic Disorders 2014;2(1):52-9.

18. Lattimer CR, Geroulakos G, Kalodiki E. Calf volume changes with venous occlusion air plethysmography in assessment of patients after deep venous thrombosis. Journal of Vascular Surgery: Venous and Lymphatic Disorders 2014;2(4):416-23.

19. Lattimer CR, Kalodiki E, Kafeza M, Azzam M, Geroulakos G. Quantifying the degree graduated elastic compression stockings enhance venous emptying. Eur J Vasc Endovasc Surg 2014;47(1):75-80.

20. Nicolaides AN. Investigation of chronic venous insufficiency: A consensus statement (France, March 5-9, 1997). Circulation 2000;102(20):E126-63.

21. APG Air-Plethysmograph models APG-1000C and APG-1000CP instruction and service manual. San Marcos, CA, USA: ACI Medical; 1990.

22. Lurie F, Comerota A, Eklof B, et al. Multicenter assessment of venous reflux by duplex ultrasound. J Vasc Surg 2012;55(2):437-45.

23. Neglen P, Raju S. Detection of outflow obstruction in chronic venous insufficiency. J Vasc Surg 1993;17(3):583-9. 
24. Thomas ML, Fletcher EW, Cockett FB, Negus D. Venous collaterals in external and common iliac vein obstruction. Clin Radiol 1967;18(4):403-11.

25. Lattimer CR, Kalodiki E, Azzam M, Geroulakos G. Pneumatic thigh compression reduces calf volume and augments the venous return. Phlebology 2015;30(5):316-22.

26. Lattimer CR, Kalodiki E, Mendoza E. Venous Drainage in Controls and Patients With Chronic Venous Insufficiency. Journal of Vascular Surgery: Venous and Lymphatic Disorders 2015;3(1):125-6.

27. Kurstjens RL, de Wolf MA, van Laanen JH, de Haan MW, Wittens CH, de Graaf R. Hemodynamic significance of collateral blood flow in chronic venous obstruction. Pblebology 2015;30(1 Suppl):27-34. 



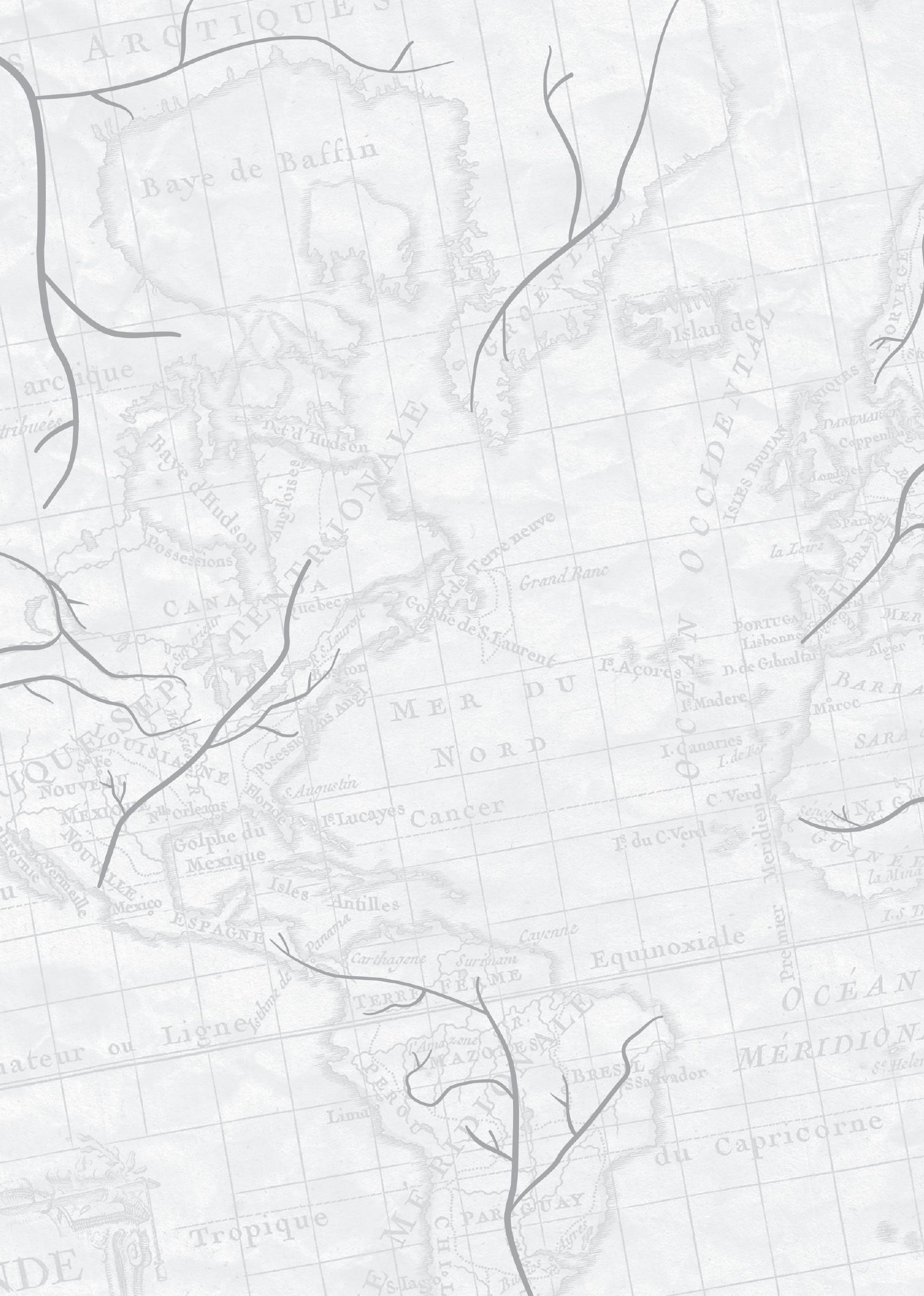




\section{CHAPTER 4}

\section{The ability of air plethysmography to identify patients who will benefit from stenting of deep venous obstruction}

Ralph L.M. Kurstjens

Fabio S. Catarinella Yee Lai Lam

Mark A.F. de Wolf Irwin M. Toonder

Cees H.A. Wittens

Submitted 


\begin{abstract}
Objective: Deep venous obstruction can be adequately treated by stenting, though not all patients improve. The aim of this study was to assess whether parameters obtained during the air plethysmography outflow fraction test can be used to identify deep vein obstruction and predict clinical success of treatment by recanalisation and stenting.

Methods: Patients referred to our tertiary, outpatient clinic with suspected deep venous obstruction were analysed using air plethysmography at the time of presentation. The ability of total venous volume, one-second outflow volume and outflow fraction to discriminate between the presence and absence of deep venous obstruction proximal to the femoral confluence, as measured by duplex ultrasound and magnetic resonance venography, was assessed using receiver operated characteristic curves. The same was done for the ability to discriminate between successful and non-successful stenting, as measured by the VEINES-QOL/Sym.

Results: A total of 237 limbs in 196 patients demonstrated either obstruction proximal to the femoral confluence or no obstruction at all. Mean age was $44.5 \pm 14.2$ years, and $64.8 \%$ were female. Post-thrombotic obstruction proximal to the femoral confluence was present in $62.0 \%$, non-thrombotic iliac vein compression in $11.0 \%$ and no obstruction in $27.0 \%$. Areas under the curve for post-thrombotic obstruction were as follows: one-second outflow volume 0.71 (95\% confidence interval [C], 0.63-0.78), total venous volume 0.69 (95\% CI, 0.61-0.77) and outflow fraction 0.59 (95\% CI, 0.51-0.67). Analyses of non-thrombotic obstruction did not yield superior results. Stenting was performed in 45 limbs of 39 patients with quality of life scores pre- and one year post-stenting. Areas under the curve for identifying patients with successful treatment at one year after stenting were as follows: one-second outflow volume 0.57 (95\% CI, 0.40-0.74), total venous volume 0.54 (95\% CI, 0.37-0.72) and outflow fraction 0.63 (95\% CI, 0.46-0.81).

Conclusions: None of the parameters resulting from the air plethysmography outflow test can be used to adequately identify deep venous obstruction proximal to the femoral confluence, nor can they be used to distinguish which patients will benefit from treatment and which will not. Therefore, use of this test is not warranted in daily clinical practice and future research should focus on other applications of this modality.
\end{abstract}




\section{Introduction}

Deep venous obstruction is a frequent cause of venous leg complaints and can be instigated by iliac vein compression or inadequate recanalisation after deep vein thrombosis. ${ }^{1,2}$ Both types of obstruction can be diagnosed using duplex ultrasound (DUS), ${ }^{3,4}$ computed tomography venography, ${ }^{5}$ magnetic resonance venography (MRV), ${ }^{4,5}$ intravascular ultrasound, ${ }^{6}$ and conventional venography. If the obstructive component is proximally located to the femoral confluence, it can be adequately treated by percutaneous transluminal angioplasty and stenting. ${ }^{7-9}$ Both generic and disease specific quality of life (QoL) scores and venous scoring systems significantly improve, ${ }^{8-11}$ with patency rates ranging from $50 \%$ to $100 \% \cdot{ }^{8,9,11,12}$ Nonetheless, $15-$ $20 \%$ of patients show little to no relief of complaints, ${ }^{13}$ often despite adequate recanalisation and patent stents that are free of stenosis. Moreover, most modalities used to identify obstruction are expensive, invasive and can be difficult to perform, especially in non-specialised centres. Therefore, an inexpensive, non-invasive test is needed to establish which patients warrant referral to a vascular surgeon and will ultimately benefit from treatment by stenting.

Air plethysmography (APG) is a non-invasive, functional test that can continuously assess realtime volumetric changes in the calf. This test uses an air-inflated cuff around the calf that detects pressure changes resulting from variation in calf circumference. Although APG was initially validated for deep vein incompetence, ${ }^{14,15}$ an outflow test for measuring obstruction was designed. ${ }^{16-18}$ However, use of this outflow test is debatable due to varying study results, ${ }^{17-24}$ with recent studies suggesting it mainly tests elastic recoil properties. ${ }^{21,22}$ Our own research has recently shown poor results in detecting chronic venous obstruction. ${ }^{25}$ Nevertheless, little is known about the absolute volumetric changes or the predictive ability for success of treatment using the outflow test. Outflow volume during the first second might be more informative as it is less affected by pre-existent oedema, whereas total venous volume might be lower in significant obstructions due to the limited filling capacity in the presence of pre-existent oedema.

The aim of this study was to assess whether parameters obtained during the APG outflow fraction test, including absolute volumetric changes, can be used to identify deep venous obstruction or predict clinical success of treatment by recanalisation and stenting.

\section{Methods}

\section{Study design and patient selection}

In this retrospective study, absolute volume changes and outflow fraction were measured with the APG outflow test. Their ability to discriminate between limbs with and without obstruction proximal to the femoral confluence, measured by DUS and MRV, was assessed. Additionally, the value of these parameters to discriminate between successful stenting and unsuccessful stenting, as measured by disease specific quality of life, was evaluated.

Between the period from January 2011 until August 2013, patients referred to our tertiary, outpatient clinic with suspected deep venous obstruction were analysed using APG at the time of presentation. In our clinic criteria for suspected outflow obstruction are the presence of venous claudication, history of deep vein thrombosis, the presence of an abdominal wall collateral vein, recurrence of varicosities $<5$ years after treatment and $\mathrm{C}_{4}-\mathrm{C}_{6}$ disease according to the Clinical-Etiology-Anatomy-Pathophysiology (CEAP) classification.

Patients with a reliable APG outflow examination and sufficient imaging by DUS and/or MRV were included in this study. Patients with unreliable outflow test traces because of undefinable 
actions or evident air loss from the cuff or tubing were excluded from analysis. Patients with incomplete visualisation of all vessel segments from the popliteal vein to the inferior vena cava on DUS or MRV were also excluded. Additional analyses were performed for patients who also underwent stenting and had filled out quality of life questionnaires before and one year after intervention.

Retrospective analysis of these data was approved by the Maastricht University Medical Centre institutional review board (METC 14-4-193, March 5, 2015). Individual patient consent was not obtained, as this is not required by Dutch law for retrospective studies. No patients registered an objection to anonymous use of data.

$A P G$

The outflow fraction test was performed by one of five dedicated physician researchers, using the APG Air Plethysmograph C-1000 (ACI Medical, San Marcos, CA). The procedure has been described in literature. ${ }^{16,26}$ In short, the affected lower limb was elevated above the level of the heart on a foam block while the patient was in the supine position. The APG cuff was placed around the calf and calibrated. Subsequently, a rapid deflatable cuff was placed above the knee and inflated to $80 \mathrm{mmHg}$ until venous volume reached a stable plateau phase. Consecutively, the proximal cuff was rapidly deflated and outflow was measured, waiting until a stable phase was reached again. Total venous volume and outflow volume during the first second after deflation were measured. Outflow fraction represents the one-second outflow volume as the percentage of the total venous volume (Figure 4.1).

\section{Imaging}

DUS was performed with a Hitachi Aloka ProSound Alpha 7 Premiere machine (Aloka, Tokyo, Japan). The venous system was assessed from the suprarenal inferior vena cava down to the calf veins as described elsewhere. ${ }^{4}$ Post-thrombotic obstruction was defined as obstruction with intraluminal synechiae and flow division. Non-thrombotic iliac vein compression was defined as a $>50 \%$ lumen reduction, compared with a healthy vein segment.

MRV was performed according to the protocol described in literature ${ }^{4}$ on a $1.5-\mathrm{T}$ magnetic resonance imaging system (Intera; Philips Medical Systems, Best, the Netherlands). Postthrombotic obstruction was defined as hypodense intraluminal changes indicative of trabeculation. Non-thrombotic iliac vein compression was defined as $>50 \%$ lumen reduction, compared with a normal vein segment and the presence of regional collateral veins.

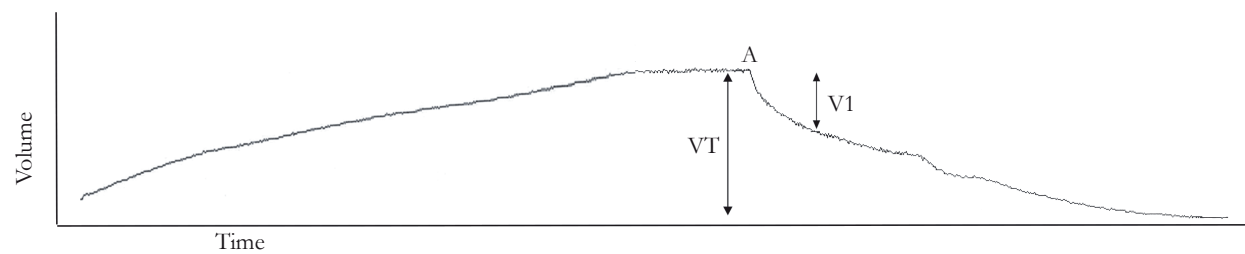

Figure 4.1 Air plethysmography outflow test. ${ }^{25}$

A maximum amount of blood is accumulated in the calf (A), after which the proximal cuff is rapidly deflated. Outflow fraction equals volume at one-second outflow (V1) / total venous volume (VT) x 100\%. 


\section{Intervention}

Patients with treatable obstruction and debilitating complaints were offered treatment by recanalisation and stenting. Those with post-thrombotic disease were treated under general anaesthesia or sedation, whereas patients with non-thrombotic iliac vein compression were treated under local anaesthesia. Access to the (common) femoral vein was obtained under ultrasound guidance, after which a guidewire was placed past the obstructed vein segments into a healthy segment. Subsequently, percutaneous transluminal angioplasty and stenting were performed, as has been described elsewhere. ${ }^{27}$ In cases where the femoral confluence was involved, a desobstruction of the common femoral vein and the orifices of its inflow vessels (endophlebectomy) was performed. A temporary arteriovenous fistula (AVF) was created to improve flow into the stents and prevent early stent occlusion. This procedure was performed as described in literature. ${ }^{28}$

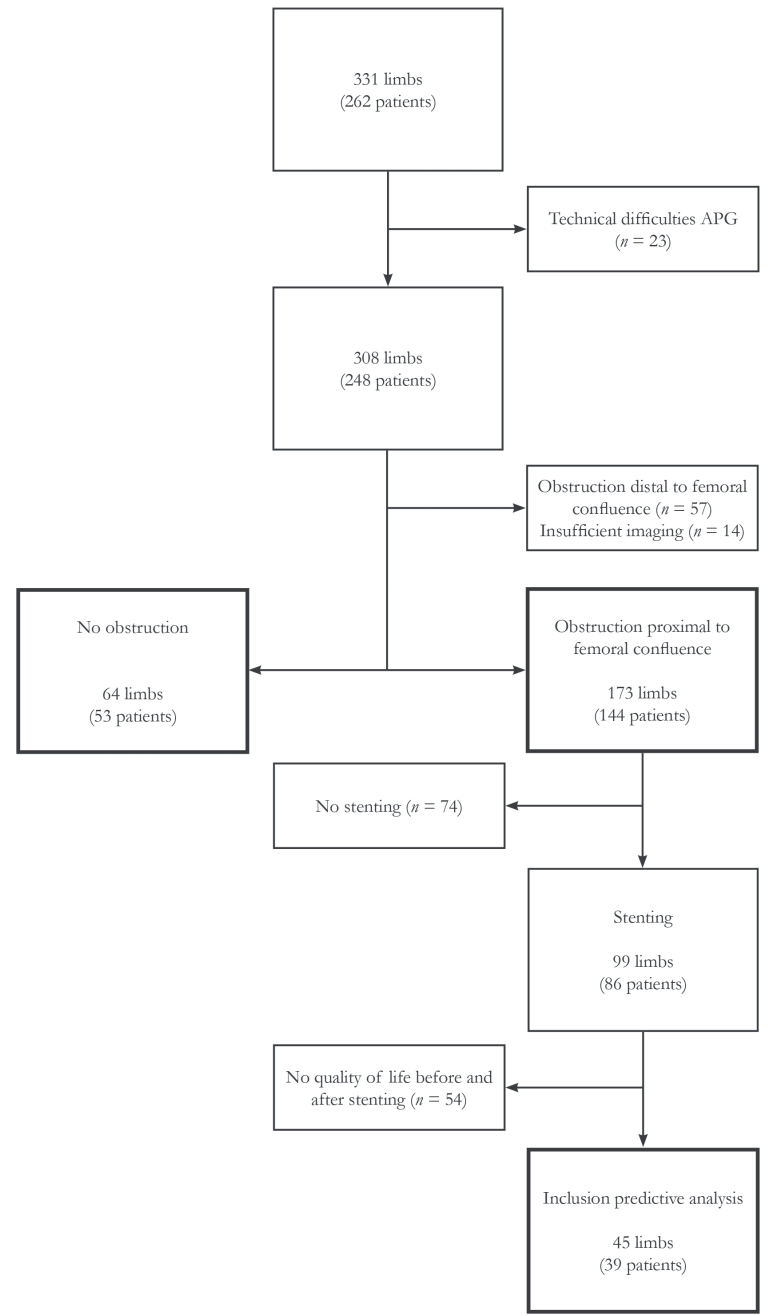

Figure 4.2 Patient inclusion flowchart.

\section{Statistical analysis}

Continuous data are presented as mean with standard deviation or median with interquartile range, depending on normality of distribution. Categorical data are presented as absolute number and percentage. Linear regression analysis was performed to compare means of APG parameters between control limbs and those with postthrombotic and non-thrombotic obstruction. To account for correlation between observations, a clustered sandwich estimator was used to calculate the variance. ${ }^{29}$ Receiver operated characteristic (ROC) curves were constructed for APG parameters and areas under the curve (AUC), with 95\% confidence intervals (CI) were calculated to assess their abilities to discriminate between obstructed and non-obstructed limbs. AUCs were also calculated to evaluate the ability of these APG parameters to discriminate between patients who show clinically relevant improvement in QoL after stenting and those who do not. Clinically relevant improvement was defined as 0.5 times the standard deviation of change in VEINES-QOL/Sym 
Table 4.1 Baseline patient characteristics.

\begin{tabular}{|c|c|c|}
\hline & Total population & $\begin{array}{l}\text { Patients undergoing stenting } \\
\text { with QoL scores }\end{array}$ \\
\hline Patients & 196 & 39 \\
\hline Limbs, $n(\%)$ & 237 & 45 \\
\hline Left & $109(55.6)$ & $26(66.7)$ \\
\hline Right & $46(23.5)$ & $7(17.9)$ \\
\hline Bilateral & $41(20.9)$ & $6(15.4)$ \\
\hline Female sex, $n(\%)$ & $127(64.8)$ & $29(74.4)$ \\
\hline Age, years & $44.5 \pm 14.2$ & $43.3 \pm 14.7$ \\
\hline Median duration of complaints, years & 3 (range, 1-52) & 5 (range, $1-48$ ) \\
\hline Symptomatic, $n(\%)^{*}$ & $224(94.5)$ & $45(100)$ \\
\hline Venous claudication, $n(\%)^{\dagger}$ & $138(58.2)$ & $31(66.7)$ \\
\hline History of venous interventions, $n(\%)$ & $67(34.4)$ & $9(23.1)$ \\
\hline \multicolumn{3}{|l|}{ Highest C of CEAP, $n(\%)^{\ddagger}$} \\
\hline $\mathrm{C}_{0}$ & $24(10.1)$ & $5(11.1)$ \\
\hline $\mathrm{C}_{1}$ & $18(7.6)$ & $1(2.2)$ \\
\hline $\mathrm{C}_{2}$ & 44 (18.6) & $7(15.6)$ \\
\hline $\mathrm{C}_{3}^{2}$ & $66(27.8)$ & $15(33.3)$ \\
\hline $\mathrm{C}_{4}$ & $55(23.2)$ & $10(22.2)$ \\
\hline $\mathrm{C}_{5}$ & $21(8.9)$ & $6(13.3)$ \\
\hline $\mathrm{C}_{6}$ & $7(3.0)$ & $1(2.2)$ \\
\hline Post-thrombotic obstruction, $n(\%)$ & $147(62.0)$ & $37(82.2)$ \\
\hline Non-thrombotic iliac vein compression, $n(\%)$ & $26(11.0)$ & $8(17.8)$ \\
\hline No obstruction, $n(\%)$ & $64(27.0)$ & - \\
\hline
\end{tabular}

one year after stenting. ${ }^{30}$ Sub-analyses were performed for post-thrombotic obstruction and those with patent stents. We decided not to perform a sub-analysis for non-thrombotic iliac vein obstruction because of the small sample size of patients with QoL data and treatment for such an obstruction $(n=8)$. QoL before and after stenting were compared using a paired-samples $t$-test. $P$-values $\leq 0.05$ were considered as statistically significant. AUC analysis and graphs were obtained using GraphPad Prism version 5.04 (GraphPad Software, San Diego, CA, USA). Other statistical analyses were performed using SPSS version 21.0 (IBM Corporation, Armonk, NY, USA) or Stata/IC version 13.1 (StataCorp, College Station, TX, USA).

\section{Results}

Using APG, 331 limbs of 262 patients were analysed for deep venous obstruction at our outpatient clinic. As a result of technical difficulties, 23 limbs did not have proper APG results. Of the remaining 308 limbs, 57 demonstrated post-thrombotic changes solely peripheral to the femoral confluence and 14 limbs had insufficient imaging data, leaving 237 limbs in 196 patients with either obstruction proximal to the femoral confluence or no obstruction at all (Figure 4.2). Mean age was $44.5 \pm 14.2$ years, and $64.8 \%$ were female. A total of $93.1 \%$ of patient were symptomatic with a median duration of 3 years $(1-52)$, and $61.4 \%$ suffered from venous 
A

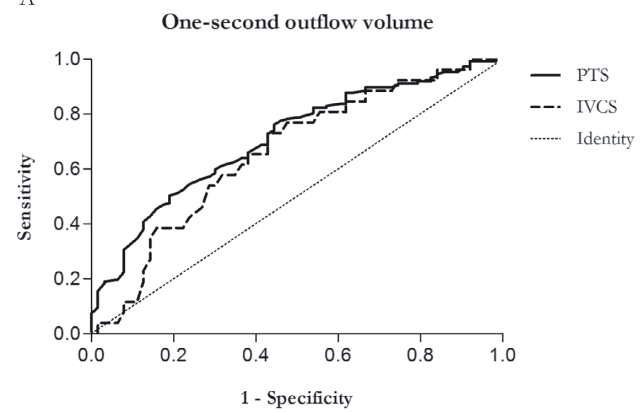

B

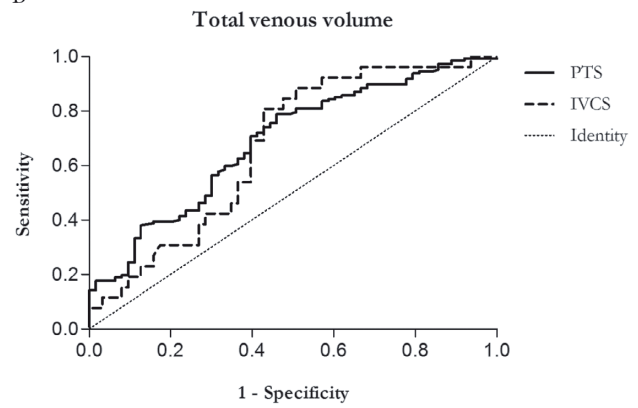

C

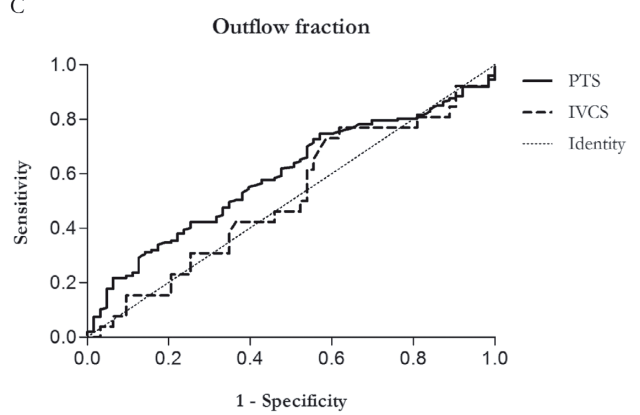

1 - Specificity
Figure 4.3 Receiver operated characteristic curves of the air plethysmography parameters for the identification of obstruction.

IVCS, iliac vein compression syndrome; PTS, postthrombotic syndrome.

claudication. Post-thrombotic obstruction proximal to the femoral confluence was present in $62.0 \%$ limbs, non-thrombotic iliac vein compression in $11.0 \%$ and no obstruction in $27.0 \%$ (Table 4.1).

Limbs without obstruction demonstrated a mean one-second outflow volume of $70.1 \pm 33.3 \mathrm{~mL}$. This was lower in limbs with post-thrombotic obstruction $(48.7 \pm 28.4 \mathrm{~mL} ; P<0.001)$ and limbs with non-thrombotic iliac vein compression $(53.6 \pm 26.0 \mathrm{~mL}, P=0.014)$. Total venous volume was $142.6 \pm 60.0 \mathrm{~mL}$ in healthy limbs, which was also lower in those with post-thrombotic obstruction $(105.9 \pm 49.6 \mathrm{~mL} ; P<0.001)$ and non-thrombotic iliac vein compression $(108.8$ $\pm 41.8 \mathrm{~mL}, P=0.003)$. Mean outflow fraction was $48.4 \pm 9.3 \%$ in control limbs. In postthrombotic limbs this was only marginally lower $(45.6 \pm 13.1 \% ; P=0.089)$. Thus, mean outflow fraction was higher than the cut-off value for the presence of obstruction $(\leq 38 \%)$. For limbs with non-thrombotic iliac vein compression, outflow fraction was also not significantly different from control limbs $(49.5 \pm 13.1 \% ; P=0.704)$.

ROC curves were constructed to test the ability of the APG parameters to discriminate between the presence and absence of deep venous obstruction proximal to the femoral confluence (Figure 4.3A-C). One-second outflow volume yielded an AUC of 0.71 (95\% CI, 0.63-0.78) for post-thrombotic obstruction and 0.66 (95\% CI, 0.54-0.78) for non-thrombotic iliac vein compression. Total venous volume demonstrated an AUC of 0.69 (95\% CI, 0.61-0.77) for postthrombotic and $0.67(95 \% \mathrm{CI}, 0.55-0.78)$ for non-thrombotic obstructions. The relative outflow fraction revealed lower AUCs: 0.59 (95\% CI, 0.51-0.67) and 0.51 (95\% CI, 0.38-0.65) for postthrombotic and non-thrombotic obstruction respectively.

Stenting was performed in 99 limbs (41.8\%) of 86 patients, yet only 45 limbs (45.5\% of those treated) in 39 patients had VEINES-QOL/Sym scores both before and one year after intervention. 
A

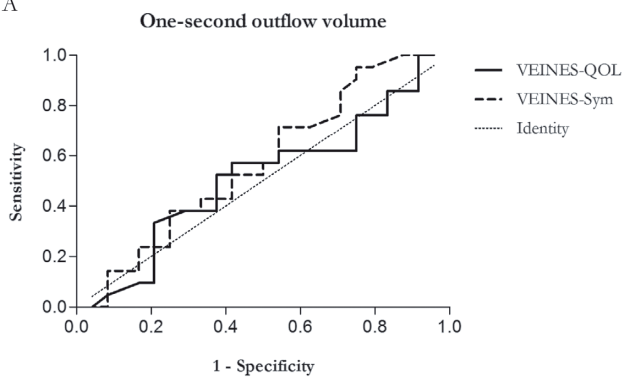

C

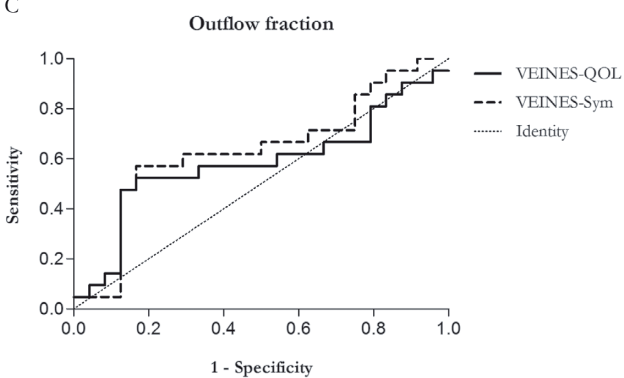

B

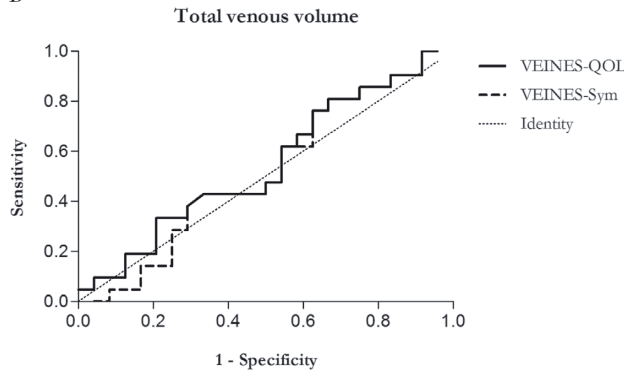

Figure 4.4 Receiver operated characteristic curves of the air plethysmography parameters for the prediction of successful treatment, as measured by VEINES-QOL/Sym.

Eight limbs received stenting for non-thrombotic compression, whereas 37 limbs received stents for post-thrombotic syndrome. Fifteen of these also received an endophlebectomy and AVF. Baseline characteristics were similar to those of the complete group (Table 4.1). Mean VEINESQOL was $49.8 \pm 21.1$ before intervention compared with $61.5 \pm 25.0$ one year after intervention $(P=0.031)$. VEINES-Sym improved from $46.9 \pm 22.9$ before stenting to $59.7 \pm 27.6$ one year $\operatorname{after}(P=0.017)$.

Employing 0.5 times the standard deviation of the change in quality of life to define patients with successful treatment, 20 patients (21 limbs) had a successful treatment. Nineteen patients (24 limbs) had an unsuccessful treatment. One-second outflow volume yielded an AUC of 0.51 (95\% CI, 0.34-0.69) for VEINES-QOL score and 0.57 (95\% CI, 0.40-0.74) for VEINES-Sym score in identifying patients with a successful treatment. The AUC of total venous volume was 0.54 (95\% CI, 0.37-0.72) for VEINES-QOL and 0.52 (95\% CI, 0.35-0.69) for VEINES-Sym. Outflow fraction demonstrated an AUC of 0.58 (95\% CI, 0.41-0.76) for VEINES-QOL and 0.63 (95\% CI, 0.46-0.81) for VEINES-Sym (Table 4.2, Figure 4.4A-C).

At one year after intervention, loss of patency was present in 7 limbs of 5 patients. Sub-analysis of patients with a patent stent at one year follow-up did not alter AUC results for one-second outflow volume (VEINES-QOL, 0.53; VEINES-Sym, 0.62), total venous volume (VEINESQOL, 0.51; VEINES-Sym, 0.55) or outflow fraction (VEINES-QOL, 0.59; VEINES-Sym, 0.61). Type of obstruction also proved of little influence on the ability of the APG parameters to predict clinical outcome, as one-second outflow volume (AUC, 0.52 for VEINES-QOL; 0.58 for VEINES-Sym), total venous volume (AUC, 0.55 for VEINES-QOL; 0.52 for VEINESSym) and outflow fraction (AUC, 0.58 for VEINES-QOL; 0.65 for VEINES-Sym) did not relevantly change (Table 4.2). 


\section{Discussion}

This study demonstrates that absolute volumetric changes measured by APG during the outflow fraction test are not able to properly identify the presence of deep venous obstruction proximal to the femoral confluence. Previous research has already shown that the relative outflow fraction is not able to do this, ${ }^{25}$ though the hypothesis was that absolute volumetric changes might be more informative. We surmised that the level of pre-existent oedema should be of lesser influence on the total venous volume and absolute outflow volume after one second. Total venous volume has been found to significantly differ between obstructed and non-obstructed limbs before, yet with considerable overlap in range. ${ }^{17}$

One of the proposed explanations that outflow fraction yields poor results is the void left by the rapid deflatable cuff. ${ }^{31}$ This could initially lead to fair propulsion of blood, causing the outflow fraction to appear normal, which could also explain a higher outflow volume at one second. However, the total venous volume should not be affected by this void. Proper elasticity of the veins may explain a normal filling capacity and therefore a higher outflow at one second and a normal total venous volume. ${ }^{31}$ Howbeit, pre-existent oedema resulting from obstruction should partly prevent this normal filling capacity as the leg is already overfilled. Another possible explanation is the distance of the iliac veins with respect to the APG cuff. A significant obstruction proximal to the femoral confluence may not lead to abnormal values if expulsion into the popliteal and femoral veins is adequate. However, in the presence of post-thrombotic disease, these vein segments are often also affected to a certain extent. Finally, differences in venous anatomy and patient size will likely lead to a significant variation in volumetric reference values and thus an inferior ability of these absolute volumetric measurements to identify obstruction.

The ultimate goal of proper patient selection for interventional treatment of deep venous obstruction is whether the appropriate patients are treated. Also, patients who will not benefit from treatment ought to be spared the possible complications and discomforts of such a treatment. Therefore, we evaluated whether the outflow parameters of APG are able to identify those who will benefit from treatment the most. However, areas under the ROC curves for both the absolute volume parameters and the relative outflow fraction were too low for clinical use. Sub-analyses for aetiology of obstruction and patency of the stented tract did not yield better results. This lack of diagnostic ability might be influenced by post-thrombotic vessel damage distal to the treatable tract. The change in VEINES-QOL/Sym was striking as this appeared to be lower than previously reported in similar patient groups. ${ }^{10}$ As a result of the limited number of patients with both APG results and valid QoL scores, we might have described a

Table 4.2 Areas under the receiver operated characteristic curves for the different air plethysmography parameters in identifying patients with clinically relevant quality of life improvement.

\begin{tabular}{|c|c|c|c|c|c|c|}
\hline & \multicolumn{2}{|c|}{ One-second outflow volume } & \multicolumn{2}{|c|}{ Total venous volume } & \multicolumn{2}{|l|}{ Outflow fraction } \\
\hline & $\begin{array}{l}\text { VEINES-QOL } \\
(95 \% \mathrm{CI})\end{array}$ & $\begin{array}{l}\text { VEINES-Sym } \\
(95 \% \mathrm{CI})\end{array}$ & $\begin{array}{l}\text { VEINES-QOL } \\
(95 \% \mathrm{CI})\end{array}$ & $\begin{array}{l}\text { VEINES-Sym } \\
(95 \% \mathrm{CI})\end{array}$ & $\begin{array}{l}\text { VEINES-QOL } \\
(95 \% \mathrm{CI})\end{array}$ & $\begin{array}{l}\text { VEINES-Sym } \\
(95 \% \mathrm{CI})\end{array}$ \\
\hline Treated patients & $\begin{array}{l}0.51 \\
(0.34-0.69)\end{array}$ & $\begin{array}{l}0.57 \\
(0.40-0.74)\end{array}$ & $\begin{array}{l}0.54 \\
(0.37-0.72)\end{array}$ & $\begin{array}{l}0.52 \\
(0.35-0.69)\end{array}$ & $\begin{array}{l}0.58 \\
(0.41-0.76)\end{array}$ & $\begin{array}{l}0.63 \\
(0.46-0.81)\end{array}$ \\
\hline $\begin{array}{l}\text { Treated patients with } \\
\text { patent stents }\end{array}$ & $\begin{array}{l}0.53 \\
(0.33-0.72)\end{array}$ & $\begin{array}{l}0.62 \\
(0.43-0.80)\end{array}$ & $\begin{array}{l}0.51 \\
(0.32-0.70)\end{array}$ & $\begin{array}{l}0.55 \\
(0.36-0.74)\end{array}$ & $\begin{array}{l}0.59 \\
(0.40-0.78)\end{array}$ & $\begin{array}{l}0.61 \\
(0.42-0.80)\end{array}$ \\
\hline $\begin{array}{l}\text { Patients treated for post- } \\
\text { thrombotic obstruction }\end{array}$ & $\begin{array}{l}0.52 \\
(0.31-0.72)\end{array}$ & $\begin{array}{l}0.58 \\
(0.39-0.77)\end{array}$ & $\begin{array}{l}0.55 \\
(0.36-0.75)\end{array}$ & $\begin{array}{l}0.52 \\
(0.33-0.71)\end{array}$ & $\begin{array}{l}0.58 \\
(0.36-0.80)\end{array}$ & $\begin{array}{l}0.65 \\
(0.45-0.85)\end{array}$ \\
\hline
\end{tabular}

CI, confidence interval 
less representative group of patients. In addition, QoL may still change in some patients after one year. ${ }^{10}$

Given these negative results, the standard APG outflow test should be abandoned. However, a different APG technique might be of more value in identifying patients with a clinically relevant obstruction. The venous drainage index is a parameter that can be obtained by postural changes of the patient using a tilt table. A small study describing three groups of participants (obstruction, primary reflux and controls) has shown promising results with respect to identification of obstructed patients, particularly given the lack of overlap in range between the obstructed patients and the other groups. ${ }^{32}$ Nonetheless, larger studies should prove its usefulness.

Several limitations of this study should be mentioned. Since control patients were also referred to our clinic with complaints that could be explained by deep venous obstruction, a selection bias may be present. Regarding the diagnostic abilities of obstruction, the lack of intravascular ultrasound use could have led to misidentification of some cases of iliac vein compression. However, this should not have influenced results in the post-thrombotic and treatment group. Finally, due to the retrospective nature of this study, missing data could have been of influence, especially with respect to analyses into the prediction of treatment effect, which resulted in a low sample size.

\section{Conclusions}

None of the parameters resulting from the air plethysmography outflow test can be used to adequately identify deep venous obstruction proximal to the femoral confluence, nor can they be used to distinguish which patients will benefit from treatment and which will not. Therefore, use of this test is not warranted in daily clinical practice and future research should focus on other applications of this modality.

\section{References}

1. Lee BB, Nicolaides AN, Myers K, et al. Venous hemodynamic changes in lower limb venous disease: the UIP consensus according to scientific evidence. Int Angiol 2016;35(3):236-352.

2. Meissner MH, Eklof B, Smith PC, et al. Secondary chronic venous disorders. J Vasc Surg 2007;46 Suppl S:68S-83S.

3. Labropoulos N, Borge M, Pierce K, Pappas PJ. Criteria for defining significant central vein stenosis with duplex ultrasound. J Vasc Surg 2007;46(1):101-7.

4. Arnoldussen CW, Toonder I, Wittens CH. A novel scoring system for lower-extremity venous pathology analysed using magnetic resonance venography and duplex ultrasound. Pblebology 2012;27 Suppl 1:163-70.

5. Arnoldussen CW, de Graaf R, Wittens CH, de Haan MW. Value of magnetic resonance venography and computed tomographic venography in lower extremity chronic venous disease. Phlebology 2013;28 Suppl 1:169-75.

6. Neglen P, Raju S. Intravascular ultrasound scan evaluation of the obstructed vein. J Vasc Surg 2002;35(4):694-700.

7. Wittens C, Davies AH, Baekgaard N, et al. Editor's Choice - Management of Chronic Venous Disease: Clinical Practice Guidelines of the European Society for Vascular Surgery (ESVS). Eur J Vasc Endovasc Surg 2015;49(6):678737.

8. Neglen P, Hollis KC, Olivier J, Raju S. Stenting of the venous outflow in chronic venous disease: long-term stentrelated outcome, clinical, and hemodynamic result. J Vasc Surg 2007;46(5):979-90.

9. Seager MJ, Busuttil A, Dharmarajah B, Davies AH. Editor's Choice - A Systematic Review of Endovenous Stenting in Chronic Venous Disease Secondary to Iliac Vein Obstruction. Eur J Vasc Endovasc Surg 2016;51(1):100-20.

10. Catarinella FS, Nieman FH, de Wolf MA, Toonder IM, de Graaf R, Wittens CH. Quality-of-life in interventionally treated patients with post-thrombotic syndrome. Phlebology 2015;30(1 Suppl):89-94.

11. Yin M, Shi H, Ye K, et al. Clinical Assessment of Endovascular Stenting Compared with Compression Therapy Alone in Post-thrombotic Patients with Iliofemoral Obstruction. Eur J Vasc Endovasc Surg 2015;50(1):101-7.

12. de Wolf MA, de Graaf R, Kurstjens RL, Penninx S, Jalaie H, Wittens CH. Short-Term Clinical Experience with a Dedicated Venous Nitinol Stent: Initial Results with the Sinus-Venous Stent. Eur J Vasc Endovasc Surg 2015;50(4):518-26.

13. de Wolf MAF, Arnoldussen CW, Grommes J, et al. Minimally invasive treatment of chronic iliofemoral venous 
occlusive disease. Journal of Vascular Surgery: Venous and Lymphatic Disorders 2013;1(2):146-53.

14. Gillespie DL, Cordts PR, Hartono C, et al. The role of air plethysmography in monitoring results of venous surgery. J Vasc Surg 1992;16(5):674-8.

15. Christopoulos D, Nicolaides AN, Szendro G. Venous reflux: quantification and correlation with the clinical severity of chronic venous disease. BrJ Surg 1988;75(4):352-6.

16. APG Air-Plethysmograph models APG-1000C and APG-1000CP instruction and service manual. San Marcos, CA, USA: ACI Medical; 1990.

17. Kalodiki E, Calahoras LS, Delis KT, Zouzias CP, Nicolaides AN. Air plethysmography: the answer in detecting past deep venous thrombosis. J Vasc Surg 2001;33(4):715-20.

18. Labropoulos N, Volteas N, Leon M, et al. The role of venous outflow obstruction in patients with chronic venous dysfunction. Arch Surg 1997;132(1):46-51.

19. Delis KT, Bountouroglou D, Mansfield AO. Venous claudication in iliofemoral thrombosis: long-term effects on venous hemodynamics, clinical status, and quality of life. Ann Surg 2004;239(1):118-26.

20. Hurst DR, Forauer AR, Bloom JR, Greenfield LJ, Wakefield TW, Williams DM. Diagnosis and endovascular treatment of iliocaval compression syndrome. J V asc Surg 2001;34(1):106-13.

21. Lattimer CR, Geroulakos G, Kalodiki E. Calf volume changes with venous occlusion air plethysmography in assessment of patients after deep venous thrombosis. Journal of Vascular Surgery: Venous and Lymphatic Disorders 2014;2(4):416-23.

22. Lattimer CR, Kalodiki E, Kafeza M, Azzam M, Geroulakos G. Quantifying the degree graduated elastic compression stockings enhance venous emptying. Eur J V asc Endovasc Surg 2014;47(1):75-80.

23. Locker T, Goodacre S, Sampson F, Webster A, Sutton AJ. Meta-analysis of plethysmography and rheography in the diagnosis of deep vein thrombosis. Emerg Med J 2006;23(8):630-5.

24. Raju S, Kirk O, Davis M, Olivier J. Hemodynamics of "critical" venous stenosis and stent treatment. Journal of Vascular Surgery: Venous and Lymphatic Disorders 2014;2(1):52-9.

25. Kurstjens RL, de Wolf MA, Alsadah SA, et al. The value of hemodynamic measurements by air plethysmography in diagnosing venous obstruction of the lower limb. J V asc Surg Venous Lymphat Disord 2016;4(3):313-9.

26. Nicolaides AN. Investigation of chronic venous insufficiency: A consensus statement (France, March 5-9, 1997). Circulation 2000;102(20):E126-63.

27. de Graaf R, Wittens CH. Endovascular treatment options for chronic venous obstructions. Phlebology 2012;27 Suppl 1:171-7.

28. Kurstjens RL, de Graaf R, Barbati ME, et al. Arteriovenous fistula geometry in hybrid recanalisation of postthrombotic venous obstruction. Phlebology 2015;30(1 Suppl):42-9.

29. Williams RL. A note on robust variance estimation for cluster-correlated data. Biometrics 2000;56(2):645-6.

30. Norman GR, Sloan JA, Wyrwich KW. Interpretation of changes in health-related quality of life: the remarkable universality of half a standard deviation. Med Care 2003;41(5):582-92.

31. Lattimer CR, Kalodiki E, Azzam M, Geroulakos G. Pneumatic thigh compression reduces calf volume and augments the venous return. Phlebology 2015;30(5):316-22.

32. Lattimer CR, Mendoza E. Simultaneous Air-Plethysmography and Duplex Scanning on a Tilt-Table in Assessing Gravitational Venous Drainage. J Vasc Surg Venous Lymphat Disord 2016;4(1):151-2. 


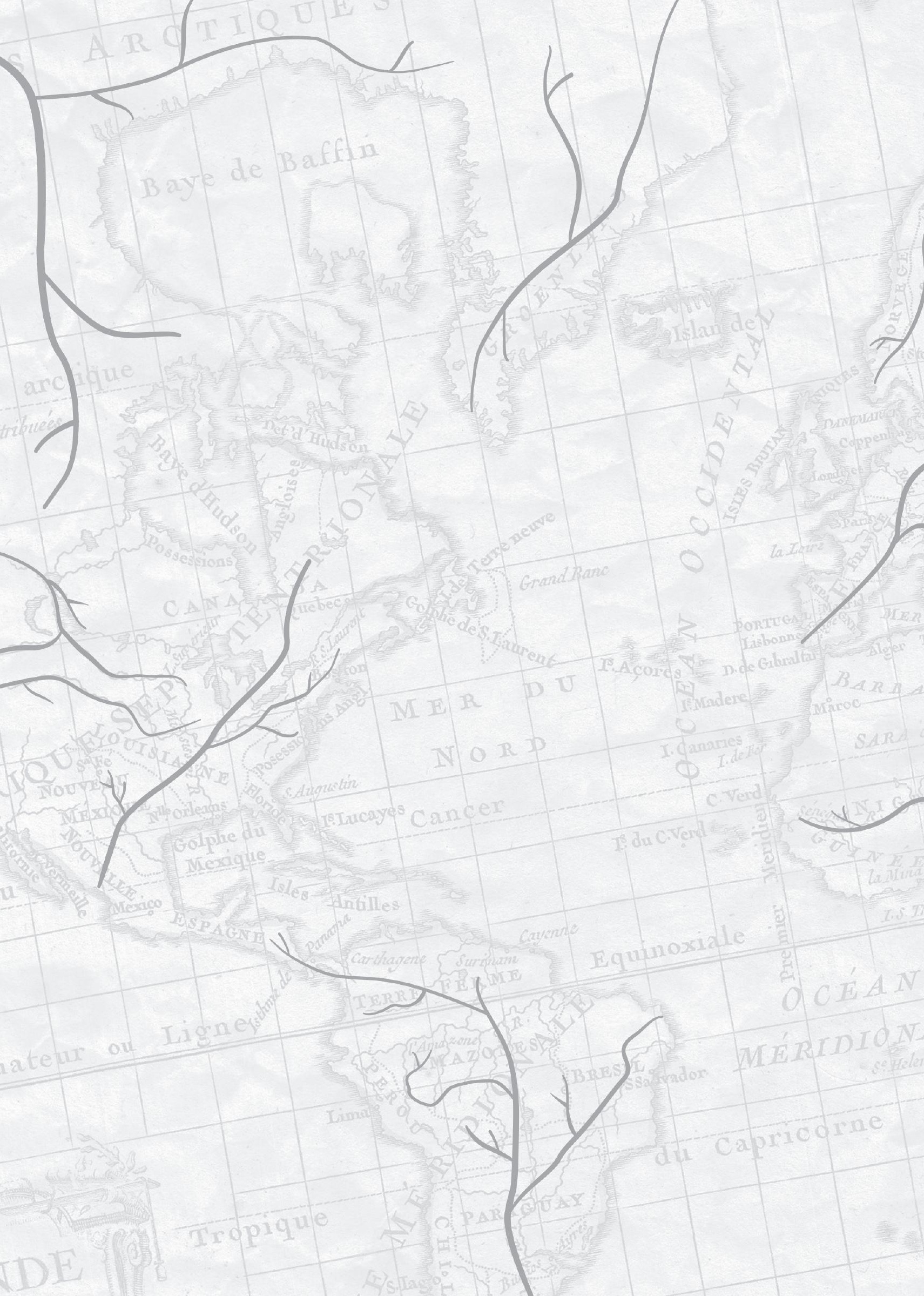




\title{
CHAPTER 5
}

\section{Abdominal and pubic collateral veins as indicators of deep venous obstruction}

\author{
Ralph L.M. Kurstjens \\ Timme. M.A.J. van Vuuren \\ Mark A.F. de Wolf \\ Rick de Graaf \\ Carsten W.K.P. Arnoldussen \\ Cees H.A. Wittens
}

J Vasc Surg Venous Lymphat Disord. 2016;4(4):426-33 


\begin{abstract}
Objective: Chronic deep venous obstruction can cause a significant loss of quality of life, although it can be treated successfully by stenting. A clear referral pattern for additional imaging is warranted in patients with lower limb complaints. The aim of this study was to determine the value of clinically visible abdominal wall collateral veins in the diagnosis of a potentially treatable deep venous obstruction.

Methods: A total of 295 patients referred for evaluation at a tertiary, venous clinic with a collateral vein on the abdominal wall or pubic bone, visible upon physical examination, were retrospectively analysed. They were compared with a randomly selected control group of 365 patients without such a collateral vein. Duplex ultrasound, magnetic resonance venography, computed tomography venography and conventional venography were used to determine the presence or absence of deep venous obstruction.

Results: Mean age of the group with a positive collateral was $43.5 \pm 13.7$ years (6-76), compared to $44.7 \pm 14.2$ years (16-89) in the control group. In the collateral group $66.1 \%$ were female compared to $63.3 \%$ in the control group. Sensitivity of the abdominal wall collateral vein for any obstruction at the level of the groin or more proximal was 53\% (95\% confidence interval [C], 48-57), specificity 86\% (95\% CI, 79-91), PPV 93\% (95\% CI, 90-96) and NPV 32\% (95\% CI, 28-37). Sensitivity was $68 \%$ (95\% CI, 62-73) for higher degrees of post-thrombotic obstruction and $27 \%(95 \% \mathrm{CI}, 19-36)$ in iliac vein compression.

Conclusions: A collateral vein on the abdominal wall or across the pubic bone in patients with complaints of the lower limb has an excellent positive predictive value for deep venous obstructive disease at the level of the groin or higher. Such collateral veins should therefore not be removed and symptomatic patients could be offered further diagnostics and treatment.
\end{abstract}




\section{Introduction}

Chronic deep venous obstruction can lead to various complaints. This is often accompanied by a significant reduction in quality of life similar to diabetes mellitus, congestive heart failure and chronic obstructive pulmonary disease. ${ }^{1,2}$ The main reason for developing such a chronic obstruction is inadequate recanalisation after deep vein thrombosis (DVT), resulting in the post-thrombotic syndrome (PTS). ${ }^{3}$ Annually, one to two per 1000 of the Western population will develop a DVT, ${ }^{4,5} 25-56 \%$ of whom develop PTS., ${ }^{2,-9}$ In patients with a Lower Extremity Thrombosis classification 3 or 4, a DVT of the iliocaval or common femoral veins impairing the central venous outflow, the recanalisation rate is even worse and more patients suffer from PTS afterwards. ${ }^{10,11}$ The other main cause of chronic deep venous obstruction causing a central venous outflow obstruction is non-thrombotic iliac vein compression. ${ }^{3}$ This is often referred to as May-Thurner syndrome, which describes compression of the left common iliac vein (CIV) by the overlying right common iliac artery against the lumbar vertebral column. ${ }^{12}$ However, different anatomic compression variants exist.,13 The prevalence of such an obstruction is unclear as these compressions are often not clinically relevant; e.g. compression of $>50 \%$ has been found in $24 \%$ of the general population. ${ }^{14}$

In cases of iliac and/or CFV obstruction where conservative therapy by compression stockings and mobilisation does not yield sufficient results, percutaneous transluminal angioplasty and stenting can be performed with good clinical success. ${ }^{15-18}$ However, adequate identification of possibly treatable pathology is necessary. Therefore, it is essential to establish a clear referral pattern. Whilst a history of deep vein thrombosis and venous claudication can be indicators of deep vein obstruction and mandate additional analysis, ${ }^{19,20}$ these signs do not indicate the level of obstruction and therefore possible treatability. Another parameter that might be useful in patient selection is the presence of a collateral vein visible on the abdominal wall or over the pubic bone during physical examination. ${ }^{21}$ This develops as an alternative outflow tract for central venous outflow obstruction and underlines the potential importance of collateral circulation in deep venous obstruction. ${ }^{22-24}$ Post-thrombotic obstruction or iliac vein compression can be diagnosed using duplex ultrasound (DUS), ${ }^{25,26}$ computed tomography venography (CTV), ${ }^{27}$ magnetic resonance venography (MRV), ${ }^{26,27}$ intravascular ultrasound (IVUS), ${ }^{28}$ or venography. ${ }^{24,29}$ Since these techniques can be costly and sometimes invasive, it is vital to be as selective as possible when deciding to perform imaging studies to evaluate the deep veins.

The aim of this study was to determine the value of clinically visible abdominal wall collateral veins in the diagnosis of a potentially treatable deep venous obstruction and to investigate whether they should be used as a sign of referral for further diagnostics and potential treatment.

\section{Methods}

\section{Study design and participants}

In this retrospective observational study we evaluated the clinical value of the presence of collateral veins on the abdominal wall or over the pubic bone (Figure 5.1), visible upon physical examination. This was assessed during first patient visit at our tertiary, outpatient clinic. Clinical value was based on the presence of deep venous obstruction on imaging in patients with and without these collaterals.

Between May 2009 and November 2015, 1099 patients were referred to our tertiary, venous outpatient clinic. Patients who presented with a collateral vein on the abdominal wall or 


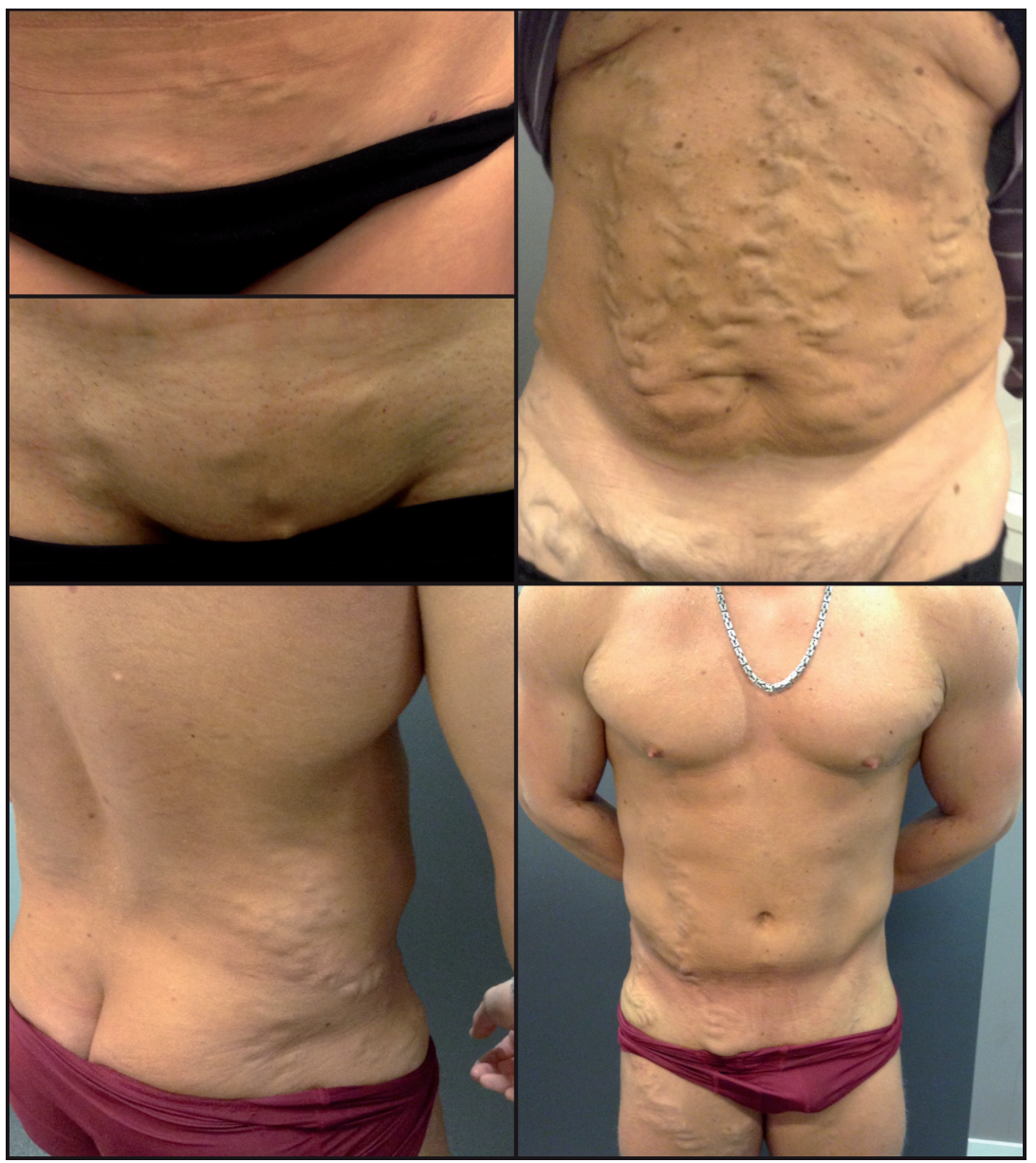

Figure 5.1 Examples of collateral veins over the pubic bone or abdominal wall.

pubic bone (from hereon referred to as abdominal wall collateral), as determined by physical examination during their first visit, were included in this study. Patients also needed to have undergone DUS, CTV, MRV or conventional venography to diagnose presence of deep venous obstruction. Those who presented with an abdominal wall collateral during a later visit or who suffered a DVT $<1$ year before their visit were excluded. To create a control group, we randomly selected 403 patients from our database of patients referred to our outpatient clinic. These patients were generally referred because of suspicion of deep venous obstruction, based on complaints, a history of deep vein thrombosis or quickly recurrent varicosities. We first identified patients who did not present with an abdominal wall collateral. Thereafter, a researcher blinded for patient data randomly sampled 403 cases. Patients with insufficient imaging data of the deep venous system or a DVT $<1$ year before their visit were excluded from analysis in this control group. Information on complaints, venous claudication, history of DVT, previous venous interventions, C-class of the Clinical-Etiology-Anatomy-Pathophysiology (CEAP) classification for chronic venous disorders, Venous Clinical Severity Score (VCSS) and Villalta scale ${ }^{2}$ were collected for both groups of patients. Venous claudication was defined as the occurrence of 
heaviness or pain during walking, which subsides when the patient assumes a sitting or supine position with the leg elevated.

This study was approved by the Maastricht University Medical Centre institutional review board (METC 15-4-243). Individual patient consent was not obtained, as this is not required under Dutch law for retrospective studies.

\section{Procedures}

Imaging protocols described below were the same for both groups of patients.

\section{Duplex Ultrasound}

Patients underwent DUS during their first visit to our outpatient clinic. All DUS examinations were performed using a MyLab Alpha (Esaote, Genoa, Italy) or a ProSound Alpha 7 Premier machine (Hitachi Aloka, Tokyo, Japan). The deep venous system was visualised from the suprarenal inferior vena cava (IVC) to the CFV in the supine position, using a convex probe (frequency range 1-8 MHz). Evaluation of the groin downwards was performed using a linear probe (frequency range 3-13 MHz) with the patient standing upright. However, for the purpose of this study only evaluation of the CFV was included from investigations in the erect position. Throughout the examination, available colour modalities were used to determine flow in both transverse and longitudinal planes. ${ }^{26}$ Flow division and intraluminal synechiae were considered as signs for post-thrombotic obstruction. Iliac vein compression was defined as $>50 \%$ lumen reduction compared with the diameter and transverse surface area of a normal contralateral common iliac vein or a healthy vessel segment more distal to the supposed compression.

\section{Magnetic Resonance Venography}

Patients referred to our dedicated venous clinic with a suspicion of outflow obstruction of the lower limb are routinely analysed with MRV. All MR examinations were performed on a 1.5-T magnetic resonance imaging system (Intera; Philips Healthcare, Best, the Netherlands). A dedicated 12-element phased-array peripheral vascular coil with a cranio-caudal coverage of $128 \mathrm{~cm}$ (Philips Healthcare, Best, the Netherlands) was used for signal reception. Patients were imaged in the supine position. Prior to contrast delivery, all patients underwent a standard two-dimensional non-contrast enhanced balanced turbo field echo sequence to visualise the abdominal and pelvic veins. Then, a gadolinium-based contrast agent (Gadobutrol; Gadavist; Bayer Healthcare, Berlin, Germany) was administered intravenously at $1.0 \mathrm{~mL} / \mathrm{s}(0.2 \mathrm{~mL}$ per kg body weight, equals to $0.2 \mathrm{mmol} / \mathrm{kg}$ ) in the median cubital vein. Subsequently, a $20 \mathrm{~mL}$ saline flush was injected at the same flow rate, using a remote controlled dual head injector (Spectris; Bayer Healthcare, Berlin, Germany). Acquisition of the first scan volume was started 30 seconds after contrast administration. A three-dimensional ultrafast gradient echo sequence (Ultrafast GE; THRIVE; Philips Healthcare, Best, the Netherlands) with fat suppression (spectral presaturation with inversion recovery) was used for high-resolution steady-state imaging of the venous vasculature, ensuring coverage of at least the popliteal veins up to the suprarenal IVC. ${ }^{26}$ Compression of a vein was defined as $>50 \%$ lumen reduction with the presence of collateral veins. Post-thrombotic obstruction was identified as the presence of intraluminal synechiae, which has been described and successfully performed before..$^{26,30}$ 


\section{Computed Tomography Venography}

CTV was performed in patients who had a contraindication for MRV. Each examination was performed on a Siemens Flash CT scanner (Siemens Healthcare, Erlangen, Germany). An intravenous injection of $120 \mathrm{~mL}$ iodine contrast medium (Ultravist 300; Bayer Healthcare, Berlin, Germany) was administered at $3.5 \mathrm{~mL} / \mathrm{s}$ via an 18-gauge antecubital infusion catheter, followed by a saline flush of $40 \mathrm{~mL}$ at $3.5 \mathrm{~mL} / \mathrm{s}$. CT images were obtained and reconstructed with a slice thickness of $2.0 \mathrm{~mm}$ from the dome of the diaphragm to the toes, $180 \mathrm{~s}$ after the start of the injection. Images were routinely interpreted by a subspecialty trained cardiovascular radiologist on a regular picture archiving and communication system workstation using IMPAX 6.5 (Agfa Healthcare, Mortsel, Belgium). The primary criteria for deep venous obstruction were segmental non-visualisation, lack of opacification of the vein lumen, luminal narrowing with or without external compression, and identification of collateralisation. Compression was defined as $>50 \%$ lumen reduction compared to a normal vessel segment.

\section{Conventional venography}

Venography was performed in all cases in which treatment was indicated based on non-invasive imaging. In some cases it was performed when no pathology was found on DUS or MRV/CTV, yet deep venous obstruction was suspected on the basis of patient signs or symptoms. In the latter instance, anteroposterior venography was performed to identify typical signs of non-thrombotic iliac vein lesions, e.g. contrast translucency appearing as a filling defect; broadening/pancaking of the vein; and axial, transpelvic or ascending lumbar collaterals. ${ }^{31}$ Ultrasound guidance was used to puncture the femoral vein, circa $10 \mathrm{~cm}$ below the main deep femoral vein branch. This was done to identify any collateral veins above the level of the saphenofemoral junction, if present. Venography was performed during inspiration through a 6F sheath (PreludePRO; Merit Medical Systems, South Jordan, UT, USA) with 10cc of iodinated contrast (Ultravist 300; Bayer Healthcare, Berlin, Germany) at a flow velocity of $5 \mathrm{~mL} / \mathrm{s}$. In the presence of aforementioned classic non-thrombotic iliac vein lesion signs, we determined a haemodynamically relevant downstream obstruction, i.e. significant iliac vein compression. The presence of collateral veins has been suggested to be of haemodynamic importance. ${ }^{32}$ No efforts were made to estimate iliac vein stenosis grade, since venography has never been validated to determine iliac vein lumen reduction accurately.

\section{Outcomes}

Primary outcome was the presence of deep venous obstruction of the CFV or more proximal. Obstruction was also divided into post-thrombotic disease and non-thrombotic iliac vein compression. Sub-analysis for patients with $>50 \%$ lumen reduction was performed in the postthrombotic group. Obstruction was scored as positive if DUS or MRV/CTV identified the obstruction. Obstruction was scored as negative if both DUS and MRV/CTV did not show obstruction. If a segment was negative on one modality and not evaluated or not visualised on another modality it was also scored as negative. When no obstruction was identified on DUS, MRV or CTV, and conventional venography was performed, obstruction was scored as positive if one was identified on venography. 


\section{Statistical analysis}

Continuous data were presented as mean with standard deviation or median with interquartile range (IQR), depending on normality of distribution. An independent $t$-test or Man-Whitney $\mathrm{U}$ test was performed to assess for differences between the two patient groups (presence and absence of abdominal wall collateral), depending on normality of distribution. Categorical data were presented using percentages and a Pearson's $\chi^{2}$ test was used to test for differences in patient characteristics. Fisher's exact test was used in cases where expected counts were less than five. $P$-values $\leq 0.05$ were considered as statistically significant. Sensitivity, specificity, positive predictive value (PPV) and negative predictive value (NPV) were calculated for the ability of abdominal wall collaterals to identify deep venous obstruction. Obstructions were stratified according to aetiology and a sub-analysis was performed for patients with $>50 \%$ lumen reduction, based on DUS. Diagnostic value analyses were performed using GraphPad Prism version 5.04 (GraphPad Software, San Diego, CA, USA), whereas all other analyses were performed using SPSS version 21.0 (IBM Corporation, Armonk, NY, USA).

\section{Results}

Of the 1099 patients who were referred to our clinic, 308 presented with an abdominal wall collateral. Eleven patients were excluded based on our exclusion criteria and an additional two patients were excluded because of insufficient imaging data. In the randomly selected control group of 403 patients, 30 patients had to be excluded according to our exclusion criteria and

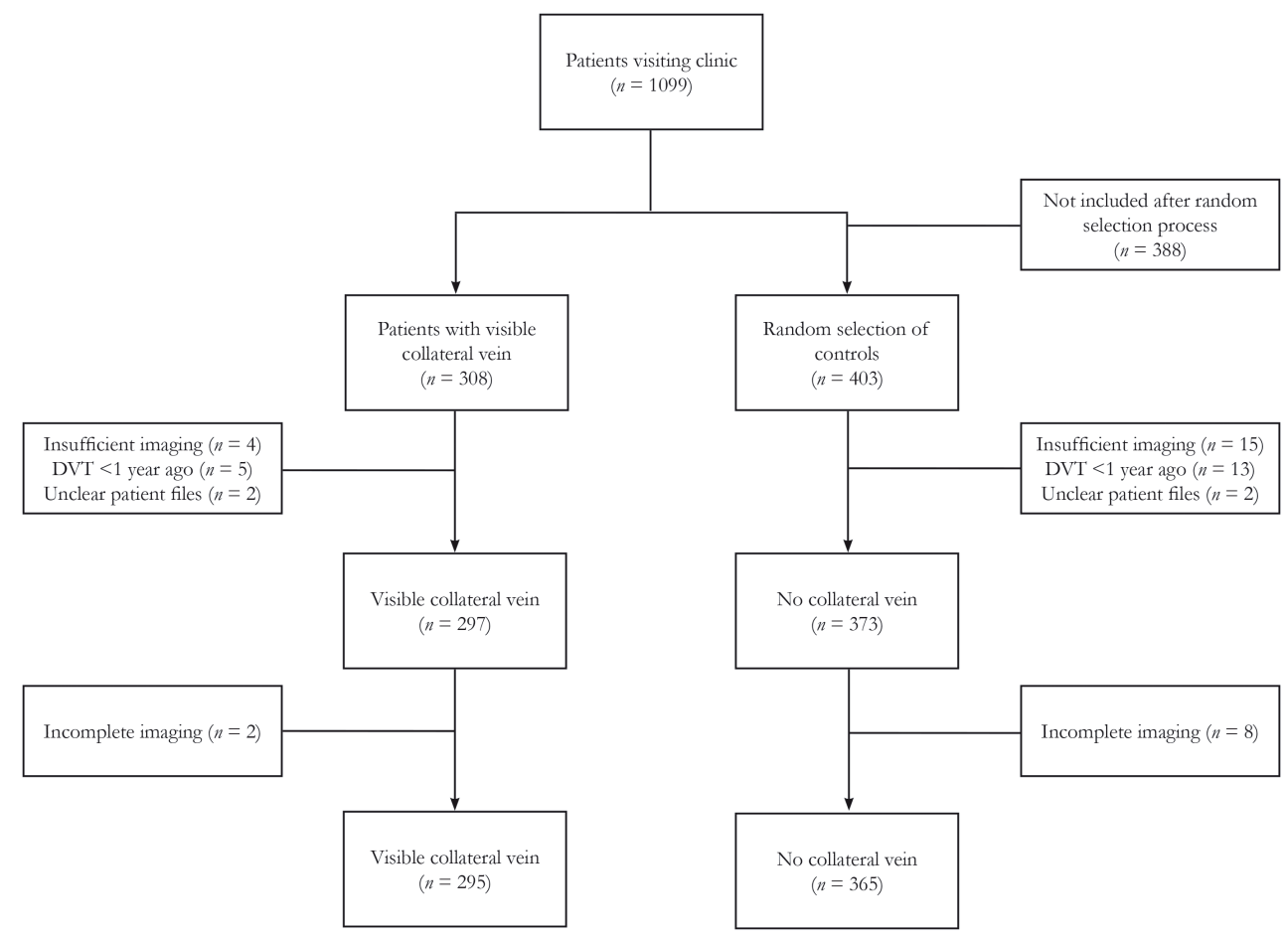

Figure 5.2 Flowchart of imaging studies. 
eight did not have full visualisation of the deep venous system. Thus, a total of 660 patients were analysed: 295 patients with an abdominal wall collateral and 365 patients without. (Figure 5.2)

Mean age of the group with a visible collateral was $43.5 \pm 13.7$ years (6-76) compared to 44.7 \pm 14.2 years $(16-89)$ in the control group $(P=0.276)$. Of all patients with a collateral, $66.1 \%$ were female compared to $63.3 \%$ in controls $(P=0.452)$. History of venous interventions was comparable between the two groups $(30.9 \%$ vs. $35.1 \%, P=0.549)$. One patient in the control group had an abdominal wall collateral removed for cosmetic reasons in the past. Patients with a visible collateral more often had a history of DVT $(79.3 \%$ compared with $61.9 \%, P<0.001)$. Of those patients with a history of DVT or iatrogenic lesions, the group with a visible collateral presented at our outpatient clinic at 9.0 years (IQR, 3.0-18.0) after the event, compared to

Table 5.1 Patient characteristics.

\begin{tabular}{|c|c|c|c|}
\hline & $\begin{array}{l}\text { Abdominal wall collateral } \\
(n=295)\end{array}$ & $\begin{array}{l}\text { No abdominal wall } \\
\text { collateral }(n=365)\end{array}$ & $P$ \\
\hline Age, years & $43.5 \pm 13.7$ (range, 6-76) & $44.7 \pm 14.2$ (range, $16-89)$ & 0.276 \\
\hline Female sex , $n(\%)$ & $195(66.1)$ & $231(63.3)$ & 0.452 \\
\hline History of venous intervention, $n(\%)^{*}$ & & & 0.549 \\
\hline No & $206(70.1)$ & $237(64.9)$ & \\
\hline Superficial & $79(26.9)$ & $113(30.9)$ & \\
\hline Deep & $13(4.5)$ & $20(5.4)$ & \\
\hline Removal of abdominal wall collateral & - & $1(0.3)$ & \\
\hline History of DVT , $n(\%)$ & & & $<0.001^{\#}$ \\
\hline No & $55(18.6)$ & $137(37.5)$ & $<0.001 \#$ \\
\hline Yes & $234(79.3)$ & $226(61.9)$ & $<0.001^{\#}$ \\
\hline Iatrogenic lesion & $6(2.0)$ & $2(0.5)$ & 0.149 \\
\hline Median years since event ${ }^{\dagger}$ & 9.0 (IQR, 3.0-18.0) & $6.0(\mathrm{IQR}, 3.0-14.0)$ & 0.061 \\
\hline Location of complaints, $n(\%)^{\ddagger}$ & & & 0.285 \\
\hline No complaints & $7(2.3)$ & $8(2.2)$ & \\
\hline Left leg & $163(55.4)$ & $163(45.2)$ & \\
\hline Right leg & $43(14.6)$ & $73(20.2)$ & \\
\hline Both legs & $76(25.9)$ & $109(30.2)$ & \\
\hline Abdomen/pelvis & $27(9.2)$ & $34(9.4)$ & \\
\hline Venous claudication, $n(\%) \S$ & $156(54.2)$ & $172(49.0)$ & 0.194 \\
\hline VCSS & $7.4 \pm 3.5$ & $6.9 \pm 3.8$ & 0.137 \\
\hline Highest $\mathrm{C}$ of CEAP,$n(\%)^{* *}$ & & & 0.193 \\
\hline $\mathrm{C}_{0}$ & $21(7.2)$ & $39(10.8)$ & \\
\hline $\mathrm{C}_{1}$ & $24(8.2)$ & $29(8.0)$ & \\
\hline $\mathrm{C}_{2}$ & $56(19.2)$ & $51(14.1)$ & \\
\hline $\mathrm{C}_{3}^{2}$ & $96(33.0)$ & $121(33.5)$ & \\
\hline $\mathrm{C}_{4}$ & $61(21.0)$ & $69(19.1)$ & \\
\hline $\mathrm{C}_{5}$ & $21(7.2)$ & $24(6.6)$ & \\
\hline $\mathrm{C}_{6}$ & $12(4.1)$ & $28(7.8)$ & \\
\hline Villalta scale, $n(\%)^{\text {t+ }}$ & & & 0.343 \\
\hline No PTS & $20(9.8)$ & $18(13.0)$ & \\
\hline Mild PTS & $74(36.3)$ & $46(33.3)$ & \\
\hline Moderate PTS & $69(33.8)$ & $38(27.5)$ & \\
\hline Severe PTS & $41(20.1)$ & $36(26.1)$ & \\
\hline
\end{tabular}

DVT, deep venous thrombosis; VCSS, venous clinical severity score; CEAP, Clinical-Etiology-Anatomy-

Pathophysiology classification for chronic venous disease. Plus-minus values are means \pm standard deviations. *1 missing, ${ }^{\dagger} 6$ missing, ${ }^{\star 5}$ missing, ${ }^{\$} 21$ missing, ${ }^{\top 108}$ missing, ${ }^{* *} 8$ missing, ${ }^{+\dagger}$ only given for patients with postthrombotic disease $(n=401), 59$ missing, ${ }^{+*}$ statistically significant. 
6.0 years (IQR, 3.0-14.0) for controls $(P=$ 0.061). Severity of disease, determined by venous claudication, $\mathrm{C}$ of CEAP, VCSS and Villalta score, was not different between the two groups (Table 5.1).

A total of 522 obstructions on the level of the groin or higher were observed using DUS, CTV, MRV and venography; 404 $(77.4 \%)$ were of post-thrombotic nature, $116(22.2 \%)$ of non-thrombotic nature and in $2(0.4 \%)$ patients compression was observed without adequate visualisation of all lower limb vessel segments. Thus, the latter two patients might have postthrombotic changes in the not visualised vessel segments, leading to exclusion of these patients for sub-analysis. Imaging with more than one modality was performed in 612 patients $(92.7 \%)$. More detailed information on identified pathology can be found in Figure 5.3. Of all detected postthrombotic lesions, $60.4 \%$ were indentified in the collateral group and $39.6 \%$ in the control group $(P<0.001)$. Conversely, $26.7 \%$ of all detected non-thrombotic iliac vein compressions were identified in the collateral group compared with $73.3 \%$ in the control group $(P=0.015)$.

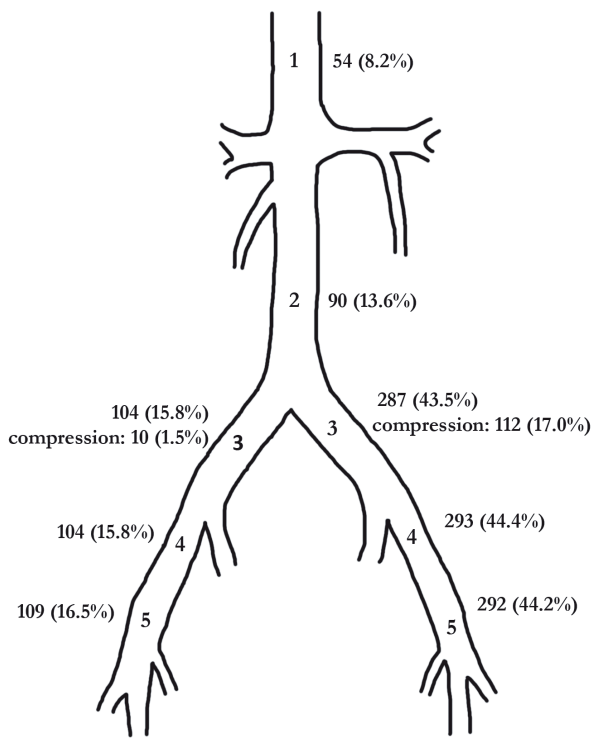

Figure 5.3 Pathology found with duplex ultrasound, magnetic resonance venography, computed tomography venography, and conventional venography $(n=660)$. Iliac vein compression is only indicated in the absence of postthrombotic changes of the iliac tract.

1 , suprarenal inferior vena cava; 2 , infrarenal inferior vena cava; 3, common iliac vein; 4, external iliac vein; 5 , common femoral vein. In 138 cases $(20.9 \%)$ no obstruction was found. In 1 case $(0.2 \%)$ post-thrombotic occlusion of the right axillary and jugular veins was found.

The presence of an abdominal wall collateral visible during physical examination yielded a sensitivity of 53\% (95\% CI, 48-57), specificity of 86\% (95\% CI, 79-91), PPV of 93\% (95\% CI, 90-96) and NPV of 32\% (95\% CI, 28-37) for any obstruction found on imaging from the groin up to the right atrium (Table 5.2). Sub-analysis for post-thrombotic obstruction demonstrated similar results with a sensitivity of $60 \%$ (95\% CI, 55-65), specificity of $86 \%$ (95\% CI, 79-91), PPV of $92 \%$ (95\% CI, 89-95) and NPV of 43\% (95\% CI, 37-49). Positive predictive value did not change when investigating degree of obstruction: $90 \%$ (95\% CI, 85-94) for post-thrombotic obstructions with $>50 \%$ lumen reduction. Yet, the sensitivity increased (68\%; 95\% CI, 62-73), as did the NPV (58\%; 95\% CI, 51-65). For the subgroup of non-thrombotic iliac vein compression PPV (61\%; 95\% CI, 46-74) and sensitivity $(27 \%$; 95\% CI, 19-36) were considerably lower (Table 5.2).

Patients with a positive collateral vein sign without objectified obstruction often demonstrated some degree of venous pathology. For example, two patients demonstrated gonadal vein incompetence during venography. In two additional patients gonadal veins were dilated on MRV, and one patient showed slight compression of the left renal vein by the superior mesenteric artery on DUS, though not significant enough to warrant a Nutcracker syndrome diagnosis. Also, eight patients suffered from superficial vein incompetence in the area of the saphenofemoral junction, one from an aneurysmatic dilatation of the stump of a previously treated great saphenous vein, 
Table 5.2 Diagnostic value of the abdominal wall collateral for different types of obstruction on the level of the groin or higher.

\begin{tabular}{lllll}
\hline & $\begin{array}{l}\text { Sensitivity, } \% \\
(95 \% \mathrm{CI})\end{array}$ & $\begin{array}{l}\text { Specificity, } \% \\
(95 \% \mathrm{CI})\end{array}$ & $\begin{array}{l}\text { Positive predictive } \\
\text { value, } \%(95 \% \mathrm{CI})\end{array}$ & $\begin{array}{l}\text { Negative predictive } \\
\text { value, (95\% CI })\end{array}$ \\
\hline $\begin{array}{l}\text { Any obstruction } \\
(n=295,365)\end{array}$ & 53 & 86 & 93 & 32 \\
Post-thrombotic obstruction & $(48-57)$ & $(79-91)$ & $(90-96)$ & $(28-37)$ \\
$(n=264,278)$ & $(55-65)$ & $(79-91)$ & $(89-95)$ & $(37-49)$ \\
Post-thrombotic obstruction & 68 & 86 & 90 & 58 \\
$>50 \%(n=201,204)$ & $(62-73)$ & $(79-91)$ & $(85-94)$ & $(51-65)$ \\
$\begin{array}{l}\text { Non-thrombotic obstruction } \\
(n=51,203)\end{array}$ & 27 & 86 & 61 & 58 \\
\hline $\begin{array}{l}\text { Number of patients included in analyses is first given for those with a collateral vein and then for those } \\
\text { without. CI, confidence interval }\end{array}$ & $(19-36)$ & $(79-91)$ & $(46-74)$ & $(51-65)$
\end{tabular}

one of retrograde flow of the superficial epigastric vein and one from an incompetent internal pudendal vein. Four patients had no suggestion of venous pathology whatsoever.

\section{Discussion}

This study has shown that an abdominal wall collateral vein visible during physical examination has a positive predictive value of $93 \%$ for diagnosing deep venous obstructive disease at the level of the groin or higher. This clinical sign of venous obstruction has been described in literature before, ${ }^{21}$ as has its presence during duplex ultrasound examinations when it is often called a spontaneous Palma shunt. ${ }^{33}$ However, to our knowledge, no investigations were made with respect to its diagnostic abilities. The high PPV indicates that an abdominal wall collateral is a sign that patients should be referred for additional imaging. Specificity was fair $(86 \%)$, indicating few false negative test results, though negative predictive value was consistently very low $(32 \%)$, suggesting that no conclusions should be drawn in the absence of such a collateral vein during physical examination.

Post-thrombotic disease appears to have the most influence on the formation of a visible collateral vein, since sub-analysis yielded superior results to non-thrombotic iliac vein compression. This difference is substantiated by the fact that the collateral group more often had a history of DVT. Conversely, iliac vein compression without the presence of post-thrombotic abnormalities was more often present in patients without a visible abdominal wall collateral. The lower prevalence of abdominal wall collaterals in patients with non-thrombotic iliac vein compression therefore explains its inferior sensitivity in these patients.

An interesting observation is the removal of a collateral vein over the pubic bone for cosmetic reasons in one of the patients in the control group. This patient had lower limb complaints that remained stable after removal of the pubic collateral vein, which is certainly not always the case in our experience. We have also seen patients whose complaints deteriorated after removal of such a collateral vein. It is crucial that the physician realises that these collaterals are an essential part of the outflow of the leg and should never be removed, because the complaints related to the impaired outflow will likely increase. Visible collaterals on the abdominal wall or across the pubic bone are only the tip of the iceberg. In cases of CIV obstruction, blood flow can be diverted via the internal iliac vein through the pre-sacral and parametrial plexuses, ipsilateral ascending lumbar vein, ovarian veins, or paravertebral plexuses. ${ }^{22-24,26}$ When obstruction also 
involves the external iliac vein or CFV, the deep circumflex iliac vein, obturator vein or deep external pudendal vein can be activated too. ${ }^{22,23}$ Additionally, blood flow can be diverted through the superficial external pudendal, pubic and superficial epigastric veins, ${ }^{22,23}$ which leads to the visible collateral veins on the abdominal wall or across the pubic bone. Involvement of the IVC likely results in a more extensive collateral network, involving the paravertebral plexus and epigastric veins draining into the azygos system and the superior vena cava. ${ }^{23,26}$ These veins can lead to wide-ranging externally visible collateral formation.

Results could have been confounded by the presence of labial or scrotal varicosities. A distinction between such varicosities and collateral veins across the pubic bone could not always be determined due to succinct reporting. Isolated pudendal incompetence or incompetence of the saphenofemoral junction might have led to the presence of varicosities in the groin area. Nonetheless, better distinction between such varicosities and collateral veins would likely have led to an even higher PPV. Furthermore, save for four patients, all patients with a visible collateral showed some form of venous pathology. For example, incompetence in the area of the saphenofemoral junction might have led to retrograde flow in the superficial epigastric vein and therefore a visible collateral vein. Finally, it is conceivable that abdominal wall collaterals could also be connected to pelvic congestion syndrome, which is a complex phenomenon that is currently not completely understood and can be difficult to diagnose. ${ }^{34}$

Some limitations should be mentioned. Despite extensive imaging, the lack of intravascular ultrasound use might have influenced diagnosis of non-thrombotic iliac vein compression. Also, selection bias may be present as all patients were referred to our outpatient clinic with either complaints of the abdomen or lower limb, suspected to be of venous origin, or with known obstruction of the deep venous system. Collateral circulation can also be found in a number of different disorders. Ovarian tumours can cause dilated ovarian veins and gestational trophoblastic neoplasms can lead to a more pronounced uterine plexus, as can uterine arteriovenous malformations. ${ }^{23}$ These deep collateral networks could theoretically lead to a collateral sign visible upon physical examination. Finally, portal hypertension can cause collateral formation and is known to demonstrate clinically visible abdominal veins. ${ }^{35}$ Studies in a general population with complaints of the lower limb could determine whether such a bias was actually present.

\section{Conclusions}

A collateral vein on the abdominal wall or across the pubic bone in patients with complaints of the lower limb has an excellent positive predictive value for potentially treatable deep venous obstructive disease at the level of the groin or higher. This warrants closer inspection of the groin and abdominal area in all patients with lower limb symptoms. Such collateral veins should never be removed for aesthetic purposes and symptomatic patients should be referred for additional imaging, and possibly treatment, of their obstruction.

\section{References}

1. Carradice D, Mazari FA, Samuel N, Allgar V, Hatfield J, Chetter IC. Modelling the effect of venous disease on quality of life. BrJ Surg 2011;98(8):1089-98.

2. Kahn SR, Shbaklo H, Lamping DL, et al. Determinants of health-related quality of life during the 2 years following deep vein thrombosis. J Thromb Haemost 2008;6(7):1105-12.

3. Meissner MH, Eklof B, Smith PC, et al. Secondary chronic venous disorders. J Vasc Surg 2007;46 Suppl S:68S-83S.

4. White RH. The epidemiology of venous thromboembolism. Circulation 2003;107(23 Suppl 1):I4-8.

5. Naess IA, Christiansen SC, Romundstad P, Cannegieter SC, Rosendaal FR, Hammerstrom J. Incidence and 
mortality of venous thrombosis: a population-based study. J Thromb Haemost 2007;5(4):692-9.

6. Mohr DN, Silverstein MD, Heit JA, Petterson TM, O'Fallon WM, Melton LJ. The venous stasis syndrome after deep venous thrombosis or pulmonary embolism: a population-based study. Mayo Clin Proc 2000;75(12):1249-56.

7. Prandoni P, Villalta S, Bagatella P, et al. The clinical course of deep-vein thrombosis. Prospective long-term followup of 528 symptomatic patients. Haematologica 1997;82(4):423-8.

8. Schulman S, Lindmarker P, Holmstrom M, et al. Post-thrombotic syndrome, recurrence, and death 10 years after the first episode of venous thromboembolism treated with warfarin for 6 weeks or 6 months. J Thromb Haemost 2006;4(4):734-42.

9. Tick LW, Kramer MH, Rosendaal FR, Faber WR, Doggen CJ. Risk factors for post-thrombotic syndrome in patients with a first deep venous thrombosis. J Thromb Haemost 2008;6(12):2075-81.

10. Strijkers RH, Arnoldussen CW, Wittens CH. Validation of the LET classification. Phlebology 2015;30(1 Suppl):14-9.

11. Akesson H, Brudin L, Dahlstrom JA, Eklof B, Ohlin P, Plate G. Venous function assessed during a 5 year period after acute ilio-femoral venous thrombosis treated with anticoagulation. Eur J Vasc Surg 1990;4(1):43-8.

12. May R, Thurner J. [A vascular spur in the vena iliaca communis sinistra as a cause of predominantly left-sided thrombosis of the pelvic veins]. Z Kreislaufforsch 1956;45(23-24):912-22.

13. Neglen P, Berry MA, Raju S. Endovascular surgery in the treatment of chronic primary and post-thrombotic iliac vein obstruction. Eur J Vasc Endovasc Surg 2000;20(6):560-71.

14. Kibbe MR, Ujiki M, Goodwin AL, Eskandari M, Yao J, Matsumura J. Iliac vein compression in an asymptomatic patient population. J Vasc Surg 2004;39(5):937-43.

15. Neglen P, Hollis KC, Olivier J, Raju S. Stenting of the venous outflow in chronic venous disease: long-term stentrelated outcome, clinical, and hemodynamic result. J Vasc Surg 2007;46(5):979-90.

16. Wen-da W, Yu Z, Yue-Xin C. Stenting for chronic obstructive venous disease: A current comprehensive metaanalysis and systematic review. Phlebology 2016;31(6):376-89.

17. Seager MJ, Busuttil A, Dharmarajah B, Davies AH. Editor's Choice - A Systematic Review of Endovenous Stenting in Chronic Venous Disease Secondary to Iliac Vein Obstruction. Eur J Vasc Endovasc Surg 2016;51(1):100-20.

18. de Wolf MA, de Graaf R, Kurstjens RL, Penninx S, Jalaie H, Wittens CH. Short-Term Clinical Experience with a Dedicated Venous Nitinol Stent: Initial Results with the Sinus-Venous Stent. Eur J Vasc Endovasc Surg 2015;50(4):518-26.

19. Wittens C, Davies AH, Baekgaard N, et al. Editor's Choice - Management of Chronic Venous Disease: Clinical Practice Guidelines of the European Society for Vascular Surgery (ESVS). EurJ Vasc Endovasc Surg 2015;49(6):678737.

20. Kurstjens R, de Wolf M, de Graaf R, Wittens C. Hemodynamic changes in iliofemoral disease. Pblebology 2014;29(1 suppl):90-6.

21. Wittens $\mathrm{CH}$, Bukkems SF, Toonder IT. Abdominal wall venous collaterals: the latent clinical sign for central chronic venous obstruction. Circulation 2010;122(20):2089-90.

22. Thomas ML, Fletcher EW, Cockett FB, Negus D. Venous collaterals in external and common iliac vein obstruction. Clin Radiol 1967;18(4):403-11.

23. Umeoka S, Koyama T, Togashi K, Kobayashi H, Akuta K. Vascular dilatation in the pelvis: identification with CT and MR imaging. Radiographics 2004;24(1):193-208.

24. Neglen P, Raju S. Balloon dilation and stenting of chronic iliac vein obstruction: technical aspects and early clinical outcome. J Endovasc Ther 2000;7(2):79-91.

25. Labropoulos N, Borge M, Pierce K, Pappas PJ. Criteria for defining significant central vein stenosis with duplex ultrasound. J Vasc Surg 2007;46(1):101-7.

26. Arnoldussen CW, Toonder I, Wittens CH. A novel scoring system for lower-extremity venous pathology analysed using magnetic resonance venography and duplex ultrasound. Phlebology 2012;27 Suppl 1:163-70.

27. Arnoldussen CW, de Graaf R, Wittens CH, de Haan MW. Value of magnetic resonance venography and computed tomographic venography in lower extremity chronic venous disease. Phlebology 2013;28 Suppl 1:169-75.

28. Neglen P, Raju S. Intravascular ultrasound scan evaluation of the obstructed vein. J Vasc Surg 2002;35(4):694-700.

29. Nicolaides AN. Investigation of chronic venous insufficiency: A consensus statement (France, March 5-9, 1997). Circulation 2000;102(20):E126-63.

30. Fraser DG, Moody AR, Morgan PS, Martel A. Iliac compression syndrome and recanalization of femoropopliteal and iliac venous thrombosis: a prospective study with magnetic resonance venography. J Vasc Surg 2004;40(4):6129.

31. Raju S, Neglen P. High prevalence of nonthrombotic iliac vein lesions in chronic venous disease: a permissive role in pathogenicity. J Vasc Surg 2006;44(1):136-43; discussion 44.

32. Kurstjens RL, de Wolf MA, van Laanen JH, de Haan MW, Wittens CH, de Graaf R. Hemodynamic significance of collateral blood flow in chronic venous obstruction. Phlebology 2015;30(1 Suppl):27-34. 
33. Mendoza E, Lattimer CR. Examination of superficial veins in the presence of deep venous disease. In: Mendoza E, Lattimer CR, Morrison N, eds. Duplex ultrasound of superficial leg veins: Springer; 2014: 279-83.

34. Tu FF, Hahn D, Steege JF. Pelvic congestion syndrome-associated pelvic pain: a systematic review of diagnosis and management. Obstet Gynecol Surv 2010;65(5):332-40.

35. Pillai AK, Andring B, Patel A, Trimmer C, Kalva SP. Portal hypertension: a review of portosystemic collateral pathways and endovascular interventions. Clin Radiol 2015;70(10):1047-59. 


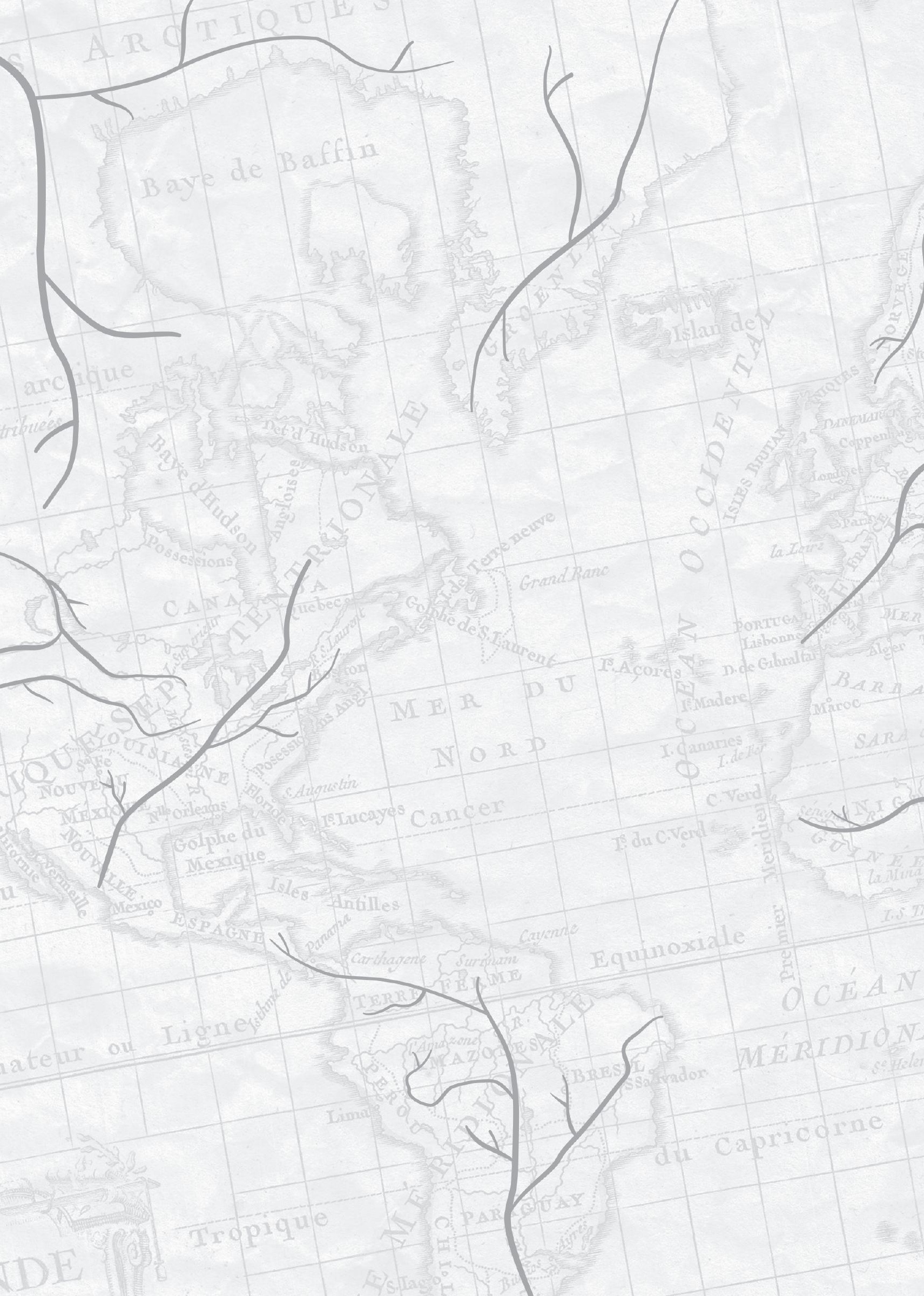




\title{
CHAPTER 6
}

\section{Haemodynamic significance of collateral blood flow in chronic venous obstruction}

\author{
Ralph L.M. Kurstjens \\ Mark A.F. de Wolf \\ Jorinde H.H. van Laanen \\ Michiel W. de Haan \\ Cees H.A. Wittens \\ Rick de Graaf
}

Phlebology. 2015;30(1S):27-34 


\begin{abstract}
Objective: Complaints related to the post-thrombotic syndrome do not always correlate well with the extent of post-thrombotic changes on diagnostic imaging. One explanation might be a difference in development of collateral blood flow. The aim of this study was to investigate the haemodynamic effect of collateralisation in deep venous obstruction.

Methods: Resting intravenous pressure of the common femoral vein was measured bilaterally in the supine position of patients with unilateral iliofemoral post-thrombotic obstruction. Pressure in control limbs was also measured in the common femoral vein after sudden balloon occlusion in the external iliac vein.

Results: Fourteen patients (median age 42 years, 12 female) were tested. In 11 limbs postthrombotic disease extended below the femoral confluence. Median common femoral vein pressure was $17.0 \mathrm{mmHg}$ in diseased limbs compared with $12.8 \mathrm{mmHg}$ in controls $(P=0.001)$ and $23.5 \mathrm{mmHg}$ in controls after sudden balloon occlusion $(P=0.009)$. Results remained significant after correcting for non-occlusive post-thrombotic disease.

Conclusions: This study shows that common femoral vein pressure is increased in post-thrombotic iliofemoral deep venous obstruction, though not as much as after sudden balloon occlusion. The latter difference could explain the importance of collateralisation in deep venous obstructive disease and the discrepancy between complaints and anatomical changes; notwithstanding, the presence of collaterals does not eliminate the need for treatment.
\end{abstract}




\section{Introduction}

Post-thrombotic syndrome (PTS) can be a debilitating condition with extensive effects on quality of life. ${ }^{1}$ Annually, one to two per 1000 adults will develop a deep vein thrombosis (DVT), ${ }^{2} 25-$ $56 \%$ of whom will develop PTS. ${ }^{1,3-6}$ The extent of complaints caused by PTS greatly varies; some patients show minor evidence of post-thrombotic disease on diagnostic imaging techniques, yet present with severe complaints, whereas other patients with extensive disease visible on imaging show very little to no complaints. ${ }^{7-10}$ Spontaneous recanalisation of the affected tract can probably partly explain this difference. However, a discrepancy between complaints and evidence of postthrombotic changes detected by imaging techniques such as duplex ultrasonography (DUS), magnetic resonance venography (MRV) and venography still persists.

Another possible explanation for this discrepancy may be the development of a network of collateral veins, diverting blood flow, in patients with prolonged central venous outflow obstruction. Several studies have reported on the occurrence of such patterns and its clinical presentation in patients with pelvic deep venous obstruction. ${ }^{11-15}$ Nevertheless, little is known about the haemodynamic implications of these collateral blood flow patterns.

The aim of this study was to investigate the haemodynamic effect of collateralisation in iliofemoral deep venous obstruction.

\section{Methods}

In this study, intravenous common femoral vein pressures were compared between limbs with post-thrombotic iliofemoral vein obstruction, healthy control limbs and control limbs with an acute occlusion of the same patients.

\section{Patient selection}

Patients with unilateral post-thrombotic iliofemoral obstruction who were planned to undergo percutaneous angioplasty and stenting were approached to participate in this study. Those who were also to receive concomitant endophlebectomy and creation of an arteriovenous fistula were eligible for inclusion as well. Exclusion criteria were venous obstructive disease in the contralateral limb, peripheral arterial disease, pregnancy and age $<18$ years. Extent of postthrombotic disease was assessed using DUS and MRV as described in literature. ${ }^{14}$ Intra-operative venography was used to confirm whether, at some point of the obstructed tract, an occlusion was present. Patients were examined pre-operatively, during which Villalta scale, ClinicalEtiology-Anatomy-Pathophysiology (CEAP) classification, medical history, general complaints, and presence of collaterals on the abdomen or in the groin were assessed.

This study was approved by the medical ethical review board (METC 13-2-027) and principles according to the 2013-revised declaration of Helsinki were followed. All participants gave informed consent.

\section{Model}

With the patient in the supine position and under general anaesthesia, both femoral veins were cannulated under ultrasound guidance using a 5 French sheath, placing the tips of the sheaths in the common femoral vein (CFV). Subsequently, pressures in both CFVs were measured using a pressure monitoring set (Edwards Lifesciences LLC, Irvine, CA, USA) attached to either an 


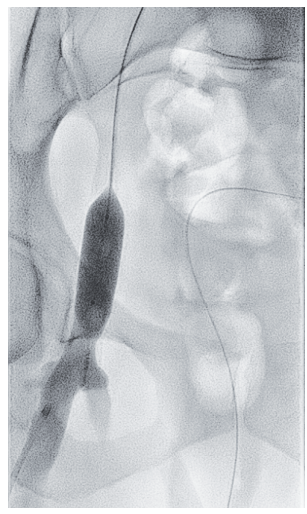

Figure 6.1 Sudden balloon occlusion test.

A $16 \mathrm{~mm}$ x $40 \mathrm{~mm}$ noncompliant balloon is inflated in the external iliac vein of the control limb and a small amount of contrast is injected to check for complete obstruction.

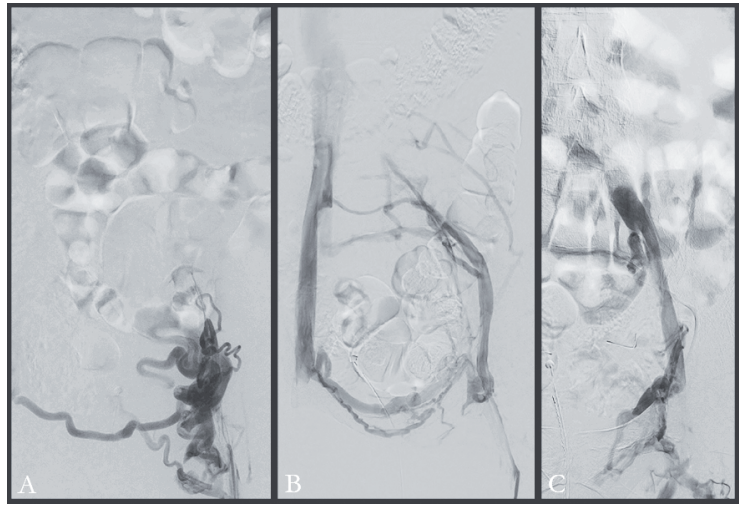

Figure 6.2 Occlusive and non-occlusive post-thrombotic disease.

A. Example of occlusive post-thrombotic disease. B. Example of what we also defined as occlusive disease. Minute flow is seen in the occluded tract, yet flow via collateral veins and the contralateral side is far quicker. C. Example of non-occlusive post-thrombotic disease with flow in a recanalised iliac tract.

IntelliVue MX800 or an IntelliVue MP30 patient monitoring system (Philips Medical Systems, Best, the Netherlands). Next, a catheter was placed in the inferior vena cava (IVC), just proximal from the iliac confluence, to also measure pressure proximal from the obstruction. Following pressure measurements, the obstructed tract was recanalised as described before. ${ }^{16}$ When the post-thrombotic tract was passed, a balloon catheter was placed over the iliac confluence into the contralateral external iliac vein and a $16 \mathrm{~mm}$ x $40 \mathrm{~mm}$ non-compliant balloon (Maxi LD; Cordis/Johnson \& Johnson, Warren, NJ, USA) was inflated. A small amount of contrast was injected through the sheath in the control limb to assess whether the vein was fully occluded by the balloon (Figure 6.1). While the balloon was inflated, pressure was continuously measured in the $\mathrm{CFV}$, distal from the balloon. The balloon occlusion test was ended when pressure remained stable for at least ten seconds.

\section{Statistical analysis and definitions}

IBM SPSS Statistics version 21.0 (IBM Corporation, Armonk, NY, USA) was used for statistical analysis and graphs were created using GraphPad Prism version 5.04 (GraphdPad Software, San Diego, CA, USA). Since most parameters were not normally distributed, continuous variables are described as median values with concomitant range, and the Wilcoxon signed rank test was used to test for statistical differences. $P$-values $\leq 0.05$ were considered as statistically significant. A sub-analysis was performed for affected limbs with only occlusive post-thrombotic changes and control limbs that showed no collateral flow on venography during the sudden balloon occlusion test. Post-thrombotic tracts that showed either no or minute flow of contrast, passing the obstruction far slower than the diverted collateral flow, were defined as occlusive (Figure 6.2). PTS according to the Villalta scale is presented as follows: no PTS (score 0-4), mild PTS (score 5-9), moderate PTS (score 10-14) or severe PTS (score $\geq 15$ or presence of an ulcer). ${ }^{1}$ 


\section{Results}

Fourteen patients were included for analysis. Median age was 42 years (23-65), and 12 patients were female. Median duration of complaints was 5.3 years (1.3-42.9). Seven of the 14 patients had a history of previous venous intervention, five of whom were treated for superficial incompetence, one had occluded bypasses from the left deep femoral vein (DFV) to the left common iliac vein and the left DFV to the IVC, and the last had a patent DePalma bypass from left to right. In 11 cases, post-thrombotic disease extended below the femoral confluence, five of which involved both the DFV and femoral vein. Severity of PTS according to the Villalta scale was mild, moderate and severe in seven, four and three post-thrombotic limbs respectively. Two control limbs were classified with mild PTS according to Villalta. Six affected limbs showed a C-class according

Table 6.1 Patient characteristics $(n=14)$.

\begin{tabular}{|c|c|c|}
\hline Age, years & \multicolumn{2}{|l|}{$42(23-65)$} \\
\hline Female sex,$n(\%)$ & \multicolumn{2}{|l|}{$12(85.7)$} \\
\hline BMI, $\mathrm{kg} / \mathrm{m}^{2}$ & \multicolumn{2}{|l|}{$26.7(19.4-37.6)$} \\
\hline Duration of complaints, years & \multicolumn{2}{|l|}{$5.3(1.3-42.9)$} \\
\hline History of previous venous interventions, $n(\%)^{*}$ & \multicolumn{2}{|l|}{$7(50.0)$} \\
\hline Superficial abdominal wall collateral, $n(\%)$ & \multicolumn{2}{|l|}{$11(78.6)$} \\
\hline \multicolumn{3}{|l|}{ Trabeculated segments in diseased limb, $n(\%)$} \\
\hline CIV - CFV & \multicolumn{2}{|l|}{$14(100)$} \\
\hline DFV & \multicolumn{2}{|l|}{$5(35.7)$} \\
\hline $\mathrm{FV}$ & \multicolumn{2}{|l|}{$11(78.6)$} \\
\hline \multirow[t]{2}{*}{$\mathrm{DFV}$ and $\mathrm{FV}$} & \multicolumn{2}{|l|}{$5(35.7)$} \\
\hline & Diseased limb & Control limb \\
\hline \multicolumn{3}{|l|}{ Highest $\mathrm{C}$ of CEAP, $n(\%)$} \\
\hline $\mathrm{C}_{0}$ & $1(7.1)$ & $2(14.3)$ \\
\hline $\mathrm{C}_{1}$ & $2(14.3)$ & $5(35.7)$ \\
\hline $\mathrm{C}_{2}$ & - & $3(21.4)$ \\
\hline $\mathrm{C}_{3}$ & $6(42.9)$ & $4(28.6)$ \\
\hline $\mathrm{C}_{4 \mathrm{a}}$ & $2(14.3)$ & - \\
\hline $\mathrm{C}_{4 \mathrm{~b}}$ & $1(7.1)$ & - \\
\hline $\mathrm{C}_{5}$ & $1(7.1)$ & - \\
\hline $\mathrm{C}_{6}$ & $1(7.1)$ & - \\
\hline \multicolumn{3}{|l|}{ Villalta scale, $n(\%)$} \\
\hline No PTS & - & $12(85.7)$ \\
\hline Mild PTS & $7(50.0)$ & $2(14.3)$ \\
\hline Moderate PTS & $4(28.6)$ & - \\
\hline Severe PTS & $3(21.4)$ & - \\
\hline
\end{tabular}

CFV, common femoral vein; CIV, common iliac vein; DFV, deep femoral vein; FV, femoral vein; PTS, post-thrombotic syndrome. Continuous variables are presented as median with range.

* Only two of these patients had a history of previous deep venous interventions: one had a bypass from the left DFV to the left CIV and from the left DFV to the inferior vena cava, which were both occluded, and the other had a still patent DePalma bypass from left to right. to CEAP of 3, five a C-class of 4-6 and three a C-class $<3$, though all suffered from significant venous claudication, which is not reflected in CEAP or Villalta. Control limbs all showed a C-class of lower than 3. Eleven out of 14 patients presented with abdominal wall collaterals (Table 6.1).

Median pressure in the CFV of postthrombotic limbs was $17.0 \mathrm{mmHg}$ (4.0-31.0) compared with 12.8 $\mathrm{mmHg} \quad(2.0-24.0) \quad$ in controls $(P=0.001$, Figure 6.3). Median difference in pressure between the IVC and CFV was 3.8 $\mathrm{mmHg}(-2.0$ to 19.0$)$ in post-thrombotic and $1.0 \mathrm{mmHg} \quad(-6.0$ to 2.0) in control limbs $(P=0.001)$. After balloon occlusion of the external iliac vein in the control limb, CFV pressure significantly rose to a median pressure of $23.5 \mathrm{mmHg}$ (7.0-66.0) $(P=0.001$, 
Table 6.2 Pressure measurements.

\begin{tabular}{llll}
\hline & Pressure CFV & $\begin{array}{l}\text { Pressure gradient } \\
\text { IVC-CFV }\end{array}$ & $\begin{array}{l}\text { Pressure CFV after } \\
\text { balloon occlusion }\end{array}$ \\
\hline Diseased limbs $(n=14)$ & $17.0(4.0-31.0)$ & $3.8(-2.0$ to 19.0$)$ & - \\
Control limbs $(n=14)$ & $12.8(2.0-24.0)$ & $1.0(-6.0$ to 2.0$)$ & $23.5(7.0-66.0)$ \\
\hline All values are presented as median with range in mmHg. & \\
CFV, common femoral vein; IVC, inferior vena cava.
\end{tabular}

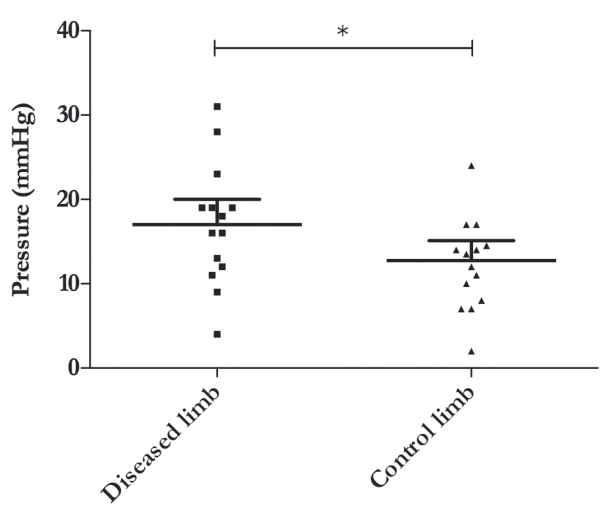

Figure 6.3 Common femoral vein pressures in postthrombotic limbs and control limbs.

$* P=0.001$, Wilcoxon Signed Rank Test

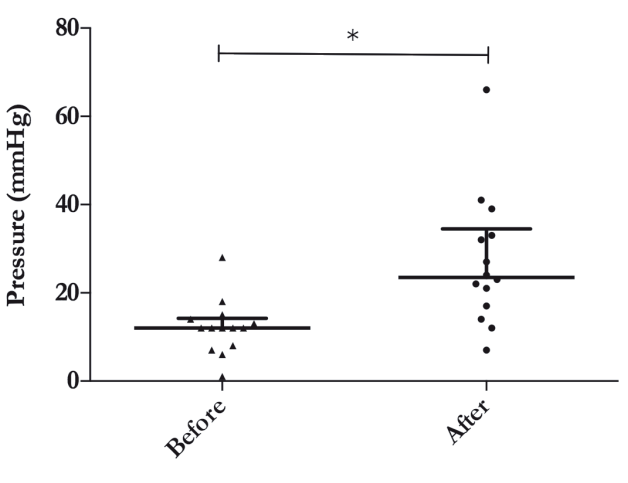

Figure 6.4 Common femoral vein pressures before and after sudden balloon occlusion in control limbs.

$* P=0.001$, Wilcoxon Signed Rank Test

Figure 6.4). Compared with post-thrombotic limbs, control limbs with sudden balloon occlusion demonstrated a significantly higher pressure $(P=0.009$, Figure 6.5 , Table 6.2).

After contrast injection to check for complete balloon occlusion, venography in one patient revealed a collateral vein bypassing the balloon occlusion in the control limb (Figure 6.6). Intravenous pressure in this patient changed from $1.0 \mathrm{mmHg}$ at the moment right before occlusion to $7.0 \mathrm{mmHg}$ after balloon occlusion. Based on venography, two of the postthrombotic limbs did not have an occlusion at any point of the obstructed tract. Results did not significantly change after performing a sub-analysis without the aforementioned limbs.

\section{Discussion}

This study shows that supine CFV pressure is significantly increased in limbs with chronic deep venous iliofemoral obstruction, compared with healthy control limbs. Although pressure measurements have been extensively performed in the past, little has been reported on CFV pressure in relation to PTS. Recent insights, however, suggest that dorsal foot vein pressures, as have been measured in the past, do not reflect the severity of iliofemoral deep venous obstruction as well as $\mathrm{CFV}$ pressures. ${ }^{17}$

Neglén et al. ${ }^{12}$ did measure CFV pressures and reported a mean pressure of $12 \mathrm{mmHg}$ (5-25), which is comparable to what we found in control limbs. Comparison with their control limbs is not possible though, since they did not report on those pressures. Furthermore, our study included a large number of patients with occlusive disease, which was not the case in their study. 
Neglén et al. ${ }^{12}$ reported on a broad range of obstruction, varying from 0 to $99 \%$ stenosis, which may explain the higher pressures in our study. Another study that reported on CFV pressures in these types of patients was that of Delis et al. ${ }^{18}$ They reported a median pressure of $8 \mathrm{mmHg}$ (7-10.5) in post-thrombotic limbs, which was lower than both diseased and control limbs in our study. However, comparison between pressures in control limbs is not possible, since they did not report on this. Additionally, more than half of the measurements were obtained by testing patients undergoing bilateral recanalisation, which could have confounded results, and occlusive disease was again more prevalent in our study, potentially explaining why our study yielded higher pressures in both control and diseased limbs.

Haemodynamic changes can also be expressed by measuring pressure gradients over the obstructed tract, which has been previously done by Hurst et al. ${ }^{19}$ They described a mean pressure gradient of $5.6 \pm 3.6 \mathrm{mmHg}$ in a similar population size, though only seven patients showed post-thrombotic changes. Six patients had an acute DVT and five suffered from iliocaval compression without acute or chronic thrombotic changes. Pressure gradient was measured over the obstructed tract, though exact locations were not given and do not seem to be consistent. Despite these differences, ranges of measured pressure gradients were similar to those in our study.

To our knowledge, sudden occlusion tests akin to ours have not been performed in the past. Notwithstanding, the importance of collateral blood flow has been suggested in several studies. Neglén et al. ${ }^{12,13}$ published two papers in which they stated that up to $78 \%$ of post-thrombotic limbs showed collateralisation on venography. After percutaneous angioplasty and stenting, $72 \%$ of those limbs did not show collateral veins on venography anymore. In 17\% of the limbs collateralisation was less evident and in only $11 \%$ collateralisation patterns remained unchanged. This vast reduction clearly illustrates the importance of collateral blood flow in deep venous obstruction.

The significantly lower pressure in chronic obstructions compared with the acute balloon occlusion test, as seen in our study, shows that collateral blood flow limits the pressure increase caused by an obstruction. It can therefore assist in lower limb venous outflow, which is further illustrated by the high number of patients with abdominal wall collateralisation in this study.

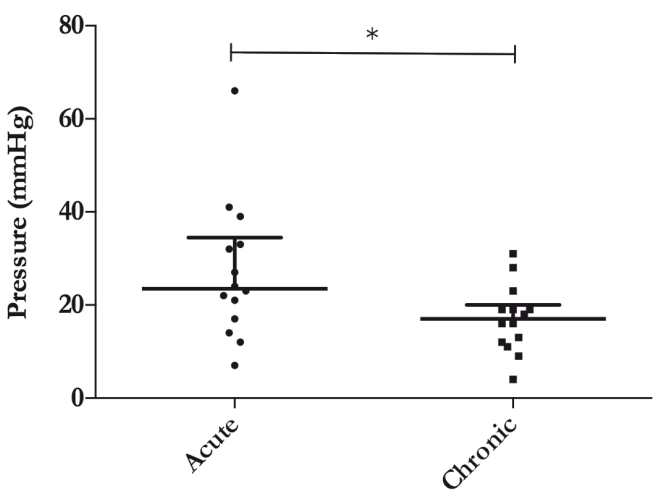

Figure 6.5 Common femoral vein pressure: post-thrombotic limbs versus sudden balloon occlusion in control limbs.

$* P=0.009$, Wilcoxon Signed Rank Test

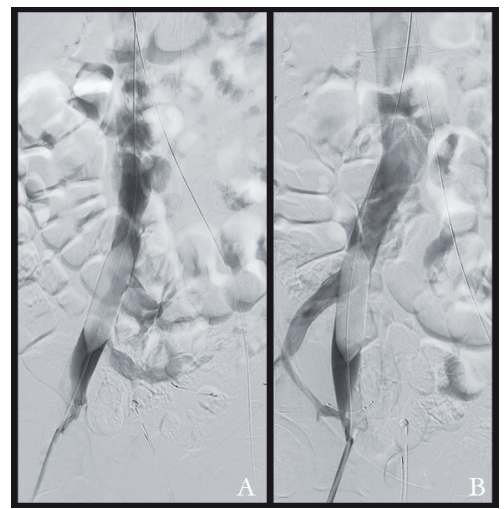

Figure 6.6 Spontaneous collateral vein after sudden balloon occlusion in a control limb.

A. Anterior plane, B. Lateral plane. 
However, results were obtained from patients in the supine position under general anaesthesia. Differences in pressure between control and diseased limbs are likely to be even more profound during ambulation, and the effect of collaterals may be even more significant.

The patient in whom a collateral vein spontaneously appeared on venography after balloon occlusion further exemplifies the importance of collateral flow. Contrast was washed away with an almost normal speed via a direct bypass around the vein segment where the balloon was inflated. At first we suspected that the balloon was not fully inflated or that the pre-existent collateral system resulting from the chronic obstruction in the contralateral limb was used as an alternative pathway. Venography in a lateral plane, however, showed that blood flow was diverted via a collateral vein on the ipsilateral side. The minor pressure increase of $6 \mathrm{mmHg}$ during the occlusion test corroborates the hypothesis that development of adequate collateral flow can reduce the haemodynamic effects of deep venous obstruction.

Interestingly, the results of the balloon occlusion test might help explain the more striking acute clinical signs of a DVT, compared with PTS. In PTS, collaterals develop over time and the extent of the collateral network may relate to the clinical presentation and could thus explain the discrepancy often noticed between complaints and the degree of iliac vein obstruction. However, this appealing theory should be substantiated by assessing the quantitative effects of collateral blood flow on patient complaints in PTS. Conversely, it should not be concluded that the presence of collateralisation implies that these patients ought not to be treated. Intravenous pressure in limbs with chronic obstruction was still significantly higher than in control limbs, and treatment of such patients has shown positive results in the past. In this study we only tested patients with sufficient complaints, warranting an intervention, though future research should include patients with post-thrombotic deep venous obstruction and little to no complaints.

It might be postulated that collateral flow patterns already in place as a result of the postthrombotic obstruction on the contralateral side can exhibit reversed flow due to the sudden occlusion in the control limb, influencing results of the sudden balloon occlusion test. However, no evidence of this was present during venography. Furthermore, two control limbs suffered from mild PTS according to the Villalta scale, yet on DUS, MRV and venography no evidence of venous obstruction was found in the control limbs of these patients. It is known though that in patients with PTS the Villalta scale can suggest PTS in healthy contralateral limbs. ${ }^{20}$

\section{Conclusions}

This study shows that pressure in the CFV is significantly increased in clinically relevant postthrombotic iliofemoral obstruction, but that a sudden occlusion in a healthy CFV leads to an even higher pressure. The latter difference explains the importance of collateralisation in deep venous obstruction and substantiates the theory that adequate collateral blood flow can prevent severe complaints in patients with extensive post-thrombotic disease; notwithstanding, the presence of collaterals does not eliminate the need for treatment.

\section{References}

1. Kahn SR, Shbaklo H, Lamping DL, et al. Determinants of health-related quality of life during the 2 years following deep vein thrombosis. J Thromb Haemost 2008;6(7):1105-12.

2. Cohen AT, Agnelli G, Anderson FA, et al. Venous thromboembolism (VTE) in Europe. The number of VTE events and associated morbidity and mortality. Thromb Haemost 2007;98(4):756-64.

3. Mohr DN, Silverstein MD, Heit JA, Petterson TM, O'Fallon WM, Melton LJ. The venous stasis syndrome after 
deep venous thrombosis or pulmonary embolism: a population-based study. Mayo Clin Proc 2000;75(12):1249-56.

4. Prandoni P, Villalta S, Bagatella P, et al. The clinical course of deep-vein thrombosis. Prospective long-term followup of 528 symptomatic patients. Haematologica 1997;82(4):423-8.

5. Schulman S, Lindmarker P, Holmstrom M, et al. Post-thrombotic syndrome, recurrence, and death 10 years after the first episode of venous thromboembolism treated with warfarin for 6 weeks or 6 months. J Thromb Haemost 2006;4(4):734-42.

6. Tick LW, Kramer MH, Rosendaal FR, Faber WR, Doggen CJ. Risk factors for post-thrombotic syndrome in patients with a first deep venous thrombosis. J Thromb Haemost 2008;6(12):2075-81.

7. Haenen JH, Janssen MC, van Langen H, et al. The postthrombotic syndrome in relation to venous hemodynamics, as measured by means of duplex scanning and strain-gauge plethysmography. J Vasc Surg 1999;29(6):1071-6.

8. Johnson BF, Manzo RA, Bergelin RO, Strandness DE, Jr. Relationship between changes in the deep venous system and the development of the postthrombotic syndrome after an acute episode of lower limb deep vein thrombosis: a one- to six-year follow-up. J Vasc Surg 1995;21(2):307-12; discussion 13.

9. Meissner MH, Caps MT, Zierler BK, et al. Determinants of chronic venous disease after acute deep venous thrombosis. J Vasc Surg 1998;28(5):826-33.

10. Yamaki T, Nozaki M, Sakurai H, Takeuchi M, Soejima K, Kono T. High peak reflux velocity in the proximal deep veins is a strong predictor of advanced post-thrombotic sequelae. J Thromb Haemost 2007;5(2):305-12.

11. Umeoka S, Koyama T, Togashi K, Kobayashi H, Akuta K. Vascular dilatation in the pelvis: identification with CT and MR imaging. Radiographics 2004;24(1):193-208.

12. Neglen P, Berry MA, Raju S. Endovascular surgery in the treatment of chronic primary and post-thrombotic iliac vein obstruction. Eur J Vasc Endovasc Surg 2000;20(6):560-71.

13. Neglen P, Raju S. Balloon dilation and stenting of chronic iliac vein obstruction: technical aspects and early clinical outcome. J Endovasc Ther 2000;7(2):79-91.

14. Arnoldussen CW, Toonder I, Wittens CH. A novel scoring system for lower-extremity venous pathology analysed using magnetic resonance venography and duplex ultrasound. Phlebology 2012;27 Suppl 1:163-70.

15. Wittens $\mathrm{CH}$, Bukkems SF, Toonder IT. Abdominal wall venous collaterals: the latent clinical sign for central chronic venous obstruction. Circulation 2010;122(20):2089-90.

16. de Graaf R, Wittens CH. Endovascular treatment options for chronic venous obstructions. Phlebology 2012;27 Suppl 1:171-7.

17. Kurstjens R, de Wolf M, de Graaf R, Wittens C. Hemodynamic changes in iliofemoral disease. Phlebology 2014;29(1 suppl):90-6.

18. Delis KT, Bjarnason H, Wennberg PW, Rooke TW, Gloviczki P. Successful iliac vein and inferior vena cava stenting ameliorates venous claudication and improves venous outflow, calf muscle pump function, and clinical status in post-thrombotic syndrome. Ann Surg 2007;245(1):130-9.

19. Hurst DR, Forauer AR, Bloom JR, Greenfield LJ, Wakefield TW, Williams DM. Diagnosis and endovascular treatment of iliocaval compression syndrome. J Vasc Surg 2001;34(1):106-13.

20. Galanaud JP, Holcroft CA, Rodger MA, et al. Comparison of the Villalta post-thrombotic syndrome score in the ipsilateral vs. contralateral leg after a first unprovoked deep vein thrombosis. J Thromb Haemost 2012;10(6):1036-42. 


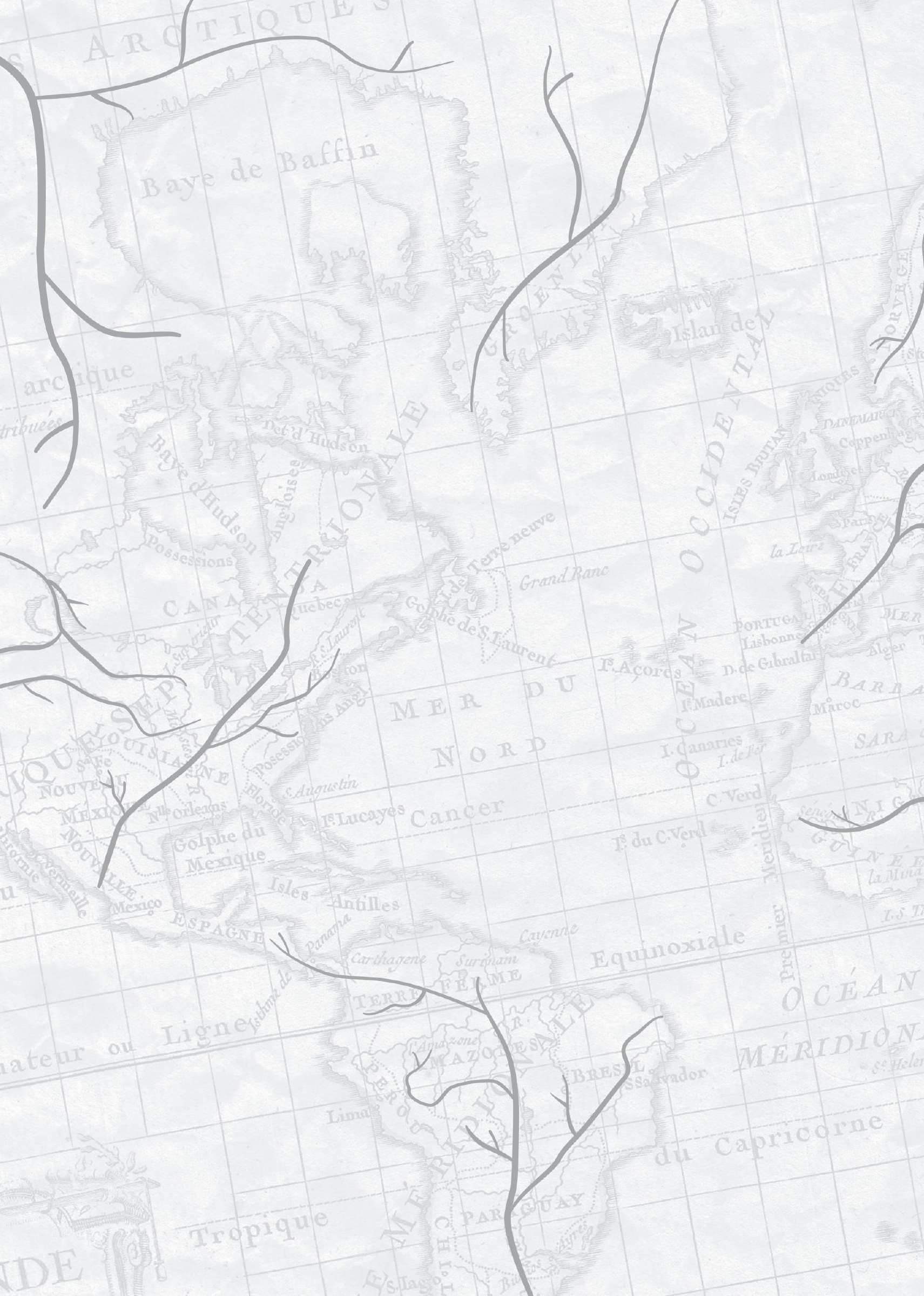




\section{CHAPTER 7}

\section{Intravenous pressure changes in patients with post-thrombotic deep venous obstruction:}

results using a treadmill stress test

Ralph L.M. Kurstjens Mark A.F. de Wolf Helena W. Konijn Irwin M. Toonder Patty J. Nelemans Rick de Graaf Cees H.A. Wittens J Thromb Haemost. 2016;14(6):1163-70 


\begin{abstract}
Background: Little is known about the haemodynamic consequences of deep venous obstructive disease.

Objective: The aim of this study was to investigate the haemodynamic effect of post-thrombotic obstruction of the iliofemoral veins and to determine what pressure parameters differentiate best between limbs with post-thrombotic obstructive disease of the iliofemoral veins and those without obstruction.

Methods: Twenty-two participants with unilateral obstruction of the iliac and common femoral veins underwent a standardised treadmill test with simultaneous, bilateral, invasive pressure measurements in the common femoral vein and dorsal foot vein.

Results: Mean age was $42.8 \pm 11.9$ years, and $86.4 \%$ of participants were female. Post-thrombotic limbs showed a mean common femoral vein (CFV) pressure increase of $28.1 \pm 21.0 \mathrm{mmHg}$ after walking compared with $2.1 \pm 6.2 \mathrm{mmHg}$ in control limbs $(26.0 \mathrm{mmHg}$ difference; $95 \%$ confidence interval [CI], 17.1-34.9). Less difference was observed in the dorsal foot vein (net drop of $36.8 \pm 22.7 \mathrm{mmHg}$ in affected limbs vs. $48.7 \pm 23.1 \mathrm{mmHg}$ in non-affected limbs; 11.9 $\mathrm{mmHg}$ difference; $95 \% \mathrm{CI},-1.3$ to 25.0$)$. Change in CFV pressure after walking yielded the best discrimination between affected and non-affected limbs (area under the receiver operated characteristic curve of 0.94 [95\% CI, 0.85-1.00], compared with 0.57 [95\% CI: $0.37-0.76$ ] in the dorsal foot vein, $P<0.001)$.

Conclusions: Common femoral vein pressure significantly increases during ambulation in patients with iliofemoral post-thrombotic obstruction, which could explain the debilitating effects of venous claudication. This is an indication that patients with an iliofemoral obstruction may benefit from further treatment that resolves the deep vein obstruction.
\end{abstract}




\section{Introduction}

The annual incidence of deep vein thrombosis is one to two per $1000^{1}$, about a quarter of which occur in the iliofemoral tract. ${ }^{2}$ In $25-56 \%$ of those cases, a post-thrombotic syndrome (PTS) develops. ${ }^{2-6}$ This is a debilitating disease with a quality of life loss comparable to diabetes mellitus, chronic pulmonary obstructive disease and congestive heart failure. ${ }^{2,7}$ In the past it was believed that valve destruction leading to chronic venous incompetence was the main cause of these complaints after deep venous thrombosis. However, residual deep venous obstruction appears to have a more prominent effect on PTS, especially when occurring in the iliac veins. ${ }^{8,9}$ Although there is evidence that treatment of these types of obstruction by percutaneous transluminal angioplasty and stenting may be effective, little is known about the haemodynamic consequences of deep venous obstructive disease..$^{10-14}$ In the past, extensive research involving invasive pressure measurements was performed, with the focus on deep vein incompetence and pressure measurements in the dorsal foot veins. ${ }^{15,16}$ Recent insights have suggested that pressure near the obstructed area might be more relevant than dorsal foot vein pressures in cases of deep venous obstruction. ${ }^{17}$

More knowledge of the haemodynamic consequences of deep venous obstructive disease is needed to substantiate the reasoning behind the best treatment strategy and to be able to identify which patients might benefit from further treatment. About $15-20 \%$ of patients show little to no reduction in complaints after treatment by stenting, despite careful patient selection through extensive investigations and diagnostic imaging. ${ }^{13}$ To our knowledge, no clinical parameters that are predictive of success have been found; therefore, we ought to find haemodynamic references to establish which patients may benefit from interventional treatment.

The primary aim of this study was to investigate the haemodynamic effect of post-thrombotic obstruction of the iliofemoral veins and to determine what pressure parameters best differentiate between limbs with post-thrombotic obstructive disease of the iliofemoral veins and those without deep venous obstruction. Additionally, we wanted to evaluate the influence of femoral inflow on pressure changes in the common femoral veins of the diseased limbs.

\section{Methods}

\section{Study design and participants}

In this study, intravenous pressures at the level of the common femoral vein (CFV) and dorsal foot vein were compared between affected and non-affected limbs of participants with unilateral post-thrombotic iliofemoral obstruction.

Twenty-four consecutive participants were recruited from our tertiary, outpatient clinic. Patients with a unilateral post-thrombotic venous obstruction of the iliac veins and/or common femoral vein possibly extending into the popliteal-femoral tract, based on duplex ultrasound and magnetic resonance venography, and willing to undergo stenting were eligible for this study. Patients with deep venous obstruction in the contralateral limb or inferior vena cava, peripheral arterial disease, pregnancy, life expectancy of $<6$ months, and age $<18$ years were excluded. The Venous Clinical Severity Score and Villalta score were obtained by the same physician for all patients, as were general patient characteristics such as duration of complaints and previous medical history. Patients were allocated to one of four groups according to the Villalta scale: no PTS (0-4), mild PTS (5-9), moderate PTS (10-14) or severe PTS (>14 or the presence of an ulcer). ${ }^{2}$

This study was approved by the medical ethical review board (METC 13-2-027) and principles 
according to the 2013-revised declaration of Helsinki were followed. All participants gave informed consent.

\section{Procedures}

The day before treatment, a dorsal foot vein and the femoral vein were cannulated bilaterally. An 18, 20 or 22-gauge Vasofix Safety IV catheter (B. Braun, Melsungen, Germany) was used for cannulation of the dorsal foot veins, depending on vein size. The femoral veins were cannulated under ultrasound guidance, using a 4 French sheath (PreludePRO; Merit Medical Systems, South Jordan, UT, USA), its tip being placed within the CFV. Measurements were performed bilaterally to compare the affected limb with the non-affected limb, using TruWave pressure monitoring sets (Edwards Lifesciences, Irvine, CA, USA) attached to a Hewlett Packard M1165A patient monitoring system (Philips Medical Systems, Best, the Netherlands). As a control measurement, unilateral access to the median cubital vein was also obtained for the first 12 participants; however, interim analysis proved this to be redundant. Pressure was measured continuously after access was acquired.

After measuring intravenous pressure in the supine position, the participant was asked to assume the erect position with the support of a frame. When pressures were calibrated again and a stable pressure was observed, the participant was instructed to perform ten tiptoe movements. Subsequently, we waited for hydrostatic pressure to stabilise again and the participant underwent a standardised treadmill test. Throughout the test, a steady speed of $3.2 \mathrm{~km} / \mathrm{h}$ was maintained, with a slope starting at $0 \%$, increasing by $2 \%$ every 120 s. Participants were not coerced during the test and were asked to notify the investigator when they started feeling the pain in their legs they associated with venous claudication. They were also asked to indicate when the test should be ceased because of this pain. Pain-free and maximum walking distances were noted. At 26 min the test was discontinued if the participant had not yet indicated the test should be terminated by then. Finally, participants were asked to answer a series of four questions to determine the influence of the intravenous lines on action radius and perception of pain.

\section{Outcomes}

The primary outcome measure was change in venous pressure between start and termination of ambulation. Secondary outcome measures were venous pressures in the supine and erect positions at baseline.

\section{Statistical analysis}

Nominal data are presented as percentages. Continuous data are presented as mean values with corresponding standard deviation or as median values with interquartile range (IQR), depending on normality of distribution. Paired-samples t-tests were used for comparison of continuous variables between affected and non-affected limbs. Univariate linear regression analysis was performed to evaluate the association between femoral inflow, based on post-thrombotic state of the femoral vein, and post-exercise change in CFV pressure of affected limbs. The resulting regression coefficient represents the mean difference in pressure change between affected limbs with suspected poor inflow and affected limbs with proper inflow. A post-thrombotic (deep) femoral vein was defined as a (deep) femoral vein showing intraluminal synechiae on magnetic resonance venography.

Receiver operated characteristic (ROC) curves were constructed for pressure measurements 
in the supine position, erect position and after walking. Areas under the curve (AUC) with corresponding $95 \%$ confidence intervals were calculated as a measure of ability to discriminate between limbs affected by deep venous obstruction and non-affected control limbs. Differences in AUCs were tested for statistical significance using a method for comparison of AUCs in paired samples. ${ }^{18} P$-values $\leq 0.05$ were considered to indicate statistical significance. Statistical analysis was performed using SPSS version 21.0 (IBM Corporation, Armonk, NY, USA). Comparison of ROC curves was performed using Stata version 13.1 (StataCorp, College Station, TX, USA) and graphs were constructed using GraphPad Prism version 5.04 (GraphPad Software, San Diego, CA, USA).

\section{Results}

Two out of 24 participants discontinued the study before pressures could be measured and were excluded from analysis: one because cannulation of the CFV was too painful and one because of a vasovagal reaction after cannulation of the dorsal foot vein. Mean age of the remaining participants was $42.8 \pm 11.9$ years, with $86.4 \%$ of participants being female and a median duration of complaints of 4.8 years (IQR, 2.1-12.7). Previous venous interventions had been performed in eight participants (36.4\%): one had a patent DePalma bypass with persisting complaints, one had occluded bypasses from the deep femoral vein to the common iliac vein and

Table 7.1 Demographics.

\begin{tabular}{|c|c|c|}
\hline Age, years & \multicolumn{2}{|l|}{$42.8 \pm 11.9$} \\
\hline Female sex, $n(\%)$ & \multicolumn{2}{|l|}{$19(86.4)$} \\
\hline Body mass index, $\mathrm{kg} / \mathrm{m}^{2}$ & \multicolumn{2}{|l|}{$27.6 \pm 4.8$} \\
\hline Previous venous interventions, $n(\%)$ & \multicolumn{2}{|l|}{$8(36.4)^{*}$} \\
\hline Thrombophilia & \multicolumn{2}{|c|}{6 out of 10 tested } \\
\hline Median duration of complaints, years & \multicolumn{2}{|c|}{4.8 (IQR, 2.1-12.7) } \\
\hline Venous claudication, $n(\%)$ & \multicolumn{2}{|l|}{$22(100)$} \\
\hline \multirow[t]{2}{*}{ Left-sided complaints, $n(\%)$} & \multicolumn{2}{|l|}{$20(90.9)$} \\
\hline & Affected limb & Non-affected limb \\
\hline \multicolumn{3}{|l|}{ Highest C of CEAP, $n(\%)$} \\
\hline $\mathrm{C}_{0}$ & $2(9.1)$ & $5(22.7)$ \\
\hline $\mathrm{C}_{1}$ & $2(9.1)$ & $6(27.3)$ \\
\hline $\mathrm{C}_{2}$ & - & $4(18.2)$ \\
\hline $\mathrm{C}_{3}$ & $11(50.0)$ & $6(27.3)$ \\
\hline $\mathrm{C}_{4}$ & $5(22.7)$ & $1(4.5)$ \\
\hline $\mathrm{C}_{5}$ & $1(4.5)$ & - \\
\hline $\mathrm{C}_{6}$ & $1(4.5)$ & - \\
\hline \multicolumn{3}{|l|}{ Villalta scale, $n(\%)$} \\
\hline No PTS & - & $20(90.9)$ \\
\hline Mild PTS & $11(50.0)$ & $2(9.1)$ \\
\hline Moderate PTS & $8(36.4)$ & - \\
\hline Severe PTS & $3(13.6)$ & - \\
\hline Venous clinical severity score & $7.9 \pm 2.5$ & $1.3 \pm 1.3$ \\
\hline
\end{tabular}


inferior vena cava, and all others had received interventions for superficial venous reflux. All participants suffered from venous claudication and control limbs had a low mean venous clinical severity score $(1.3 \pm 1.3)$ and low mean numeric Villalta score $(2.0 \pm 1.8)$ (Table 7.1). Save for two symptomatic participants with a maximum obstruction of $10-50 \%$, based on duplex ultrasound, all participants suffered from a (near) occlusion within the iliofemoral tract (Table 7.2). In one case, no femoral access was obtained and in four there was no dorsal foot vein access. In one instance, it was not possible to place the tip within the common femoral vein, thus it was positioned in the femoral vein as close to the confluence as possible. Furthermore, in two cases CFV pressure and in six cases dorsal foot vein pressure could not be adequately measured in one of the limbs (Figure 7.1, Table 7.S1).

Before the treadmill test, post-thrombotic limbs had a supine CFV pressure of $24.2 \pm 6.2$ $\mathrm{mmHg}$, compared with $21.4 \pm 7.3 \mathrm{mmHg}$ in controls (2.8 mmHg difference; 95\% CI, 0.1-5.5). This significant difference persisted when assuming the erect position; affected CFVs exhibited a mean pressure of $60.4 \pm 12.4 \mathrm{mmHg}$, as opposed to a mean pressure of $45.0 \pm 17.2$ in nonaffected limbs (15.4 mmHg difference; 95\% CI, 5.8-25.0) (Table 7.3, Figure 7.2A,C).

At the level of the dorsal foot vein, supine pressure was also higher for affected limbs (3.9 $\mathrm{mmHg}$ difference; 95\% CI, 1.2-6.5), but this difference was not significant when patients were erect (2.2 $\mathrm{mmHg}$ difference; $95 \% \mathrm{CI},-9.9$ to 14.2$)$ (Table 7.2, Figure 7.2B,D).

After ten tiptoe movements, CFV pressure rose by $3.9 \pm 5.1 \mathrm{mmHg}$ in affected limbs $(P=0.009)$, compared with $1.4 \pm 2.1$ in controls $(P=0.034)$, which was not statistically significant between the two groups $(2.5 \mathrm{mmHg}$ difference; $95 \% \mathrm{CI},-0.9$ to 5.9$)$. Decrease in pressure in the dorsal foot vein after ten tiptoe movements also did not differ between affected and nonaffected limbs (7.3 mmHg difference; $95 \%$ CI, -4.9 to 19.4) (Table 7.3).

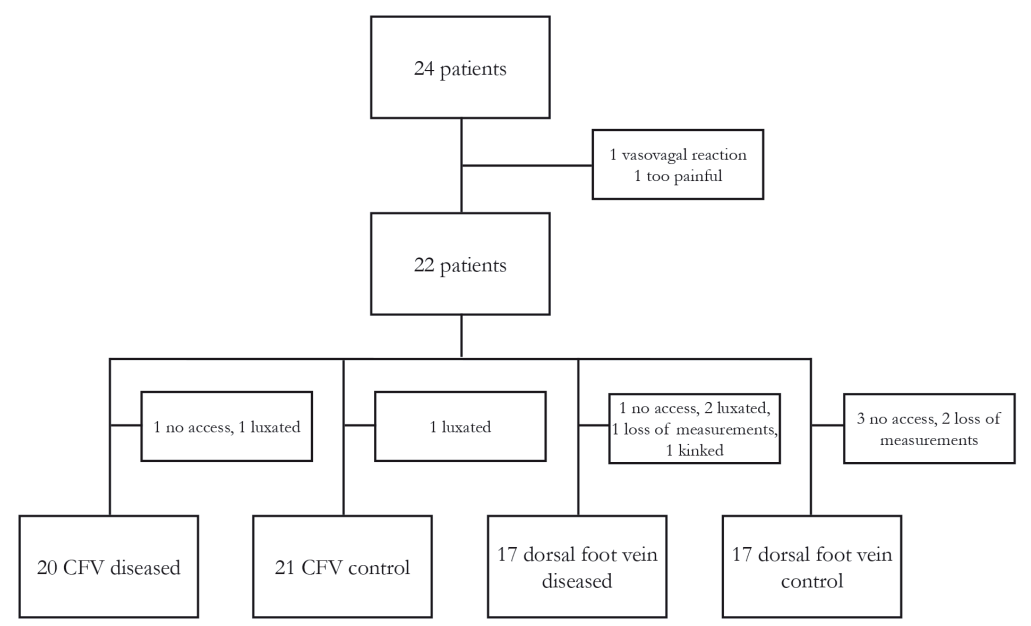

Figure 7.1 Flowchart of pressures measured per location and limb. 
Supine pressure in common femoral vein

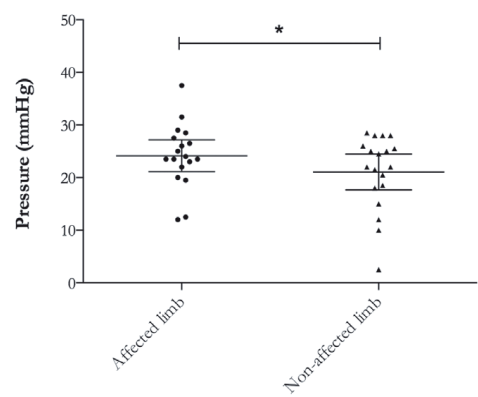

C

Erect pressure in common femoral vein

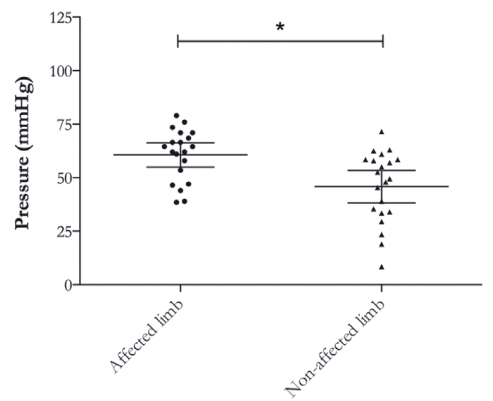

B
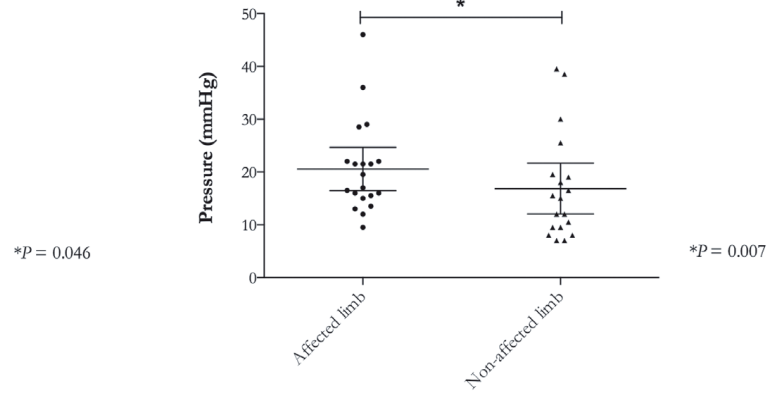

$\mathrm{D}$

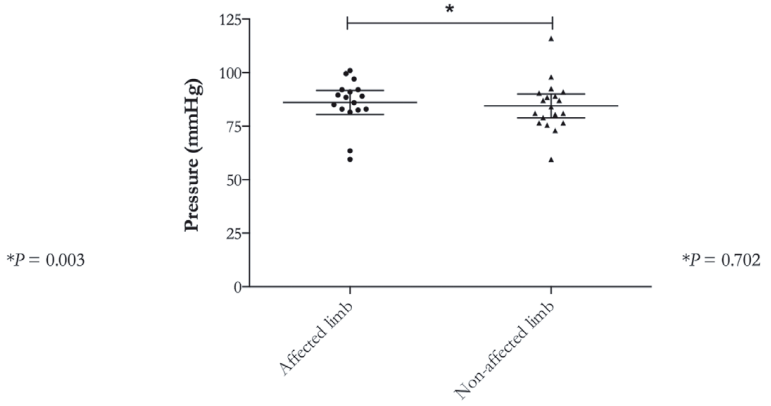

Figure 7.2 Pressures in the supine and erect positions at the levels of the common femoral and dorsal foot vein.

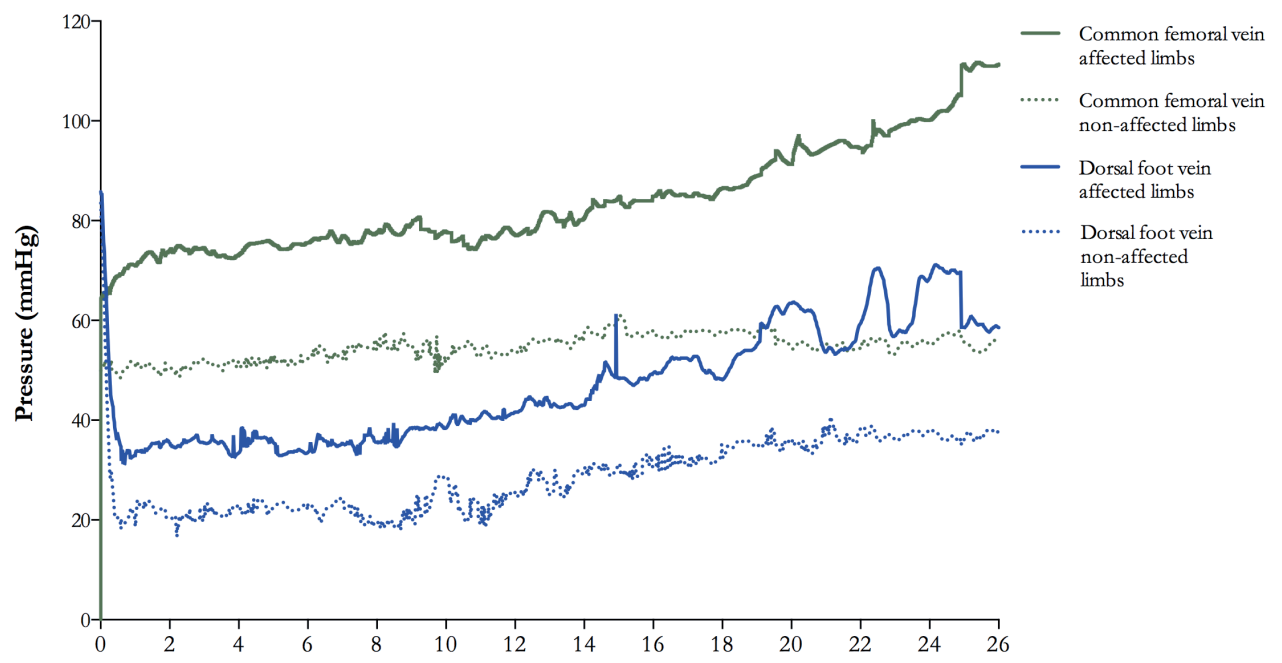

Figure 7.3 Median curves of pressure changes during the treadmill stress test at the levels of the common femoral and dorsal foot vein. 
Table 7.3 Pressure measurements.

\begin{tabular}{|c|c|c|c|c|c|c|c|c|}
\hline \multirow[b]{2}{*}{ Pressure $-\mathrm{mmHg}$} & \multicolumn{4}{|c|}{ Common femoral vein } & \multicolumn{4}{|c|}{ Dorsal foot vein } \\
\hline & Affected limb & $\begin{array}{l}\text { Non-affected } \\
\operatorname{limb}\end{array}$ & $\begin{array}{l}\text { Difference } \\
(95 \% \mathrm{CI})\end{array}$ & $P$ & Affected limb & $\begin{array}{l}\text { Non-affected } \\
\operatorname{limb}\end{array}$ & $\begin{array}{l}\text { Difference } \\
(95 \% \mathrm{CI})\end{array}$ & $P$ \\
\hline Supine position & $24.2 \pm 6.2$ & $21.4 \pm 7.3$ & $\begin{array}{l}2.8 \\
(0.1 \text { to } 5.5)\end{array}$ & $0.046^{*}$ & $18.1 \pm 5.4$ & $14.3 \pm 6.6$ & $\begin{array}{l}3.9 \\
(1.2 \text { to } 6.5)\end{array}$ & $0.007^{*}$ \\
\hline Erect position & $60.4 \pm 12.4$ & $45.0 \pm 17.2$ & $\begin{array}{l}15.4 \\
(5.8 \text { to } 25.0)\end{array}$ & $0.003^{*}$ & $86.6 \pm 12.0$ & $84.4 \pm 13.1$ & $\begin{array}{l}2.2 \\
(-9.9 \text { to } 14.2)\end{array}$ & 0.702 \\
\hline $\begin{array}{l}\text { Change after ten } \\
\text { tiptoe movements }\end{array}$ & $3.9 \pm 5.1$ & $1.4 \pm 2.1$ & $\begin{array}{l}2.5 \\
(-0.9 \text { to } 5.9)\end{array}$ & 0.133 & $-19.9 \pm 11.7$ & $-27.2 \pm 16.6$ & $\begin{array}{l}7.3 \\
(-4.9 \text { to } 19.4)\end{array}$ & 0.208 \\
\hline $\begin{array}{l}\text { Change after } \\
\text { walking }\end{array}$ & $28.1 \pm 21.0$ & $2.1 \pm 6.2$ & $\begin{array}{l}26.0 \\
(17.1 \text { to } 34.9)\end{array}$ & $0.001^{*}$ & $-36.8 \pm 22.7$ & $-48.7 \pm 23.1$ & $\begin{array}{l}11.9 \\
(-1.3 \text { to } 25.0)\end{array}$ & 0.074 \\
\hline
\end{tabular}

Plus-minus values are means $\pm \mathrm{SD},{ }^{*}$ Statistically significant.

During walking, a gradual increase in mean CFV pressure of $28.1 \pm 21 \mathrm{mmHg}$ was observed in post-thrombotic limbs $(P<0.001)$, whereas the change in CFV pressure was minor in control limbs $(2.1 \pm 6.2 \mathrm{mmHg}, P=0.096)$. The difference in pressure increase between affected and non-affected limbs was statistically significant (26.0 mmHg difference; 95\% CI, 17.1-34.9). Poor inflow, as measured by comparing post-thrombotic femoral veins with normal femoral veins, was significantly associated with less pressure increase after walking in post-thrombotic limbs (regression coefficient of $-22.8 ; 95 \% \mathrm{CI},-41.2$ to $-4.4 ; P=0.018$ ). In the dorsal foot vein, an initial steep drop in pressure was observed, followed by a gradual increase. The net drop in pressure was $36.8 \pm 22.7 \mathrm{mmHg}$ for affected limbs, compared with $48.7 \pm 23.1 \mathrm{mmHg}$ in controls (11.9 mmHg difference; 95\% CI, -1.3 to 25.0) (Table 7.3, Figure 7.3).

Mean pain-free walking distance was $389 \pm 299 \mathrm{~m}$ and maximum walking distance was $805 \pm 411$ $\mathrm{m}$, with three patients finishing the test despite developing pain (Figure 7.4). Nine participants $(40.9 \%)$ were moderately or severely hindered by their CFV sheath. Four participants $(18.2 \%)$ stated that their movements were impaired due to the dorsal foot vein catheter. Conversely, all participants were able to distinguish their usual complaints from the discomfort of the sheaths and intravenous cannulas, with 19 participants (86.4\%) indicating they were able to do this reasonably well to well.

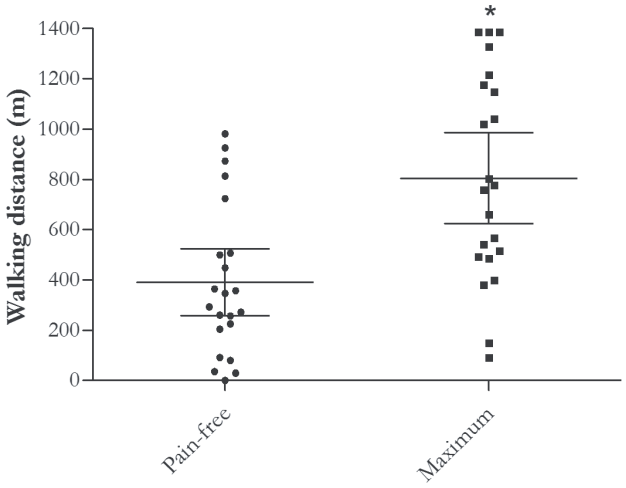

Figure 7.4 Walking distance as assessed by the treadmill test. $* 3$ participants completed test
Change in CFV pressure after walking yielded an AUC of 0.94 (95\% CI, 0.851.00). Erect $\mathrm{CFV}$ pressure showed less favourable results (AUC, 0.77; 95\% CI, 0.63-0.91; $P=0.057$ ), as did supine CFV pressure (AUC, 0.61; 95\% CI, 0.43-0.79; $P=0.002)$. Pressure changes after walking in the dorsal foot vein proved to be inferior in identifying deep venous obstruction (AUC, 0.57; 95\% CI, 0.37-0.76; $P<0.001$ compared with $\mathrm{CFV}$ ). Dorsal foot vein measurements in the erect position (AUC, $0.61 ; 95 \% \mathrm{CI}, 0.42-0.80 ; P=0.928)$ or the supine position (AUC, 0.67; 95\% CI, $0.49-0.85 ; P=0.426$ ) also proved to be poor in discriminating between affected and non-affected limbs (Figure 7.5). 


\section{Discussion}

This is the first study that has measured intravenous pressure in the common femoral vein during actual ambulation in patients with a post-thrombotic syndrome. CFV pressure appears to be more relevant than dorsal foot vein pressure in post-thrombotic iliac vein obstruction, as changes in the CFV were far more apparent than dorsal foot vein pressures and superior in discriminating between affected and non-affected limbs. In the past, ambulatory pressures have only been measured at the level of the dorsal foot vein during a pseudo-ambulatory state of ten tiptoe movements. Kolbach et al. ${ }^{19}$ were able to find a statistical difference between affected and non-affected limbs in patients who had suffered from a deep venous thrombosis in the past. However, no imaging was performed in their study, so no comparison can be drawn between the different study populations. Therefore, a different type of population with respect to location and extent of post-thrombotic obstruction or presence and location of venous incompetence could have caused disparity in the results.

Other studies performed similar tests, but without a reference group of healthy control limbs. ${ }^{10,20}$ Nonetheless, Neglén et al. ${ }^{10}$ did demonstrate a marginal, statistically significant improvement in ambulatory venous pressure drop after stenting, suggesting elevated dorsal foot vein pressures as a result of an obstructive component. We found a difference of $7.3 \mathrm{mmHg}$ (95\% CI, -4.9 to 19.4) in dorsal foot vein pressure between affected and non-affected limbs after ten tiptoe movements. After actual ambulation the difference between the two groups was $11.9 \mathrm{mmHg}$ (95\% CI, -1.3 to 25.0). Lack of statistical significance may be attributed to our low sample size. Additionally, direct measurements during actual ambulation in this study have demonstrated that dorsal foot vein pressures gradually increase again after the initial drop, which establishes that ten tiptoe movements do not truly represent the full ambulatory effect on dorsal foot vein pressure.

Little research has been performed with respect to CFV pressure. Neglén et al. ${ }^{20}$ reported a median pressure of $12 \mathrm{mmHg}$ (range, 5-25) and Delis et al. ${ }^{21}$ of $8.0 \mathrm{mmHg}(\mathrm{IQR}, 7.0-10.5)$ in the supine position, which are lower than the pressures in both our affected and non-affected limbs. This difference might be explained by the fact that the measurements in this study were not performed under general anaesthesia. ${ }^{22}$ As the aforementioned studies have not included control limbs, it is difficult to determine the significance of those pressures in relation to establishing severity of outflow obstruction.

Negus et al..$^{23}$ did compare post-thrombotic limbs with controls and found mean pressures of $11.1 \mathrm{mmHg}$ and $5.6 \mathrm{mmHg}$ in affected and non-affected limbs respectively. These results were,

A

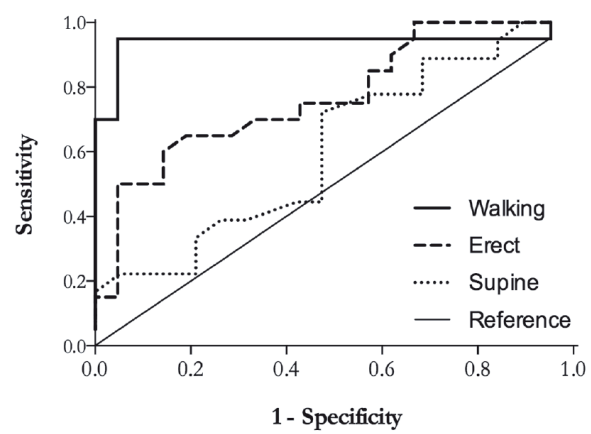

B

Dorsal foot vein

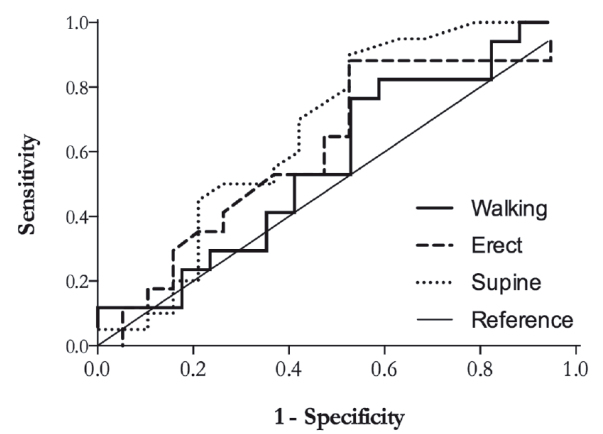

Figure 7.5 Receiver operated characteristic curves of the various pressure measurements. 
again, obtained under general anaesthesia, possibly explaining our higher pressures. The mean difference between affected and non-affected limbs was $5.5 \mathrm{mmHg}$, which is comparable to our study $(3.1 \mathrm{mmHg})$, especially when taking into account that this difference was obtained from 15 out of 25 patients. The other 10 patients only showed a mean difference of $0.59 \mathrm{mmHg}$ between affected and non-affected limbs. Concurrently, this demonstrates that morphology does not necessarily correspond with haemodynamic changes. Furthermore, exercise in the supine position using a foot pedal was performed in that study and triggered a pressure increase of $9.9 \mathrm{mmHg}$ in the group of 15 . Although the mean pressure change is decidedly less than in our study, this demonstrates that pressure increase can be generated in the supine position. However, this is not a true simulation and no conclusions can be drawn with respect to the quantification of venous claudication.

The poor discriminative ability of pressures measured in the supine position suggests that these measurements are not useful for establishing haemodynamic need for treatment without some form of flow augmentation. Conversely, CFV pressure change after ambulation discriminates well between post-thrombotic and control limbs. The substantial difference in ambulatory CFV pressure between affected and non-affected limbs might help to explain venous claudication, as pressure gradually increased during exercise and might consequently lead to an elevated intramuscular pressure. ${ }^{24}$ Thus, patients exhibiting an ambulatory CFV pressure increase may benefit from further treatment that resolves the present obstruction. Follow-up data on procedures intended to abolish deep vein obstruction are necessary to determine whether such interventions have a haemodynamic effect.

Despite these insightful results, some limitations need to be mentioned. Not all pressure measurements could be performed because of loss of pressure data or unreasonably high measurements, probably because of (temporary) obstruction of the sheath or intravenous cannula, despite taking appropriate countermeasures. Additionally, we were not able to fully explain the pathophysiologic changes observed in this study as femoral inflow and extent of collateralisation cannot be adequately quantified with current existing techniques. What is more, pathophysiologic investigations at the tissue level should be performed to analyse the effect of these high ambulatory pressures on venous claudication.

\section{Conclusions}

Common femoral vein pressure significantly increases during ambulation in patients with iliofemoral post-thrombotic obstruction, which could explain the debilitating effects of venous claudication. Moreover, this change in pressure is an indication that patients with an iliofemoral obstruction may benefit from further treatment aimed at resolving this deep vein obstruction. Follow-up studies with invasive pressure measurements should determine whether such treatments can reduce intravenous hypertension in the common femoral vein.

\section{References}

1. Cohen AT, Agnelli G, Anderson FA, et al. Venous thromboembolism (VTE) in Europe. The number of VTE events and associated morbidity and mortality. Thromb Haemost 2007;98(4):756-64.

2. Kahn SR, Shbaklo H, Lamping DL, et al. Determinants of health-related quality of life during the 2 years following deep vein thrombosis. J Thromb Haemost 2008;6(7):1105-12.

3. Mohr DN, Silverstein MD, Heit JA, Petterson TM, O'Fallon WM, Melton LJ. The venous stasis syndrome after deep venous thrombosis or pulmonary embolism: a population-based study. Mayo Clin Proc 2000;75(12):1249-56.

4. Prandoni P, Villalta S, Bagatella P, et al. The clinical course of deep-vein thrombosis. Prospective long-term follow- 
up of 528 symptomatic patients. Haematologica 1997;82(4):423-8.

5. Schulman S, Lindmarker P, Holmstrom M, et al. Post-thrombotic syndrome, recurrence, and death 10 years after the first episode of venous thromboembolism treated with warfarin for 6 weeks or 6 months. J Thromb Haemost 2006;4(4):734-42.

6. Tick LW, Kramer MH, Rosendaal FR, Faber WR, Doggen CJ. Risk factors for post-thrombotic syndrome in patients with a first deep venous thrombosis. J Thromb Haemost 2008;6(12):2075-81.

7. Carradice D, Mazari FA, Samuel N, Allgar V, Hatfield J, Chetter IC. Modelling the effect of venous disease on quality of life. BrJ Surg 2011;98(8):1089-98.

8. Strijkers RH, Arnoldussen CW, Wittens CH. Validation of the LET classification. Phlebology 2015;30(1 Suppl):14-9.

9. Killewich LA, Martin R, Cramer M, Beach KW, Strandness DE, Jr. Pathophysiology of venous claudication. J Vasc Surg 1984;1(4):507-11.

10. Neglen P, Hollis KC, Olivier J, Raju S. Stenting of the venous outflow in chronic venous disease: long-term stentrelated outcome, clinical, and hemodynamic result. J V asc Surg 2007;46(5):979-90.

11. Wen-da W, Yu Z, Yue-Xin C. Stenting for chronic obstructive venous disease: A current comprehensive metaanalysis and systematic review. Phlebology 2016;31(6):376-89.

12. Yin M, Shi H, Ye K, et al. Clinical Assessment of Endovascular Stenting Compared with Compression Therapy Alone in Post-thrombotic Patients with Iliofemoral Obstruction. Eur J Vasc Endovasc Surg 2015;50(1):101-7.

13. de Wolf MAF, Arnoldussen CW, Grommes J, et al. Minimally invasive treatment of chronic iliofemoral venous occlusive disease. Journal of Vascular Surgery: Venous and Lymphatic Disorders 2013;1(2):146-53.

14. Seager MJ, Busuttil A, Dharmarajah B, Davies AH. Editor's Choice - A Systematic Review of Endovenous Stenting in Chronic Venous Disease Secondary to Iliac Vein Obstruction. Eur J Vasc Endovasc Surg 2016;51(1):100-20.

15. Nicolaides AN, Hussein MK, Szendro G, Christopoulos D, Vasdekis S, Clarke H. The relation of venous ulceration with ambulatory venous pressure measurements. J Vasc Surg 1993;17(2):414-9.

16. Nicolaides AN, Zukowski AJ. The value of dynamic venous pressure measurements. World J Surg 1986;10(6):91924.

17. Kurstjens R, de Wolf M, de Graaf R, Wittens C. Hemodynamic changes in iliofemoral disease. Pblebology 2014;29(1 suppl):90-6.

18. DeLong ER, DeLong DM, Clarke-Pearson DL. Comparing the areas under two or more correlated receiver operating characteristic curves: a nonparametric approach. Biometrics 1988;44(3):837-45.

19. Kolbach DN, Neumann HA, Prins MH. Definition of the post-thrombotic syndrome, differences between existing classifications. Eur J Vasc Endovasc Surg 2005;30(4):404-14.

20. Neglen P, Berry MA, Raju S. Endovascular surgery in the treatment of chronic primary and post-thrombotic iliac vein obstruction. Eur J Vasc Endovasc Surg 2000;20(6):560-71.

21. Delis KT, Bjarnason H, Wennberg PW, Rooke TW, Gloviczki P. Successful iliac vein and inferior vena cava stenting ameliorates venous claudication and improves venous outflow, calf muscle pump function, and clinical status in post-thrombotic syndrome. Ann Surg 2007;245(1):130-9.

22. Delis KT, Knaggs AL, Mason P, Macleod KG. Effects of epidural-and-general anesthesia combined versus general anesthesia alone on the venous hemodynamics of the lower limb. A randomized study. Thromb Haemost 2004;92(5):1003-11.

23. Negus D, Cockett FB. Femoral vein pressures in post-phlebitic iliac vein obstruction. BrJ Surg 1967;54(6):522-5.

24. Gemayel G CJ. Tissue Pressures in Venous Disease. Phlebology 2010;25(6):301.

Table 7.S1 Complications during pressure measurements.

\begin{tabular}{lll}
\hline & Common femoral vein & Dorsal foot vein \\
\hline Luxated intravenous cannula/sheath & $2(4.5)$ & $2(4.5)$ \\
Failure to obtain access & $1(2.3)$ & $4(9.1)$ \\
Suspected (temporary) obstruction of intravenous cannula/sheath & $8(18.2)^{*}$ & $1(2.3)^{\dagger}$ \\
lumen & & $3(6.8)$ \\
Periods with loss of measurements & - & \\
\hline
\end{tabular}

"In 6 cases only in the supine position (leading to unusable measurements in 4 cases), in 2 cases in both the supine and erect position. ${ }^{\text {D }}$ uring the erect position and at the start of the treadmill test. 


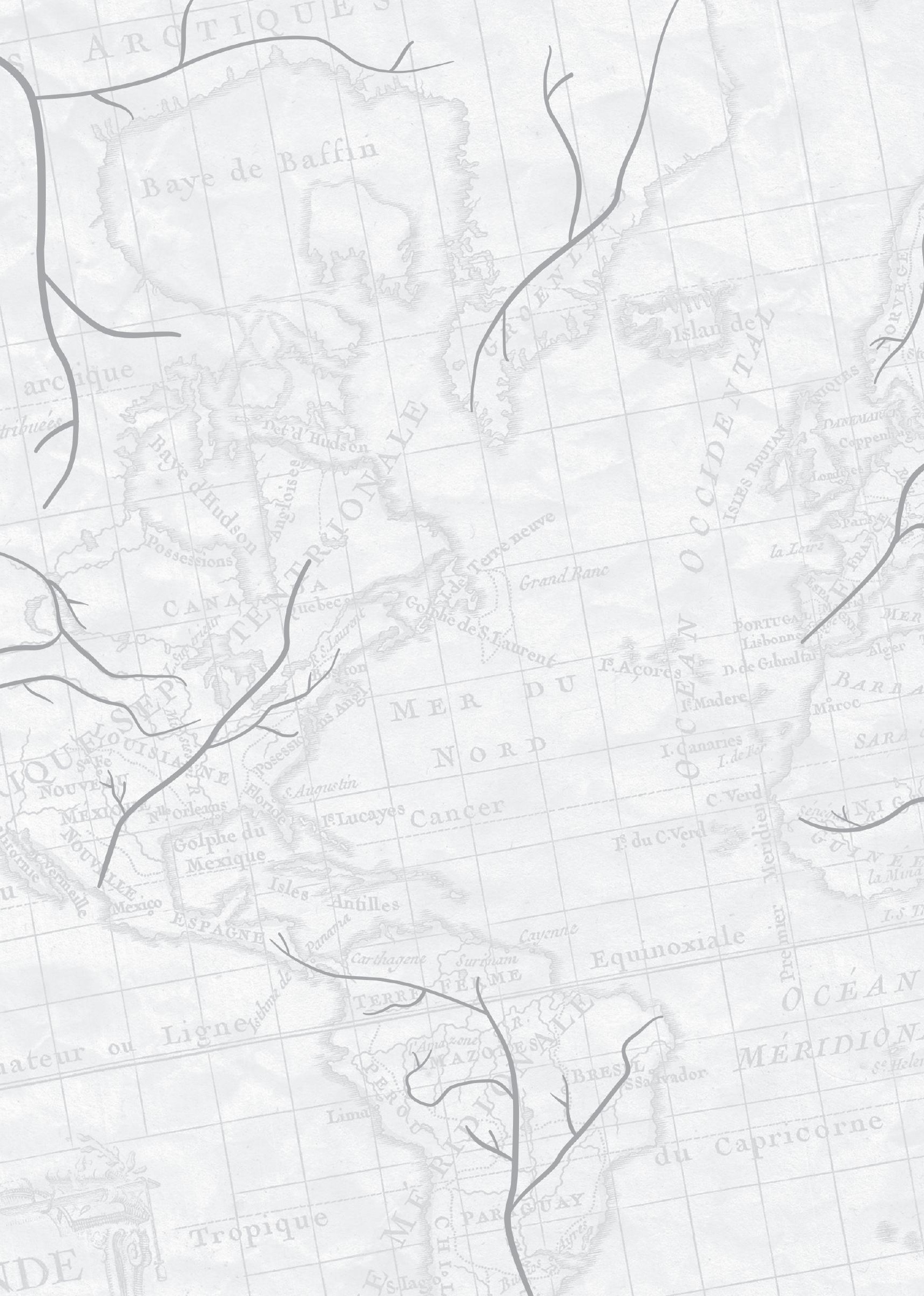




\title{
CHAPTER 8
}

The effect of stenting on venous hypertension: results using a treadmill stress test in patients with deep vein obstruction

\author{
Ralph L.M. Kurstjens \\ Mark A.F. de Wolf \\ Helena W. Konijn \\ Irwin M. Toonder \\ Patty J. Nelemans \\ Jorinde H.H. van Laanen \\ Rick de Graaf \\ Cees H.A. Wittens \\ Submitted
}




\begin{abstract}
Background: Stenting has been accepted as a valid treatment for patients with iliofemoral venous obstruction and significant complaints. However, little is known about its haemodynamic effect.

Objective: The primary aim of this study was to investigate whether stenting of such obstructions reduces venous hypertension. The secondary aim was to establish whether improvement in haemodynamic parameters has impact on quality of life.

Methods: Twenty-two participants with unilateral post-thrombotic obstruction of the iliac and/ or common femoral veins (CFVs) underwent a treadmill stress test with invasive pressure measurements in the CFVs and dorsal foot veins of both the affected and non-affected limb. This was performed the day before and three months after stenting of the obstructed tract.

Results: Before treatment, CFV pressure increased by $27.7 \pm 20.5 \mathrm{mmHg}$ after walking in affected limbs compared with $2.2 \pm 5.9 \mathrm{mmHg}$ in non-affected limbs. This pressure build-up decreased by $22.3 \pm 24.8 \mathrm{mmHg}$ at three months' follow-up compared with a $4.0 \pm 6.0 \mathrm{mmHg}$ increase in non-affected limbs $(-26.2 \mathrm{mmHg}$ difference; 95\% confidence interval [C], -41.2 to -11.3$)$. No such effect was found in the dorsal foot veins. VEINES-QOL increased by $25.2 \pm 17.3$ points after stenting and was significantly correlated with decrease in CFV pressure build-up after walking (regression coefficient $0.4 ; 95 \%$ CI, 0.1-0.6).

Conclusions: Stenting of post-thrombotic iliofemoral obstruction significantly reduces venous hypertension when compared to control limbs and correlates with an improvement in quality of life. Larger studies with a broader range of degree of obstruction need be performed to assess whether pre-stenting pressure measurements can predict post-stenting clinical success.
\end{abstract}




\section{Introduction}

Post-thrombotic syndrome (PTS) is a frequent disease with a prevalence of $20-50 \%$ among people who have suffered from deep vein thrombosis. ${ }^{1}$ Patients with PTS show quality of life (QoL) loss comparable to diseases such as congestive heart failure, diabetes mellitus and chronic pulmonary obstructive disease. ${ }^{2,3}$ In a quarter of patients with deep vein thrombosis the iliac and common femoral veins (CFV) are involved, which can severely limit outflow when not properly recanalised. ${ }^{4,5}$ Although PTS management usually consists of conservative treatment with therapeutic elastic stockings and mobilisation, the aforementioned subset of patients can also be treated by minimally invasive interventions if conservative treatment is not sufficient. ${ }^{6,7}$ Percutaneous transluminal angioplasty (PTA) with stenting has been accepted as a first choice of treatment for patients with symptomatic deep venous obstruction of the iliac veins and/or $\mathrm{CFV}^{7}$

PTA and stenting has been investigated in large case series and case-control studies with good clinical results and follow-up up to ten years. ${ }^{8-12}$ Patency rates for post-thrombotic obstructions treated by stenting vary from $79 \%$ to $100 \% 0^{8,10}$ with a significant improvement in clinical severity scores $^{8}$ and QoL. ${ }^{913}$ However, little is known about the haemodynamic impact of venous stenting. Recent insights have demonstrated that pressure in the CFV can vastly increase during exercise ${ }^{14}$ though it is unknown whether recanalisation of the obstructed tract can mitigate this venous hypertension and potentially reduce the risk of complications such as venous ulcers.

Despite positive study results, $15-20 \%$ of patients show only minor to no improvement in complaints after successful stenting. ${ }^{15}$ Therefore, a better understanding of the pathophysiology of this condition and the effect of its treatment is warranted in order to identify patients who would truly benefit from PTA and stenting.

The primary aim of this study was to investigate whether stenting of iliofemoral deep venous obstruction reduces venous hypertension. The secondary aims were to establish whether the improvement in haemodynamic parameters has impact on QoL and to determine whether preoperative pressure measurements can predict treatment outcome, as measured by change in QoL.

\section{Methods}

\section{Study design and participants}

In this prospective study, pressures in the CFV and dorsal foot vein of participants with unilateral post-thrombotic deep venous obstruction were compared with pressures in their healthy contralateral limbs as a control, before and after PTA and stenting.

Between December 2013 and June 2015, 24 participants were recruited from our tertiary outpatient clinic. Participants with unilateral post-thrombotic obstruction of the iliac veins and/ or CFV, possibly with lesions extending into the popliteal -femoral tract, willing to undergo PTA and stenting were eligible for this study. Post-thrombotic obstruction was diagnosed with duplex ultrasound and magnetic resonance venography. Exclusion criteria were obstruction of the inferior vena cava and/or contralateral deep veins, peripheral arterial disease, pregnancy, a life expectancy of $<6$ months, and age younger than 18 years. Participants requiring endophlebectomy (desobstruction of the CFV) and the creation of a temporary arteriovenous fistula (AVF) were not excluded from this study as these procedures are only necessary to (temporarily) improve inflow of the CFV and prevent early stent occlusion. ${ }^{16}$ 
This study was approved by the institutional review board of Maastricht University Medical Centre (METC 13-2-027) and principles according to the 2013-revised declaration of Helsinki were followed. Informed consent was obtained from all participants.

\section{Procedures}

Two tests were performed; one on the day before intervention and one three months after PTA and stenting. During a test session, the femoral vein was bilaterally cannulated under ultrasound guidance and a 4 French sheath (PreludoPRO; Merit Medical Systems, South Jordan, UT, USA) was placed with its tip in the CFV. Bilateral cannulation of a dorsal foot vein was performed using an 18, 20 or 22-gauge Vasofix Safety IV Catheter (B. Braun, Melsungen, Germany), depending on vein size. All pressures were measured continuously to compare affected with non-affected limbs, using TruWave pressure transducer sets (Edwards Lifesciences, Irvine, CA, USA) attached to a Hewlett Packard M1165A patient monitoring system (Philips Medical Systems, Best, the Netherlands).

Pressures were first measured in the supine position. Subsequently, the participant was asked to assume an erect position with the support of a frame. After stable pressures were observed, the participant was instructed to perform a stress test on a treadmill. Speed was set at $3.2 \mathrm{~km} / \mathrm{h}$ on a $0 \%$ slope, increasing $2 \%$ every 120 s until participants indicated they had to stop walking due to pain. Pain-free and maximum walking distances were registered. Participants were not coerced during the stress test and the test was ceased when participants indicated they had to stop or at a maximum of $26 \mathrm{~min}$.

The day after the first test session participants were treated by PTA and stenting of the iliac veins and/or CFV. Access to the femoral vein of the affected limb was obtained under ultrasound guidance and a 5 French sheath (PreludoPRO; Merit Medical Systems, South Jordan, UT, USA) was placed. Venography was performed and recanalisation of the obstructed tract was performed using a hydrophilic guidewire (Radifocus M; Terumo Interventional Systems, Somerset, NJ, USA). Subsequently, PTA was performed using non-compliant balloons with sizes varying from 12 to $16 \mathrm{~mm}$ (Powerflex and Maxi LD; Cordis, Johnson \& Johnson, New Brunswick, NJ, USA; Armada; Abbott, Chicago, Ill, USA). Stenting of the iliac veins and/or CFV was performed using Sinus Venous stents (Optimed, Ettlingen, Germany). In one participant it was decided to use Zilver Vena stents (Cook, Galway, Ireland), whereas in one participant two AndraStents (Andramed, Reutlingen, Germany) were used, complimentary to sinus Venous stents, as this participant also suffered from retroperitoneal fibrosis.

Participants with poor CFV inflow on venography also underwent endophlebectomy with the creation of a temporary polytetrafluoroethylene AVF to improve inflow and prevent early stent occlusion (hybrid procedure). ${ }^{16,17}$ After recanalisation, a longitudinal incision of $10-15 \mathrm{~cm}$ was made in the groin, and the common femoral artery and CFV with all its side branches were identified. A longitudinal venotomy of the $\mathrm{CFV}$ was performed and intraluminal synechiae were removed from the CFV and the orifices of all large branches draining into the CFV, mostly by sharp dissection. The CFV was either primarily closed or with a bovine patch, depending on the surgeon's judgment of vessel size. Subsequently, a 6-mm Gore-Tex Stretch Vascular Graft (Gore Medical, Flagstaff, AZ, USA) was used to create an AVF between the common femoral artery and the CFV with the venous anastomosis cranially in the venotomy. Finally, PTA and stenting was performed as mentioned earlier. Six weeks after intervention, a new venography was performed with temporary balloon occlusion of the AVF. The AVF was percutaneously closed by an Amplatzer vascular plug (St. Jude Medical, Little Canada, MN, USA), unless venography 
demonstrated insufficient stent inflow without a patent AVF.

During the intervention, pressures were also measured, using an IntelliVue MX800 or an IntelliVue MP30 patient monitoring system (Philips Medical Systems, Best, the Netherlands). Measurements were performed in both CFVs and the inferior vena cava before recanalisation, after PTA and after stenting. In participants who received an AVF, pressures were measured with and without clamping the AVF.

\section{Outcomes}

The primary outcome measure was change in CFV pressure during the treadmill test. Pressure changes before and after intervention were compared to assess the effect of stenting in the affected limb. Secondary outcome measurements were supine and erect CFV pressures, dorsal foot vein pressures for the same positions, Venous Clinical Severity Score (VCSS), Villalta score, QoL measured by the VEINES-QOL/Sym, and patency of the stented tract determined by duplex ultrasound.

\section{Statistical analysis}

Continuous data are presented as means with standard deviations or medians with interquartile ranges (IQR), dependent on normality of distribution. Categorical data are expressed as percentages. Paired-samples $t$-tests were used to compare treatment effect between affected limbs and non-affected control limbs. Univariable linear regression analysis was performed to determine the association between improvement in QoL and reduction in CFV pressure build-

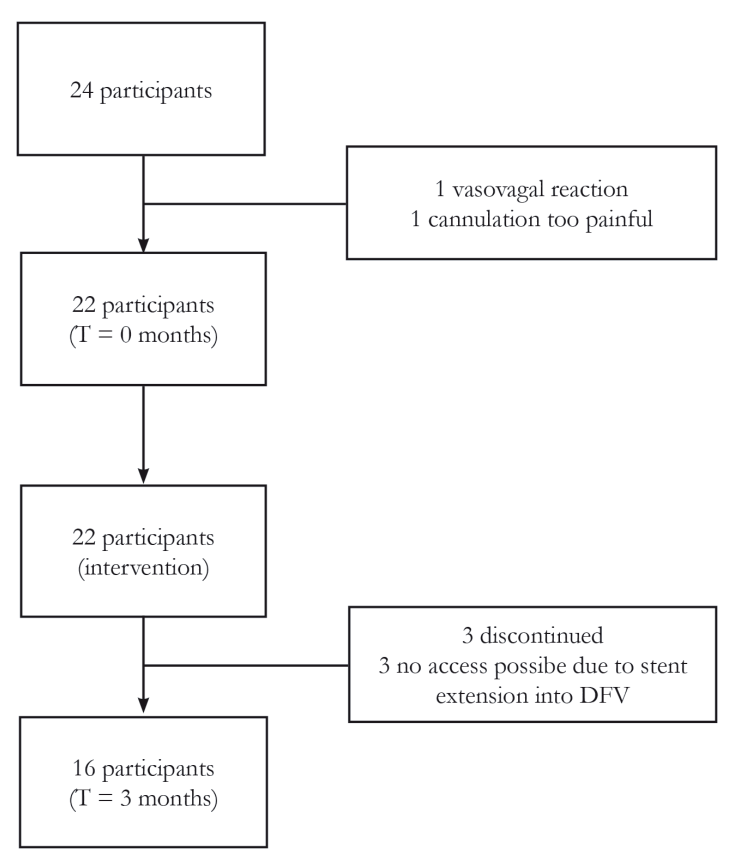

Figure 8.1 Flowchart of participants with available pressure measurements. (Three participants where no access was possible during follow-up were tested for secondary outcome parameters only, leading to $n=19$ at three months for those parameters.). up in the affected limb. Univariable linear regression analysis was also performed to evaluate the association between baseline CFV pressure build-up during the treadmill test and improvement in QoL after stenting. $P$-values $\leq 0.05$ were considered as statistically significant. Analyses were performed using SPSS version 21.0 (IBM Corporation, Armonk, NY, USA) and graphs were created using GraphPad Prism version 5.04 (GraphPad Software, San Diego, CA, USA).

\section{Results}

Twenty-four participants were included in this study. One participant discontinued the study before intervention because of intolerable pain during sheath insertion and one as a result of a vasovagal reaction when gaining access to the dorsal foot vein, 
leaving 22 participants with pressure measurements at baseline. After stenting, three participants discontinued their participation because of invasiveness of the study. At three months' followup, access to the affected CFV was not possible in three participants because of stent extension into the deep femoral vein (Figure 8.1). Therefore, these participants underwent the treadmill test without pressure measurements, leaving 16 participants with pressure measurements at three months after (re-)intervention (Table 8.S1 for details on available pressure measurements).

Mean age for the whole group of 22 participants was $42.8 \pm 11.9$ years, and 19 (86.4\%) were female. Median duration of complaints was 4.8 years (IQR, 2.1-12.7). Participants suffered from a lumen reduction of $\geq 90 \%$, determined by duplex ultrasound, except for two symptomatic participants with an obstruction of only 10-50\%. In nine participants (40.9\%) some form of deep or superficial venous reflux was found; in five $(22.7 \%)$ deep vein incompetence was present. Two participants had undergone previous deep venous surgery: one symptomatic participant had a patent DePalma bypass and one participant had occluded bypasses from the deep femoral

Table 8.1 Baseline participant characteristics

\begin{tabular}{|c|c|c|}
\hline Age, years & \multicolumn{2}{|l|}{$42.8 \pm 11.9$} \\
\hline Female sex, $n(\%)$ & \multicolumn{2}{|l|}{$19(86.4)$} \\
\hline Previous venous interventions, $n(\%)$ & \multicolumn{2}{|l|}{$8(36.4)$} \\
\hline Duration of complaints, years & \multicolumn{2}{|c|}{4.8 (IQR, 2.1-12.7) } \\
\hline Left sided complaints, $n(\%)$ & \multicolumn{2}{|l|}{$20(90.9)$} \\
\hline \multicolumn{3}{|l|}{ Post-thrombotic segments, $n(\%)$} \\
\hline Common iliac vein & \multicolumn{2}{|l|}{$22(100)$} \\
\hline External iliac vein & \multicolumn{2}{|l|}{$22(100)$} \\
\hline Common femoral vein & \multicolumn{2}{|l|}{$20(90.9)$} \\
\hline Deep femoral vein & \multicolumn{2}{|l|}{$10(45.5)$} \\
\hline Femoral vein & \multicolumn{2}{|l|}{$18(81.8)$} \\
\hline Deep femoral and femoral vein & \multicolumn{2}{|l|}{$10(45.5)$} \\
\hline Reflux, $n(\%)$ & \multicolumn{2}{|l|}{$9(40.9)$} \\
\hline Deep vein incompetence & \multicolumn{2}{|l|}{$5(22.7)$} \\
\hline Superficial vein reflux & \multicolumn{2}{|l|}{$4(18.2)$} \\
\hline Venous claudication, $n(\%)$ & \multicolumn{2}{|l|}{$22(100)$} \\
\hline \multicolumn{3}{|l|}{ VEINES QOL/Sym } \\
\hline QOL & \multicolumn{2}{|l|}{$46.4 \pm 17.7$} \\
\hline \multirow[t]{2}{*}{ Sym } & \multicolumn{2}{|l|}{$44.7 \pm 19.5$} \\
\hline & Affected limb & Non-affected limb \\
\hline Numeric Villalta score & $10.6 \pm 3.6$ & $2.0 \pm 1.8$ \\
\hline VCSS & $7.9 \pm 2.5$ & $1.3 \pm 1.3$ \\
\hline \multicolumn{3}{|l|}{ Highest $\mathrm{C}$ of CEAP, $n(\%)$} \\
\hline $\mathrm{C}_{0}$ & $2(9.1)$ & $5(22.7)$ \\
\hline $\mathrm{C}_{1}$ & $2(9.1)$ & $6(27.3)$ \\
\hline $\mathrm{C}_{2}$ & - & $4(18.2)$ \\
\hline $\mathrm{C}_{3}$ & $11(50.0)$ & $6(27.3)$ \\
\hline $\mathrm{C}_{4}$ & $5(22.7)$ & $1(4.5)$ \\
\hline $\mathrm{C}_{5}$ & $1(4.5)$ & - \\
\hline $\mathrm{C}_{6}$ & $1(4.5)$ & - \\
\hline
\end{tabular}

CEAP, Clinical-Etiology-Anatomy-Pathophysiology classification; IQR, interquartile range; VCSS, Venous Clinical Severity Score. Plus-minus values are means \pm standard deviations. 
vein to the common iliac vein and inferior vena cava (Table 8.1).

Twelve participants underwent a percutaneous intervention and ten underwent a hybrid procedure. Mean number of stents used was $2.3 \pm 0.8$. Three participants with a hybrid procedure decided to discontinue the study after the intervention as they found the tests too invasive. At three months, primary patency was 68\% (13/19), assisted primary patency $79 \%$ $(15 / 19)$ and secondary patency $89 \%$ (17/19). Five participants received additional interventions. One underwent surgical thrombectomy and AVF revision during hospital admission as a result of a kinked AVF. Four participants who had a hybrid procedure underwent stent extension into the CFV and/or deep femoral vein; two because of persisting complaints and a stenosis distal from the stented tract, and two because of stent occlusion. The latter two were first treated by ultrasound enhanced catheter directed thrombolysis. One of those participants developed another stent occlusion, for which a surgical thrombectomy with another stent extension was performed. The AVF was not percutaneously closed in this participant due to insufficient inflow and re-thrombosis. Pressure measurements were not performed at three months, as this was one of the three participants where no access could be obtained due to stent extension into the deep femoral vein.

At baseline, CFV pressure increased by $27.7 \pm 20.5 \mathrm{mmHg}$ after walking in the affected limb compared with $2.2 \pm 5.9 \mathrm{mmHg}$ in non-affected limbs $(P<0.001)$. For those with measurements at baseline and follow-up, this pressure build-up was decreased by $22.3 \pm 24.8 \mathrm{mmHg}$ at three months' follow-up compared with an increase of $4.0 \pm 6.0 \mathrm{mmHg}$ in non-affected limbs $(-26.2$ $\mathrm{mmHg}$ difference; $95 \%$ confidence interval [CI], -41.2 to $-11.3 ; P=0.003)$. Before intervention, dorsal foot vein pressure demonstrated a $38.3 \pm 21.9 \mathrm{mmHg}$ drop after walking in affected limbs compared with $46.2 \pm 23.1 \mathrm{mmHg}$ in control limbs $(P=0.074)$. No difference in effect of stenting was observed between affected and non-affected limbs $(7.4 \pm 22.4 \mathrm{mmHg}$ less pressure drop in affected compared with $8.1 \pm 12.5 \mathrm{mmHg}$ less in non-affected limbs; $-0.8 \mathrm{mmHg}$ difference; $95 \% \mathrm{CI},-24.2$ to $22.7 ; P=0.940$; Figure 8.2 ) With respect to pressure measurements in the supine and erect positions, comparison of values before and after stenting did not reveal significant differences between the affected and non-affected limbs (Table 8.2).

During the intervention, pressure in the CFV was $17.4 \pm 6.8 \mathrm{mmHg}$ in affected and $12.2 \pm 5.1$ $\mathrm{mmHg}$ in non-affected limbs before recanalisation $(P<0.001)$. After PTA, pressure decreased by $1.5 \pm 4.1 \mathrm{mmHg}$ in affected and by $0.8 \pm 3.1 \mathrm{mmHg}$ in control limbs $(-0.7 \mathrm{mmHg}$ difference;

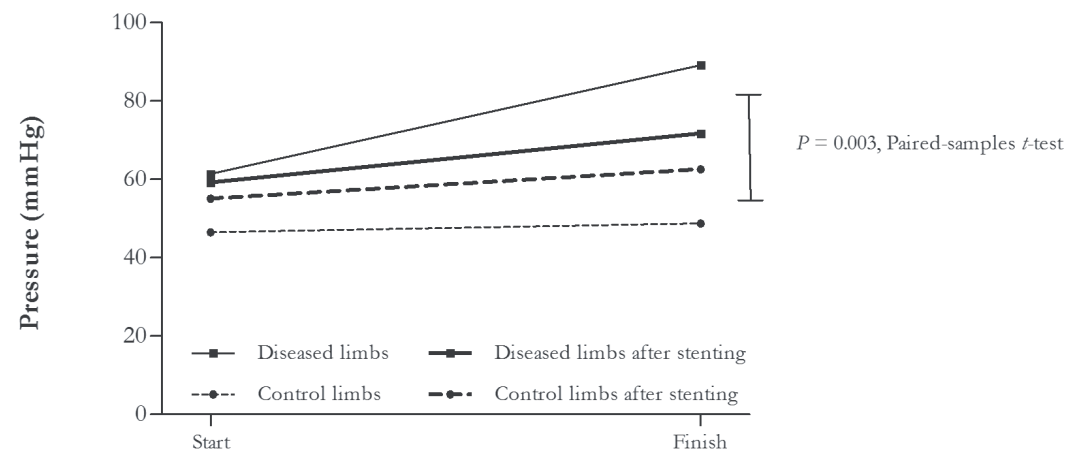

Figure 8.2 Effect of stenting on venous hypertension compared with control limbs. 
Table 8.2 Pressures in the supine and erect position and after walking.

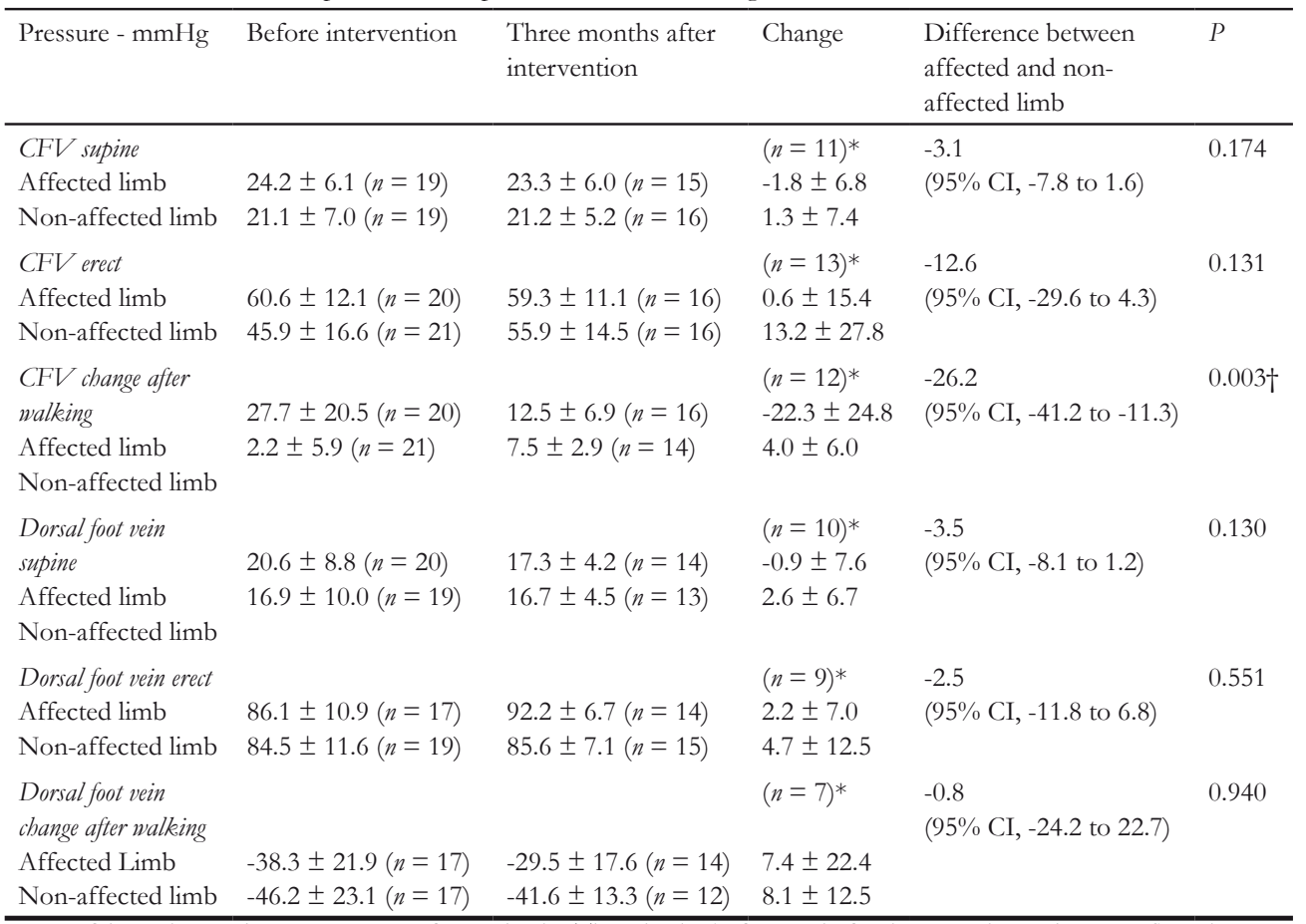

CI, confidence interval; CFV, common femoral vein. The $n$ in the before and after intervention columns reflect the amount of participants with valid pressure measurements for that position. Plus-minus values are means \pm standard deviations.

*Only including participants with successful pre- and post-operative measurements, ${ }^{\dagger}$ statistically significant.

95\% CI, -2.7 to $1.3 ; P=0.482)$. Stenting yielded a $6.1 \pm 5.2 \mathrm{mmHg}$ drop in pressure from baseline in affected limbs compared with $1.0 \pm 3.8$ in non-affected limbs $(-5.1 \mathrm{mmHg}$ difference; 95\% CI, -7.1 to $-3.0 ; P<0.001)$. Pressure gradient over the inferior vena cava and CFV was reduced by $5.2 \pm 5.0 \mathrm{mmHg}$ in affected limbs compared with $0.1 \pm 3.0 \mathrm{mmHg}$ in controls $(-5.1$ $\mathrm{mmHg}$ difference; $95 \% \mathrm{CI},-7.2$ to $-2.9 ; P<0.001)$. A patent AVF did not significantly alter CFV pressure, as the difference between measurements with a clamped versus patent AVF was $0.1 \pm$ $0.3 \mathrm{mmHg}(P=0.598)$.

For all participants with follow-up, mean VEINES-QOL score before intervention was $50.2 \pm$ 15.7 and increased by $25.2 \pm 17.3$ points to $75.3 \pm 21.6$ after stenting $(P<0.001)$. Anamnestically, four participants (21\%) reported full relief of complaints, eleven $(57 \%)$ improvement of complaints and four $(21 \%)$ no change in complaints. Numeric Villalta score improved by $3.6 \pm$ 3.8 points in affected limbs compared with an increase of $0.4 \pm 2.2$ in non-affected limbs (4.1 difference; 95\% CI, 2.2-5.9; $P<0.001)$. VCSS improved by $2.4 \pm 3.11$ in affected compared with $0.1 \pm 1.4$ in non-affected limbs (2.3 difference; $95 \%$ CI, 0.8-3.8; $P=0.004)$. Pain-free walking distance improved with $355 \pm 345 \mathrm{~m}(P<0.001)$, from $443 \pm 304$ to $798 \pm 469 \mathrm{~m}$. Maximum walking distance improved with $235 \pm 244 \mathrm{~m}(P=0.001)$, from $869 \pm 400$ to $1104 \pm 309 \mathrm{~m}$ (Table 8.3).

Improvement in VEINES-QOL was significantly associated with the decrease in CFV pressure build-up during the treadmill test, as, for every $\mathrm{mmHg}$ decrease in pressure, QoL improved by 
0.4 points (95\% CI, 0.1-0.6; $P=0.004$; Figure 8.3). No statistically significant association was found between CFV pressure build-up after walking at baseline and improvement in QoL after stenting (regression coefficient $0.2 ; 95 \% \mathrm{CI},-0.2$ to $0.6 ; P=0.226$; Figure 8.4 ).

\section{Discussion}

This study shows that venous hypertension due to post-thrombotic obstruction of the iliofemoral veins can be ameliorated through stenting of the obstructed tract. Moreover, the reduction in CFV pressure after walking significantly correlates with an increase in QoL. To our knowledge, no studies have investigated the effect of stenting on venous hypertension during actual ambulation. Some have investigated dorsal foot vein pressure after ten tiptoe movements, to simulate walking, ${ }^{9,18}$ while others have looked at CFV pressures in a supine position. ${ }^{19}$

Neglén et al. ${ }^{9}$ evaluated dorsal foot vein pressure as the percentage in pressure drop after ten tiptoe movements. This ambulatory venous pressure drop improved from $62 \pm 20 \%$ to $66 \pm$ $21 \%$, yet subgroup analysis showed that pressure drop only improved for limbs without reflux. Nonetheless, we were not able to find statistical significance for pressures at dorsal foot vein level after walking between affected and non-affected limbs. This might be explained due to our limited sample size for this secondary outcome measurement or the fact that Neglén et al. ${ }^{9}$ did not compare their results to control limbs. Furthermore, the increase in walking distance after the procedure enables dorsal foot vein pressure to gradually increase for a longer period time, leading to a lower net drop. ${ }^{14,20}$

Concerning CFV pressures, Delis et al. ${ }^{19}$ demonstrated a median pressure decrease of $7 \mathrm{mmHg}$ (95\% CI, 5.5-9), which is comparable to our study findings. Although our decrease in supine $\mathrm{CFV}$ pressure was highly significant when measured during the intervention, we were not able to reproduce these results three months after intervention. Possible explanations might be a more controlled situation under anaesthesia or the more limited sample size of patients with successful supine CFV measurements at follow-up. However, changes in pressure over time cannot be ruled out. Kurklinsky et al. ${ }^{21}$ measured pressure gradients over the obstructed tract, decreasing by $4.9 \mathrm{mmHg}$ (95\% CI, 2.84-7.0) after stenting, which is similar to our results.

No significant correlation was found between pressure build-up after walking in the affected

Table 8.3 Clinical outcomes for all participants with follow-up $(n=19)$.

\begin{tabular}{|c|c|c|c|c|}
\hline & Before intervention & After intervention & $\begin{array}{l}\text { Difference between affected } \\
\text { and non-affected limb }\end{array}$ & $P$ \\
\hline VEINES-QOL & $50.2 \pm 15.7$ & $75.3 \pm 21.6$ & & $<0.001 *$ \\
\hline VEINES-Sym & $48.3 \pm 18.4$ & $71.5 \pm 22.3$ & & $<0.001^{*}$ \\
\hline VCSS & & & $2.3(95 \%$ CI, 0.8-3.8) & $0.004^{*}$ \\
\hline Affected limb & $7.8 \pm 2.7$ & $5.4 \pm 2.9$ & & \\
\hline Non-affected limb & $1.2 \pm 1.4$ & $1.1 \pm 1.4$ & & \\
\hline Numeric Villalta score & & & $4.1(95 \%$ CI, 2.2-5.9) & $<0.001 *$ \\
\hline Affected limb & $10.0 \pm 3.3$ & $6.4 \pm 4.0$ & & \\
\hline Non-affected limb & $1.7 \pm 1.4$ & $2.1 \pm 2.2$ & & \\
\hline Pain-free walking distance, $\mathrm{m}$ & $443 \pm 304$ & $798 \pm 469$ & & $<0.001 *$ \\
\hline Maximum walking distance, $\mathrm{m}$ & $869 \pm 400$ & $1104 \pm 309$ & & $0.001 *$ \\
\hline
\end{tabular}


CFV before intervention and improvement in QoL after stenting. Yet, a higher resting pressure might indicate pre-existent vasodilatation of the arterioles. This means less capacity for additional vasodilatation, possibly leading to less pressure build-up during walking compared with limbs that have normal resting pressures. Howbeit, this study was designed as a pilot study to identify pressure changes due to stenting and is likely underpowered for such an analysis. Thus, further research has to be performed to determine whether CFV pressure build-up after walking can predict successful clinical outcome of stenting. Additionally, further research should include non-thrombotic iliac vein compression and more patients with partial post-thrombotic obstruction to determine the predictive effect of $\mathrm{CFV}$ pressure measurements in a broader population.

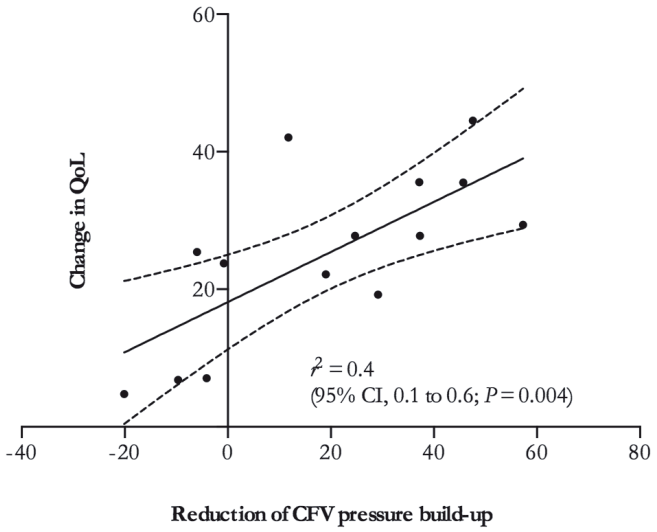

Figure 8.3 Association between post-stenting reduction of common femoral vein pressure build-up after walking in the affected limb and improvement in quality of life after stenting, measured by the VEINES-QOL.

QoL, quality of life, CFV, common femoral vein. Best fit line with 95\% confidence interval is presented.

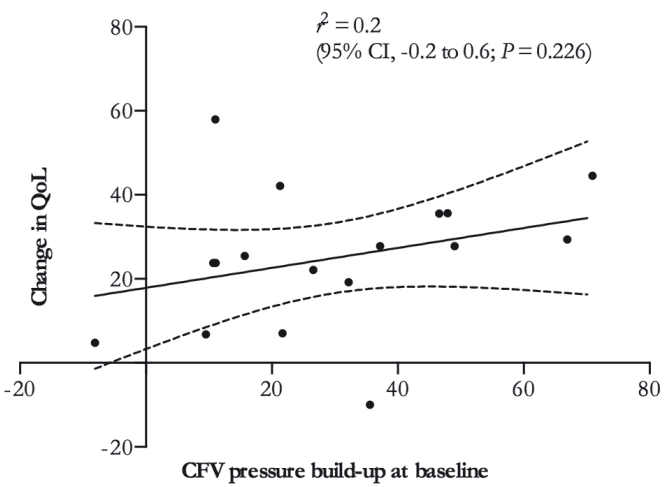

Figure 8.4 Association between common femoral vein pressure build-up after walking at baseline and improvement in quality of life after stenting, measured by the VEINES-QOL.

QoL, quality of life, CFV, common femoral vein. Best fit line with $95 \%$ confidence interval is presented. 
Nevertheless, this study also knows some limitations. Whilst dropout rate of participants was limited, some participants could not be properly examined at follow-up due to stent extension into the deep femoral vein. Also, (temporary) loss of pressure registration frequently occurred in the dorsal foot veins. Additionally, inflow ${ }^{14,17}$ and collateralisation ${ }^{22}$ are likely of importance, for which we currently have no proper techniques of quantification.

\section{Conclusions}

Stenting of iliofemoral post-thrombotic obstruction significantly reduces ambulatory venous hypertension in the common femoral vein, when compared with control limbs, and correlates with a significant improvement in quality of life. Larger studies with a broader range of degree of obstruction should be performed to assess whether pre-procedural pressure measurements can predict success of treatment.

\section{References}

1. de Wolf MA, Wittens CH, Kahn SR. Incidence and risk factors of the post-thrombotic syndrome. Phlebology 2012;27 Suppl 1:85-94.

2. Carradice D, Mazari FA, Samuel N, Allgar V, Hatfield J, Chetter IC. Modelling the effect of venous disease on quality of life. BrJ Surg 2011;98(8):1089-98.

3. Kahn SR, Shbaklo H, Lamping DL, et al. Determinants of health-related quality of life during the 2 years following deep vein thrombosis. J Thromb Haemost 2008;6(7):1105-12.

4. Kahn SR, Shrier I, Julian JA, et al. Determinants and time course of the postthrombotic syndrome after acute deep venous thrombosis. Ann Intern Med 2008;149(10):698-707.

5. Akesson H, Brudin L, Dahlstrom JA, Eklof B, Ohlin P, Plate G. Venous function assessed during a 5 year period after acute ilio-femoral venous thrombosis treated with anticoagulation. Eur J V asc Surg 1990;4(1):43-8.

6. Kahn SR, Comerota AJ, Cushman M, et al. The postthrombotic syndrome: evidence-based prevention, diagnosis, and treatment strategies: a scientific statement from the American Heart Association. Circulation 2014;130(18):163661.

7. Wittens C, Davies AH, Baekgaard N, et al. Editor's Choice - Management of Chronic Venous Disease: Clinical Practice Guidelines of the European Society for Vascular Surgery (ESVS). Eur J Vasc Endovasc Surg 2015;49(6):678737.

8. de Wolf MA, de Graaf R, Kurstjens RL, Penninx S, Jalaie H, Wittens CH. Short-Term Clinical Experience with a Dedicated Venous Nitinol Stent: Initial Results with the Sinus-Venous Stent. Eur J Vasc Endovasc Surg 2015;50(4):518-26.

9. Neglen P, Hollis KC, Olivier J, Raju S. Stenting of the venous outflow in chronic venous disease: long-term stentrelated outcome, clinical, and hemodynamic result. J V asc Surg 2007;46(5):979-90.

10. Wen-da W, Yu Z, Yue-Xin C. Stenting for chronic obstructive venous disease: A current comprehensive metaanalysis and systematic review. Pblebology 2016;31(6):376-89.

11. Yin M, Shi H, Ye K, et al. Clinical Assessment of Endovascular Stenting Compared with Compression Therapy Alone in Post-thrombotic Patients with Iliofemoral Obstruction. Eur J Vasc Endovasc Surg 2015;50(1):101-7.

12. Hartung O, Loundou AD, Barthelemy P, Arnoux D, Boufi M, Alimi YS. Endovascular management of chronic disabling ilio-caval obstructive lesions: long-term results. Eur J Vasc Endovasc Surg 2009;38(1):118-24.

13. Catarinella FS, Nieman FH, de Wolf MA, Toonder IM, de Graaf R, Wittens CH. Quality-of-life in interventionally treated patients with post-thrombotic syndrome. Phlebology 2015;30(1 Suppl):89-94.

14. Kurstjens RL, de Wolf MA, Konijn HW, et al. Intravenous pressure changes in patients with postthrombotic deep venous obstruction: results using a treadmill stress test. J Thromb Haemost 2016;14(6):1163-70.

15. de Wolf MAF, Arnoldussen CW, Grommes J, et al. Minimally invasive treatment of chronic iliofemoral venous occlusive disease. Journal of Vascular Surgery: Venous and Lymphatic Disorders 2013;1(2):146-53.

16. de Wolf MA, Arnoldussen CW, Wittens CH. Indications for endophlebectomy and/or arteriovenous fistula after stenting. Phlebology 2013;28 Suppl 1:123-8.

17. Kurstjens RL, de Graaf R, Barbati ME, et al. Arteriovenous fistula geometry in hybrid recanalisation of postthrombotic venous obstruction. Phlebology 2015;30(1 Suppl):42-9. 
18. Rosales A, Sandbaek G, Jorgensen JJ. Stenting for chronic post-thrombotic vena cava and iliofemoral venous occlusions: mid-term patency and clinical outcome. Eur J V asc Endovasc Surg 2010;40(2):234-40.

19. Delis KT, Bjarnason H, Wennberg PW, Rooke TW, Gloviczki P. Successful iliac vein and inferior vena cava stenting ameliorates venous claudication and improves venous outflow, calf muscle pump function, and clinical status in post-thrombotic syndrome. Ann Surg 2007;245(1):130-9.

20. Kurstjens R, de Wolf M, de Graaf R, Wittens C. Hemodynamic changes in iliofemoral disease. Pblebology 2014;29(1 suppl):90-6.

21. Kurklinsky AK, Bjarnason H, Friese JL, et al. Outcomes of venoplasty with stent placement for chronic thrombosis of the iliac and femoral veins: single-center experience. J Vasc Interv Radiol 2012;23(8):1009-15.

22. Kurstjens RL, de Wolf MA, van Laanen JH, de Haan MW, Wittens CH, de Graaf R. Hemodynamic significance of collateral blood flow in chronic venous obstruction. Phlebology 2015;30(1 Suppl):27-34.

Table 8.S1 Recorded pressure measurements per location and test session.

\begin{tabular}{|c|c|c|c|c|c|}
\hline CFV supine & $\mathrm{CFV}$ erect & $\begin{array}{l}\text { CFV change } \\
\text { after walking }\end{array}$ & $\begin{array}{l}\text { Dorsal foot } \\
\text { vein supine }\end{array}$ & $\begin{array}{l}\text { Dorsal foot } \\
\text { vein erect }\end{array}$ & $\begin{array}{l}\text { Dorsal foot vein } \\
\text { change after } \\
\text { walking }\end{array}$ \\
\hline
\end{tabular}

\begin{tabular}{lllllll}
\hline T0 affected limb & $18 / 22$ & $20 / 22$ & $20 / 22$ & $20 / 22$ & $17 / 22$ & $17 / 22$ \\
T0 non-affected limb & $19 / 22$ & $21 / 22$ & $21 / 22$ & $19 / 22$ & $19 / 22$ & $17 / 22$ \\
T3 affected limb & $15 / 16$ & $16 / 16$ & $16 / 16$ & $14 / 16$ & $14 / 16$ & $14 / 16$ \\
T3 non-affected limb & $16 / 16$ & $16 / 16$ & $14 / 16$ & $13 / 16$ & $15 / 16$ & $12 / 16$ \\
\hline
\end{tabular}

T0, before intervention; T3, at three months' follow-up; CFV, common femoral vein.

T0 CFV affected: 1 no access, 1 luxation, 2 suspected temporary obstruction of sheath lumen supine.

T0 CFV non-affected: 1 luxated, 2 suspected temporary obstruction of sheath lumen supine.

T0 dorsal foot vein affected: 1 no access, 2 luxated, 1 kinked, 1 loss of pressure measurements.

T0 dorsal foot vein non-affected: 3 no access, 2 loss of measurements during walking.

T3 CFV affected: 1 suspected temporary obstruction of sheath lumen.

T3 CFV non-affected: 1 luxated, 1 removed due to pain.

T3 dorsal foot vein affected: 1 no access, 1 luxated.

T3 dorsal foot vein non-affected: 1 no access, 2 loss of measurements supine, 2 luxated after walking, 1 loss of measurements during walking. 



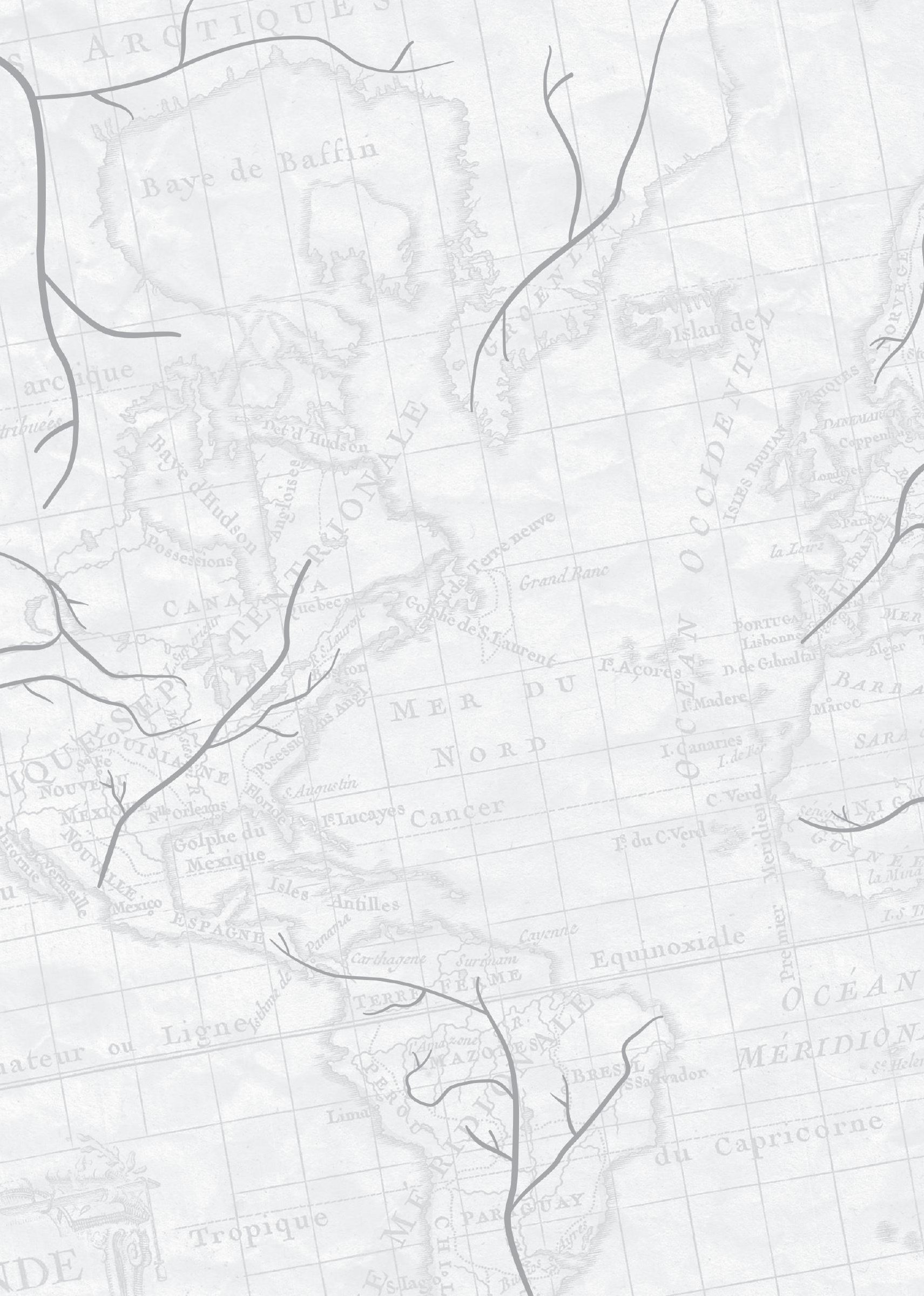




\title{
CHAPTER 9
}

\section{Arteriovenous fistula geometry in hybrid recanalisation of post-thrombotic venous obstruction}

\author{
Ralph L.M. Kurstjens \\ Rick de Graaf \\ Mohammad E. Barbati \\ Mark A.F. de Wolf \\ Jorinde H.H. van Laanen \\ Cees H.A. Wittens \\ Houman Jalaie
}

Phlebology. 2015;30(1S):42-9 


\begin{abstract}
Objective: Post-thrombotic obstruction can be adequately treated by percutaneous transluminal angioplasty and stenting. When post-thrombotic trabeculations extend below the femoral confluence, proper inflow can be facilitated by endophlebectomy and creation of an arteriovenous fistula. The aim of this study was to investigate whether it is more favourable to place the arteriovenous fistula at the cranial or caudal end of the endophlebectomy to prevent stenosis and occlusion.
\end{abstract}

Methods: We retrospectively analysed the clinical data of all patients who underwent a hybrid procedure in two tertiary centres. Demographics, interventional details and post-operative imaging were collected.

Results: Data on 42 limbs with cranially and 23 limbs with caudally placed arteriovenous fistulas were collected. Post-thrombotic disease of the deep femoral vein alone or in combination with the femoral vein was observed more often in the cranial group. The caudal group more often received a smaller sized and straight polytetrafluoroethylene fistula, whereas the cranial group comprised a significantly higher amount of stented segments. Logistic regression analysis showed that only reduced femoral inflow (odds ratio 2.9; 95\% confidence interval [CI], 1.1-7.5) was a significant predictor of stent stenosis and/or occlusion. Logistic regression analysis for risk of occlusion showed a significant influence of stent-related complications (odds ratio 4.7; 95\% CI, 1.2-18.3) and a tendency towards influence of arteriovenous fistula geometry in favour of the cranially placed fistula.

Conclusions: Placement of the arteriovenous fistula in the cranial part of the endophlebectomy during hybrid recanalisation may result in a more favourable outcome, yet this tendency was not statistically significant. Moreover, femoral inflow is pivotal in maintaining patency and should thus be adequately assessed pre-operatively. 


\section{Introduction}

Post-thrombotic obstruction of the iliocaval veins can be adequately treated by percutaneous transluminal angioplasty (PTA) and stenting. Several studies with large populations have shown good technical success and patency rates, with follow-up as high as 72 months. ${ }^{1-4}$ Furthermore, quality of life and venous clinical severity score have shown to significantly improve. ${ }^{1}$ However, successful treatment becomes more difficult if post-thrombotic disease extends below the inguinal ligament, particularly the femoral confluence. ${ }^{5}$ These types of patients can be treated by a hybrid procedure. During such a procedure, endophlebectomy of the common femoral vein (CFV) and orifices of all significant veins draining into the CFV is performed in addition to PTA and stenting of the more proximal tract. ${ }^{4,-8}$ To ensure proper inflow of the recanalised tract and prevent early thrombotic complications, an arteriovenous fistula (AVF) is placed between the common femoral artery (CFA) and the CFV. ${ }^{4,9-11}$

Use of such an AVF can be counterproductive, though, since stenosis or occlusion in the region of the venous anastomosis of the AVF has been observed in our centre. In the past, we placed the AVF caudally from the endophlebectomy to ensure good flow in the complete recanalised, i.e. stented and endophlebectomy, tract, yet because of patency-related problems in the endophlebectomy area we started to place the AVF cranially in the endophlebectomy area at the distal end of the stented tract. These patency-related problems were possibly due to intimal hyperplasia, comparable to the problems seen in access surgery. The idea was that, by performing it in this region, the distance between the anastomosis and the opposite vein wall would be greater. Therefore, a reduction in the potential intimal hyperplasia, caused by areas of low shear stress due to the created arterial inflow, was expected (Figure 9.1).

The aim of this study was to evaluate whether this theoretically more favourable position of the AVF at the cranial end of the endophlebectomy would indeed prevent stenosis and occlusion of the complete recanalised tract.

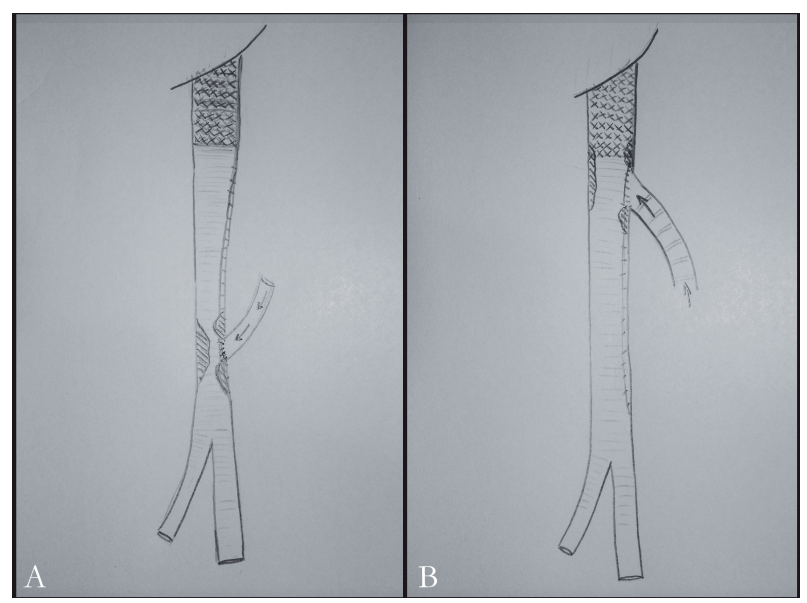

Figure 9.1 Possible effects of intimal hyperplasia.

A. Caudal placement of an arteriovenous fistula leading to functional lumen obstruction and hindering femoral inflow. B. Cranial placement of an arteriovenous fistula where vessel diameter is larger and therefore theoretically leading to less functional lumen obstruction. 


\section{Methods}

In this study, we retrospectively compared the incidence of stenosis and occlusion between creation of an AVF at the cranial end and creation of an AVF at the caudal end of the endophlebectomy in patients undergoing a hybrid procedure for post-thrombotic deep venous obstruction.

We retrospectively analysed all patients who, during the last five years, underwent a hybrid venous recanalisation of the caval, iliac and/or CFVs in the Maastricht University Medical Centre or University Hospital Aachen. Patients who received an AVF for another purpose, e.g. in addition to bypass surgery or thrombectomy, were excluded from analysis, as were patients who had $<2$ post-operative follow-up visits with imaging. In patients who received an AVF bilaterally, we decided to solely include the right limb since only independent samples can be used for logistic regression analysis.

Hybrid procedures are performed under general anaesthesia with the patient in the supine position. Access to the femoral vein (FV) of the affected limb is obtained through a 10 French sheath. Subsequently, various types of guiding sheaths, catheters and guidewires are used to recanalise the post-thrombotic tract until a healthy vessel lumen is reached. In cases where recanalisation from the FV is impossible, access is obtained via the contralateral FV or right jugular vein. After successful recanalisation, a groin incision is made and the CFA and CFV with their confluences and all side branches are identified. Then, the CFV is longitudinally opened and intraluminal synechiae and septae are removed from the CFV and orifices of the FV, deep femoral vein (DFV) and other large branches draining into the CFV to optimise inflow. The $\mathrm{CFV}$ is closed either primarily or with the use of a patch, depending on post-venectomy vessel diameter. Subsequently, PTA and stenting of the obstructed tract is performed, with the most distal part of the stents landing right above or in the top of the endophlebectomy area. In between the closure of the CFV and stenting of the obstructed tract, an AVF is constructed. However, creation of the AVF was not always performed in the same fashion. In our centre, AVFs have been created using a ring-enforced polytetrafluoroethylene (PTFE) loop, a straight non-enforced PTFE tube or a side branch of the great saphenous vein to connect the CFA with the CFV, either cranially (Figures 9.2 and 9.3) or caudally (Figure 9.4) in the endophlebectomy area.

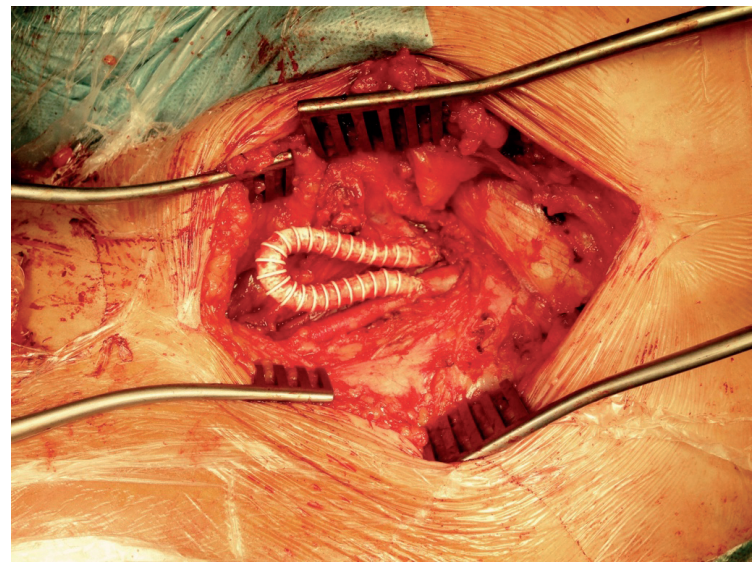

Figure 9.2 Example of an operation where the arteriovenous fistula was placed cranially in a loop shape.
Perioperative data concerning the type of AVF and location of its placement were collected, as were data pertaining to the extent of stenting and closure of the venotomy. Follow-up imaging data, i.e. duplex ultrasonography (DUS) and fourplane abdominal X-ray, were collected to evaluate the occurrence of stenoses, occlusions or problems related to stent configuration. Pre-operative data regarding the C-score according to the ClinicalEtiology-Anatomy-Pathophysiology (CEAP) classification, previous deep venous interventions and potential 


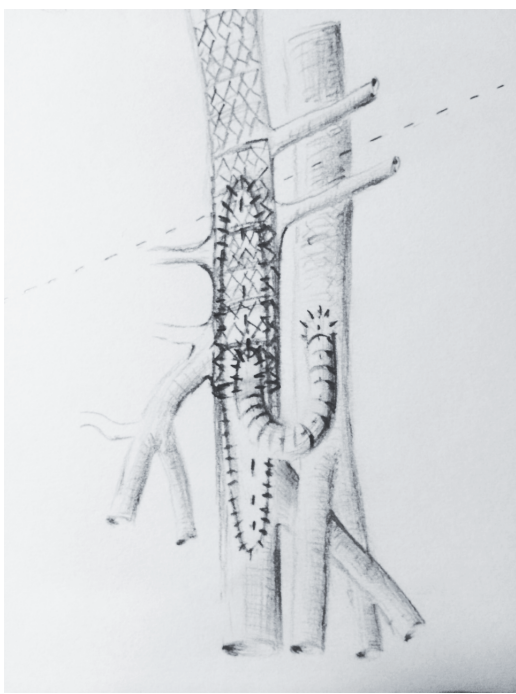

Figure 9.3 Example of a loop-shaped arteriovenous fistula placed cranially in the endophlebectomy area, directly caudal from the stented tract.

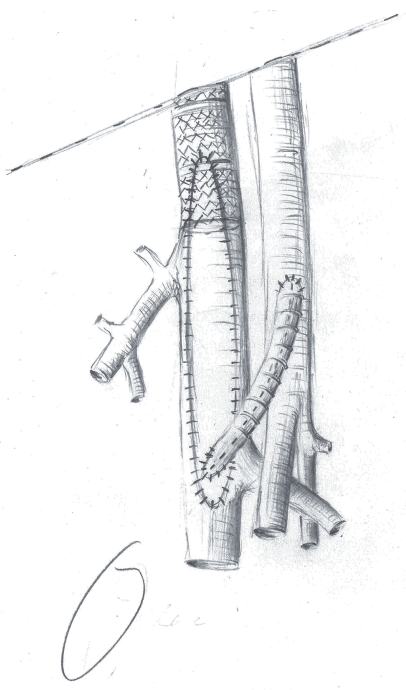

Figure 9.4 Example of a straight-shaped arteriovenous fistula placed caudally in the endophlebectomy area.

thrombophilia were also obtained. The FV and DFV were scored as either healthy or postthrombotic based on DUS and magnetic resonance venography (MRV).

\section{Statistical analysis and definitions}

Statistical analysis was performed using IBM SPSS Statistics version 21.0 (IBM Corporation, Armonk, NY, USA). Continuous variables are expressed as mean values with concomitant standard deviations, whereas categorical data are expressed using percentages. The $\chi^{2}$ test or independent-samples $t$-test was used to test for baseline differences between groups. Fisher's exact test was used in cases where the expected count of one or more cells was less than five and the Mann-Whitney $U$ test was used in cases where variables were not normally distributed. Multiple logistic regression analysis was performed to determine the influence of several variables on the risk of stenosis or occlusion. Kaplan-Meier survival analysis was performed using GraphPad Prism version 5.04 (GraphPad Software, San Diego, CA, USA). P-values $\leq 0.05$ were considered as statistically significant. Loss of primary patency was defined as occlusion of the treated tract or an additional procedure to prevent occlusion, loss of assisted primary patency as occlusion of the treated tract after additional interventions to prevent occlusion and loss of secondary patency as occlusion after an initially successfully treated re-occlusion. Reduced femoral inflow was defined as post-thrombotic changes in the FV, DFV, or FV and DFV as diagnosed on DUS and MRV. This was scored as follows: 0 if both veins were not affected, 1 if either the FV or DFV was post-thrombotic, and 2 if both veins were post-thrombotic.

\section{Results}

A total of 78 limbs in 70 patients were identified. Two limbs were excluded due to insufficient perioperative data concerning the placement of the AVF, one limb was excluded due to technical 
Table 9.1 Patient characteristics.

\begin{tabular}{|c|c|c|c|}
\hline & Cranial group $(n=42)$ & Caudal group $(n=23)$ & $P$ \\
\hline Age, years & $39.5 \pm 16.6$ (range, $18-75)$ & $38.8 \pm 11.6$ (range, $20-62$ ) & 0.538 \\
\hline Female sex, $n(\%)$ & $27(64.3)$ & $13(56.5)$ & 0.778 \\
\hline Thrombophilia, $n(\%)$ & $\begin{array}{l}12(70.6) \\
\text { Out of } 17 \text { tested }\end{array}$ & $\begin{array}{l}5(62.5) \\
\text { Out of } 8 \text { tested }\end{array}$ & 1.000 \\
\hline Previous deep venous intervention, $n(\%)$ & $3(7.1)$ & $1(4.3)$ & 1.000 \\
\hline \multicolumn{4}{|l|}{$\begin{array}{l}\text { Post-thrombotic changes below femoral } \\
\text { confluence, } n(\%)\end{array}$} \\
\hline DFV & $23(54.8)$ & $5(21.7)$ & $0.010^{*}$ \\
\hline $\mathrm{FV}$ & $37(88.1)$ & $19(82.6)$ & 0.709 \\
\hline Both DFV and FV & $21(50.0)$ & $5(21.7)$ & $0.026^{*}$ \\
\hline \multicolumn{4}{|l|}{ C-class of $\mathrm{CEAP}^{\dagger}, n(\%)$} \\
\hline $\mathrm{C}_{0}$ & $4(9.8)$ & $2(8.7)$ & 1.000 \\
\hline $\mathrm{C}_{1}$ & $5(12.2)$ & - & 0.152 \\
\hline $\mathrm{C}_{2}$ & $7(17.1)$ & - & $0.010^{*}$ \\
\hline $\mathrm{C}_{3}$ & $16(39.0)$ & $12(52.2)$ & 0.273 \\
\hline $\mathrm{C}_{4 \mathrm{a}}$ & $6(14.6)$ & $3(13.0)$ & 1.000 \\
\hline $\mathrm{C}_{4 \mathrm{~b}}$ & - & $2(8.7)$ & 0.137 \\
\hline $\mathrm{C}_{5}$ & $2(4.9)$ & $1(4.3)$ & 1.000 \\
\hline $\mathrm{C}_{6}$ & $1(2.4)$ & $3(13.0)$ & 0.123 \\
\hline
\end{tabular}

CEAP, Clinical-Etiology-Anatomy-Pathophysiology classification; DFV, deep femoral vein; FV, femoral vein. Plus-minus values are means with standard deviations.

*Statistically significant, ${ }^{\dagger}$ Unknown for one patient in the cranial group.

Table 9.2 Intervention details.

\begin{tabular}{llll}
\hline & Cranial $(n=42)$ & Caudal $(n=23)$ & $P$ \\
\hline Intervention type, $n(\%)$ & & & \\
Unilateral iliofemoral & $28(66.7)$ & $18(78.3)$ & 0.326 \\
$\quad$ Bilateral iliofemoral & $2(4.8)$ & - & 0.536 \\
Unilateral iliofemoral and IVC & $1(2.4)$ & $1(4.3)$ & 1.000 \\
$\quad$ Bilateral iliofemoral and IVC & $11(26.2)$ & $4(17.4)$ & 0.421 \\
Mean number of stented segments & $3.4 \pm 0.6$ (range, 3-5) & $2.8 \pm 0.7$ (range, 2-4) & $0.002^{*}$ \\
Patch, $n(\%)$ & $26(61.9)$ & $12(52.2)$ & 0.447 \\
PTFE size (5-mm / 6-mm), $n(\%)$ & $5 / 37(11.9 / 88.1)$ & $10 / 13(43.5 / 56.5)$ & $0.004^{*}$ \\
PTFE shape (loop / straight), $n(\%)$ & $41 / 1(97.6 / 2.4)$ & $14 / 9(60.9 / 39.1)$ & $<0.001^{*}$ \\
\hline
\end{tabular}

IVC, inferior vena cava; PTFE, polytetrafluoroethylene. Plus-minus values are means with standard deviations. *Statistically significant. 


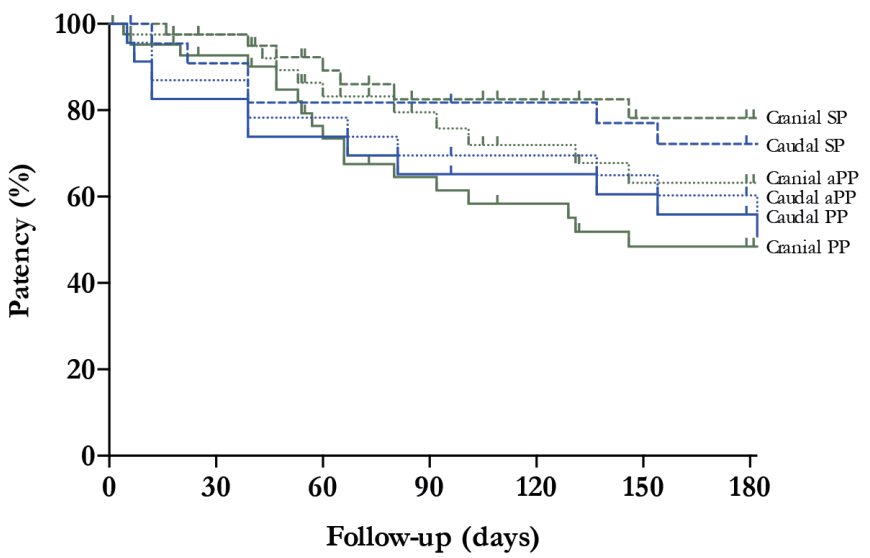

$\begin{array}{llllllll}\text { Number at risk } & & & & & & \\ \text { Cranial PP } & 42 & 37 & 26 & 22 & 19 & 15 & 14 \\ \text { Cranial aPP } & 42 & 37 & 27 & 22 & 18 & 15 & 14 \\ \text { Cranial SP } & 42 & 39 & 30 & 24 & 22 & 18 & 17 \\ \text { Caudal PP } & 23 & 21 & 19 & 16 & 15 & 14 & 12 \\ \text { Caudal aPP } & 23 & 22 & 20 & 17 & 16 & 15 & 13 \\ \text { Caudal SP } & 23 & 21 & 20 & 20 & 18 & 17 & 15\end{array}$

Figure 9.5 Kaplan-Meier survival analysis according to the different surgical groups.

$\mathrm{PP}$, primary patency; aPP, assisted primary patency; SP, secondary patency. SEM $<10$, except for PP and aPP in the caudal group (10.3 and 10.0 after 4 months, 10.5 and 10.3 after 5 months respectively).

failure of the endophlebectomy and eight left limbs of patients with bilateral AVF construction were excluded in order to be able to perform multiple logistic regression analysis. Anastomosis of a native vessel to the AFC was performed in two limbs, which were therefore excluded, leaving 65 limbs in 65 patients for analysis.

Two groups were created: patients with an AVF placed cranially in the endophlebectomy area (group 1, $n=42$ ) and patients with an AVF placed caudally in the endophlebectomy area (group 2, $n=23$ ) (Figures 9.3 and 9.4). Patient characteristics were comparable between the groups, except for post-thrombotic involvement of the DFV (54.8\% vs. $21.7 \%, P=0.010)$, postthrombotic involvement of both the FV and DFV (50.0\% vs. $21.7 \%, P=0.026)$, and number of $\mathrm{C}_{2}$-classified patients (CEAP classification, $17.1 \%$ vs. $0 \%, P=0.010$ ) (Table 9.1). Intervention details were also comparable, except mean number of stented segments (3.4 vs. 2.8, $P=0.002)$, PTFE size (88.1\% 6-mm vs. 56.5\%, $P=0.004)$ and PTFE shape (97.6\% loop vs. $60.9 \%$, $P<0.001$ ) (Table 9.2). Mean follow-up was $6.9 \pm 5.0$ months for group one compared with 17.8 \pm 8.6 months for group 2. During follow-up, problems with stent configuration such as tapering or kinking were found in five patients within the cranial group $(11.9 \%)$ compared with six in the caudal group $(26.1 \%, P=0.176)$.

At six months, primary patency was $48 \%$, assisted primary patency $63 \%$ and secondary patency $78 \%$ for the group who underwent the cranial technique. Primary patency was $56 \%$, assisted primary patency $60 \%$ and secondary patency $72 \%$ in the caudal group. This was not significantly different from group $1(P=0.616, P=0.683, P=0.894$ respectively) (Figure 9.5). 
Table 9.3 Odds ratios for patency of the recanalised tract.

\begin{tabular}{|c|c|c|c|c|}
\hline \multirow[b]{2}{*}{ Caudal compared with cranial AVF } & \multicolumn{2}{|c|}{ Any event (occlusion or stenosis) } & \multicolumn{2}{|c|}{ Occlusion } \\
\hline & 2.6 & $(95 \% \mathrm{CI}, 0.7-10.1)$ & 3.8 & $(95 \%$ CI, $0.8-18.5)$ \\
\hline Straight compared with loop shaped AVF & $-{ }^{*}$ & & 0.9 & $(95 \%$ CI, $0.1-13.6)$ \\
\hline 6-mm compared with 5-mm PTFE AVF & 0.3 & $(95 \% \mathrm{CI}, 0.1-1.5)$ & 0.3 & $(95 \% \mathrm{CI}, 0.0-1.9)$ \\
\hline Reduced femoral inflow ${ }^{\dagger}$ & $2.9^{\ddagger}$ & $(95 \% \mathrm{CI}, 1.1-7.5)$ & 3.4 & $(95 \%$ CI, $0.9-12.6)$ \\
\hline Patch compared with primary closure of venotomy & 0.9 & $(95 \% \mathrm{CI}, 0.3-2.8)$ & 0.9 & $(95 \% \mathrm{CI}, 0.2-3.8)$ \\
\hline Number of stented segments ${ }^{\S}$ & 1.8 & $(95 \% \mathrm{CI}, 0.7-4.5)$ & 2.8 & $(95 \%$ CI, 0.9-8.2) \\
\hline Problems with stent configuration & 1.1 & $(95 \%$ CI, 0.2-5.8) & $4.7^{\ddagger}$ & $(95 \%$ CI, $1.2-18.3)$ \\
\hline
\end{tabular}

Multiple logistic regression analysis for the risk of any patency-related event with correction for PTFE size, PTFE shape (loop or straight), reduced femoral inflow, type of venotomy closure, number of stented segments and stent complications did not yield a significant difference between the two surgical techniques. The odds ratio (OR) for the caudal technique was 2.6 (95\% CI, 0.7-10.1) as compared to the cranial technique. Only reduced femoral inflow was found to be predictive of patency-related problems with an OR of 2.9 (95\% CI, 1.1-7.5) per affected vein, i.e. DFV or FV (Table 9.3). PTFE shape showed collinearity with PTFE size in this regression model, thus only the latter variable was used for this analysis.

Multiple logistic regression analysis for the risk of occlusion did not show a statistically significant difference between the two surgical groups (OR, 3.8; 95\% CI, 0.8-18.5 for group 2) either. Based on backward likelihood ratio test analysis, all variables but for stent-related complications like kinking, compression and tapering could be removed from the model without changing it significantly. Stent-related complications were found to influence outcome significantly (OR, 4.7; 95\% CI, 1.2-18.3) (Table 9.3).

\section{Discussion}

Both risk of stenosis or occlusion and risk of occlusion alone were not significantly different between patients who received an AVF at the caudal end of the endophlebectomy and those who received one at the cranial end, yet a tendency in favour of the cranial technique is noted. Due to the many variables influencing patency, this study was most likely underpowered to prove a significant effect. The high OR for the caudal method might perhaps be explained by de novo intimal hyperplasia of the vein near the anastomosis of the AVF, which has been described before after vascular access surgery. ${ }^{12,13}$ If the AVF is placed caudally in the endophlebectomy area, it is conceivable that such intimal hyperplasia may encumber already poor femoral inflow and gradually lead to a stenosis or occlusion more easily. Conversely, a cranially placed AVF might lead to less stenosis or occlusion, because of the increased distance to the opposite vein wall. Impaired inflow as a result of intimal hyperplasia could cause occlusion of the complete stented tract. This would potentially add to the already impaired inflow due to FVs or DFVs with post-thrombotic lesions, as the risk of stenosis or occlusion was almost three times higher in patients with diseased FVs or DFVs compared with patients with healthy FVs/DFVs. This is not surprising since poor inflow is logically related to a higher risk of occlusion, as has been discussed in literature before.-11,14-16 
Closure with the use of a patch did not significantly affect outcome, which could have been anticipated since the patch was only used when the vein was considered too narrow for primary closure. A patch creates extra space to prevent stricture of the vein and thus does not limit inflow or outflow. Conversely, neither does primary closure necessarily constitute risk of occlusion, since the surgeon deemed the vein to be large enough for primary closure. PTFE size was not a factor influencing patency either. A certain amount of arterial inflow is needed to ensure proper stent inflow, thus it is likely that beyond such point any additional arterial inflow is irrelevant to safeguard patency. Both 5-mm and 6-mm AVFs are assumedly sufficient to reach that point, which is consistent with previous research. ${ }^{17}$ Since placing the PTFE in a loop or a straight did not influence results, it is apparently not relevant whether flow enters the vein in an antegrade or retrograde direction. Ostensibly, outflow of the lower limb does not seem to suffer under the initial different flow direction of the blood from the AVF.

Similarly, we did not find the number of stented segments to be of influence. However, given the distribution of the confidence interval and the amount of variables tested in relation to the amount of events, it is likely that this study was underpowered to properly test for such effects. Number of stented segments could be indirectly related to outcome, though, since it conveys extent of disease. Stent-related complications were found to be of significant influence, which is not surprising since complications such as kinking, residual compression and tapering impair optimal flow through the stented tract and thus contribute to risk of stent occlusion. This problem is probably addressed by new, dedicated venous stents. ${ }^{16}$

Additionally, continuous compression of the endophlebectomy area, due to low venous pressures inside the vein, after closure of the inguinal wound might also form an important problem in maintaining patency. Hence, measures to prevent collapse of the endophlebectomy area could be considered. An endovenous device preventing such collapse may perhaps improve patency rates in the future. Furthermore, instead of using an AVF, possibilities of developing less invasive techniques that can optimise flow within the treated tract during the first couple of weeks after treatment need also be explored.

Because of the retrospective nature of this study, some limitations have to be taken into account. First of all, we were not able to correct for post-operative anticoagulation since a separate institution in our region monitors and regulates this. However, we have a standard postoperative regimen to anticoagulate with coumarin for at least six months. In the initial phase after surgery, patients also receive therapeutic low molecular weight heparins (LMWH) until the international normalised ratio (INR) has reached its target ratio of 3.0-4.0. Afterwards, if the INR drops below 2.5, a single therapeutic dose of LMWH is again given daily, until the INR returns within its specified range. Furthermore, most patients were not tested for thrombophilia, thus we could not correct for such disease. Second, patient characteristics and specifications of the intervention were not always equally distributed over the two groups. Whilst PTFE size and shape might have had some minor impact, the number of stented segments showed a tendency in increased risk for occlusion and reduced femoral inflow had a significant influence on risk of stenosis. The skewed distribution of the latter two factors might therefore have contributed to the fact that we did not find a statistically significant difference in method of AVF placement. Third, not all variables were properly registered, leading to exclusion of two patients due to lack of perioperative details concerning the type of AVF. For all included patients, only one patient had a missing baseline C-score though. Finally, some bias may be present due to the chronologic nature of the study. When we started performing these hybrid procedures, we typically placed the AVFs caudally, after which a period came when both methods were used, followed by 
sole placement of the cranial AVFs. Therefore, confounding due to change in intensity of follow-up, improved experience and improvement of stent design could be present. However, no correction is possible for the first two and the different combinations of stent types used were too comprehensive for correction in this population. Conversely, we did correct for stent complications, which likely obviates any significant effects different types of stent might have had.

\section{Conclusions}

Placement of an AVF at the cranial end of the endophlebectomy during hybrid venous recanalisation may result in a more favourable outcome than placement at the caudal end of the endophlebectomy area, though this tendency was not yet shown to be statistically significant. Moreover, femoral inflow is found to be pivotal in maintaining patency. Hence, it is crucial to adequately assess the condition of inflow providing vessels before attempting recanalisation of the obstructed tract.

\section{References}

1. Neglen P, Hollis KC, Olivier J, Raju S. Stenting of the venous outflow in chronic venous disease: long-term stentrelated outcome, clinical, and hemodynamic result. J Vasc Surg 2007;46(5):979-90.

2. Lou WS, Gu JP, He X, et al. Endovascular treatment for iliac vein compression syndrome: a comparison between the presence and absence of secondary thrombosis. Korean J Radiol 2009;10(2):135-43.

3. Hartung O, Loundou AD, Barthelemy P, Arnoux D, Boufi M, Alimi YS. Endovascular management of chronic disabling ilio-caval obstructive lesions: long-term results. EurJ Vasc Endovasc Surg 2009;38(1):118-24.

4. de Wolf MAF, Arnoldussen CW, Grommes J, et al. Minimally invasive treatment of chronic iliofemoral venous occlusive disease. Journal of Vascular Surgery: Venous and Lymphatic Disorders 2013;1(2):146-53.

5. Neglen P, Tackett TP, Jr., Raju S. Venous stenting across the inguinal ligament. J Vasc Surg 2008;48(5):1255-61.

6. Comerota AJ, Grewal NK, Thakur S, Assi Z. Endovenectomy of the common femoral vein and intraoperative iliac vein recanalization for chronic iliofemoral venous occlusion. J V asc Surg 2010;52(1):243-7.

7. Puggioni A, Kistner RL, Eklof B, Lurie F. Surgical disobliteration of postthrombotic deep veins--endophlebectomy-is feasible. J Vasc Surg 2004;39(5):1048-52; discussion 52.

8. Garg N, Gloviczki P, Karimi KM, et al. Factors affecting outcome of open and hybrid reconstructions for nonmalignant obstruction of iliofemoral veins and inferior vena cava. J Vasc Surg 2011;53(2):383-93.

9. Vogel D, Comerota AJ, Al-Jabouri M, Assi ZI. Common femoral endovenectomy with iliocaval endoluminal recanalization improves symptoms and quality of life in patients with postthrombotic iliofemoral obstruction. $J$ Vasc Surg 2012;55(1):129-35.

10. Jost CJ, Gloviczki P, Cherry KJ, Jr., et al. Surgical reconstruction of iliofemoral veins and the inferior vena cava for nonmalignant occlusive disease. J Vasc Surg 2001;33(2):320-7; discussion 7-8.

11. Nazarian GK, Austin WR, Wegryn SA, et al. Venous recanalization by metallic stents after failure of balloon angioplasty or surgery: four-year experience. Cardiovasc Intervent Radiol 1996;19(4):227-33.

12. Allon M, Litovsky S, Young CJ, et al. Medial fibrosis, vascular calcification, intimal hyperplasia, and arteriovenous fistula maturation. Am J Kidney Dis 2011;58(3):437-43.

13. Roy-Chaudhury P, Arend L, Zhang J, et al. Neointimal hyperplasia in early arteriovenous fistula failure. Am J Kidney Dis 2007;50(5):782-90.

14. de Wolf MA, Arnoldussen CW, Wittens CH. Indications for endophlebectomy and/or arteriovenous fistula after stenting. Phlebology 2013;28 Suppl 1:123-8.

15. Rosales A, Sandbaek G, Jorgensen JJ. Stenting for chronic post-thrombotic vena cava and iliofemoral venous occlusions: mid-term patency and clinical outcome. Eur J Vasc Endovasc Surg 2010;40(2):234-40.

16. Jalaie H, Arnoldussen C, Barbati M, et al. What predicts outcome after recanalization of chronic venous obstruction: hemodynamic factors, stent geometry, patient selection, anticoagulation or other factors? Phlebology 2014;29(1 suppl):97-103.

17. Menawat SS, Gloviczki P, Mozes G, Whitley D, Anding WJ, Serry RD. Effect of a femoral arteriovenous fistula on lower extremity venous hemodynamics after femorocaval reconstruction. J Vasc Surg 1996;24(5):793-9. 



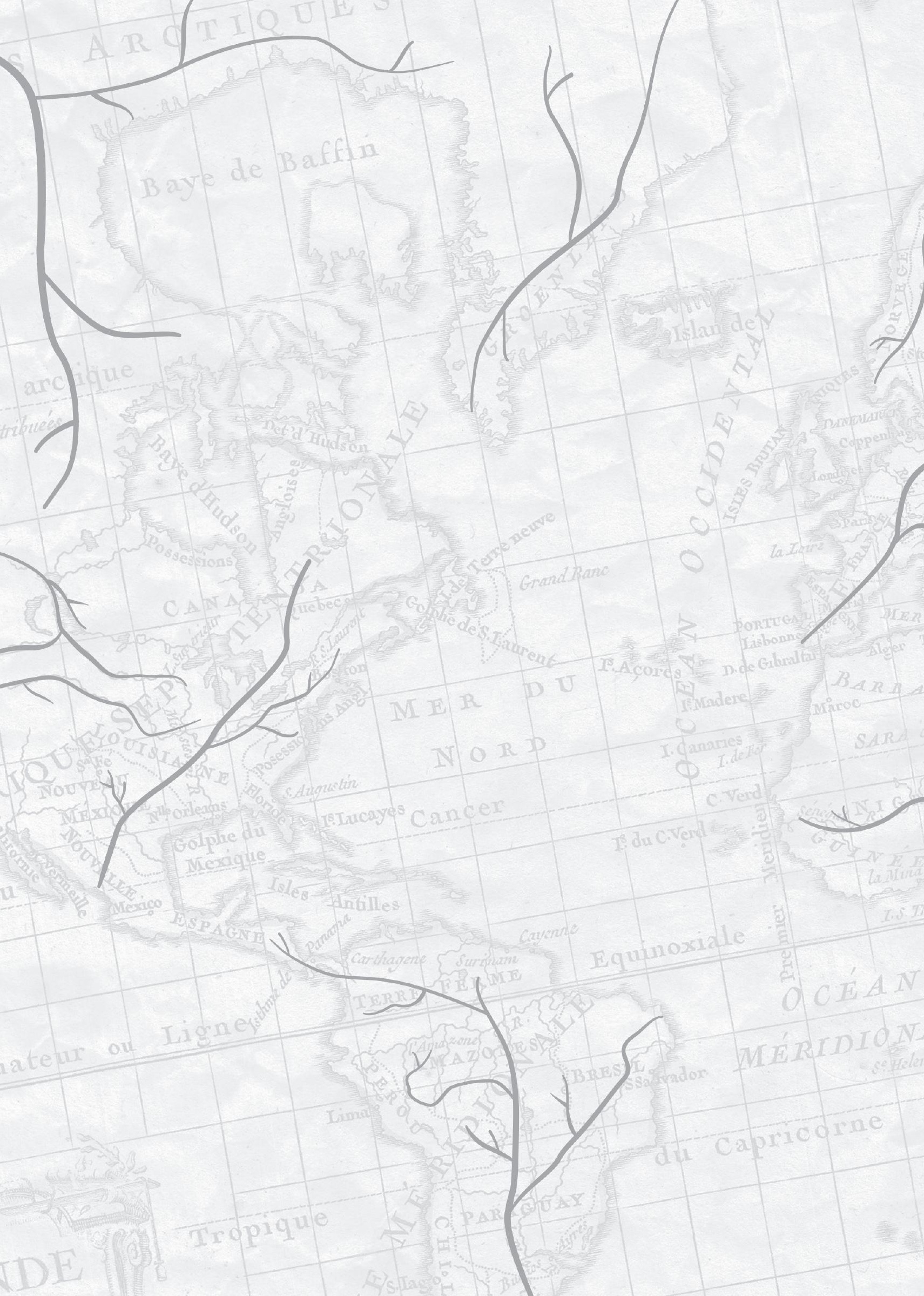




\section{CHAPTER 10}

General discussion 

The purpose of this thesis was to gain insight into the haemodynamic changes that occur as a result of deep venous obstruction. In order to successfully treat patients afflicted with this condition, one needs to have adequate knowledge of its effects and implications of proposed treatments. Interventional treatments appear to enjoy good technical ${ }^{1-4}$ and clinical success, which is reflected in improved venous severity scores ${ }^{1,2,5}$ and quality of life. ${ }^{2,6}$ However, evidence is of limited quality, ${ }^{3,4}$ and more insight is warranted. Moreover, a relevant number of patients show little to no symptomatic improvement, ${ }^{7}$ often despite technically successful interventions with patent stents during follow-up. Thus, better patient selection is necessary in order to determine which patients will benefit from interventional treatment, and endeavours should be made to unveil why some patients do not.

\section{What we know...}

Chapter two illustrates what little knowledge we currently possess regarding the influence of fundamental haemodynamic changes on the outcome of interventional treatment for deep venous obstruction. Although venous stenting has been performed for about two decades, ${ }^{8}$ and bypass surgery even longer, ${ }^{9}$ it seems that beneficial effects have been accepted without properly investigating haemodynamic consequences. The literature search flowcharts in chapter two make this abundantly clear. The systematic search on the predictive value of haemodynamic measurements for the efficacy of post-thrombotic obstruction treatment yielded 4,306 results; as few as four could ultimately be included in our review, one of which resulted from this thesis. Granted, the searches were intentionally broad to avoid missing valuable publications. Results of the literature search concerning non-thrombotic iliac vein compression were even more dismal: only one study out of 1,463 hits could be included. What is more, this one study did not distinguish aetiology of obstruction, necessary for the primary outcome measure of the systematic review.

The studies that could be included proved to be of limited quality. All showed a significant risk of attrition bias because of the lack of a control group, and possible confounding factors were often poorly described. Furthermore, two of the studies had a high bias risk because of the outcome measure they used. The study by Neglén et al. ${ }^{2}$ categorised stented limbs into "healing" and "nonhealing", yet did not specify either definition. AbuRahma et al. ${ }^{10}$ focused on outcome prediction of bypass surgery, yet used changes in their investigated haemodynamic parameters as part of their primary outcome measure. Consequently, correlation between the parameters and outcome is a given and does not establish clinical usefulness of those same haemodynamic parameters.

Plethysmography was used to assess haemodynamic properties in three of the four included studies. AbuRahma et al. ${ }^{10}$ found an association between strain-gauge plethysmography and clinical success after bypass surgery, which should not be taken into consideration given the aforementioned bias in outcome measure. Outflow tests using impedance ${ }^{11}$ and air plethysmography ${ }^{2}$ were not identified as potential predictors for outcome of bypass surgery or stenting. The venous filling index, an air plethysmography parameter validated for use in venous incompetence, did, however, show an association between healing of limbs in the Neglén study. ${ }^{2}$ The lack of definition for their outcome measure unfortunately renders it unclear whether this association was found in both post-thrombotic and non-thrombotic obstruction, as baseline venous filling index was higher for post-thrombotic limbs. Furthermore, results may have been confounded by the presence of deep vein incompetence as a result of post-thrombotic valve damage. The latter hypothesis finds substantiation in the fact that the venous filling index did 
not improve after stenting without additional interventions for incompetence. ${ }^{2}$

Pressure-derived parameters were also frequently investigated with respect to treatment of obstruction. However, the parameters used are usually applied to measure venous incompetence. Although a drop in dorsal foot vein pressure after ten tiptoe movements and venous filling time were associated with "healing" of limbs, confounding due to venous incompetence is likely. Since the obstructive component eligible for treatment is more centrally located, common femoral vein (CFV) pressures should yield more interesting results in these types of patients. Glovickzi et al. ${ }^{11}$ investigated whether femoral-central pressure gradients can predict outcome of bypass surgery, but did not find statistically significant differences. Nevertheless, median pressure gradient at baseline was $16 \mathrm{mmHg}$ (5-27) for patients with excellent clinical outcome compared with $8 \mathrm{mmHg}$ (4-17) for patients with no clinical improvement. No definitive conclusions can be drawn given the small sample size and lack of details on statistical analysis.

The systematic review did not identify any studies investigating the importance of collateral circulation and only one that investigated a derivative parameter for inflow of the treated vein tract. ${ }^{12}$ Nonetheless, these parameters are thought to be of influence with respect to both clinical and technical outcome. ${ }^{13-16}$ Since the aforementioned study resulted from this thesis, it will be discussed later.

\section{Volumetric changes}

In chapters three and four air plethysmography (APG) was investigated. Using an airinflated cuff around the calf, this apparatus can detect minor changes in calf circumference corresponding with volumetric changes. APG has been frequently used in the past to test for deep and superficial incompetence. ${ }^{17,18}$ It was described to be also useful in patients with deep venous obstruction, ${ }^{19,20}$ yet several studies did not show favourable results. ${ }^{21-24}$ Despite this unclarity, APG is still being referred to in guidelines and consensus documents. ${ }^{18,25}$ Therefore, we aimed to determine its value in deep venous obstruction.

In chapter three we started by using APG parameters as described and recommended in literature. ${ }^{25,26}$ Since it is generally accepted that obstructions distal to the femoral confluence should not be stented, we focused on those proximal to the femoral confluence. When maintaining the cut-off value for severe obstruction, specificity was $98 \%$ and positive predictive value $92 \%$, whereas sensitivity was a mere $7 \%$ and negative predictive value only $32 \%$. By enforcing the least strict cut-off value, sensitivity and negative predictive value increased to $29 \%$ and $35 \%$ respectively, still resulting in a poor diagnostic value.

Although specificity and positive predictive value are good, the combination with a poor sensitivity leads to numerous false negatives. This is reflected in the low negative predictive value. However, that is precisely where the strength of APG should lie. Its potential benefit would be to determine which patients do not meet the criteria for additional imaging or, in a primary care setting, referral. With this combination of specificity and sensitivity, positive results likely identify actual obstruction, and patients will therefore undergo additional imaging to identify whether the obstruction is treatable. On the other hand, given the poor negative predictive value, patients with a negative APG examination will follow the exact same course as those with a positive examination in order to establish whether obstruction is truly not present.

On top of that, patient complaints did not influence diagnostic properties. It is therefore not likely that a discrepancy between pathology on imaging and actual haemodynamic severity of obstruction played a role in the low diagnostic abilities of APG. This is substantiated by several 
studies that identified high outflow fractions in patients with symptomatic obstruction. ${ }^{21-24}$ Lack of agreement with the positive findings of Labropoulos et al. ${ }^{20}$ may be explained by their relatively small sample size, which is reflected in the markedly large standard deviations for outflow fraction. Incongruity with Kalodiki et al. ${ }^{19}$ is more difficult to explain. Their sample size was considerable (96 post-thrombotic obstructions), yet still smaller than the one of this thesis (207 post-thrombotic obstructions). Kalodiki et al. ${ }^{19}$ used venography, which is considered the gold standard, whereas we used a combination of duplex ultrasound and magnetic resonance venography. Although the latter combination is not considered the gold standard, studies have shown these modalities to be effective in identifying deep venous obstruction. ${ }^{27-29}$ Our population could have suffered from less vessel wall fibrosis, which can lead to superior elastic recoil properties and therefore higher outflow fractions, thus explaining the discrepancy. ${ }^{23,30}$ Lack of agreement with Lattimer et al..$^{23}$ could be explained by the fact that a quarter of their patients were analysed within three weeks following deep vein thrombosis, and therefore the use of APG in chronic venous obstruction was not truly assessed.

Chapter four assessed whether the relative nature of the outflow fraction test could be an explanation for the negative results detailed in the prior chapter. For example, pre-existent oedema could theoretically lead to only a minor increase in lower leg volume after inflation of the proximal cuff. This cuff compresses the veins and thus stops venous outflow from the lower limb whilst still enabling arterial inflow. Due to the sudden release of pressure after deflation of the cuff and the theoretically minor increase in calf volume, initial expulsion of the collected volume might be distortedly high. However, analysis of absolute volume changes did not yield favourable results in identifying deep venous obstruction, nor were we able to find a more appropriate cut-off value for the outflow fraction. Areas under the receiver operated characteristic curves did not surpass 0.71 for outflow at one second, 0.69 for total venous volume or 0.59 for outflow fraction.

Since the ultimate goal is to identify which patients will benefit from treatment, we also evaluated how accurately parameters of the APG outflow test could discriminate between patients for whom one-year clinical success was recorded after stenting and those for whom it was not. This analysis did not prove to be fruitful either: areas under the receiver operated characteristic curves for discriminating between successful and unsuccessful treatment were 0.57 for onesecond outflow volume, 0.54 for total venous volume and 0.63 for the relative outflow fraction. However, sample size for these analyses was small: only $45 \%$ of treated patients had a valid quality of life measurement before and after treatment, possibly introducing bias. It is likely that too many factors influence clinical success for APG to have a meaningful predictive value, especially given the possible residual pathology between point of measurement and location of stenting.

\section{Collateral circulation}

Numerous speculations have been made with respect to the importance of collateral circulation in chronic deep venous obstruction, ${ }^{13-16}$ yet no attempts were made to investigate its relevance. The aim of chapters five and six of this thesis was to obtain more insight into the importance of collateral circulation.

Although most collateral pathways are hidden deep in the body, ${ }^{31-33}$ some can be seen with the naked eye, ${ }^{34}$ notably those on the abdominal wall or over the pubic area. The presence of iliocaval obstruction in patients with this sign has been alluded to in the past, ${ }^{34}$ though no 
investigations were made into its diagnostic value. Chapter five determined that the positive predictive value of such a vein for the presence of deep venous obstruction proximal to the femoral confluence is excellent (93\%). However, although specificity was acceptable at $86 \%$, sensitivity and negative predictive value were poor (respectively $53 \%$ and $32 \%$ ).

Selection bias may be present as patients were all referred to our outpatient clinic with signs that might represent deep venous obstruction: mainly a history of deep vein thrombosis, venous claudication and quickly recurrent varicose veins. Therefore, other factors such as portal hypertension ${ }^{35}$ or gynaecological abnormalities leading to more pronounced pelvic veins $^{31}$ should still be considered in a more general population. In this retrospective analysis we encountered some patients who presented with an abdominal wall collateral vein, but for whom no obstruction was found. This might be explained by misclassification of labial or scrotal varicosities, succinct reporting not always being clear on whether a collateral vein runs across the pubic bone or the labia. On the other hand, a pelvic congestion component could be of influence since this condition is poorly understood with no clearly defined abnormalities that should be present during imaging. ${ }^{36-39}$

Given the diagnostic qualities of this sign, it should not be used to exclude the possibility of venous obstruction. However, in the presence of such a collateral vein referral to a vascular surgeon for further analysis is warranted because of its high positive predictive value. This sign is easily and non-invasively identifiable, and could therefore be readily incorporated into the routine physical examination of patients presenting with lower limb complaints that could conceivably be of venous origin. Moreover, one should not be tempted to remove such a collateral vein for cosmetic reasons, since collateral veins can have an important function in sustaining outflow of the lower limb as was demonstrated in chapter six.

In that chapter we compared the effects of no obstruction, chronic obstruction and acute obstruction as measured by CFV pressures. We found that pressure was significantly higher in limbs affected by post-thrombotic obstruction (median CFV pressure, $17.0 \mathrm{mmHg}$; range, 4.0-31.0) as compared to in healthy control limbs (median CFV pressure, $12.8 \mathrm{mmHg}$; range, 2.0-24.0). However, pressure after a sudden balloon occlusion of the external iliac vein in healthy control limbs was even higher, with a median of $23.5 \mathrm{mmHg}$ (range, 7.0-66.0). The importance of collateral circulation may be explained by the fact that pressure is significantly lower in chronic obstruction than in acute obstruction. The process of recanalisation could, theoretically, also explain a reduction in pressure, though this is unlikely since all but for two patients suffered from a (near) occlusion. Sub-analysis excluding the two patients with partial recanalisation still yielded a significant pressure difference between chronic and acute states. Therefore, recanalisation cannot be the sole explanation for this reduction in pressure over time.

The observation that collateral circulation can reduce venous pressure through improvement of overall lower limb outflow is further exemplified by one of the control cases. When we checked whether the balloon achieved complete obstruction in the healthy limb, an ipsilateral collateral vein was observed on venogram. This collateral vein went right around the balloon and was confirmed with imaging in the lateral plane. Strikingly, CFV pressure in this limb increased from $1.0 \mathrm{mmHg}$ at the moment right before occlusion to only $7.0 \mathrm{mmHg}$ after occlusion.

It is important to note that these measurements were carried out in the supine position with the patient under general anaesthesia. Chapter seven demonstrated that pressures can vastly increase during exercise, thus differences between obstructed limbs with and obstructed limbs without collateralisation are likely more profound during exercise. The development of a network of collateral circulation could explain why some patients with extensive obstruction have little to 
no complaints, whereas others with a minor obstructive component can demonstrate debilitating complaints. To that end, a method of quantifying the influence of collateral circulation could help in establishing which patients are in need of treatment.

\section{Intravenous pressures}

Little effort has been made to establish how venous pressure changes in the presence of a deep venous obstruction, nor is it known what abolishing this obstruction can achieve. Both issues were addressed in this thesis, the former in chapter seven and the latter in chapter eight.

Chapter seven established that pressure in the CFV of limbs with post-thrombotic iliofemoral obstruction is higher than in control limbs, and that this pressure significantly increases during ambulation. In the supine position, mean pressure difference between obstructed and control limbs is only $2.8 \mathrm{mmHg}$, as opposed to $15.4 \mathrm{mmHg}$ when resting in an erect position. The most notable differences, however, were observed during exercise. Mean pressure build-up during ambulation was $28.1 \mathrm{mmHg}$ in limbs with obstruction as compared to $2.1 \mathrm{mmHg}$ in healthy control limbs.

To our knowledge, this is the first study measuring pressures during actual ambulation in such a population. Some studies did measure CFV pressures in the supine position and found somewhat lower pressures. ${ }^{15,40}$ However, these studies were performed under general anaesthesia, ${ }^{41}$ during which pressures were also lower in our population. In addition, these studies did not compare affected limbs with control limbs, except for Negus et al. ${ }^{42}$ who found differences between affected and non-affected limbs similar to ours.

Dorsal foot vein pressures have been investigated more extensively in the past, specifically with respect to venous incompetence. In this thesis, overall differences between obstructed and control limbs were less evident for dorsal foot vein pressures. Instead of a steady increase of pressure over time, dorsal foot vein pressures demonstrated an initial steep drop when the participant commenced walking, followed by a gradual increase. This is an important observation as other studies have used a pseudo-ambulatory state of ten tiptoe movements, which yielded different results than the actual ambulation practiced in this thesis. Although affected limbs demonstrated $11.9 \mathrm{mmHg}$ less net pressure drop during ambulation than control limbs, this did not reach statistical significance. Kolbach et al. ${ }^{43}$ did find a statistical difference between limbs with a history of deep vein thrombosis and those without in their investigation of pressure changes following ten tiptoe movements. However, no imaging was performed to test for residual obstruction or incompetence, and the level of the initial thrombus was not reported. It is therefore probable that the population studied by Kolbach et al. ${ }^{43}$ is considerably different, with a large amount of patients suffering from deep vein incompetence due to valve damage, which is known to cause venous hypertension at the level of the dorsal foot vein. ${ }^{44,45}$

The superiority of CFV measurements during ambulation as compared to those in the dorsal foot vein were also illustrated by an excellent area under the receiver operated characteristic curve (CFV, 0.94; dorsal foot vein, 0.57). CFV pressure increase could possibly lead to elevated intramuscular pressure ${ }^{46}$ and explain the debilitating complaints of venous claudication.

Three months after stenting, CFV pressure build-up during walking was decreased by 22.3 $\mathrm{mmHg}$ in obstructed limbs compared with a $4.0 \mathrm{mmHg}$ increase in control limbs. Other studies have only shown improvement in CFV pressure in the supine position. ${ }^{40,47}$ Those findings are comparable to what is established in chapter eight, even though pressures were measured during intervention without comparison to a control limb. In this thesis no effect of treatment 
was observed for dorsal foot vein pressure, though it should be noted that ambulatory dorsal foot vein pressure did not show a statistically significant difference between affected and nonaffected limbs at baseline either. Neglén et al. ${ }^{2}$ did find a minor improvement in dorsal foot vein pressure drop after ten tiptoe movements in patients who did not suffer from incompetence in a larger population, yet did not compare this effect to control limbs.

One of the more important observations of this thesis is the significant association between reduction in CFV pressure build-up and improvement in quality of life after stenting, implying a causal link, likely due to an improvement in overall action radius, i.e. a reduction in venous claudication. These data thus support the use of stenting on a haemodynamic level.

Ideally, this thesis would have identified an indicator that evinces a haemodynamically significant obstruction. Unfortunately, no significant association was found between CFV pressure buildup at baseline and improvement of quality of life after stenting. Howbeit, the study was not designed to assess this relation and its sample size was likely too small, which was partly exacerbated by missing data due to difficulties in pressure measurements. Future studies should investigate the predictive effects of these pressure measurements, particularly in patients with partial obstruction or non-thrombotic iliac vein compression, and focus on the interaction between pressure build-up during exercise and baseline pressure. Theoretically, a higher resting pressure could be indicative of pre-existent vasodilatation of the arterioles, resulting in less capacity for further vasodilatation and thus a relatively minor pressure build-up during walking. In other words, focusing on pressure build-up alone could prove to be short-sighted and may result in erroneous data interpretation. For patients with non-thrombotic compression, postural changes must also be borne in mind. A clinically relevant iliac vein compression is difficult to diagnose, and whilst investigations in the supine position might not uncover a significant compression, investigations in certain other positions might elicit a positive diagnosis after all.

\section{Importance of inflow}

In certain cases, stenting alone does not appear to be sufficient in order to maintain patency. If the confluence of the femoral vein and deep femoral vein is severely affected with postthrombotic obstruction and no proper landing zone can be found within the CFV, stents will almost certainly occlude. To improve flow into the stented tract a desobstruction, or endophlebectomy, of the CFV and the orifices of its tributaries can be performed. However, in spite of proper anticoagulation to counteract increased thrombogenicity, occlusion can still occur. To avoid such an occlusion an arteriovenous fistula is created, generating a higher flow velocity in a low-flow environment. ${ }^{14}$

In chapter nine this thesis describes a study investigating two techniques of arteriovenous fistula creation: placing the venous anastomosis distal in the endophlebectomy area right above the femoral confluence (caudal group), and placing it proximal in the endophlebectomy area right below the stents (cranial group). We were not able to demonstrate statistically significant differences between the two groups, which could be attributed to the small sample size of this retrospective study. Nevertheless, the caudal group tended to demonstrate a higher risk of stent occlusion (odds ratio 3.8; 95\% confidence interval, 0.8-18.5). This difference may be explained by the occurrence of de novo intimal hyperplasia of the vein segment near the anastomosis of the arteriovenous fistula, which is a well-known complication in vascular access surgery. ${ }^{48,49}$ Hyperplasia at this location could encumber femoral inflow more easily in an already dismal environment. 
The more important observation made in chapter nine is that patients with reduced femoral inflow have a higher risk of developing a stenosis or occlusion (odds ratio 2.9 per inflow vessel). Reduced femoral inflow was defined as a post-thrombotic femoral and/or deep femoral vein. Although post-thrombotic state does not directly attest to poor flow, obstruction will lead to reduced flow in the femoral and deep femoral veins and thus a smaller flow volume supplied to the CFV. Given the high odds ratio per vein, this thesis illustrates that inflow is of the utmost importance in maintaining stent patency.

Whilst the post-thrombotic state of inflow vessels could be used as a surrogate measure to identify precarious inflow, a more direct and quantitative measure is preferred. However, no proper techniques to assess flow in these types of vessels are currently available. Future research should therefore focus on finding an adequate technique that can quantify venous outflow, which would allow a tailored treatment approach for each patient. Moreover, flow might not only be pertinent to technical success, but could perhaps also be used to identify clinical success based on preferential flow patterns.

\section{What next?}

This thesis partly filled the chasm that is our knowledge of the haemodynamics of deep venous obstruction and its abolishment. First, we established that air plethysmography is a technique illsuited for use in daily clinical practice. Barring the evaluation of a new test in a research setting, it is not recommended for the analysis of deep venous obstruction. Second, we identified the presence of a collateral vein on the abdominal wall or over the pubic bone as a red flag. The abdominal region should be routinely inspected in patients with lower limb complaints that might be of venous origin. When positive, this sign should evoke restraint with respect to treating superficial venous reflux and stimulate referral to a vascular surgeon for analysis of the deep venous system. Third, we determined that collateral circulation has an important role in the natural response to chronic venous obstruction. Future studies should pursue to develop a method that can quantify this collateral circulation in order to ascertain which patients will benefit from interventional treatment and which will not. Fourth, we established the detrimental effects of iliofemoral deep venous obstruction on ambulatory hypertension of the common femoral vein and its relation to venous claudication. Fifth, we revealed that stenting significantly reduces this ambulatory venous hypertension, which correlates with improvement in quality of life. Future studies should determine whether common femoral vein pressure can predict clinical success of stenting, particularly in patients with partial obstruction or non-thrombotic iliac vein compression. Finally, we recognised the importance of inflow with respect to technical outcome of stenting. It may also be of influence on clinical outcome as it is possibly related to a preferred course of flow. Therefore, better methods of quantifying flow should be identified in these types of patients.

All in all, resistance of the obstruction in question is the factor we ultimately want to define. As severity of resistance is a quotient of pressure difference and flow, the answer to how patients should be selected is likely not a one-size-fits-all solution. Future research should aim to establish an algorithm containing factors associated with flow and pressure in order to come to a tailored treatment for deep venous obstruction. 


\section{References}

1. de Wolf MA, de Graaf R, Kurstjens RL, Penninx S, Jalaie H, Wittens CH. Short-Term Clinical Experience with a Dedicated Venous Nitinol Stent: Initial Results with the Sinus-Venous Stent. Eur J Vasc Endovasc Surg 2015;50(4):518-26.

2. Neglen P, Hollis KC, Olivier J, Raju S. Stenting of the venous outflow in chronic venous disease: long-term stentrelated outcome, clinical, and hemodynamic result. J V asc Surg 2007;46(5):979-90.

3. Seager MJ, Busuttil A, Dharmarajah B, Davies AH. Editor's Choice - A Systematic Review of Endovenous Stenting in Chronic Venous Disease Secondary to Iliac Vein Obstruction. Eur J Vasc Endovasc Surg 2016;51(1):100-20.

4. Wen-da W, Yu Z, Yue-Xin C. Stenting for chronic obstructive venous disease: A current comprehensive metaanalysis and systematic review. Phlebology 2015;31(6):376-89.

5. Yin M, Shi H, Ye K, et al. Clinical Assessment of Endovascular Stenting Compared with Compression Therapy Alone in Post-thrombotic Patients with Iliofemoral Obstruction. Eur J Vasc Endovasc Surg 2015;50(1):101-7.

6. Catarinella FS, Nieman FH, de Wolf MA, Toonder IM, de Graaf R, Wittens CH. Quality-of-life in interventionally treated patients with post-thrombotic syndrome. Phlebology 2015;30(1 Suppl):89-94.

7. de Wolf MAF, Arnoldussen CW, Grommes J, et al. Minimally invasive treatment of chronic iliofemoral venous occlusive disease. Journal of Vascular Surgery: Venous and Lymphatic Disorders 2013;1(2):146-53.

8. Nazarian GK, Austin WR, Wegryn SA, et al. Venous recanalization by metallic stents after failure of balloon angioplasty or surgery: four-year experience. Cardiovasc Intervent Radiol 1996;19(4):227-33.

9. Palma EC, Esperon R. Vein transplants and grafts in the surgical treatment of the postphlebitic syndrome. $J$ Cardiovasc Surg (Torino) 1960;1:94-107.

10. AbuRahma AF, Robinson PA, Boland JP. Clinical, hemodynamic, and anatomic predictors of long-term outcome of lower extremity venovenous bypasses. J Vasc Surg 1991;14(5):635-44.

11. Gloviczki P, Pairolero PC, Toomey BJ, et al. Reconstruction of large veins for nonmalignant venous occlusive disease. J Vasc Surg 1992;16(5):750-61.

12. Kurstjens RL, de Graaf R, Barbati ME, et al. Arteriovenous fistula geometry in hybrid recanalisation of postthrombotic venous obstruction. Phlebology 2015;30(1 Suppl):42-9.

13. Jalaie H, Arnoldussen C, Barbati M, et al. What predicts outcome after recanalization of chronic venous obstruction: hemodynamic factors, stent geometry, patient selection, anticoagulation or other factors? Phlebology 2014;29(1 suppl):97-103.

14. de Wolf MA, Arnoldussen CW, Wittens CH. Indications for endophlebectomy and/or arteriovenous fistula after stenting. Phlebology 2013;28 Suppl 1:123-8.

15. Neglen P, Berry MA, Raju S. Endovascular surgery in the treatment of chronic primary and post-thrombotic iliac vein obstruction. Eur J Vasc Endovasc Surg 2000;20(6):560-71.

16. Neglen P, Raju S. Balloon dilation and stenting of chronic iliac vein obstruction: technical aspects and early clinical outcome. J Endovasc Ther 2000;7(2):79-91.

17. Christopoulos D, Nicolaides AN, Szendro G. Venous reflux: quantification and correlation with the clinical severity of chronic venous disease. BrJ Surg 1988;75(4):352-6.

18. Lee BB, Nicolaides AN, Myers K, et al. Venous hemodynamic changes in lower limb venous disease: the UIP consensus according to scientific evidence. Int Angiol 2016;35(3):236-352.

19. Kalodiki E, Calahoras LS, Delis KT, Zouzias CP, Nicolaides AN. Air plethysmography: the answer in detecting past deep venous thrombosis. J Vasc Surg 2001;33(4):715-20.

20. Labropoulos N, Volteas N, Leon M, et al. The role of venous outflow obstruction in patients with chronic venous dysfunction. Arch Surg 1997;132(1):46-51.

21. Delis KT, Bountouroglou D, Mansfield AO. Venous claudication in iliofemoral thrombosis: long-term effects on venous hemodynamics, clinical status, and quality of life. Ann Surg 2004;239(1):118-26.

22. Hurst DR, Forauer AR, Bloom JR, Greenfield LJ, Wakefield TW, Williams DM. Diagnosis and endovascular treatment of iliocaval compression syndrome. J Vasc Surg 2001;34(1):106-13.

23. Lattimer CR, Geroulakos G, Kalodiki E. Calf volume changes with venous occlusion air plethysmography in assessment of patients after deep venous thrombosis. Journal of Vascular Surgery: Venous and Lymphatic Disorders 2014;2(4):416-23.

24. Raju S, Kirk O, Davis M, Olivier J. Hemodynamics of “critical” venous stenosis and stent treatment. Journal of Vascular Surgery: Venous and Lymphatic Disorders 2014;2(1):52-9.

25. Nicolaides AN. Investigation of chronic venous insufficiency: A consensus statement (France, March 5-9, 1997). Circulation 2000;102(20):E126-63.

26. ACI Medical. APG Air-Plethysmograph Models APG-1000C and APG-1000CP Instruction and Service Manual. San Marcos, CA, USA; 1990. 
27. Arnoldussen CW, de Graaf R, Wittens CH, de Haan MW. Value of magnetic resonance venography and computed tomographic venography in lower extremity chronic venous disease. Phlebology 2013;28 Suppl 1:169-75.

28. Labropoulos N, Borge M, Pierce K, Pappas PJ. Criteria for defining significant central vein stenosis with duplex ultrasound. J Vasc Surg 2007;46(1):101-7.

29. Fraser DG, Moody AR, Morgan PS, Martel A. Iliac compression syndrome and recanalization of femoropopliteal and iliac venous thrombosis: a prospective study with magnetic resonance venography. J Vasc Surg 2004;40(4):6129.

30. Lattimer CR, Kalodiki E, Kafeza M, Azzam M, Geroulakos G. Quantifying the degree graduated elastic compression stockings enhance venous emptying. Eur J Vasc Endovasc Surg 2014;47(1):75-80.

31. Umeoka S, Koyama T, Togashi K, Kobayashi H, Akuta K. Vascular dilatation in the pelvis: identification with CT and MR imaging. Radiographics 2004;24(1):193-208.

32. Thomas ML, Fletcher EW, Cockett FB, Negus D. Venous collaterals in external and common iliac vein obstruction. Clin Radiol 1967;18(4):403-11.

33. Arnoldussen CW, Toonder I, Wittens CH. A novel scoring system for lower-extremity venous pathology analysed using magnetic resonance venography and duplex ultrasound. Phlebology 2012;27 Suppl 1:163-70.

34. Wittens $\mathrm{CH}$, Bukkems SF, Toonder IT. Abdominal wall venous collaterals: the latent clinical sign for central chronic venous obstruction. Circulation 2010;122(20):2089-90.

35. Pillai AK, Andring B, Patel A, Trimmer C, Kalva SP. Portal hypertension: a review of portosystemic collateral pathways and endovascular interventions. Clin Radiol 2015;70(10):1047-59.

36. Borghi C, Dell'Atti L. Pelvic congestion syndrome: the current state of the literature. Arch Gynecol Obstet 2016;293(2):291-301.

37. Hobbs JT. The pelvic congestion syndrome. Br J Hosp Med 1990;43(3):200-6.

38. Williams RE, Hartmann KE, Steege JF. Documenting the current definitions of chronic pelvic pain: implications for research. Obstet Gynecol 2004;103(4):686-91.

39. Tu FF, Hahn D, Steege JF. Pelvic congestion syndrome-associated pelvic pain: a systematic review of diagnosis and management. Obstet Gynecol Surv 2010;65(5):332-40.

40. Delis KT, Bjarnason H, Wennberg PW, Rooke TW, Gloviczki P. Successful iliac vein and inferior vena cava stenting ameliorates venous claudication and improves venous outflow, calf muscle pump function, and clinical status in post-thrombotic syndrome. Ann Surg 2007;245(1):130-9.

41. Delis KT, Knaggs AL, Mason P, Macleod KG. Effects of epidural-and-general anesthesia combined versus general anesthesia alone on the venous hemodynamics of the lower limb. A randomized study. Thromb Haemost 2004;92(5):1003-11.

42. Negus D, Cockett FB. Femoral vein pressures in post-phlebitic iliac vein obstruction. BrJ Surg 1967;54(6):522-5.

43. Kolbach DN, Neumann HA, Prins MH. Definition of the post-thrombotic syndrome, differences between existing classifications. Eur J Vasc Endovasc Surg 2005;30(4):404-14.

44. Nicolaides AN, Hussein MK, Szendro G, Christopoulos D, Vasdekis S, Clarke H. The relation of venous ulceration with ambulatory venous pressure measurements. J Vasc Surg 1993;17(2):414-9.

45. Nicolaides AN, Zukowski AJ. The value of dynamic venous pressure measurements. World J Surg 1986;10(6):91924.

46. Gemayel G CJ. Tissue Pressures in Venous Disease. Phlebology 2010;25(6):301.

47. Kurklinsky AK, Bjarnason H, Friese JL, et al. Outcomes of venoplasty with stent placement for chronic thrombosis of the iliac and femoral veins: single-center experience. J Vasc Interv Radiol 2012;23(8):1009-15.

48. Allon M, Litovsky S, Young CJ, et al. Medial fibrosis, vascular calcification, intimal hyperplasia, and arteriovenous fistula maturation. Am J Kidney Dis 2011;58(3):437-43.

49. Roy-Chaudhury P, Arend L, Zhang J, et al. Neointimal hyperplasia in early arteriovenous fistula failure. Am J Kidney Dis 2007;50(5):782-90. 


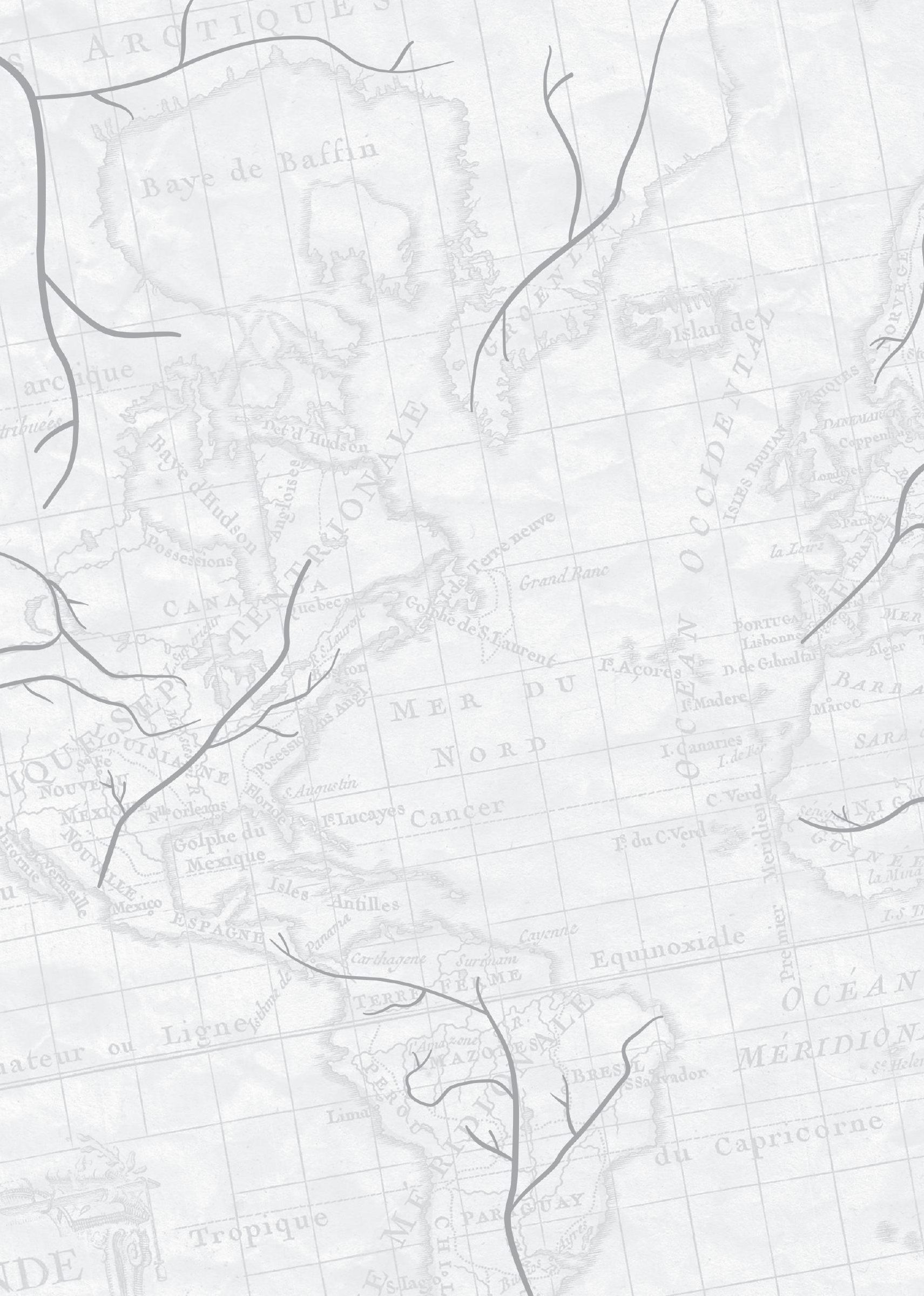




\title{
Addenda
}

\author{
Summary \\ Nederlandse samenvatting \\ Valorisation addendum \\ Dankwoord \\ Curriculum Vitae \\ List of publications
}





\section{Summary}

The aim of this thesis was to investigate haemodynamic consequences of deep venous obstruction and its treatment. The most common causes of deep venous obstruction are postthrombotic changes, as a result of inadequate recanalisation after deep vein thrombosis, and compression by the overlying arteries. Such obstructions can cause debilitating complaints if not recognised and treated effectively. During the last decades, stenting of deep venous obstruction has emerged as a favourable treatment, despite the limited quality of evidence supporting this treatment and scant haemodynamic knowledge. Moreover, some patients do not show clinical improvement, even after technical success. This thesis addresses several aspects concerning the haemodynamic changes following deep venous obstruction and implications for treatment, as well as points of reference for further research into proper patient selection.

Chapter two contains a systematic review assessing current knowledge on the predictive value of haemodynamic parameters for outcome of deep venous reconstruction. Information on this subject is scarce; only four relevant publications were found. Of the methods to derive haemodynamic parameters plethysmography was investigated most, yet with varying results. One study found a significant association between plethysmography and clinical effect of bypass surgery; however, plethysmography results were also included in their primary outcome measure. Two other studies were not able to find a statistically significant association between plethysmography results and clinical outcome of bypass surgery or stenting. Studies investigating pressure changes mostly focused on parameters that are normally used in incompetence. Due to lack of details and risk of bias no decisive conclusions could be made regarding pressurerelated parameters. In conclusion, haemodynamic information regarding patient selection for interventional treatment is sparse and further research is warranted.

In chapter three, the use of air plethysmography in the identification of patients with potentially treatable deep venous obstruction, i.e. obstruction proximal to the femoral confluence, is evaluated. An excellent specificity $(98 \%)$ and positive predictive value $(92 \%)$ were found for the air plethysmography outflow test, though its sensitivity $(29 \%)$ and negative predictive value $(35 \%)$ were found to be poor. This implies that the added value of air plethysmography would be restricted to the identification, and not exclusion, of patients with a potential obstruction, and its clinical value would therefore be too low.

In chapter four, air plethysmography is examined even more closely by evaluating absolute volumetric changes rather than relative parameters. Receiver operated characteristic curves did not yield positive results for any of the parameters in discriminating between limbs with and without obstruction. The effect of treatment was also investigated in a subset of patients who underwent stenting and had quality of life measurements before and one year after intervention. Unfortunately, none of the plethysmography parameters were able to predict clinical improvement in quality of life. It can be concluded that the air plethysmography outflow test has no clinical value in these types of patients, and different techniques should be pursued.

In chapter five, the diagnostic value of collateral veins on the abdominal wall or over the pubic region in determining the presence of a treatable deep venous obstruction is evaluated. Such a collateral vein has an excellent positive predictive value for identifying an obstruction proximal to the femoral confluence (93\%), combined, however, with a low sensitivity $(53 \%)$ and negative predictive value $(32 \%)$. This sign should therefore not be used to eliminate the possibility of deep venous obstruction. Nevertheless, since these collateral veins are easily and non-invasively identifiable, a standard inspection of the abdominal and pubic region in patients with abdominal 
or lower limb complaints that could be of venous origin is recommended. The presence of such a collateral vein should be as a red flag, and patients showing this sign ought to be referred to a vascular specialist for further imaging. Meanwhile, the referring physician should refrain from performing interventions for superficial incompetence, and the collateral vein should not be removed for cosmetic reasons since abolishing this collateral pathway could hamper outflow of the lower limb.

Chapter six delves further into the function of collateral circulation in patients with deep venous obstruction. Common femoral vein pressure in the obstructed and contralateral control limb was measured in patients suffering from a unilateral, post-thrombotic iliofemoral obstruction. In addition, pressure was measured in the healthy limb whilst performing an acute balloon occlusion. This study found that pressure was significantly lower in healthy control limbs than in limbs with post-thrombotic obstruction. However, the latter situation still yielded lower pressures than the control limbs undergoing acute balloon occlusion. This difference between chronic and acute occlusion cannot be explained by recanalisation over time, since the included participants suffered from (near) occlusion. It follows that collateral circulation may mitigate the effects of chronic post-thrombotic obstruction and improve outflow.

Chapter seven describes a study evaluating the changes in pressure following a post-thrombotic iliofemoral obstruction. The results are compared to the healthy contralateral limbs of the same participant. Pressures in the common femoral veins and dorsal foot veins were simultaneously measured during actual ambulation on a treadmill, which has never been done before. Pressures in the common femoral veins of affected limbs were found to be significantly higher whilst resting. Differences between affected and non-affected limbs were more profound during ambulation on the treadmill test; pressure vastly increased in affected limbs whereas pressure in control limbs remained stable. Pressure differences in the dorsal foot veins were less apparent. Only minor differences were found in the supine position, and a tendency towards a higher net pressure drop in control limbs was found. The results of this chapter suggest that venous claudication could be explained by venous hypertension during ambulation.

Chapter eight describes the results of pressure measurements repeated in the same population, three months after stenting. Common femoral vein hypertension during ambulation significantly decreased compared with control limbs. Furthermore, both pain-free and maximum walking distance improved after intervention. An improvement in quality of life was also recorded, which was significantly associated with the reduction in common femoral vein pressure build-up. At the level of the dorsal foot vein no statistically significant differences were found, possibly due to a small sample size. These results demonstrate that stenting of venous obstruction diminishes ambulatory venous hypertension and that this is associated with improvement in quality of life.

In chapter nine, two techniques to improve stent inflow in patients with severe post-thrombotic obstruction are evaluated. In addition to a desobstruction of the common femoral vein and its tributaries, a temporary arteriovenous fistula was created to prevent early stent occlusion. This arteriovenous fistula is placed either cranially or caudally into the endophlebectomy area. No statistical significance was found between the two different techniques. However, we did find that post-thrombotic state of the femoral and deep femoral veins are of importance with respect to patency-related events. Patients with an affected femoral and/or deep femoral vein had a higher risk of stenosis or occlusion of the treated tract (odds ratio of 2.9 per femoral vein). This illustrates that proper flow into the groin is paramount in maintaining stent patency.

Finally, in chapter ten, the results of this thesis are put into perspective. Our knowledge of the haemodynamics regarding deep venous obstruction and its treatment has progressed, yet still 
warrants improvement. This thesis recognises the importance of collateral circulation, venous pressure and femoral inflow as points of reference for further research. We should develop methods for quantifying these haemodynamic characteristics and investigate whether they can be used to determine which patients will benefit from interventional treatment and which will not. Ultimately, an algorithm enabling a tailored treatment approach for deep venous obstruction should be acquired. 



\section{Nederlandse samenvatting}

Het doel van dit was om meer inzicht te verkrijgen in het hemodynamische effect van een diep veneuze obstructie en de behandeling ervan. Diep veneuze obstructie wordt voornamelijk veroorzaakt door posttrombotische afwijkingen, als gevolg van inadequate rekanalisatie na een diep veneuze trombose, of compressie door kruisende slagaders. Een dergelijke obstructie kan ernstig beperkende klachten veroorzaken. Gedurende de laatste decennia is stenten van diep veneuze obstructies in opkomst als een gunstige behandeloptie, echter is het bewijs hiervoor van beperkte kwaliteit en hemodynamische informatie schaars. Helaas ervaren sommige patiënten, ondanks technisch succes, geen klinische verbetering na stenten. In dit proefschrift richten we ons op verscheidene aspecten betreffende de hemodynamische veranderingen ten gevolge van diep veneuze obstructie en de behandeling ervan. Dit doen we met het doel om de hemodynamische implicaties van een behandeling vast te stellen en om aanknopingspunten te identificeren voor toekomstig onderzoek naar patiëntselectie.

In hoofdstuk twee hebben we een systematische review uitgevoerd om uit te zoeken wat reeds bekend is over de voorspellende waarde van hemodynamische parameters voor de uitkomst van een diep veneuze reconstructie. Hierbij hebben we vastgesteld dat de beschikbare informatie schaars is, daar er slechts vier publicaties voortvloeiden uit onze zoekopdracht. Plethysmografie werd het meest onderzocht, met wisselende resultaten. Een van de studies vond een associatie tussen deze techniek en het effect van bypass chirurgie, echter waren de plethysmografieresultaten ook deel van de primaire uitkomstmaat. Twee andere studies waren niet in staat een statistisch significante associatie aan te tonen tussen plethysmografie en klinische verbetering na bypass chirurgie of stenten. Studies die naar drukken keken richtten zich vaak op parameters die ontwikkeld zijn voor gebruik bij veneuze insufficiëntie. Er konden verder geen afdoende uitspraken worden gedaan over drukgerelateerde parameters ten gevolge van een gebrek aan gedetailleerde informatie en een risico op bias. Concluderend blijkt de kennis met betrekking tot de identificatie van patiënten die baat hebben bij interventionele behandeling schaars en is verder onderzoek noodzakelijk.

Hoofdstuk drie evalueerde het vermogen van luchtplethysmografie om patiënten met een potentieel behandelbare diep veneuze obstructie, oftewel een obstructie proximaal van de femorale samenvloeiing, te identificeren. We vonden een uitstekende specificiteit (98\%) en positief voorspellende waarde $(92 \%)$ voor de outflow test, echter waren sensitiviteit $(29 \%)$ en negatief voorspellende waarde $(35 \%)$ erg slecht. De klinische waarde van deze test is dus te laag, omdat de toegevoegde waarde van plethysmografie in het identificeren, en niet het uitsluiten, van een obstructie zou moeten liggen.

Hoofdstuk vier onderzocht luchtplethysmografie nog verder door naar de absolute volumeveranderingen te kijken in plaats van de relatieve parameters. Desondanks lieten receiver operated characteristic curves geen goede resultaten zien voor het vermogen om benen met en zonder obstructie van elkaar te onderscheiden. In dit hoofdstuk werd ook rekening gehouden met het effect van behandeling. Een subgroep van patiënten werd gestent en hadden kwaliteit van leven metingen voor de behandeling en één jaar erna. Helaas kon geen van de plethysmografieparameters een klinische verbetering in kwaliteit van leven voorspellen. Met andere woorden, een outflow test middels luchtplethysmografie heeft geen plaats in de klinische zorg en toekomstig onderzoek zal zich moeten richten op andere technieken.

In hoofdstuk vijf onderzochten we de diagnostische waarde van een collaterale ader op de buikwand of over de schaamheuvel met betrekking tot het identificeren van een potentieel 
behandelbare obstructie. We vonden dat een dergelijke collaterale ader een uitstekende positief voorspellende waarde heeft om een obstructie aan te tonen (93\%). Aangezien dit een gemakkelijk te herkennen teken is, adviseren we daarom ook dat een arts altijd de buikwand en schaamstreek inspecteert bij patiënten met klachten van de buik of onderste extremiteiten die mogelijk van veneuze origine zijn. De aanwezigheid van zulke venen moet als rode vlag worden beschouwd en het wordt geadviseerd om patiënten in dat geval door te sturen naar een vasculair specialist voor verdere beeldvorming. Daarnaast dient de verwijzend arts geen spataderbehandeling uit te voeren of de collaterale ader te verwijderen omwille van cosmetiek, daar dit de afvloed van het been kan beperken doordat er een collaterale route wordt verwijderd. Aangezien de sensitiviteit $(53 \%)$ en negatief voorspellende waarde (32\%) laag zijn, kan dit teken niet gebruikt worden om eventuele diep veneuze obstructie uit te sluiten.

Hoofdstuk zes gaat dieper in op de functie van collaterale circulatie bij patiënten met een diep veneuze obstructie. In dit hoofdstuk onderzochten we patiënten met een unilaterale, posttrombotische, iliofemorale obstructie. Bij deze proefpersonen werden drukken in de vena femoralis communis van het been met obstructie en hun contralaterale gezonde been gemeten. Daarnaast werden drukken gemeten gedurende een plotse ballonocclusie in het gezonde been. Deze studie toonde aan dat de druk significant lager was in gezonde benen dan in benen met een posttrombotische obstructie. Benen met een dergelijke obstructie lieten echter weer significant lagere drukken zien dan controlebenen waarbij een ballonocclusie werd uitgevoerd. Omdat de geïncludeerde proefpersonen een (vrijwel) totale obstructie hadden, kan rekanalisatie het drukverschil tussen een acute en chronische occlusie niet verklaren. Derhalve toont dit aan dat collaterale circulatie het effect van een posttrombotische obstructie kan verlichten en afvloed kan verbeteren.

Hoofdstuk zeven onderzocht drukveranderingen bij een posttrombotische, iliofemorale obstructie in vergelijking met het contralaterale gezonde been binnen dezelfde proefpersonen. In deze studie werden de drukken in de vena femoralis communis en dorsale voetvene gemeten gedurende het lopen op een loopband. Dit is in het verleden nog nooit uitgevoerd. We zagen dat de druk in de vena femoralis communis van aangedane benen significant hoger was in rust, echter waren verschillen tussen de aangedane en niet-aangedane benen duidelijker gedurende het lopen: de druk in de aangedane benen liep sterk op ten opzichte van een stabiele druk in de gezonde benen. Drukveranderingen in de dorsale voetvenen waren minder evident. We vonden slechts minimale verschillen tijdens rust en een neiging naar een grotere netto drukdaling in gezonde benen. De resultaten van dit hoofdstuk suggereren dat veneuze claudicatio verklaard kan worden door een veneuze hypertensie tijdens lopen.

In hoofdstuk acht werd dezelfde patiëntenpopulatie gestent en herhaalden we de drukmetingen drie maanden na de interventie. Ambulatoire hypertensie van de vena femoralis communis nam significant af ten opzichte van controlebenen. Daarnaast namen pijnvrije en maximale loopafstand significant toe. Ook kwaliteit van leven nam toe, wat een significante associatie vertoonde met de reductie in drukopbouw van de vena femoralis communis aan de angedane kant. Op het niveau van de dorsale voetvenen werden geen statistisch significante verschillen geobserveerd, mogelijk ten gevolge van een kleinere steekproefgrootte. Concluderend stelt dit hoofdstuk vast dat stenten van een veneuze obstructie ambulatoire veneuze hypertensie verminderd en dat dit geassocieerd is met een verbetering in kwaliteit van leven.

Hoofdstuk negen evalueerde twee technieken om stent inflow te verbeteren bij patiënten met een ernstige posttrombotische obstructie. Aanvullend op een desobstructie van de vena femoralis communis en haar tributaire vaten werd er een tijdelijke arterioveneuze fistel gecreëerd 
om vroege stentocclusie te voorkomen. Deze fistel werd craniaal of caudaal geplaatst in het desobstructiegebied. Er werd geen statistisch significant verschil gevonden tussen de twee verschillende methoden van arterioveneuze fistelcreatie. We constateerden echter wel dat de posttrombotische toestand van de vena femoralis en vena femoralis profunda van invloed waren op het risico op stenose of occlusie van het behandelde gebied. Patiënten met een aangedane vena femoralis en/of vena femoralis profunda hadden hier een hoger risico op (odds ratio van 2,9 per femoraalvene). Dit toont aan dat behoorlijke flow richting de lies enorm belangrijk is om openheid van de stents te waarborgen.

Tot slot, worden de resultaten van dit proefschrift bediscussieerd in hoofdstuk tien. In dit hoofdstuk concluderen we dat onze kennis van de hemodynamiek betreffende diep veneuze obstructie en de behandeling hiervan is toegenomen, maar dat verdere verbetering nog steeds vereist is. Dit proefschrift herkent het belang van collaterale circulatie, veneuze druk en femorale inflow als aanknopingspunten voor verder onderzoek. We dienen technieken te ontwikkelen waarmee we deze hemodynamische aspecten kunnen kwantificeren om vervolgens te onderzoeken of deze gebruikt kunnen worden om vast te stellen welke patiënten baat zullen hebben van een interventie en welke niet. Uiteindelijk zou er een algoritme verkregen moeten worden waarmee we een behandelplan op maat kunnen opstellen voor patiënten met een diep veneuze obstructie. 



\section{Valorisation addendum}

\section{Socioeconomic relevance of the scientific results in this thesis}

Chronic deep venous obstruction is a frequently occurring problem. Although the number of patients suffering from a significant iliac vein compression syndrome is unclear, post-thrombotic obstruction appears to be present in $25-56 \%$ of patients who suffered from a deep vein thrombosis (DVT) ${ }^{1-5}$ Considering that $1-2$ per 1,000 people in Western society develop a DVT, this number is vast. ${ }^{6,7}$ When the iliofemoral tract is affected by such an obstruction, complaints can be more severe and the obstruction could be treated by stenting. ${ }^{8-10}$ About a quarter of patients affected by DVT suffer from an iliofemoral DVT. ${ }^{1}$ This means that, annually, approximately 40,000 people in the Netherlands develop severe PTS caused by iliofemoral obstruction. This results in more than 1.5 million patients for the whole of Europe. Studies have shown that PTS can have a detrimental effect on quality of life and leads to increased absence from work. ${ }^{1,11}$ On top of that, healthcare costs due to chronic venous obstruction is estimated at $1-2 \%$ of the national healthcare budget in developed countries. ${ }^{12}$ Thus, post-thrombotic obstruction has a significant negative effect on the economy.

The results of this thesis lead to a better understanding of the pathophysiologic effects of such an obstruction. Moreover, these results are the first step in identifying patients who are in need of further examination and will benefit from interventional treatment options. However, the current evidence on stenting of such an obstruction is of limited quality and lacks proper randomised controlled trials. This thesis has shown that stenting of post-thrombotic venous obstruction has a direct positive effect on venous haemodynamics and is associated with significant improvement in quality of life, which provides substantiation for its use on a haemodynamic level. Therefore, this thesis provides better evidence to justify the associated health care costs of this intervention.

\section{Target population}

Results of this thesis may be interesting for various target groups outside the scientific community. First and foremost, physicians in contact with patients who suffer from venous obstruction and who are not involved in scientific research should take heed of the results in this thesis. Physicians who examine patients with lower limbs complaints that could be of venous origin should routinely inspect the abdominal wall and pubic area. This thesis establishes that the presence of a collateral vein in these areas is highly predictive for chronic deep venous obstruction proximal to the femoral confluence. Such a collateral vein should therefore be considered as a red flag and symptomatic patients should be referred to a dedicated specialised centre.

Other chapters contain valuable information for those physicians who consider treating an obstruction by stenting. The results presented in this thesis demonstrate that patients with iliofemoral obstruction can suffer from a significant ambulatory venous hypertension and that this can be markedly reduced by stenting the obstructed tract, which is associated with improvement in quality of life. The beneficial effects of stenting that have been identified in this thesis should ensure that the treating physician considers referral to or consultation with a venous expert in patients with severe post-thrombotic disease. A dedicated specialist can better establish whether interventional therapy may be beneficial, as opposed to conservative therapy alone. 
Furthermore, this thesis also identified post-thrombotic obstruction of the femoral and deep femoral vein as predictors for stenosis or occlusion of the treated tract. This is of particular importance for vascular surgeons and interventional radiologists who perform stent placements for deep venous obstruction. Before intervention, they should take this information into consideration and adequately investigate the quality of inflow to avoid complications or an unsuccessful procedure.

Medical technology companies are another very important target group. In several chapters of this thesis the need for development of innovative techniques was discussed. Techniques that can quantify flow in the lower extremity and those that can quantify collateral circulation are warranted to be able to identify which patients will benefit from interventional treatment. Also, easier to use, non-invasive techniques for measuring venous pressure should be developed. Support from medical technology companies is paramount to achieve this goal as soon as possible.

\section{Knowledge utilisation, innovation and future perspectives}

The results of this thesis have led to the development of a system that can monitor intravenous pressure while the patient is mobile. At this moment the project is in its design phase. A guidewire with the ability to measure intravenous pressure is attached to a device that records, transmits and stores data obtained from this pressure guidewire. The guidewire will be percutaneously placed inside the common femoral vein and the recording device will facilitate more optimal mobilisation than the techniques used in this thesis. Restrictions will be less as a result from the superior mobile nature of the device. The ability of the device to transmit data real time will ensure that the researcher can monitor measured pressures directly on a portable electronic device. This real time connection enables the researcher to respond to changes in pressure.

The results in this thesis are already innovative of itself: no studies have aimed to investigate the haemodynamic effects of a chronic deep venous obstruction during actual ambulation. The method of wireless transmission of the invasive pressure measurements will surpass that. Using this device, we will be able to gain more insight into pressure changes throughout the day in various positions and during different activities. This could prove particularly helpful in patients with partial obstruction or non-thrombotic iliac vein compression. The aim of the next study will be to investigate whether these pressure measurements will be able to predict clinical success of treatment, as measured by improvement in quality of life. After in vitro tests have been successfully performed, we will start a pilot study to test the feasibility of its use in patients. If this pilot study proves successful, it will be extended with more patients to investigate whether the hypothesised predictive value is true. Those data would result in a more profound understanding of deep venous obstruction and well-defined indications for invasive treatment of obstruction, leading to a reduction in unnecessary procedures and complications.

Two other aspects this thesis highlights are the importance of flow and collateralisation in the presence of deep venous obstruction. Developments of new techniques that can quantify these aspects are of the utmost importance in predicting which patients will benefit from interventional treatment and which will not. Furthermore, quantification of flow and collateralisation might also be important in understanding obstruction caused by non-thrombotic compression of certain vein segments. Innovation in this area would ultimately lead to improved quality of care. Risks of developing such techniques are very low since development of devices can be based on innovation of existing techniques through observational studies. When embarking on such 
a path financial costs are difficult to predict, though market opportunities will likely be ideal since such techniques could be amended to facilitate their use in other areas of medicine as well. Moreover, it could have a great societal impact if such innovations will lead to a tailored treatment approach. Improved quality of care can lead to a reduction in overall health care costs and have a beneficial effect on the economy through reintegration of people affected by this condition into the workforce.

\section{References}

1. Kahn SR, Shbaklo H, Lamping DL, et al. Determinants of health-related quality of life during the 2 years following deep vein thrombosis. J Thromb Haemost. 2008;6(7):1105-1112

2. Mohr DN, Silverstein MD, Heit JA, Petterson TM, O’Fallon WM, Melton LJ. The venous stasis syndrome after deep venous thrombosis or pulmonary embolism: A population-based study. Mayo Clin Proc. 2000;75(12):12491256

3. Prandoni P, Villalta S, Bagatella P, et al. The clinical course of deep-vein thrombosis. Prospective long-term follow-up of 528 symptomatic patients. Haematologica. 1997;82(4):423-428

4. Schulman S, Lindmarker P, Holmstrom M, et al. Post-thrombotic syndrome, recurrence, and death 10 years after the first episode of venous thromboembolism treated with warfarin for 6 weeks or 6 months. J Thromb Haemost. 2006;4(4):734-74

5. Tick LW, Kramer MH, Rosendaal FR, Faber WR, Doggen CJ. Risk factors for post-thrombotic syndrome in patients with a first deep venous thrombosis. J Thromb Haemost. 2008;6(12):2075-2081

6. Cohen AT, Agnelli G, Anderson FA, et al. Venous thromboembolism (vte) in europe. The number of vte events and associated morbidity and mortality. Thromb Haemost. 2007;98(4):756-76

7. Naess IA, Christiansen SC, Romundstad P, Cannegieter SC, Rosendaal FR, Hammerstrom J. Incidence and mortality of venous thrombosis: A population-based study. J Thromb Haemost. 2007;5(4):692-699

8. Seager MJ, Busuttil A, Dharmarajah B, Davies AH. Editor's choice - a systematic review of endovenous stenting in chronic venous disease secondary to iliac vein obstruction. Eur J Vasc Endovasc Surg. 2016;51(1):100-120

9. Strijkers RH, Arnoldussen CW, Wittens CH. Validation of the let classification. Pblebology. 2015;30(1 Suppl):14-19

10. Wittens C, Davies AH, Baekgaard N, et al. Editor's choice - management of chronic venous disease: Clinical practice guidelines of the European Society for Vascular Surgery (ESVS). Eur J Vasc Endovasc Surg. 2015;49(6):678-737

11. Alhadad A, Kolbel T, Herbst A, Holst J, Alhadad H, Gottsater A. Iliocaval vein stenting: Long term survey of postthrombotic symptoms and working capacity. J Thromb Thrombolysis. 2011;31(2):211-216

12. Milic DJ. Prevalence and socioeconomic data in chronic venous disease: How useful are they in planning appropriate management? Medicographia. 2011;33(3):253-258 



\section{Dankwoord}

Dit is het dan, vier jaar werk die culmineren in dit boekje. Een periode waarin ik veel heb geleerd, ik ontdekt heb wat ik wil in het leven en ik ook niet ben vergeten te genieten. Als ik terug kijk op mijn proefschrift durf ik toch wel trots te zijn op wat we in relatief korte tijd bereikt hebben. Dit was me niet in mijn eentje gelukt, dus wil ik bij deze van de gelegenheid gebruik maken om een aantal personen te bedanken.

Prof. dr. Wittens, beste Cees, vier jaar lang heb je me de kans gegeven om mezelf te ontplooien als onderzoeker en arts. Hoewel we met regelmaat niet exact dezelfde gedachten hadden, vloeide hier een gezonde discussie uit voort die het onderzoek ten goede kwam. Ik wil je bedanken voor het feit dat ik op de voorgrond kon staan van vernieuwend onderzoek en dat er voldoende mogelijkheden waren om onze expertise uit te dragen naar de internationale gemeenschap. Dit ging uiteraard ook gepaard met de nodige sociale momenten die een $\mathrm{PhD}$-periode tot een onvergetelijke tijd kunnen maken. Daarnaast heb je door je enthousiasme er voor weten te zorgen dat er altijd sprake was van een hecht team, waarin het enorm prettig was om binnen te werken. Naast het onderzoek was er ook ruimte voor kliniek, waardoor ik mijn competenties als arts heb kunnen ontwikkelen. Gedurende deze periode ben ik er dan ook achter kunnen komen wat voor soort arts ik wil zijn. Bedankt voor deze vier jaar.

Prof. dr. Wildberger, beste Joachim, ook jou wil ik bedanken voor je invloed op de totstandkoming van dit boekje. Hoewel je niet zozeer betrokken was bij het day-to-day onderzoek, heb ik met name richting het einde van mijn $\mathrm{PhD}$-periode veel aan je input gehad. Je kon met een wat neutralere blik naar de betreffende problematiek kijken en hebt er zeker voor gezorgd dat dit boekje tot een hoger niveau werd getild.

Dr. de Graaf, beste Rick, met jou had ik de allerkortste lijntjes. Voor overleg namen we altijd ruim de tijd en het was nooit saai. Onder het genot van een goede kop koffie hebben we soms uren aan een stuk over het onderzoek kunnen discussiëren, wat heeft geleid tot allerlei interessante zijprojecten. Twee daarvan zijn ook in dit boekje geëindigd. Je keek altijd met een kritische blik naar de methodologie van ons onderzoek en hebt me enthousiast weten te krijgen met een scala aan verfrissende ideeën. Natuurlijk was er ook regelmatig gelegenheid tot een goede borrel, waarbij, net als tijdens de koffie, zowel onderzoek als de belangrijkere dingen des levens de revue passeerden.

De beoordelingscommissie, bestaande uit prof. dr. ten Cate, dr. van Dijk, prof. dr. ir. Ince, prof. dr. Jacobs en prof. dr. Steijlen, wil ik bedanken voor hun tijd om dit proefschrift te beoordelen.

Zonder proefpersonen was dit proefschrift nooit compleet geweest, daarom wil ik ook alle patiënten die mee hebben gedaan aan onze onderzoeken bedanken.

Mark, ik kende je al voordat ik bij Cees ging werken. Je wist dat ik graag wilde promoveren en dat Cees van plan was nieuwe projecten op te starten. Dit heeft er toe geleid dat ik al kon starten voordat de financiën helemaal rond waren. Tijdens onze periode bij de vaten zijn we betere vrienden geworden en hebben we het nodige meegemaakt. De jaarlijkse vakantie naar de VS was een traditie die ik zeker zal missen, maar ook het samenwerken mis ik. Je was een grote hulp bij het uitvoeren van de loopbandstudie: in het weekend of in de avond, als het HVC uitgestorven was, het idee hebben dat je met écht onderzoek bezig bent. Naast het serieuze aspect hebben we altijd veel kunnen lachen. Vaak was één blik tijdens het MDO al voldoende. Ik wens je heel veel succes met je verdere toekomst en hoop binnenkort ook jouw boekje te mogen ontvangen. Rob, ook jou kende ik al geruime tijd. Hoewel onze onderwerpen wat verder van elkaar lagen, 
was er toch altijd een gezonde discussie over de meest diverse zaken. Of dit nu met betrekking tot een van onze onderzoeken was, het onderzoek van iemand anders, of meer maatschappelijke of juist onzinnige zaken. Ik heb altijd met veel plezier met je samengewerkt en vond het dan ook jammer dat je halverwege mijn promotietraject alweer door moest met de volgende fase in je carrière. Wat heb ik dat gelach en die gevatte, regelmatig ongenuanceerde, opmerkingen gemist! Van de meest memorabele AVF-trip maakte ook jij deel uit. Die eerste keer Mardi Gras in NOLA was een trip die ik niet snel zal vergeten. Ik wens je in ieder geval heel veel succes met je volgende avontuur.

Irwin, ik wil je bedanken voor de altijd kritische blik op de onderzoeken die we in Maastricht uitvoeren. Dit stimuleerde me regelmatig om toch nog een extra keer over bepaalde zaken na te denken. Daarnaast hebben we de nodige tijd doorgebracht bij het aanprikken van al die lijnen voor de loopbandstudie. Bedankt voor al je hulp en tips.

Ineke, jou mag ik ook zeker niet vergeten te bedanken. Hoewel je slechts vanuit de zijlijnen bij mijn onderzoek betrokken bent geweest, hebben we veel goede gesprekken gehad onder het genot van een "borrel”. Of dit nu over persoonlijke zaken, onderzoek of mijn frustraties ging, je was er altijd. Je kon vaak al aan mijn neus zien als ik weer eens iets "ondeugends" in gedachten had. Ik ga het samenwerken erg missen, maar als ik de tijd krijg om in Rotterdam op de racefiets te stappen, zal ik zeker aan je denken.

Yee Lai, jij was ook een van de vaatboys. Met z'n vijven vormden we een goede groep, waarin jij zo nu en dan voor de nodige rust zorgde. Verder was je altijd in voor zowel gezelligheid als een gesprek over serieuzere zaken. Ik wens je heel veel succes met je toekomst bij de dermatologie en hoop snel op jouw verdediging aanwezig te mogen zijn.

Fabio, als kamergenoot moest ik vaak de rest van het lab overtuigen dat je daadwerkelijk bestond en ik dit niet verzon om een extra groot bureau te hebben (in de praktijk maakte ik daar uiteraard wel dankbaar gebruik van). Je was altijd overal en nergens te bekennen, maar als je er was, werd er altijd gelachen. Ik wens je veel succes met de afronding van je boekje en met wat daarna nog zal komen.

Carina, jij bent een van de weinigen die al deel van het team uitmaakte toen ik begon en er nog steeds was toen ik vertrok. Bij jou kon ik altijd terecht als er iets klinisch geregeld moest worden waarvan ik niet zeker wist hoe ik dit logistiek het beste aan kon pakken. Niet lang nadat ik begonnen was heb ik echter ook met je samen mogen werken op de ulcuspoli. Ik kijk hier met plezier op terug en wens je al het beste met het ulcusonderzoek. Ik hoop dat ik hier regelmatig nog een update over mag ontvangen en over mee mag denken.

Irma, we zijn begonnen als kamergenoten. Dit betekende voldoende gezellige gesprekken als variatie op al dat onderzoek. Uiteraard hebben we ook nog de tijd gevonden om onze plantjes goed te verzorgen. Eentje heeft het bijzonder lang vol gehouden en lijkt niet stuk te krijgen. Op een gegeven moment verhuisde je van kamer, maar gezien de dynamiek van ons team hebben we het nog vaak genoeg over van alles en nog wat kunnen hebben. Tot slot wil ik je nog bedanken dat je altijd hulp probeerde te bieden, in het bijzonder met een moeilijk aanprikbare voetvene.

Jorinde, toen jij je bij het team voegde veranderde er veel. Van één vaatchirurg die over onze patiëntenpopulatie ging naar twee. Ik heb veel van je geleerd en mogen observeren hoe dingen soms ook op een iets andere manier opgepikt kunnen worden. Bij jou kon ik altijd terecht voor klinische ondersteuning. Bedankt!

Maaike, jij begon in een periode van veranderingen. De samenstelling binnen de groep promovendi is hier duidelijk beginnen te verschuiven van de Wittens Boyband naar een meidengroep. Qua 
gevatheid en borrelmogelijkheden deed je echter niet onder voor de mannen. Ik wens je veel succes met het afronden van de CAVA-studie en je verdere carrière.

Timme, jij was de recentste toevoeging aan het team, maar zeker niet de minste. Vanwege het onderwerp van je promotie hebben we in korte tijd veel en prettig samen kunnen werken. Veel succes met het schrijven van je boekje en je toekomst bij de plastische.

En dan mag ik de rest van het veneuze team niet vergeten. Het was een fantastische groep om in te werken en ik heb het enorm naar mijn zin gehad. Jolanda ("mams"), Cora, Carsten, Margriet, Wijnand en alle artsen en studenten die in de afgelopen jaren te gast bij ons zijn geweest. Auch danke ich meine Deutsche Kollegen: Houman, Jochen, Mohammad und Alex.

Natuurlijk wil ik ook alle co-auteurs en andere mensen die bijgedragen hebben aan dit werk en die nog niet genoemd zijn bedanken. In het bijzonder Patty: je hebt me de nodige epidemiologie en statistiek weten bij te brengen, wat altijd gevolgd werd door een goed gesprek. Verder wil ik ook Michiel, Jos en Estelle bedanken.

Een groot deel van het onderzoek was niet tot stand gekomen zonder de goede samenwerking met de vaatkamer en het vaatlab. Ik wil daarom allen die hier werkzaam waren van harte bedanken. Iedereen was altijd erg behulpzaam en veel was mogelijk.

Bij het noemen van namen wordt er altijd iemand zonder bijbedoelingen vergeten, vandaar dat ik me hier ook niet aan ga wagen. Ik wil graag iedereen van de heelkunde, in het bijzonder het lab en de lichting op UNS40 bedanken voor een prettige vier jaar.

Heeren der eCI: Rik, Yves, Marco, Marc, Jeroen, Yvo, Frans, en de rest. Hoewel jullie eigenlijk niets met het onderzoek te maken hadden en vaak geen idee hadden wat we daar nu precies deden, wil ik ook jullie bedanken. Ik heb een geweldige studententijd met jullie gehad en heb nog de nodige sociale activiteiten mogen meepikken tijdens mijn promotieperiode. Ik woon tegenwoordig niet meer naast de deur, maar ik ben ervan overtuigd dat er enkele vriendschappen voor het leven zijn gesloten.

Kirsten, wij hebben elkaar al leren kennen toen we nog in de bachelorfase van onze studie zaten. $\mathrm{Na}$ samen in een bestuur te hebben gezeten was ik ook erg blij om te horen dat we allebei op het lab van de heelkunde gingen werken. Jij was zelfs een van de eersten uit de draaideur van personen die zich mijn kamergenoot kon noemen (sorry dat ik je plek heb ingepikt!). Het was altijd gezellig om samen een koffie te pakken en weer even bij te kletsen over de alledaagse dingen. Bedankt dat je mijn paranimf wil zijn. Ik wens je al het geluk toe bij de MDL en hoop dat je binnenkort in Canada je boekje af kan schrijven. Ik weet hoeveel moeite je erin hebt gestopt en zal blij voor je zijn als ik je boekje zie verschijnen.

Etienne, als paranimf heb je eigenlijk nooit iets van mijn onderzoek van dichtbij gezien, maar dat mag de pret niet drukken. Kindergeneeskunde en vaatchirurgie lijken werelden apart, maar nu ik bij de gynaecologie zit komen we figuurlijk weer wat dichter bij elkaar in de buurt. We kenden elkaar natuurlijk al voor eCI, maar nadat je je bij ons hebt gevoegd zijn we erg goede vrienden geworden. Vanuit Rotterdam is dit wat lastiger te onderhouden, maar dit zal zeker goed komen. Een mooi excuus om op twee plaatsen erop uit te gaan zou ik zeggen. Wel zullen we even ons best moeten doen om een pubquiz te vinden die aansluit op de reisafstand. Ik wens je het allerbeste toe bij de kindergeneeskunde, en wie weet mogen we in de toekomst nog nauwer samenwerken.

Pap, mam, wat ik nu precies heb gedaan tijdens mijn promotietraject en waarom dit ook handig kan zijn voor de toekomst is iets wat lastig uit te leggen is. Desondanks hebben jullie altijd veel belangstelling getoond en stonden jullie voor me klaar als dat nodig was. Jullie rol in de 
totstandkoming van dit proefschrift lijkt op het eerste oog misschien niet aanwezig, maar jullie hebben een grote invloed gehad op hoe ik als persoon ben gevormd, wat zich uiteindelijk toch uit in dit proefschrift. Graag wil ik jullie bedanken voor alles wat jullie voor me betekend hebben en nog zullen betekenen. Met genoegen kijk ik terug op hoe de "thuis-thuis" situatie veranderd is. Met twee zonen die nu toch een serieuze relatie hebben, is de dynamiek enorm veranderd en is het steeds gezelliger om het een en ander met z'n allen te ondernemen. Ook Dennis en Mark wil ik hiervoor bedanken.

Ilona, mijn dankwoord wil ik afsluiten met jou in gedachten, zoals bij eigenlijk alles in mijn leven. Je hebt gedurende mijn hele promotietraject aan mijn zijde gestaan. Of dit nu op persoonlijk vlak of op professioneel vlak was. Ik kon altijd met bedenkingen of stukken die ik graag nog door iemand wilde laten lezen bij je terecht. Je hebt zelfs nog een actieve rol binnen een van mijn onderzoeken weten te spelen omdat ik plots handen tekort kwam en jij net gunstig met je co-schappen zat. Ook met mijn frustraties kon ik bij je terecht en als ik weer eens te lang ergens mee bezig was, was jij degene die wist wanneer je voor afleiding moest zorgen. We hebben de afgelopen tijd al veel meegemaakt, veel gezien en veel genoten. Alles lijkt beter te zijn als ik het met jou kan delen, je bent mijn maatje. Schatje, ik hou van jou. 


\section{Curriculum Vitae}

Ralph L.M. Kurstjens was born on July 19 th $^{\text {t }} 1988$ in Roermond, the Netherlands. In 2006 he graduated from the Atheneum at BC Broekhin in Roermond. Thereafter, he went to read medicine at Maastricht University. During his time there he was an active member of O.M.H.D. "e Causa Ignota" and the medical students' association "Pulse", of both of which he was also president. He followed an elective course in International Healthcare Systems at the University of Birmingham and an elective clinical rotation in Community Medicine in Quito and Puembo, Ecuador. In the final year of his medical studies he attended a clinical training programme at the department of Surgery of Maastricht University Medical Centre+ and a scientific internship at the department of Hepato-Pancreato-Biliary Surgery of the Royal Free Foundation Trust in London. In 2012 he obtained his medical degree with honours in International Medicine and started working as a PhD-candidate at the CARIM School for Cardiovascular Diseases under supervision of Prof. C.H.A. Wittens, Prof. J.E. Wildberger and Dr. R. de Graaf. This thesis is the result of his research there into the haemodynamic consequences of chronic deep venous obstruction and its treatment. During his PhD research he took seat on the faculty council of the Faculty of Health, Medicine and Life Sciences.

In September 2016 he started as a senior house officer (ANIOS) at the department of Obstetrics and Gynaecology at the Haga Teaching Hospital in The Hague. 



\section{List of publications}

Kurstjens RLM, de Wolf MAF, Kleijnen J, de Graaf R, Wittens, CHA. The predictive value of haemodynamic parameters for outcome of deep venous reconstructions in patients with chronic deep vein obstruction: a systematic review. Phlebology. 2016 Oct 27 [Published Online First]

Kurstjens RLM, Whiteley M, Wittens CHA. Effectiveness of treatment for pelvic congestion syndrome. Phlebolymphology. 2016;23(3):154-161.

Kurstjens RLM, van Vuuren TMAJ, de Wolf MAF, de Graaf R, Arnoldussen CWKP, Wittens CHA. Abdominal and pubic collateral veins as indicators of deep venous obstruction. J Vasc Surg Venous Lymphat Disord. 2016;4(4):426-33.

van Mierlo KMC, Lodewick TM, Dhar DK, van Woerden V, Kurstjens RLM, Schaap FG, van Dam RM, Vyas S, Mallagó M, Dejong CHC, Olde Damink SWM. Validation of the peak bilirubin criterion for outcome after partial hepatectomy. HPB. 2016;18(10):806-812.

Kurstjens RLM, De Wolf MAF, Alsadah SA, Arnoldussen CWKP, Strijkers RHW, Toonder IM, Wittens CHA. The value of hemodynamic measurements by air plethysmography in diagnosing venous obstruction of the lower limb. J V asc Surg Venous Lymphat Disord. 2016;4(3):313-319.

Kurstjens RLM, De Wolf MAF, Konijn HW, Toonder IM, Nelemans PJ, De Graaf R, Wittens $\mathrm{CHA}$. Intravenous pressure changes in patients with postthrombotic deep venous obstruction: results using a treadmill stress test. J Thromb Haemost. 2016;14(6):1163-1170.

Lee BB, Nicolaides AN, Myers K, Meissner M, Kalodiki E, UIP Consensus Faculty (including Kurstjens RLM). Venous hemodynamic changes in lower limb venous disease: the UIP consensus according to scientific evidence. Int Angiol. 2016;35(3):236-352.

Comerota AJ, Sandset PM, Konstantinides S, De Graaf R, Wakefield TW, Arnoldussen CWKP, Lam YL, Van Gent WB, DeWolf MAF, Catarinella FS, Kurstjens RLM, Alshabatat A, Wittens CHA. Theme 4: Invasive management of (recurrent) VTE and PTS. Thromb Res. 2015;136(S1):S19-25.

De Wolf MAF, De Graaf R, Kurstjens RLM, Penninx S, Jalaie H, Wittens CHA. Short-term clinical experience with a dedicated venous nitinol stent: initial results with the Sinus-Venous stent. Eur J Vasc Endovasc Surg. 2015;50(4):518-26.

Kurstjens RLM, De Graaf R, Barbati ME, De Wolf MAF, Van Laanen JHH, Wittens CHA, Jalaie H. Arteriovenous fistula geometry in hybrid recanalisation of post-thrombotic venous obstruction. Phlebology. 2015;30(1S):42-9.

Kurstjens RLM, De Wolf MAF, Van Laanen JHH, De Haan MH, Wittens CHA, De Graaf R. Hemodynamic significance of collateral blood flow in chronic venous obstruction. Phlebology. 2015;30(1S):27-34.

Jalaie H, Arnoldussen C, Barbati M, Kurstjens RLM, De Graaf R, Grommes J, Greiner A, De Wolf MAF, Wittens CHA. What predicts outcome after recanalization of chronic venous obstruction: hemodynamic factors, stent geometry, patient selection, anticoagulation or other factors? Phlebology. 2014;29(1S):97-103. 
Kurstjens RLM, De Wolf MAF, De Graaf R, Wittens CHA. Hemodynamic changes in iliofemoral disease. Phlebology. 2014;29(1S):90-96.

Kurstjens RLM, Olde Damink SWM, Dejong CHC. [Colorectal liver metastasis? - case report.] Lever. 2012;36(1):15-16. [Dutch]

Kurstjens RLM, Geomini PMAJ. [Transvaginal drainage of the tubo-ovarian abscess - critical appraisal of a topic.] Medisch Journaal. 2011;40(3):170-71. [Dutch] 